ANDRÉ NOZAWA BRITO

\title{
APLICAÇÃO DE UM PROCEDIMENTO USANDO PREFERÊNCIA DECLARADA PARA A ESTIMATIVA DO VALOR DO TEMPO DE VIAGEM DE MOTORISTAS EM UMA ESCOLHA ENTRE ROTAS RODOVIÁRIAS PEDAGIADAS E NÃO PEDAGIADAS
}

Dissertação apresentada à Escola Politécnica da Universidade de São Paulo para obtenção do título de Mestre em Engenharia 
ANDRÉ NOZAWA BRITO

\section{APLICAÇÃO DE UM PROCEDIMENTO USANDO PREFERÊNCIA DECLARADA PARA A ESTIMATIVA DO VALOR DO TEMPO DE VIAGEM DE MOTORISTAS EM UMA ESCOLHA ENTRE ROTAS RODOVIÁRIAS PEDAGIADAS E NÃO PEDAGIADAS}

Dissertação apresentada à Escola Politécnica da Universidade de São Paulo para obtenção do título de Mestre em Engenharia

Área de concentração: Engenharia de Transportes

Orientador: Prof. Associado Orlando Strambi

São Paulo 
Este exemplar foi revisado e alterado em relação à versão original, sob responsabilidade única do autor e com a anuência de seu orientador.

São Paulo, 16 de abril de 2007.

Assinatura do autor

Assinatura do orientador

FICHA CATALOGRÁFICA

Brito, André Nozawa

Aplicação de um procedimento com preferência declarada para estimativa do valor do tempo de viagem de motoristas em uma escolha entre rotas rodoviárias pedagiadas e não pedagiadas I A.N. Brito. -- ed.rev. -- São Paulo, 2007.

$185 \mathrm{p}$.

Dissertação (Mestrado) - Escola Politécnica da Universidade de São Paulo. Departamento de Engenharia de Transportes.

1.Planejamento de transportes 2.Valor do tempo de viagem 3.Preferência declarada 4.Modelos de escolha 5.Rodovias 6.Pedágios I.Universidade de São Paulo. Escola Politécnica. Departamento de Engenharia de Transportes II.t. 
À minha mãe Rita, que sempre comemorou cada conquista minha como se fosse sua. 


\section{AGRADECI MENTOS}

Ao meu orientador Orlando Strambi, um dos professores mais sensacionais que já conheci, por toda a dedicação e entusiasmo durante este trabalho.

À Karin Anne van de Bilt, pelo constante interesse em discutir diversos temas relacionados a esta dissertação e por todas as críticas sinceras e construtivas.

Ao Bernardo Guatimosim Alvim, pelo valioso aprendizado que venho tendo ao longo de uma grande - e recorrente - convivência profissional e pessoal.

Ao colega de turma e de trabalho Rodrigo Florio Moser pelo companheirismo e ajuda durante o decorrer do curso.

Ao Milton Xavier por todo o apoio e por ter me atentado para a importância de continuar estudando.

Aos professores Hugo Pietrantonio e José Alberto Quintanilha, pelo incentivo dado ao longo do curso e pelos ensinamentos que foram fundamentais nesta dissertação.

Ao Michel Bierlaire, por ter sempre respondido prontamente às duvidas que tive em relação ao uso do software Biogeme.

Ao professor Eiji Kawamoto, pelas recomendações que resultaram em importantes contribuições a este trabalho.

À Artesp e à Secretaria dos Transportes do Estado de São Paulo, pela cessão da pesquisa de preferência declarada utilizada neste estudo.

Ao Eduardo Germani, pelo importante incentivo.

A todo o pessoal da secretaria do PTR, especialmente à Simone e à Sarah, pela sempre ágil ajuda.

Aos meus tios engenheiros Wilson Tsukasa Nozawa, pelo otimismo, e Airton Nozawa, pelas provocações, que me incentivaram a não fugir dos desafios.

Aos meus pais Demeure e Rita, que por durante muito tempo sempre se esforçaram e me deram todas as condições para que eu tivesse o privilégio de poder dedicar todo o tempo necessário aos estudos.

À minha querida esposa Helena, por sua paciência, amizade e eterna disposição em me ajudar. 


\section{RESUMO}

Esta dissertação baseia-se na aplicação de um procedimento empírico envolvendo técnicas de preferência declarada para a estimativa do valor do tempo de viagem de motoristas em deslocamentos regionais, em um contexto de escolha entre rotas pedagiadas e não pedagiadas. Inicialmente é feita uma revisão das abordagens teórica e empírica sobre a valoração do tempo. São também revistos os conceitos básicos de outros dois elementos fundamentais na metodologia aqui utilizada: a teoria da escolha e técnicas de preferência declarada. Uma aplicação a um estudo de caso específico é feita usando informações coletadas em ampla pesquisa de preferência declarada, realizada em 2005 com motoristas de automóvel em diversos pontos da malha rodoviária do estado de São Paulo. O desenho experimental da preferência declarada envolvia três atributos: tempo de viagem por uma rota pedagiada, custo tarifário e tempo de viagem por uma rota não pedagiada. O conjunto das informações foi analisado e utilizado na obtenção de modelos de escolha discreta do tipo logit multinomial; os valores do tempo de viagem foram obtidos a partir dos coeficientes estimados em funções de utilidade aditivas e lineares nos parâmetros. Analisou-se também a variação do valor do tempo em função de características do motorista e da viagem, questão abordada através da estimação de diferentes modelos por segmentos da amostra e da especificação de funções de utilidade que incorporam variáveis dummies para representação das características analisadas. Os resultados indicaram, para a escolha específica estudada, valores de tempo médios de cerca de $R \$ 16 / h$, variando de $R \$ 12 / h$ a $\mathrm{R} \$ 23 / \mathrm{h}$ para diferentes segmentos de viajantes analisados. A duração da viagem foi uma importante característica associada a variações no valor do tempo, que decresceu na medida em que as durações aumentaram. Variações expressivas no valor do tempo de viagem foram também observadas para viagens a lazer, motoristas de renda familiar baixa e aqueles com alta posse de veículos. 


\begin{abstract}
This dissertation is based on the application of an empirical procedure using stated preference techniques for the estimation of the value of travel time for drivers in regional trips, in the context of a choice between tolled and non-tolled routes. It first reviews the theoretical and the empirical approaches for the valuation of travel time and then presents the basic concepts of two other topics relevant for the methodology adopted: choice theory and stated preference methods. An application to a specific case study is then presented, using information from a stated preference survey conducted in 2005 with a large sample of car drivers intercepted at several points in the highway network of the state of São Paulo. The stated preference experimental design considered three attributes: trip time on a tolled route, value of toll and trip time on a non-tolled route. Survey data were analyzed and used for the estimation of discrete choice (multinomial logit) models; values of travel time were derived from estimates of coefficients of an additive linear in the parameters utility function. The specification of the models and the segmentation of the sample allowed the estimation of the variation of travel time according to some selected driver and trip characteristics. Results indicated, for the specific choice context analyzed, an average value of travel time of approximately $R \$ 16 / h$, varying from about $R \$ 12 / h$ to $R \$ 23 / h$ for different segments of travelers. Trip length was an important characteristic influencing the variation of the value of travel time, which declined as trip length increased. Other important effects were found for leisure trips, for travelers with low income and for those with high family car ownership.
\end{abstract}




\section{SUMÁRI O}

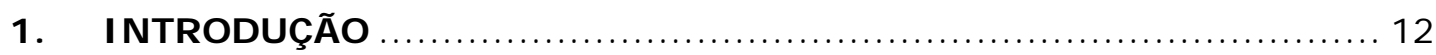

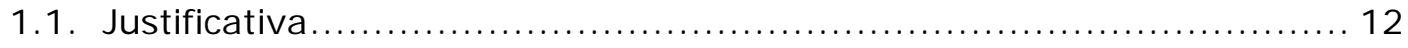

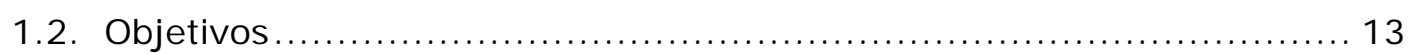

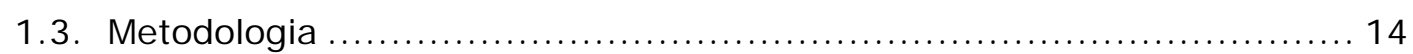

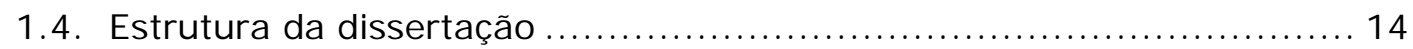

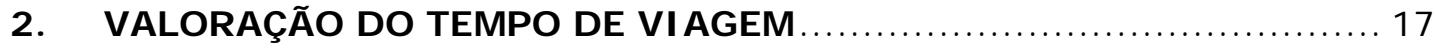

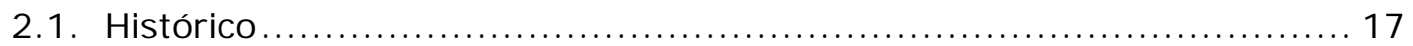

2.2. O Valor Subjetivo do Tempo de Viagem ............................. 19

2.3. O Valor Social do Tempo de Viagem .................................... 23

2.4. Abordagem Empírica ................................................ 25

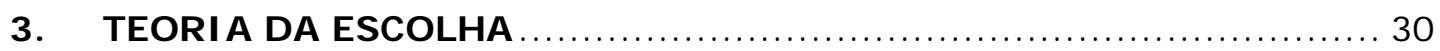

3.1. Elementos do Processo de Escolha....................................... 30

3.2. Teoria da Utilidade Aleatória .......................................... 33

3.3. Tipos de Modelos de Escolha Discreta ................................. 35

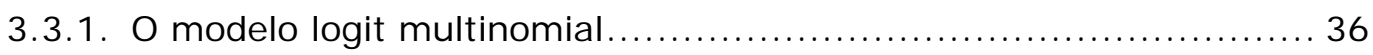

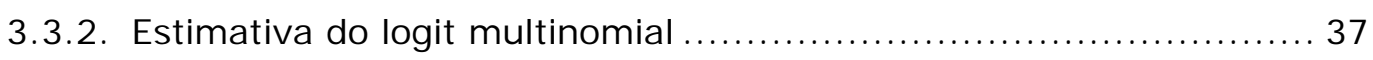

3.3.2.1. Obtenção dos parâmetros ...................................... 37

3.3.2.2. Testes estatísticos............................................ 38

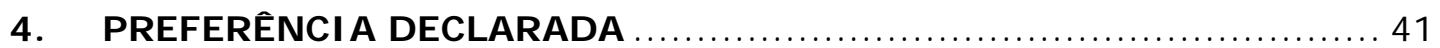

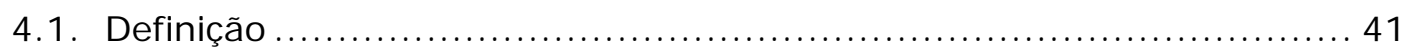

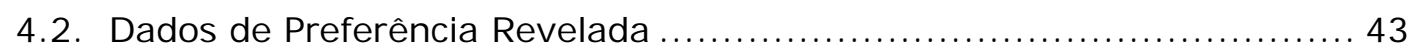

4.3. Características dos Dados de Preferência Declarada ....................... 44

4.4. Formatos de Resposta nas Questões de PD ............................ 47

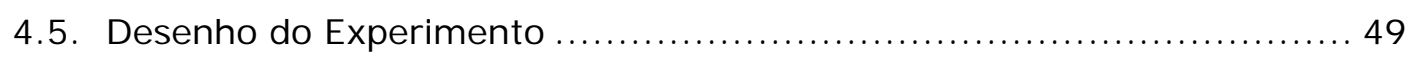

4.5.1. Etapas da construção do desenho.................................. 50

4.5.2. Observações sobre a complexidade do desenho....................... 56

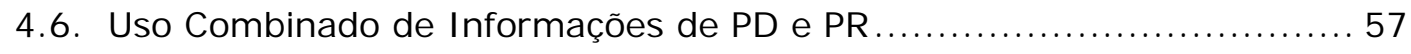

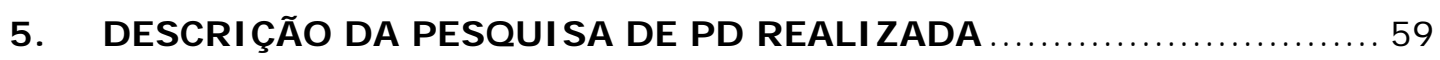

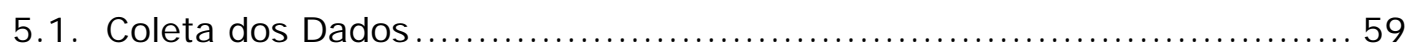

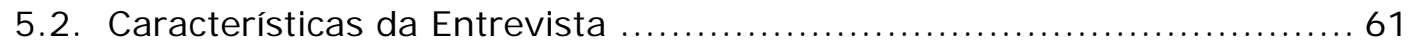

5.3. Desenho do Experimento de PD Utilizado ............................65

5.3.1. Forma de aplicação da pesquisa de PD .......................... 67 
5.3.2. Comentários sobre o desenho da pesquisa de PD................... 71

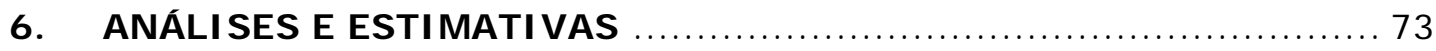

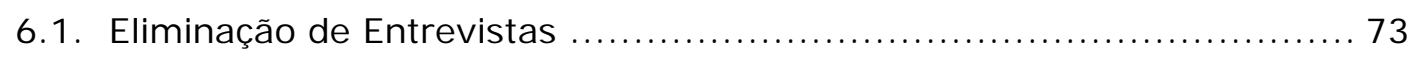

6.1.1. Consistência das respostas dadas por um entrevistado .............. 74

6.2. Caracterização da Amostra ........................................... 77

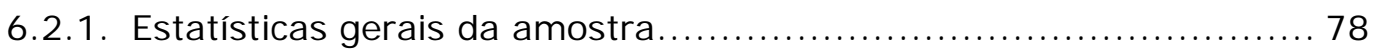

6.2.2. Análise da distribuição das respostas às questões de PD ............ 83

6.2.3. Verificação de relação entre as variáveis .......................... 86

6.3. Estimativa dos Modelos de Escolha .................................. 90

6.3.1. Definição da forma da função de utilidade ............................ 90

6.3.2. Segmentos considerados para as análises ......................... 92

6.3.3. Estimativas por motivo de viagem ............................ 93

6.3.4. Estimativas por faixa de renda .................................... 99

6.3.5. Estimativas por faixa de tempo de viagem....................... 100

6.3.6. Outras características associadas a variações no valor do tempo... 102

6.3.6.1. Análise da variação do valor do tempo com variáveis dummies. 103

6.3.6.2. Características testadas .................................... 104

6.3.6.3. Resultados dos modelos estimados ............................. 106

6.4. Comparação dos Resultados com uma Informação de PR ................ 118

6.4.1. Valores do tempo estimados por PR e por PD ................... 120

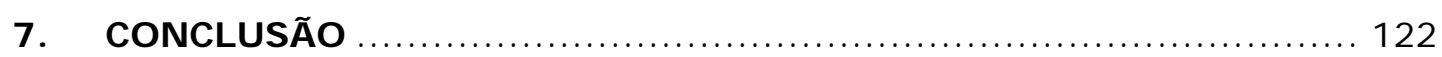

7.1. Análise dos Principais Resultados Obtidos ........................... 122

7.1.1. Variação do valor do tempo com a duração da viagem ............... 124

7.1.2. Variação do valor do tempo com a renda do motorista ............. 127

7.1.3. Variação no valor do tempo com o motivo da viagem ................ 128

7.1.3.1. Baixo valor do tempo nas viagens a negócios.................. 128

7.1.3.2. Alto valor do tempo nas viagens de lazer..................... 130

7.2. Recomendações para Estudos Futuros .............................. 131

7.3. O Novo Contexto das Aplicações para o Valor do Tempo de Viagem ... 134

7.4. A Busca do Verdadeiro Valor do Tempo de Viagem .................... 135

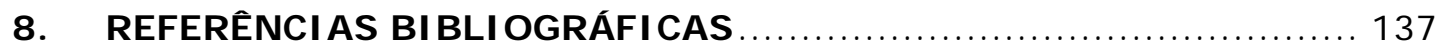

APÊNDICE A - Modelo estimado para a amostra sem segmentação..............142

APÊNDICE B - Verificações adicionais de relação entre variáveis dos modelos

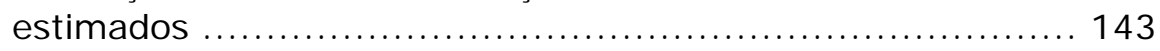

APÊNDICE C - Resultados do modelo estimado com dummies para faixas de

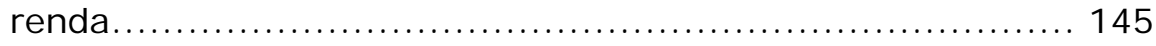

APÊNDICE D - Verificação da necessidade de desagregação da classe de renda

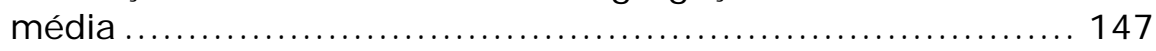


APÊNDICE E - Modelo comparando motoristas entrevistados em rodovias pedagiadas e em não pedagiadas.......................... 148

APÊNDICE F - Modelos com dummies para verificação de outras características associadas a variações no valor do tempo ...................... 149

APÊNDICE G - Observações sobre o valor negativo da constante específica .. 176

APÊNDICE H - Verificação da característica 'faixa de renda alta', para as viagens com duração entre 91 e 240 minutos ........................ 178

APÊNDICE I - Estimativa do valor do tempo com informações de PR ........... 179

APÊNDICE J - Influência da disponibilidade de tempo livre e da flexibilidade de horários na valoração do tempo.............................. 182

APÊNDICE K - Modelos segmentados por motivo de viagem para motoristas no eixo Campinas - São Paulo ................................. 183

APÊNDICE L - Distribuição das observações por faixa de renda para motivos lazer e não a lazer. ........................................ 184

APÊNDICE M - Compilação de valores de tempo em função da renda estimados em diferentes estudos...................................... 185 


\section{LISTA DE FI GURAS}

Figura 2-1: Diagrama de Beesley com diferenças de tempos e custos entre as alternativas......................................................... 26

Figura 2-2: Diagrama de Beesley e estimativa do valor do tempo de viagem... 27

Figura 2-3: Probabilidades de escolha em um modelo determinístico............ 28

Figura 2-4: Probabilidades de escolha em um modelo probabilístico.............. 29

Figura 4-1: A fronteira tecnológica e a abrangência da preferência revelada (PR) e declarada (PD) .................................................. 45

Figura 4-2: Relação entre informação obtida sobre a utilidade e o número de níveis definido para um atributo................................... 53

Figura 5-1: Localização dos pontos de pesquisa............................ 60

Figura 5-2: Formulário com as perguntas de preferência revelada...............64

Figura 5-3: Pergunta 1 da preferência declarada................................. 68

Figura 5-4: Pergunta 2 da preferência declarada................................. 68

Figura 5-5: Pergunta 3 da preferência declarada................................ 69

Figura 5-6: Pergunta 4 da preferência declarada............................. 69

Figura 5-7: Pergunta 5 da preferência declarada............................... 69

Figura 5-8: Pergunta 6 da preferência declarada................................ 69

Figura 5-9: Pergunta 7 da preferência declarada.............................. 70

Figura 5-10: Pergunta 8 da preferência declarada............................. 70

Figura 5-11: Pergunta 9 da preferência declarada.............................. 70

Figura 5-12: Exemplo ilustrativo da situação simulada na pesquisa.............. 72

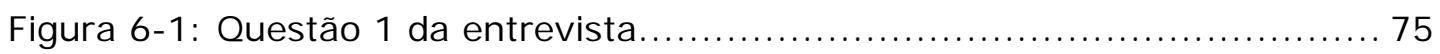

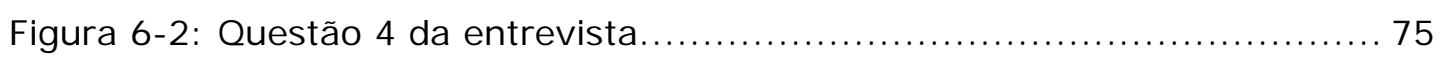

Figura 6-3: Composição da amostra por sexo do motorista...................... 78

Figura 6-4: Distribuição das idades do motorista na amostra..................... 79

Figura 6-5: Composição da amostra por posse do veículo...................... 79

Figura 6-6: Composição da amostra por posição na família....................... 80

Figura 6-7: Distribuição da posse de veículos na amostra..................... 80

Figura 6-8: Distribuição das classes de renda na amostra....................... 81

Figura 6-9: Distribuição das freqüências de viagem na amostra................. 81

Figura 6-10: Distribuição dos motivos de viagem na amostra................. 82

Figura 6-11: Distribuição dos tempos de viagem na amostra................... 83

Figura 6-12: Distribuição das escolhas por sexo do motorista................... 84

Figura 6-13: Distribuição das escolhas por posição na família................... 85

Figura 6-14: Distribuição das escolhas por faixa de renda.................... 86 
Figura 6-15: Características testadas nos modelos segmentados por faixa de duração da viagem.

Figura 6-16: Características que indicaram variações significativas no valor do tempo. 108

Figura 6-17: Probabilidades de uso de rota pedagiada para a variável renda, no segmento de viagens com duração de até 90 minutos..

Figura 6-18: Probabilidades de uso de rota pedagiada para a variável 'posse de 3 ou mais veículos', no segmento das viagens com duração entre 91 e 240 minutos.

Figura A-1: Modelos estimados para cada característica testada, nos segmentos de faixa de duração da viagem. 150 


\section{LISTA DE TABELAS}

Tabela 4-1: Formas de resposta mais utilizadas em entrevistas de preferência declarada

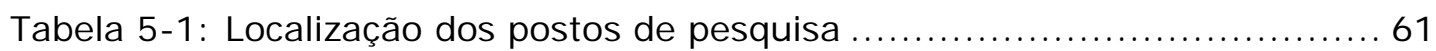

Tabela 5-2: Valores associados aos níveis dos atributos ....................... 66

Tabela 5-3: Desenho fatorial fracionado utilizado na pesquisa .................. 67

Tabela 6-1: Combinações de respostas inconsistentes em uma entrevista....... 76

Tabela 6-2: Resumo com o total de entrevistas eliminadas..................... 77

Tabela 6-3: Análise de variância para 'idade' e 'posse de veículos' ............... 87

Tabela 6-4: Análise de variância para 'faixa de renda' e 'posse de veículos'. .... 88

Tabela 6-5: Análise de variância para 'faixa de renda' e 'idade'.................. 88

Tabela 6-6: Distribuição na amostra das variáveis 'sexo do motorista' e 'faixa de renda'.

Tabela 6-7: Distribuição amostra nas variáveis 'motivo de viagem' e 'faixa de renda'.

Tabela 6-8: Resultados dos modelos inicialmente estimados para diferentes motivos de viagem

Tabela 6-9: Cruzamento das informações motivo da viagem e freqüência da viagem

Tabela 6-10: Modelos estimados por motivo de viagem após reclassificação das respostas

Tabela 6-11: Resultados dos modelos estimados para segmentos por faixa de renda familiar do motorista.

Tabela 6-12: Resultados dos modelos estimados para segmentos por faixa de duração da viagem.

Tabela 6-13: Resultados do modelo estimado para verificação de características associadas a variações no valor do tempo no segmento de viagens com até 90 minutos de duração.

Tabela 6-14: Estimativas do valor do tempo para as categorias analisadas no segmento das viagens com até 90 minutos de duração.

Tabela 6-15: Resultados do modelo estimado para verificação características associadas a variações no valor do tempo no segmento de viagens com duração entre 91 e 240 minutos.

Tabela 6-16: Estimativas do valor do tempo para as categorias analisadas no segmento das viagens com duração entre 91 e 240 minutos..... 114

Tabela A-1: Teste de independência da distribuição das observações das classes de renda nos motivos 'negócios' e 'trabalho diário'.

Tabela A-2: Teste de independência da distribuição das observações por faixas de tempo de viagem nos motivos 'negócios' e 'trabalho diário'.... 144

Tabela A-3: Nomenclatura dos coeficientes do modelo apresentado. 145 
Tabela A-4: Nomenclatura dos coeficientes nos resultados dos modelos com

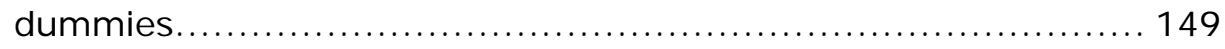

Tabela A-5: Estimativa do valor do tempo através de valores informados..... 179

Tabela A-6: Resultados da regressão para obtenção dos parâmentros da função de utilidade com dados de PR.................................. 181

Tabela A-7: Resultados dos modelos por motivo de viagem para a amostra pesquisada no eixo Campinas - São Paulo........................ 183

Tabela A-8: Teste de independência da distribuição das observações por faixa de renda para os motivos 'lazer' e 'não lazer'.......................... 184

Tabela A-9: Valores do tempo de viagem em função da renda estimados por diversos estudos................................................... 185 


\section{I NTRODUÇÃO}

\subsection{J ustificativa}

O valor que se atribui ao tempo de viagem das pessoas é uma variável crítica nas análises de benefícios associados a projetos de transporte e em estudos envolvendo previsões de escolha modal ou de rotas.

Uma aplicação particular que descreve a importância dessa variável é dada pelos estudos de simulação da escolha de rotas e alocação de viagens em redes. Softwares comumente utilizados nesses estudos trabalham com funções de impedância - ou custo generalizado - nas quais o valor do tempo é essencial para que elementos de custo monetário que influenciam fortemente na atratividade de uma rota, como as cobranças de pedágio, sejam representados juntamente com elementos de tempo ${ }^{1}$. Assim, o valor que se atribui à variável 'valor do tempo de viagem' é decisivo no resultado de uma simulação (VAN ZYL; RAZA, 2006).

Não é incomum que, na prática, se admita essa variável como sendo igual ao valor do salário médio horário das pessoas. Esse valor, no entanto, pode estar pouco relacionado com aquele que as pessoas associam subjetivamente ao seu tempo de viagem, e que é o realmente considerado na tomada de uma decisão como uma escolha de rota ou de um modo de transporte.

Este estudo utilizará um procedimento empírico para a estimativa do valor subjetivo do tempo com técnicas de preferência declarada que, de acordo com Ortúzar e Willumsen (2001), tornaram-se o método mais utilizado e recomendado para a obtenção dessa variável.

\footnotetext{
${ }^{1}$ Hensher e Goodwin (2004) reconhecem a legitimidade e o amplo uso da variável 'valor do tempo de viagem' como um dos parâmetros de calibração da alocação de viagens em redes, em modelos que trabalham com funções de custo generalizado. Esses autores citam, no entanto, uma série de importantes recomendações neste tipo de aplicação.
} 
A preferência declarada é um tema relativamente recente no campo dos transportes, sendo suas primeiras aplicações datadas do início dos anos 80 (KROES; SHELDON, 1988). Se no início de seu uso pairavam grandes dúvidas sobre sua confiabilidade, com o constante aprimoramento e a experiência acumulada vem se tornando uma técnica de aceitação quase unânime na área dos transportes, já fazendo parte da prática dos estudos de demanda. Ortúzar e Willumsen (2001) no início desta década já citavam haver suficientes evidências de que o uso das técnicas de preferência declarada, adequadamente aplicadas, pode levar a resultados confiáveis. Atualmente, em países como a Inglaterra é comum que os próprios clientes exijam a utilização de técnicas de preferência declarada em determinados estudos (BATES, 1998). Diante desse cenário, convém que pesquisadores e analistas envolvidos com estudos de demanda de transportes estejam familiarizados com a aplicação dessas técnicas.

\subsection{Objetivos}

A aplicação de um procedimento para a estimativa do valor subjetivo do tempo de viagem e, principalmente, a compreensão geral do processo para tal estimativa, representam os objetivos deste estudo. Assim, tem-se aqui a intenção de percorrer um conjunto de etapas em busca do valor subjetivo do tempo de viagem, empregando técnicas de preferência declarada, seguidas da aplicação de modelos de escolha para a obtenção de funções de utilidade.

Com relação à aplicação dos procedimentos práticos, será também um dos objetivos deste trabalho a análise da variação do valor do tempo de viagem para diferentes grupos de indivíduos ou diferentes tipos de viagem, presentes na amostra. 


\subsection{Metodologia}

Este trabalho inicia-se com a revisão bibliográfica de estudos sobre a valoração do tempo sob o aspecto teórico. Com isso, pretende-se analisar quais fatores seriam condicionantes ao valor que cada pessoa atribui ao seu tempo, em particular o tempo de viagem. Será dada atenção à questão que justificaria o estudo aqui desenvolvido: se esse valor subjetivo do tempo pode ou não ser considerado como igual à renda salarial da pessoa ${ }^{2}$. Ainda sobre o valor do tempo, serão também revisadas as formas empíricas utilizadas para a sua estimativa.

A revisão de aspectos teóricos pertinentes ao desenvolvimento da metodologia compreenderá ainda dois temas fundamentais: i) a teoria da escolha, e ii) a preferência declarada.

Sob o aspecto prático, este estudo utilizará como base para a aplicação dos conceitos estudados o conjunto de informações de uma pesquisa de preferência declarada realizada em 2005 com motoristas de automóveis nas principais rodovias do estado de São Paulo. Essa pesquisa consistiu da realização de entrevistas em campo em 28 pontos, incluindo rodovias pedagiadas e não pedagiadas. Sua descrição detalhada será apresentada no capítulo 5. A metodologia de aplicação dos procedimentos consistirá fundamentalmente das seguintes etapas:

- Análise do conjunto de informações da pesquisa de preferência declarada disponível e estabelecimento de critérios para definição das entrevistas que serão aproveitadas para o estudo.

\footnotetext{
${ }^{2}$ Caso a teoria indique que o valor subjetivo do tempo de viagem possa ser simplesmente dado pela renda de cada indivíduo, a utilização de procedimentos empíricos para sua estimativa, como o aqui estudado, seria dispensável.
} 
- Estimativa de modelos de escolha discreta e obtenção dos parâmetros das funções de utilidade, que permitem estimar o valor subjetivo do tempo.

- Utilização de diferentes especificações para a função de utilidade que permitam a observação da variação do valor subjetivo do tempo para pessoas e viagens com características distintas.

No item 1.4 a seguir descreve resumidamente o desenvolvimento das etapas citadas acima dentro da estrutura deste trabalho.

\subsection{Estrutura da Dissertação}

Inicialmente será feita no capítulo 2 uma descrição da base teórica para a valoração do tempo de viagem sob o ponto de vista da teoria microeconômica. A seguir, será revisada a evolução dos procedimentos empíricos utilizados para estimativas dessa variável.

Sendo a obtenção de um modelo de escolha discreta uma etapa fundamental neste estudo, o capítulo 3 fará uma revisão de aspectos pertinentes à teoria da escolha, em particular a teoria da utilidade aleatória, buscando um entendimento mínimo de como se dá o processo de decisão individual, seus elementos e regras. A seguir, serão brevemente discutidos os principais tipos de modelos de escolha e suas características, sendo dada ênfase ao modelo logit multinomial.

O capítulo 4 tratará do tema central deste estudo, sob o aspecto metodológico: os dados de preferência declarada. Serão abordadas as características das informações obtidas por esse método e a comparação desse tipo de dado com os obtidos através de preferência revelada. Também serão revisadas algumas das atividades e conceitos envolvidos no planejamento de uma pesquisa de 
preferência declarada, como a definição do desenho do experimento e do formato da pesquisa.

A parte prática deste estudo, como mencionado, utilizará como base o conjunto de informações de uma pesquisa de preferência declarada. No capítulo 5, é feita a descrição de aspectos operacionais envolvendo a execução dessa pesquisa. São também apresentados formulários e as variáveis levantadas nas entrevistas.

O capítulo 6 compreende as análises feitas sobre a base de informações disponível. São inicialmente discutidos os critérios utilizados para a eliminação de entrevistas inválidas. A seguir é apresentada uma caracterização geral da amostra coletada, visando verificar as possibilidades de sua segmentação e a forma de relacionamento entre algumas variáveis pesquisadas. Posteriormente são estimados modelos de escolha para alguns segmentos da amostra, sendo analisada a variação do valor do tempo de viagem para cada um dos segmentos considerados. A análise da variação do valor do tempo de acordo com algumas características do motorista e da viagem é, em seguida, complementada com a estimativa de funções de utilidade com variáveis dummies para representação de efeitos adicionais para cada segmento.

Finalmente, o capítulo 7 apresenta um resumo dos resultados mais relevantes obtidos neste estudo, e lista, com base na experiência aqui adquirida, alguns aprimoramentos que podem ser implementados em estudos futuros. Esse capítulo termina retomando a questão da importância da variável valor do tempo de viagem no novo contexto dado pela participação da iniciativa privada em projetos de infra-estrutura de transportes, o que vem exigindo maior precisão nos estudos de previsão de demanda. 


\title{
2. VALORAÇÃO DO TEMPO DE VI AGEM
}

\begin{abstract}
Por que nos preocupamos com as economias em tempos de viagem? Por que associamos um valor a essas? Será porque não gostamos de viajar? Ou porque, em vez disso, gostaríamos de estar fazendo algo mais prazeroso? Ou porque poderíamos estar trabalhando mais e ganhando mais dinheiro? (MACKIE; JARADÍAZ; FOWKES, 2001).
\end{abstract}

\subsection{Histórico}

A idéia da atribuição de um valor ao tempo gasto em qualquer atividade começou com Becker (1965), em sua teoria da alocação do tempo. Nesse estudo, o valor do tempo era descrito como o custo de oportunidade de se alocar tempo em qualquer atividade que não o trabalho, o que era justificado pelo fato de que esse tempo poderia ser convertido em dinheiro se um indivíduo passasse mais horas no trabalho. Este princípio foi a origem do conceito do valor do tempo ${ }^{3}$ como equivalente ao salário horário do indivíduo.

Após o estudo de Becker, Johnson (1966) propôs que a utilidade - ou satisfação - de um indivíduo seria originalmente composta do tempo alocado ao trabalho (W), às atividades de lazer (L) e ao consumo (G); ou seja, cada indivíduo buscaria a maximização de sua utilidade considerando os três componentes:

$U_{\max }=U(W, L, G)$

A idéia foi apresentada de forma semelhante por Oort (1969), que deu importante contribuição, do ponto de vista do transporte, ao analisar a função de bem-estar individual e mencionar que deveria ser incluído nessa função o tempo

\footnotetext{
${ }^{3}$ Ou o valor da hora.
} 
exógeno de viagem, ou seja, aquele cuja alteração não depende do indivíduo 4 . Oort justificou tal hipótese com base no fato de que reduções nesse tempo de viagem, além de representarem aumento na disponibilidade para o trabalho e o lazer, aumentariam também a utilidade, ou bem-estar, do indivíduo através da redução da duração de uma atividade não aprazível que seria a viagem em si (JARA-Dí AZ, 2000). Assim, a nova forma proposta por Oort para a função seria dada por:

$U=U\left(t_{w}, t_{l}, t_{r}, \gamma\right)$

Onde $t_{w}$ representa a quantidade de tempo dedicado ao trabalho, $t_{l}$, a quantidade de tempo destinado ao lazer, $t_{r}$, o total do tempo de viagem exógeno e $\gamma$, a renda salarial do indivíduo. O tempo total disponível para cada indivíduo seria definido por:

$T=t_{w}+t_{l}+t_{r}$

Ressalta-se que na forma tradicional da função de bem-estar individual, os tempos considerados eram apenas aqueles alocados ao trabalho e ao lazer ${ }^{5}$.

No início dos anos 70, De Serpa (1971) publicou estudo em que estabelecia o conceito do tempo como um recurso e definia o valor de se estendê-lo, que seria equivalente à taxa entre a utilidade marginal do tempo e a utilidade marginal da renda (MACKIE; JARA-DÍAZ; FOWKES, 2001).

Observa-se que, se o estudo inicial de Becker considerava o valor do tempo, indistintamente de qual atividade era aplicado, o de Oort analisou o tempo de

\footnotetext{
${ }^{4}$ Alterações nesse tempo de viagem ocorrem como resultado de um evento exógeno, como a instalação de um modo de transporte mais rápido, ou a construção de um shopping center mais próximo, por exemplo (OORT, 1969).

${ }^{5}$ Em sua forma tradicional, a função era dada por $U=U\left(t_{w}, t_{l}, \gamma\right)$, onde $t_{w}$ representa a quantidade de tempo dedicado ao trabalho, $t_{l}$, a quantidade de tempo destinado ao lazer, e $\gamma$, a renda salarial do indivíduo; o tempo total disponível seria: $T=t_{w}+t_{l}$ (OORT, 1969).
} 
viagem isoladamente ${ }^{6}$, e De Serpa, o valor de tempo para cada atividade à qual se aloca alguma quantidade de tempo.

A bibliografia sobre o assunto (GONZÁLEZ, 1997, JARA-DÍAZ, 2000, MACKIE; JARA-DÍAZ; FOWKES, 2001), cita também como um estudo que trouxe importantes contribuições na abordagem teórica do valor do tempo, o de Evans (1972), que formulou um modelo de comportamento do consumidor onde a utilidade dependeria apenas do tempo alocado às atividades.

O artigo de Train e McFadden (1978), abordando o denominado goods/leisure tradeoff, tornou-se uma referência para o assunto, e também sua releitura, feita anos depois por Jara-Díaz e Farah (1987). Esses são descritos no item sobre o valor subjetivo do tempo, a seguir.

\subsection{O Valor Subjetivo do Tempo de Viagem}

O chamado valor subjetivo do tempo de viagem é definido por Mackie, Jara-Díaz e Fowkes (2001) como a predisposição que um indivíduo tem de pagar por uma redução de seu tempo de viagem em uma unidade. Este valor reflete a soma de pelo menos dois efeitos: i) a vontade de substituir o tempo perdido na viagem por uma atividade mais agradável ou útil, e ii) a percepção direta da redução na duração da viagem7 (J ARA-DÍ AZ; GUEVARA, 2003).

No dia a dia, nossas decisões envolvendo transporte são fortemente influenciadas pelo valor que atribuímos ao nosso tempo. Optamos por usar o carro para ir ao trabalho, ao invés do ônibus, porque desta forma ganhamos

\footnotetext{
${ }^{6}$ Apenas como ilustração: Oort (1969) estimou empiricamente que o valor do tempo de viagem seria igual a um terço de sua renda horária; Becker concluiu ser o valor do tempo alocado em qualquer atividade que não o trabalho, equivalente ao valor da renda por hora do indivíduo (Mackie, Jara-Díaz e Fowkes, 2001).

${ }^{7}$ Ou seja, a vontade de minimizar a duração de uma atividade supostamente incômoda que é a viagem em si.
} 
tempo para outras atividades, ainda que isto implique em maior custo de transporte. Ou quando precisamos ir a uma região congestionada para retirar um documento, preferimos pagar um serviço de entregas a enfrentar o trânsito e perder preciosas horas de trabalho.

Tais situações e decisões, embora pareçam naturais a muitas pessoas, envolvem, no entanto, um forte caráter subjetivo. Um trabalhador de baixa renda, uma pessoa em fase de dificuldades financeiras, ou um estudante do segundo grau, por exemplo, provavelmente analisariam as questões acima de outra forma. A composição, para cada indivíduo, de seu tempo disponível, nível de renda e situação financeira ditará sua decisão.

Esta observação encontra respaldo na formulação proposta por Train e McFadden (1978), segundo a qual a utilidade do indivíduo é uma função a ser maximizada, composta pelos bens consumidos $(G)$ e por seu tempo de lazer $(L)$ :

$U=\max (G, L)$

sendo,

$G=V+w \cdot W-c$

$L=T-W-t$

Na representação, o total de bens ou dinheiro (G) disponível é formado pela combinação da renda não proveniente do trabalho (V), pelo produto entre salário-hora, ou taxa de renda (w), e total de horas trabalhadas (W) e pelo custo de transporte casa-trabalho, e vice-versa (c). O tempo de lazer (L) é definido pelo tempo total disponível $(T)$, subtraído da quantidade de horas de trabalhadas (W) e do tempo de transporte casa-trabalho, e vice-versa (t).

Jara-Díaz (2002) demonstrou que, de acordo com o modelo de Train e McFadden, o valor subjetivo do tempo de viagem (VST) seria dado por três parcelas: i) a taxa de renda, ou salário por hora (w), ii) o valor subjetivo do trabalho puro, ou seja, os bens equivalentes a uma unidade de tempo adicional 
no trabalho, e iii) o valor subjetivo puro da viagem, dado pelos bens equivalentes a uma unidade de tempo economizado em uma viagem. A representação matemática seria:

$V S T=w+\frac{\partial U / \partial W}{\partial U / \partial G}-\frac{\partial U / \partial t_{i}}{\partial U / \partial G}$

Na equação acima, o termo $\partial U / \partial W$ representa a utilidade marginal do trabalho, $\partial U / \partial G$, a utilidade marginal da renda e $\frac{\partial U / \partial t_{i}}{}$, a utilidade marginal do tempo de viagem.

Observa-se da equação acima que, admitindo-se a hipótese de que as pessoas gostam do seu trabalho e não gostam de viajar, o VST será, sim, maior do que a taxa de renda ${ }^{8}$ (JARA-DÍAZ, 2000). Outra interpretação da formulação é que uma economia de, por exemplo, uma hora no tempo de viagem seria vista pelo indivíduo como mais dinheiro (w), mais satisfação obtida no trabalho e menos desprazer com a viagem (JARA-DíAZ, 2002).

Embora o caso geral seja o das pessoas associando uma desutilidade ao tempo gasto de viagem, como demonstrado em Jara-Díaz e Guevara (2003), há que se comentar um caso onde tal regra seria quebrada: pessoas que enxergam aborrecimentos do trabalho em uma ponta e deveres com a casa e a família em outra, veriam a viagem como um oásis de tranqüilidade durante o dia, onde teriam a 'companhia' de Beethoven no carro (MACKIE; JARA-DÍAZ; FOWKES, 2001). Tais motoristas teriam, pela equação, um VST menor do que suas taxas de renda, o que é bastante lógico se observarmos que esses teriam menor predisposição em pagar por reduções nos seus tempos de viagem.

\footnotetext{
${ }^{8} \mathrm{Na}$ verdade ocorre que as pessoas, em geral, vêem com desutilidade o tempo gasto no trabalho e, assim, o termo $\partial U / \partial W$ tem sinal nagativo, como demonstrado por Jara-Díaz e Guevara (2003).
} 
Uma crítica aos modelos tradicionais de alocação do tempo ${ }^{9}$, focados no tradeoff entre tempo gasto no trabalho e no lazer, é feita ao fato de que esses consideram como premissa ser o total de horas trabalhadas infinitamente flexível, podendo ser livremente variado pelo indivíduo, o que é uma hipótese bastante irrealista para grande parte das pessoas (BATES; ROBERTS, 1986).

Respondendo a essa questão, Jara-Díaz e Farah (1987) fizeram uma releitura do modelo de Train e McFadden, considerando o caso de um indivíduo com renda exógena, ou seja, aquele com salário fixo, sem a possibilidade de decidir trabalhar mais ou menos horas. Para esse caso, foi demonstrado que o valor subjetivo do tempo de viagem seria dado pelo valor monetário do lazer, menos o valor monetário subjetivo puro da viagem, sendo essa última parcela dada pelos bens equivalentes a uma unidade de tempo economizado na viagem (JARADí AZ, 2002). A representação matemática é dada por:

$V S T=\frac{\partial U / \partial L}{\partial U / \partial G}-\frac{\partial U / \partial t_{i}}{\partial U / \partial G}$

Observa-se que a taxa de renda (w) não aparece diretamente nesta formulação ${ }^{10}$. Nota-se também que a equação representa a definição dada no início deste capítulo para o valor subjetivo do tempo de viagem: a de que esse representa o efeito da vontade de substituir o tempo de viagem por uma atividade mais agradável, e o da percepção direta da redução da viagem.

Conclui-se, então, pelos modelos baseados na teoria econômica, que o valor subjetivo do tempo de viagem seria, a princípio, diferente para pessoas com liberdade para definir sua carga horária de trabalho, e para aquelas com uma carga pré-determinada de horas a cumprir.

\footnotetext{
${ }^{9}$ Como os de Becker (1965), Oort (1969) e Train e McFadden (1978).

${ }^{10}$ Isso não significa, no entanto, que para esses indivíduos o VST não seja influenciado por restrições de financeiras. Para abordagem mais aprofundada no assunto, ver em Jara-Díaz e Farah (1987) ou Jara-Diaz (2002) a definição do conceito de taxa de despesas (expenditure rate).
} 
Outra observação importante que se faz da formulação do VST para cada um dos dois casos (indivíduos com carga de trabalho e salários flexíveis e indivíduos com renda fixa), é que a única componente de mensuração direta é a taxa de renda (w), vinculada ao salário-hora das pessoas. Todas as demais têm seu valor dado intuitivamente (ou subjetivamente) pelos indivíduos que realizam a viagem, sendo necessárias abordagens empíricas para sua estimativa (MACKIE; JARADÍAZ; FOWKES, 2001). Estas serão discutidas no capítulo 2.5.

\subsection{O Valor Social do Tempo de Viagem}

Com relação ao valor do tempo e sua mensuração nos transportes, parte dos estudos utiliza-o como uma ferramenta para a análise e modelagem do comportamento de escolha do consumidor, e outra parte, como um insumo para estimativa de benefícios em avaliação de projetos (DOMENCICH; MCFADDEN, 1975). Ou seja, a valoração do tempo de viagem compreende dois enfoques: i) o do valor subjetivo, ou comportamental, e ii) o do valor para avaliação, ou social (ORTÚZAR; WILLUMSEN, 2000).

Embora o propósito do presente estudo tenha nitidamente seu foco na investigação do valor subjetivo do tempo, será apresentada uma breve abordagem da questão do valor social do tempo.

O valor social - ou para avaliação - do tempo é geralmente utilizado como parte de uma análise custo-benefício, na valoração das alterações de tempos de viagem proporcionados por projetos financiados com dinheiro da sociedade, como os originados da arrecadação de impostos (JARA-DIAZ, 2000), ou de recursos obtidos junto a organizações e bancos de desenvolvimento.

As economias em tempos de viagem representam o benefício individual mais importante nos projetos de melhorias de transporte (ORTÚZAR; WILLUMSEN, 
2001). Em projetos de novas ligações rodoviárias, estima-se que cerca de $80 \%$ dos benefícios monetarizados para os usuários $^{11}$ sejam derivados de economias de tempo de viagem (HEGGIE, 1983; BATES; ROBERTS, 1986; STRAND, 1993; MACKIE et al., 2002). Assim, análises de viabilidade e de comparação de desempenho entre projetos de infra-estrutura de transportes têm no valor social do tempo uma variável decisiva ${ }^{12}$.

Com relação à sua valoração, não há razão para que o valor da predisposição que um indivíduo tem em pagar por uma redução no tempo de viagem seja igual ao valor que a sociedade como um todo associa à realocação do tempo desse indivíduo a outras atividades. Dessa forma, o uso do valor subjetivo do tempo seria inadequado para avaliações de $\operatorname{projetos}^{13}$.

Sobre as economias de tempo de viagem para avaliação, encontra-se na bibliografia comumente a distinção entre as viagens de trabalho e não a trabalho. Mackie, Jara-Díaz e Fowkes (2001) sustentam que seriam três, e não duas, as categorias típicas de viagem a analisar: i) uma viagem a lazer ${ }^{14}$, onde o tempo ganho representaria um aumento no tempo total para todas as atividades de lazer; ii) uma viagem ao trabalho diário, que seria semelhante à de lazer, do ponto de vista de que o tempo pertence ao indivíduo, mas com maior desutilidade da viagem devido a condições de congestionamento e aglomerações, e; iii) uma viagem feita durante o período de trabalho.

\footnotetext{
${ }^{11}$ Cabe aqui comentar que a incidência inicial das economias de tempo e a incidência final dos benefícios dessas podem não ser as mesmas. Ocorre que os benefícios mais aparentes de uma melhoria de transporte são as economias de tempo para os viajantes - e é conveniente e viável computar os benefícios desse ponto de vista. Os beneficiários finais, no entanto, podem ser uma composição de viajantes, donos de propriedade e empresas, consumidores e trabalhadores (Mackie, Jara-Díaz e Fowkes, 2001).

12 Sobre essa questão, Strand (1993) apresenta uma revisão e crítica à manipulação do valor atribuído ao tempo em avaliações sócio-econômicas, visando melhorar o desempenho ou conferir maior viabilidade a determinados projetos.

${ }^{13}$ Não serão aqui abordadas metodologias e formulações para estimativa do valor social do tempo, o que pode ser encontrado em Jara-Díaz e Galvez (1998), um estudo considerado por Ortúzar e Willumsen (2001) como uma referência no tema.

${ }^{14}$ Como uma visita a parentes ou amigos, ou uma viagem ao shopping center.
} 
Para essa última categoria, pode-se considerar que o valor para avaliação das economias de tempo, pela abordagem que considera o tempo como um recurso da produção, seja dado pela renda horária de cada indivíduo ${ }^{15}$ (JARA-DíAZ, 2000).

No entanto, percebe-se que nas duas primeiras categorias de viagens, a teoria não permite dizer qual a relação entre o valor do tempo não a trabalho e a renda horária, sendo necessárias abordagens empíricas para sua estimativa, como a aplicação de modelos de escolha discreta de viagens (JARA-Dí AZ, 1994), método que será abordado a seguir.

\subsection{Abordagem Empírica}

Como observado nos capítulos anteriores, embora a teoria microeconômica forneça modelos complexos para a associação de um valor monetário ao tempo de viagem, tanto o valor subjetivo como o valor para avaliação do tempo, têm componentes que só podem ser estimados através de procedimentos empíricos.

Beesley (1965) foi pioneiro em identificar e propor um método para valoração das economias de tempo de viagem. Em seu estudo, considerado um clássico no tema, apresentou o que ficou conhecido como o Gráfico de Beesley. Nesse gráfico, foram divididas em quatro possibilidades as combinações de diferenças entre tempos e custos de duas alternativas, para uma escolha modal de transporte. Em uma representação dos dados observados, classificou os

\footnotetext{
${ }^{15}$ Esta suposição tem como premissas que: i) todo o tempo ganho na viagem seja usado para fins produtivos; ii) o tempo de viagem é totalmente improdutivo e; iii) a taxa de renda do trabalhador seja igual ao valor do produto marginal do trabalho (Mackie, Jara-Díaz e Fowkes, 2001).
} 
viajantes em traders e non-traders ${ }^{16}$, ou seja, aqueles que negociam a combinação tempo x custo e aqueles não a negociam.

$\mathrm{Na}$ representação mostrada na Figura 2-1, os non-traders representam as observações pertencentes aos quadrantes 1 (maior tempo e maior custo) e 3 (menores tempo e custo). Essa parcela da amostra não era considerada para as estimativas.

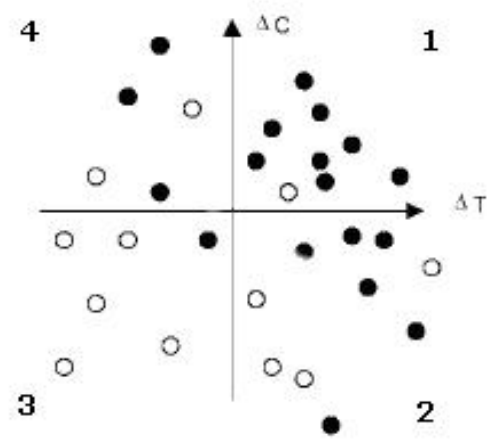

Figura 2-1: Diagrama de Beesley com diferenças de tempos e custos entre as alternativas $^{17}$. Fonte: Hensher (2001)

A partir da plotagem das observações dos traders, nos quadrantes 2 e 4, Beesley traçou a reta $A B$, cujo gradiente ' $\theta$ ' definiria o valor do tempo de viagem ${ }^{18}$ para os usuários analisados (HENSHER, 2001), como mostrado na Figura 2-2 .

\footnotetext{
${ }^{16}$ Um trader, em uma escolha de dois atributos, é uma pessoa que aparentemente escolhe uma alternativa que é melhor em um atributo e pior no outro. Um non-trader utiliza uma alternativa que é pior ou melhor em ambos os atributos (Hensher, 2001).

${ }^{17}$ No gráfico, os círculos brancos referem-se à escolha pela alternativa 1, transporte privado, e os pretos, à alternativa 2, transporte público no experimento realizado.

${ }^{18} \mathrm{O}$ valor do tempo de viagem calculado por Beesley em seu experimento de 1965 foi estimado em um terço da renda média dos trabalhadores do Reino Unido (DOMENCICH; MCFADDEN, 1975).
} 


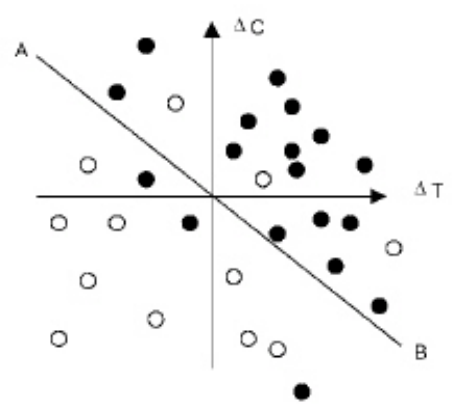

$\mathrm{AB} \quad \Delta \mathrm{C}=\theta \Delta \mathrm{T}$

Figura 2-2: Diagrama de Beesley e estimativa do valor do tempo de viagem. Fonte: Hensher (2001)

Embora inovador à época, o método proposto por Beesley apresentava limitações, como dificuldades na representação gráfica quando o número de atributos envolvidos era maior do que dois e com relação à incorporação de atributos não observados (ROGER et al., 1970 apud HENSHER, 2001). Outro aspecto é que muitos dos indivíduos classificados como traders, poderiam na verdade não estar realizando nenhuma compensação - ou tradeoff - entre custo e tempo das alternativas: esses embora estivessem nos quadrantes 2 e 4 poderiam estar decidindo com base em outros critérios que não a otimização das variáveis tempo e tarifa ${ }^{19}$.

O método do gráfico de Beesley constitui um típico exemplo de estimativa do valor do tempo usando uma base de dados obtida através da observação de decisões tomadas pelas pessoas em um determinado contexto ${ }^{20}$.

Outro método para valoração empírica do tempo citado na bibliografia envolve abordagens de regressão usando dados obtidos pelo denominado transfer-price, que pode ser entendido como o custo que deveria ser acrescido a uma alternativa para tornar sua atratividade igual a uma outra (ORTÚZAR; WILLUMSEN, 2001). Envolve, por exemplo, perguntar ao entrevistado quanto a

\footnotetext{
${ }^{19}$ Nesse caso, uma simples mudança em tarifas e tempos relativos lançaria essa parcela de pessoas aos quadrantes 1 ou 3 (HEGGIE, 1983).

${ }^{20}$ Como será definido a seguir, trata-se de uma base de dados de preferência revelada.
} 
tarifa de seu modo preferido de transporte deveria aumentar para fazê-lo mudar para uma outra alternativa. De acordo com Gunn (2000), esse método chegou a ser aplicado por alguns pesquisadores nos anos 60 . Sua limitação é devida ao tratamento determinístico dado aos erros na estimativa da atratividade de uma alternativa.

A evolução nos estudos que visavam estimar os valores de tempo foi trazida pela aplicação dos modelos de escolha. Essa abordagem reconhece os erros aleatórios pertinentes ao processo de medição, atribuindo probabilidades de escolha a uma alternativa, ao invés de determiná-la, mesmo quando as observações ou medições de custo e tempo indicam nesse sentido. No caso da representação de uma escolha em um modelo determinístico, tem-se que probabilidade de um decisor escolher a alternativa cujas medições indiquem ser a de maior atratividade (ou utilidade) é de 100\%, o que não ocorre em um modelo probabilístico, no qual haverá uma probabilidade maior de escolha da alternativa de maior utilidade estimada.

As figuras abaixo mostram a diferença conceitual entre os tipos de modelo. $\mathrm{Na}$ Figura 2-3 observa-se que, por um modelo determinístico, caso o custo da alternativa 2 seja ligeiramente ou infinitamente maior do que o da alternativa 1 , a chance dessa última ser escolhida será sempre de $100 \%$.

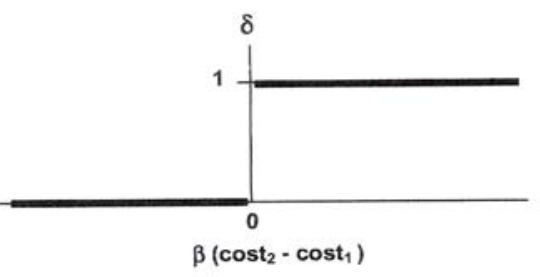

Figura 2-3: Probabilidades de escolha em um modelo determinístico

Em um modelo probabilístico as chances de escolha crescem ou decrescem de acordo com a diferença entre os custos ou atratividades das alternativas, como mostrado na Figura 2-4. 


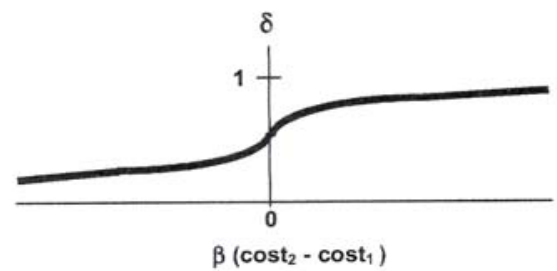

Figura 2-4: Probabilidades de escolha em um modelo probabilístico

O procedimento adotado para estimativa do valor do tempo neste estudo utilizará a abordagem dos modelos de escolha probabilísticos, cuja base teórica será discutida no capítulo a seguir. 


\section{TEORI A DA ESCOLHA}

Os procedimentos empíricos atualmente adotados para a estimativa do valor do tempo de viagem envolvem a utilização de um modelo de escolha discreta. Assim, antes de seguir adiante neste estudo, faz-se necessária uma abordagem dos fundamentos do processo de escolha, bem como a compreensão da teoria da utilidade aleatória e dos modelos de escolha discreta.

\subsection{Elementos do Processo de Escolha}

De acordo com Ben-Akiva e Lerman (1985), a escolha é um conjunto de procedimentos que compreende os elementos: i) o tomador de decisão; ii) as alternativas; iii) os atributos das alternativas, e iv) as regras de decisão.

O primeiro elemento, o tomador de decisão, pode ser uma única pessoa ou um grupo, como uma família ou uma empresa. As alternativas que se apresentam ao tomador de decisão são um subconjunto do universo de alternativas possíveis (BEN-AKIVA; LERMAN, 1985). Este subconjunto, comumente definido na bibliografia como o conjunto de escolha, deverá conter alternativas viáveis e familiares ao decisor. Por exemplo, não seria adequada, em uma pesquisa sobre escolha modal junto a trabalhadores de baixa renda, a apresentação do modo táxi como uma das alternativas para deslocamento diário. Ainda com relação ao conjunto de escolha, as alternativas apresentadas devem ser mutuamente excludentes, ou seja, a escolha de uma alternativa necessariamente implica na não escolha das 
demais, e as alternativas devem ser exaustivas, isto é, todas as possibilidades devem estar inclusas ${ }^{21}$ (TRAIN, 1986).

Os atributos das alternativas consistem das variáveis consideradas relevantes para um determinado processo de decisão. Para cada alternativa avaliada, estes são medidos em uma escala de atratividade que pode ser cardinal ou ordinal (BEN-AKIVA; LERMAN, 1985). No caso cardinal podem ser encaixados atributos como tempo, custo de viagem e atrasos. Já outros, como confiabilidade, segurança e conforto, por não poderem ser expressos em valores absolutos, podem ser avaliados apenas em termos comparativos relativos (como por ordenação) entre as alternativas disponíveis.

Com relação às regras de decisão, estas podem ser classificadas em quatro categorias (BEN-AKIVA; LERMAN, 1985): i) dominância, ii) satisfação, iii) lexicográficas e iv) utilidade. Alguns autores, como Ortúzar e Willumsen (2001), definem a decisão como regida por regras compensatórias e não compensatórias, sendo a 'utilidade' pertencente ao primeiro caso e as três demais citadas por Ben-Akiva e Lerman, ao segundo.

A dominância ocorre quando uma alternativa é melhor que as demais em pelo menos um atributo e não pior ${ }^{22}$ nos demais atributos. É, para o decisor, o menos controverso, mas também o menos usual processo de escolha no mundo real.

O critério da satisfação é geralmente usado para a eliminação de alternativas que não atendam a um determinado requisito mínimo do decisor, requisito este formado com base em experiências ou conhecimento anteriores. Por exemplo, um motorista acostumado a realizar diariamente um trajeto em 30 minutos provavelmente descartará de imediato quaisquer alternativas

\footnotetext{
${ }^{21}$ Este último aspecto, embora pareça complexo, na verdade pode ser resolvido acrescentando-se ao conjunto das alternativas apresentadas a opção 'nenhuma das anteriores'.

22 Inclui-se nesta avaliação de 'não pior' por parte do decisor uma faixa de indiferença para cada atributo. Por exemplo, para um determinado indivíduo, diferenças de tempos de viagem inferiores a 5 minutos entre diferentes alternativas podem ser entendidas como níveis iguais para este atributo na tomada de decisão.
} 
envolvendo um tempo de viagem como 50 minutos, independentemente dos demais atributos relacionados a esta. Dificilmente a utilização deste critério isoladamente levará à escolha final, sendo este combinado com outros critérios pelo tomador de decisão (BEN-AKIVA; LERMAN, 1985).

A forma de decisão dada por regras lexicográficas, também denominada escolha por eliminação (ORTÚZAR; WILLUMSEN, 2001), implica que o decisor opte pela alternativa mais atrativa para o atributo que este considera mais importante. Caso este critério não leve à eliminação de todas menos uma alternativa adota-se o mesmo procedimento para o segundo atributo mais importante e, sucessivamente, até que reste apenas uma alternativa. Por este critério, em uma hipotética escolha modal envolvendo automóvel, ônibus e metrô, onde o decisor considere o custo de viagem como fator principal, este eliminaria a alternativa relativa ao automóvel, restando o ônibus e o metrô. Sendo, por exemplo, a previsibilidade no tempo de espera o segundo atributo mais importante para este indivíduo, seria eliminado o ônibus, sendo escolhido o metrô.

A escolha pela utilidade, ao contrário das anteriores, prevê que o tomador de decisão realize compensações entre os atributos de cada alternativa, ou tradeoffs, para a escolha de uma na qual seu benefício seja o maior possível. Pressupõe o 'comportamento racional', pelo qual se espera que um indivíduo avalie o conjunto de alternativas disponíveis e escolha aquela que the proporcione a maior satisfação relativa. Esse critério de decisão implica que a atratividade de uma alternativa, expressa por um vetor de valores de cada atributo, seja redutível a um índice (BEN-AKIVA; LERMAN, 1985), permitindo a comparação numérica entre a atratividade das alternativas pertencentes a uma escolha. O índice de atratividade de uma alternativa em relação às demais dentro de um mesmo conjunto de escolha pode ser definido como sua utilidade.

Se o processo de associação de uma utilidade relativa a cada alternativa, permitindo uma escala de comparação dentro de um conjunto de escolha, é 
bastante conveniente, por outro lado, a construção deste índice é também sujeita a imprecisões e imponderabilidades, contempladas na teoria da utilidade aleatória, descrita a seguir.

\subsection{Teoria da Utilidade Aleatória}

A base teórica para a formulação dos modelos de escolha discreta é dada pela teoria da utilidade aleatória. A escolha pela utilidade, descrita anteriormente, tem como premissa fundamental que um indivíduo, em um processo de escolha, analise as variáveis envolvidas e tome suas decisões considerando todas estas, de forma a maximizar seu benefício, ou utilidade.

Assim, um tomador de decisão $n$ escolherá dentre o conjunto das $j$ alternativas disponíveis aquela que maximize sua utilidade. Este escolherá a alternativa $i$, se:

$U_{n i}>U_{n j} \quad \forall j \neq i$

Para a estimativa de uma função que relacione as variáveis observadas com a utilidade de uma alternativa para um decisor, têm-se dois grupos de variáveis: i) as relacionadas às características das alternativas e ii) as relativas às características do decisor. Assim, denominando-se $x_{n j}$ o vetor dos atributos das $j$ alternativas pertencentes ao conjunto de escolha do tomador de decisão $n$, e $r_{n} 0$ conjunto dos atributos relevantes relativos a este decisor, tem-se a utilidade descrita como (Train, 1986):

$V_{n j}=V\left(x_{n j}, r_{n}\right) \quad \forall j$

No entanto, em um processo de escolha, um indivíduo considera para sua decisão aspectos não contemplados na função $V_{n j}$ descrita, de modo que $U_{n j} \neq V_{n j}$. 
Ou seja, a utilidade de uma alternativa $j$ para um indivíduo $i$ é formada por uma parte observável ou mensurável, e uma parte não observável, como descrito a seguir:

$U_{n j}=V_{n j}+\varepsilon_{n j}$

Na equação, $\varepsilon_{n j}$ representa a parcela de fatores que também compõem a utilidade que o indivíduo $n$ percebe na alternativa $j$, mas que não são contemplados em $V_{n j}$. Esta parcela $\varepsilon_{n j}$, também denominada termo aleatório, reflete as idiossincrasias e gostos particulares de cada indivíduo, juntamente com os erros de observações e de medidas incorridos durante a modelagem (ORTÚZAR; WILLUMSEN, 2001).

Considerando-se a utilidade aleatória, a probabilidade $P$ de um decisor $n$ escolher uma dada alternativa $i$ será dada por:

$P_{n i}=P\left(U_{n i}>U_{n j}, \forall j \neq i\right)=P\left(V_{n i}+\varepsilon_{n i}>V_{n j}+\varepsilon_{n j}, \forall j \neq i\right)$

Esta probabilidade pode ser também escrita como:

$P_{n i}=P\left(\varepsilon_{n j}-\varepsilon_{n i}<V_{n i}-V_{n j}, \forall j \neq i\right)$

Pela última equação interpreta-se que a probabilidade de um indivíduo $n$ escolher a alternativa $i$ estará sujeita a que a vantagem dos fatores observados dessa alternativa sobre as demais seja maior do que sua desvantagem nos fatores não observados $\left(\varepsilon_{n}\right)$. 


\subsection{Tipos de Modelos de Escolha Discreta}

Diferentes tipos de modelos de escolha discreta são obtidos em função da distribuição admitida para a componente aleatória $\varepsilon$. Os modelos mais utilizados são os do tipo logit e probit. O probit assume que o termo aleatório comporta-se segundo uma distribuição normal, enquanto nos modelos logit, este segue a distribuição do tipo Gumbel (BEN-AKIVA; LERMAN, 1985).

Os modelos logit, empregados em escala muito maior do que os probit por sua praticidade e facilidade operacional, têm como aspecto crítico o fato de basearem-se no pressuposto de os fatores não observados não serem correlacionados entre as alternativas e possuírem a mesma variância para todas elas. Por exemplo, em uma escolha modal, mulheres de classe média que façam viagens à noite podem não escolher o ônibus por motivo de segurança. Pelo mesmo motivo, algumas não escolherão também o trem e o metrô. Caso esta variável não seja um dos atributos considerados durante a modelagem, seu efeito será incorporado na componente aleatória, em desacordo com o pressuposto da independência dos termos aleatórios que sustenta o modelo logit tradicional.

Para contornar problemas desse tipo, são geralmente empregados modelos logit hierárquicos ${ }^{23}$, que consideram a correlação existente dentro de um grupo de alternativas identificadas como semelhantes, denominadas 'ninhos', dentro do conjunto completo das alternativas. Este modelo representa uma forma de relaxamento das restrições do logit multinomial e tem seu uso bastante difundido devido a sua conveniência analítica (BATES, 2000).

Os modelos probit, por sua vez, apresentam como vantagem a possibilidade de se trabalhar com qualquer padrão de correlação do termo aleatório entre as alternativas. Os erros seguem uma distribuição normal com média zero e matriz de covariância arbitrária. Esta generalização, no entanto, não permite que o

${ }^{23} \mathrm{Ou}$ "nested logit", em inglês. 
modelo seja escrito de forma tão simples como um logit multinomial, sendo necessárias aproximações numéricas para sua solução (ORTÚZAR; WILLUMSEN, 2001). Na década de 80, Ben-Akiva e Lerman (1985) afirmaram não haver evidência, no caso multinomial, de que a maior generalização do probit compense os problemas computacionais associados a seu uso. Ainda hoje, mesmo com os avanços na área de processamento de dados, são encontradas na bibliografia menções à pouca praticidade operacional desse tipo de modelo.

Os modelos denominados mixed logit, de desenvolvimento recente, apresentamse como uma alternativa intermediária entre os logit e os probit, e baseiam-se na consideração de mais de uma componente aleatória, mantendo a forma do logit, mas permitindo a acomodação de correlações e heterocedasticidades (TRAIN, 2003). Na prática seu uso ainda é bastante restrito, se comparado ao logit multinomial ou ao hierárquico.

\subsubsection{O modelo logit multinomial}

Em um modelo logit multinomial a probabilidade de escolha de uma alternativa $i$ (dentre $j$ possíveis) para um indivíduo $n$ é dada por:

$$
P_{n i}=\frac{e^{V_{n i}}}{\sum_{j} e^{V_{n j}}}
$$

O modelo logit multinomial tem como pressuposto fundamental a independência das alternativas irrelevantes (IAI), que significa que a taxa de probabilidade de escolha de duas dadas alternativas não é afetada pela utilidade de quaisquer outras alternativas. Sendo $i$ e $k$ duas alternativas e $P_{n i}$ e $P_{n k}$ as probabilidades de escolha logit para cada uma delas, demonstra-se a propriedade matematicamente: 


$$
\frac{P_{n i}}{P_{n k}}=\frac{\frac{e^{V_{n i}}}{\sum_{j} e^{V_{n j}}}}{\frac{e^{V_{n k}}}{\sum_{j} e^{V_{n j}}}}=\frac{e^{V_{n i}}}{e^{V_{n k}}}=e^{V_{n i}-V_{n k}}
$$

Pela equação observa-se que a taxa entre as probabilidades de escolha de $i$ em relação a $k$ não depende de outras alternativas que não essas, ou seja, a probabilidade de escolha de $i$ sobre $k$ é sempre a mesma, não importando que outras alternativas estejam disponíveis ou quais seus atributos.

A independência dos atributos não observados entre as alternativas é um dos pressupostos do princípio da IAI. De acordo com McFadden (1977), a presença de erros de medida pode levar à correlação entre os fatores e os termos aleatórios. Dentro dessa questão, como já mencionado, a distribuição admitida para o termo aleatório depende da especificação da utilidade observável feita pelo analista, ou seja, quais atributos e coeficientes este considerou no termo $V_{n j}$. Quanto melhor especificado este termo, maior será a chance de independência do termo aleatório $\varepsilon_{n j}$. Ou, em outras palavras, a meta seria o analista especificar a utilidade observável $V_{n j}$ suficientemente bem, contemplando todas as variáveis pertinentes à escolha, de forma a tornar o uso do logit apropriado (TRAIN, 2003).

\subsubsection{Estimativa do logit multinomial}

\subsubsection{Obtenção dos parâmetros}

A estimativa do modelo logit multinomial é feita usualmente pelo método da máxima verossimilhança, que estima o conjunto de parâmetros que com maior freqüência gerarão a amostra observada (ORTÚZAR; WILLUMSEN, 2001). 
O procedimento consiste na maximização da função $l(\theta)$, que representa o logaritmo da função de verossimilhança, em relação ao parâmetro $\theta$ (ORTÚZAR; WILLUMSEN, 2001), dada por $^{24}$ :

$l(\theta)=\sum_{q=1}^{Q} \sum_{A j \in A(q)} g_{j q} \log P_{j q}$

Sendo $g_{j q}$ uma variável dummy de valor 1 , caso o indivíduo (ou observação) $q$ tenha escolhido a alternativa $A_{j}$, e zero caso contrário. A variável $P_{j q}$ é a probabilidade logit de escolha da alternativa $j$, pelo indivíduo $q$, definida no item 3.3.1. Da maximização de $l(\theta)$, são estimados cada um dos parâmetros $\theta^{*}$ prédefinidos, distribuídos normalmente, e suas respectivas variâncias.

\subsubsection{Testes estatísticos}

Um teste fundamental para a avaliação de um modelo estimado é o teste- $t$ de significância dos parâmetros. Esse teste verificará se o valor estimado para o parâmetro $\theta^{*}$ é estatisticamente diferente de zero.

Cada parâmetro $\theta^{*}$ é expresso por seu valor médio, calculado durante a estimação do modelo, sendo também calculada a sua variância. Assim o teste- $t$ verificará a hipótese de que a média de $\theta^{*}$ seja igual a zero, o que indicaria ser esse não significativo (no nível de confiança adotado).

Um indicador de como o modelo estimado está aderente à amostra utilizada é dado pelo valor de $\rho^{2}$, que seria análogo ao $\mathrm{R}^{2}$ calculado para um modelo de regressão linear. Se para $0 R^{2}$, modelos de boa qualidade geralmente têm valores próximos a 1 , para um modelo de escolha um $\rho^{2}$ de valor em torno de 0.4 pode indicar ótimos ajustes. Sua representação matemática é dada por:

\footnotetext{
${ }^{24}$ A função de verossimilhança é dada por: $L(\theta)=\prod_{q=1}^{Q} \prod_{A j \in A(q)}\left(P_{j q}\right)^{g_{i q}}$
} 
$\rho^{2}=1-\frac{l^{*}(\theta)}{l^{*}(0)}$

Onde $I^{*}(\theta)$ é o valor de convergência do logaritmo da função de verossimilhança e $I^{*}(0)$ o valor quando todos os coeficientes são nulos, ou seja, quando todas as alternativas têm a mesma probabilidade de serem escolhidas. Com relação a esse indicador, é importante observar que seu valor é fortemente influenciado pela proporção da divisão entre as escolhas. Assim, um modelo obtido a partir de uma amostra de escolha binária com proporção 0.9/0.1 e $\rho^{2}$ de 0.55 , será sem dúvida pior do que outro com $\rho^{2}$ de 0.25 obtido de amostra com divisão 0.5/0.5 (ORTÚZAR; WILLUMSEN, 2001). Para comparação entre modelos obtidos de amostras diferentes deve-se utilizar o $\rho^{2}$ ajustado, que representa o índice calculado considerando a divisão de escolhas na amostra. O valor do $\rho^{2}$ ajustado deve ser usado também na comparação entre diferentes modelos estimados a partir de uma mesma amostra, já que quando se adicionam novas variáveis a um modelo, o valor do $\rho^{2}$ irá sempre crescer ou, ao menos, permanecer o mesmo (BEN-AKIVA; LERMAN, 1985).

Para comparações entre modelos e funções de utilidade obtidas, outro teste de grande importância é o da taxa de verossimilhança, que atende a dois tipos de verificação (ORTÚZAR; WILLUMSEN, 2001): i) quanto ao caráter genérico do atributo, e ii) quanto à homogeneidade da amostra. No primeiro caso deseja-se investigar se os parâmetros $\theta^{*}$ estimados para um mesmo atributo, como tempo de viagem, mas em diferentes alternativas, podem ser considerados iguais. Por exemplo, avaliando-se a utilidade de duas rotas concorrentes A e B, com diferentes tempos e custos de viagem, ter-se-iam as formas gerais para o modelo:

$$
\begin{aligned}
& V_{\text {rotaA }}=\theta_{A} * t_{\text {rotaA }}+\beta_{A} * c_{\text {rotaA }} \\
& V_{\text {rotaB }}=\theta_{B} * t_{\text {rotaB }}+\beta_{B} * c_{\text {rotaB }}
\end{aligned}
$$


$\mathrm{Na}$ hipótese de que os tempos $(t)$ seriam atributos genéricos, deve ser feita a verificação da hipótese de igualdade dos parâmetros $\theta_{A}$ e $\theta_{B}$.

No segundo caso, ao se estimar modelos para diferentes segmentos da amostra, deseja-se investigar se os parâmetros $\theta^{*}$ obtidos para um mesmo atributo poderiam ser admitidos como estatisticamente iguais para os diferentes segmentos analisados.

Por exemplo, estima-se a utilidade de um modo para indivíduos do sexo feminino e outro para os do sexo masculino:

$$
\begin{aligned}
& V_{\text {ônibus,masc }}=\theta_{h} * t_{v}+\beta_{h} * c_{t} \\
& V_{\text {ônibus,fem }}=\theta_{m} * t_{v}+\beta_{m} * c_{t}
\end{aligned}
$$

Da mesma forma, para a verificação de homogeneidade da amostra com relação ao coeficiente do tempo de viagem $t_{v}$, dever-se-ia testar a hipótese de que $\theta_{h}=\theta_{m}$

Os testes, tanto no primeiro como no segundo caso, são realizados através de comparação, estimando-se inicialmente os modelos na forma geral, e depois na forma restrita para os atributos avaliados (BEN-AKIVA; LERMAN, 1985). Utilizase a estatística $-2\left(l^{*}\left(\theta_{r}\right)-l^{*}(\theta)\right)$, onde $l^{*}\left(\theta_{r}\right)$ é o valor de convergência da logverossimilhança para o modelo restrito e $I^{*}(\theta)$, o valor para o modelo genérico. A essa estatística é aplicado o teste do qui-quadrado para $n$ graus de liberdade, onde $n$ é o número de restrições lineares ${ }^{25}$. A rejeição da hipótese nula indicará que o modelo restrito não é válido. Isso implicaria, no primeiro caso, que os coeficientes $\theta_{A}$ e $\theta_{B}$ não seriam estatisticamente iguais; no segundo caso, igualmente, os parâmetros $\theta_{h}$ e $\theta_{m}$ estimados não poderiam ser considerados iguais para os segmentos da amostra em questão.

\footnotetext{
${ }^{25}$ Ou seja, $\mathrm{n}=$ (no de variáveis no modelo específico - no de variáveis no modelo genérico).
} 


\section{PREFERÊNCIA DECLARADA}

Os valores de tempo obtidos empiricamente em estudos no início dos anos 70 usavam, sem exceção, um modelo de escolha discreta de modo ou de rota, baseados em dados de preferência revelada (HENSHER; TRUONG, 1985), ou seja, as escolhas observadas dos viajantes. Consistiam da observação da divisão modal entre as alternativas e medição de diferenças de tempos e tarifas entre essas, para o estabelecimento de funções de custos (BRADLEY; GUNN, 1990). No entanto, a construção de modelos com base apenas na observação das escolhas apresentava uma série de limitações $^{26}$, problema em grande parte solucionado, a partir da década de 80 , com a incorporação da preferência declarada ao levantamento de dados, cujas técnicas fazem parte das práticas mais utilizadas para a estimativa do valor do tempo (ORTÚZAR; WILLUMSEN, 2001).

Neste capítulo serão abordados alguns tópicos relativos à aplicação dessas técnicas, sua definição e a comparação desse tipo de dado com o de preferência revelada. Será também comentada a questão do desenho do experimento para a coleta de dados, aspecto fundamental para o êxito de um estudo envolvendo preferência declarada e, de acordo com Hensher, Rose e Greene (2005), também um dos pontos de mais difícil compreensão pelos que se iniciam na prática das técnicas de preferência declarada.

\subsection{Definição}

Para o campo das aplicações em transporte, Kroes e Sheldon (1988) definem que o termo preferência declarada refere-se a uma família de técnicas que usam

\footnotetext{
${ }^{26}$ Essas serão descritas no capítulo a seguir.
} 
declarações de indivíduos sobre suas preferências em um conjunto de opções de transporte, para a estimativa de funções de utilidade. Essas opções podem ser descrições de situações existentes ou de cenários hipotéticos construídos pelo pesquisador.

A técnica foi desenvolvida para pesquisas de marketing nos anos 70 , tornandose bastante difundida ao final dessa década. É de uso relativamente recente no campo dos transportes, sendo algumas das primeiras publicações sobre o assunto datadas do início dos anos 80, por Steer e Willumsen, em 1981, e Sheldon e Steer, em 1982 (BATES, 1988).

O termo conjoint analysis, muitas vezes confundido com o de preferência declarada, é na verdade um dos métodos que fazem parte das técnicas empregadas na preferência declarada ${ }^{27}$. Define-se conjoint analysis como qualquer método de decomposição que estime a estrutura da preferência do consumidor, dada sua avaliação global de um grupo de alternativas que são préespecificadas em termos de níveis de diferentes atributos (GREEN; SRINIVASAN, 1978 apud KROES; SHELDON, 1988).

O aspecto característico envolvendo um levantamento de dados através de preferência declarada está no fato de que os dados são coletados sempre a partir de informações sobre o que os entrevistados relatam que fariam em determinada situação, e não sobre o que eles estão realmente fazendo. Isso é visto com ceticismo pelos críticos ao uso da preferência declarada. No entanto, para muitas situações que se deseja estudar, as alternativas são ou acreditar no relato dos entrevistados ou simplesmente não se fazer nada (LOUVIERE; HENSHER; SWAIT, 2000).

Em contraponto à preferência declarada, há a possibilidade tradicional do uso de dados de preferência revelada, que são aqueles obtidos através da observação de escolhas feitas pelas pessoas no mercado. Esse tipo de dado representará, ao

\footnotetext{
${ }^{27}$ De acordo com Kroes e Sheldon (1988), outros métodos que fazem parte da PD são: functional measurement, tradeoff analysis e transfer-price.
} 
contrário daquele de preferência declarada, uma escolha que realmente aconteceu. A característica desse tipo de informação confere-lhe algumas vantagens e restrições, descritas no item a seguir.

\subsection{Dados de Preferência Revelada}

As informações obtidas por preferência revelada (PR) apresentam duas características vantagens em relação a dados de preferência declarada: i) maior confiabilidade e ii) maior validação. Entende-se por confiabilidade a idéia de que repetidas medições de uma escolha levarão a resultados similares; a validação diz respeito à relação entre o que se observou ser escolhido e o que foi realmente escolhido (HENSHER; ROSE; GREENE, 2005).

Outra vantagem dos dados de PR é a incorporação das restrições em uma escolha. Ou seja, as restrições que limitam uma escolha, como as financeiras e de acessibilidade, por exemplo, fazem naturalmente parte de uma informação medida através de PR, o que não ocorre necessariamente em um dado de preferência declarada.

Uma característica amplamente citada na literatura como uma das grandes desvantagens dos dados de PR em relação aos de PD diz respeito às suas limitações de alternativas, atributos e níveis dos atributos (MORIKAWA, 1989; LOUVIERE; HENSHER; SWAIT, 2000; HENSHER; ROSE; GREENE, 2005). Como os dados de PR são coletados no mundo real, as alternativas analisadas ficarão restritas às disponíveis no momento da observação. Isso representará dificuldades caso se queiram realizar estudos envolvendo, por exemplo, a viabilidade de implantação de uma nova opção de transporte. Sobre a quantidade de atributos, nos dados de PR a observação é dominada pelos atributos principais da alternativa, como tempo e custo, sendo de difícil mensuração a importância para as pessoas de atributos secundários tais como 
segurança, pontualidade ou qualidade do sistema de informações, por exemplo. Com relação aos níveis de atributos, da mesma forma, dados obtidos por PR comumente oferecerão pouca variabilidade ou amplitude de variação dos valores das variáveis observadas. Por exemplo, em um estudo envolvendo uma modelagem de escolha para os modos ônibus, trem e metrô, utilizando dados de PR, provavelmente a capacidade de explicação da variável 'tarifa' na escolha dos indivíduos será limitada, dada sua pouca variação observada entre os três modos. Sem variação nos atributos não há como explicar a variação nas preferências dos indivíduos (HENSHER; ROSE; GREENE, 2005).

Outro aspecto a ser considerado é a correlação. Se os dados de uma escolha obtidos por PR permitem a observação de uma quantidade reduzida de atributos para análise, esse problema é ainda agravado pela correlação geralmente existente entre alguns desses. São comuns correlações entre atributos como preço e qualidade de produtos, ou tarifas e tempos de viagem, o que dificulta a separação de seus efeitos em uma modelagem.

Finalmente, um fator sempre a ser considerado em pesquisas é que dados de PR são muito comumente caros de se obter e requerem considerável tempo para coleta (LOUVIERE; HENSHER; SWAIT, 2000).

\subsection{Características dos Dados de Preferência Declarada}

Como mencionado, o que caracteriza uma informação obtida por preferência declarada (PD) é o fato dessa refletir uma escolha realizada em um cenário hipotético. Isso fornece ao pesquisador um importante benefício em relação aos dados de PR, que permitem levantamentos acerca apenas do cenário existente, limitando as alternativas e variáveis observáveis. Ou seja, uma pesquisa baseada em PD permite a exploração de questões além da denominada fronteira tecnológica atual, o que é representado na Figura 4-1: 


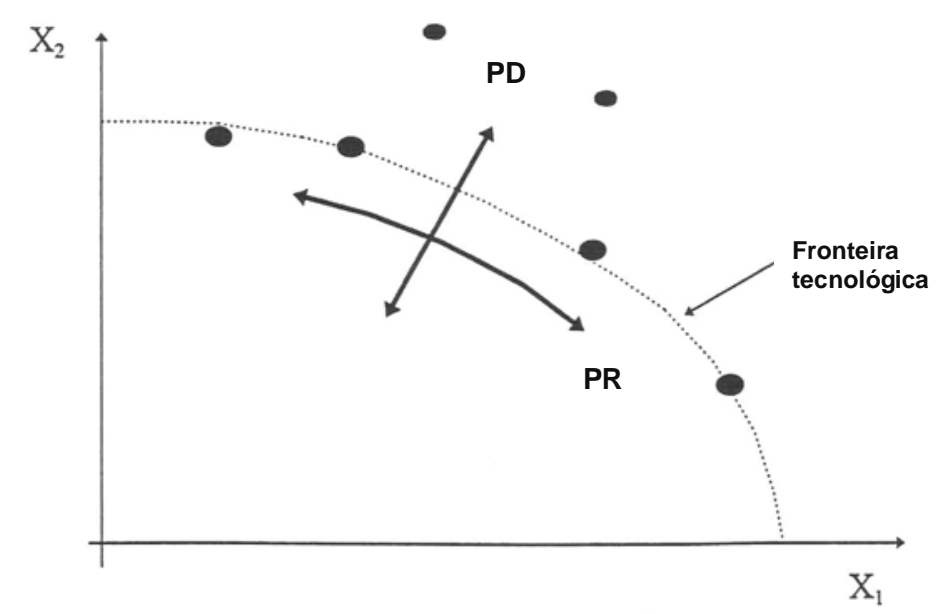

Figura 4-1: A fronteira tecnológica e a abrangência da preferência revelada (PR) e declarada (PD) - fonte: Louviere, Hensher e Swait (2000)

Na figura, as observações de PD poderiam representar, por exemplo, um novo modo de transporte como um trem de alta velocidade, com respectivos tempos de viagem $\left(X_{2}\right)$ e custos propostos $\left(X_{1}\right)$.

O principal atrativo de um levantamento de PD em relação a um de PR é o controle dos cenários de escolha por parte do analista, o que implica em (LOUVIERE; HENSHER; SWAIT, 2000; MORIKAWA; 1989):

- O conjunto de escolhas pode ser pré-especificado;

- O intervalo de variação dos atributos pode ser estendido;

- Possibilidade de controle da correlação entre os atributos;

- Atributos de difícil mensuração em um levantamento de preferência revelada, como confiabilidade e segurança, podem ser incorporados;

- Os atributos estão livres de erros de medida ${ }^{28}$;

- Possibilidade de inclusão de alternativas atualmente não existentes no cenário de escolha;

- Obtenção de múltiplas observações para um único entrevistado.

\footnotetext{
${ }^{28}$ Por exemplo, em um dado de PR um motorista pode informar que sua viagem tem duração de uma hora, quando na verdade sua duração real é de 50 minutos.
} 
$\mathrm{Na}$ comparação entre os dois tipos de dados, uma observação de Louviere, Hensher e Swait (2000) talvez resuma em uma frase os pontos fortes de cada uma das formas de obtenção de dados: os de PR contêm informação sobre a atual situação de equilíbrio do mercado, enquanto os de PD são ricos em informação de tradeoffs entre atributos.

Sobre os atributos, Bates (1998) classifica-os em três categorias: i) os 'leves', que afetam o comportamento da viagem, mas que são de difícil quantificação, como confiabilidade, conforto e segurança; ii) 'primários', são aqueles usuais e evidentes, representando os atributos mais significativos da viagem, como o tempo total e iii) 'secundários', de fácil mensuração como os primários, mas de ocorrência incidental, como sistemas de informação e equipamentos de acessibilidade.

Ainda de acordo com Bates, se as estimativas de valor das variáveis primárias para o usuário, como o valor do tempo, através de métodos de PD têm sido aceitáveis e consistentes entre os estudos bem executados, o mesmo não pode ser afirmado com relação às variáveis 'leves' e 'secundárias', cuja importância em termos monetários tende a ser supervalorizada pelos entrevistados. Citando um exemplo disso, o autor comenta estudos para implantação de pacotes de melhorias na qualidade do serviço em transporte público, que freqüentemente apresentam conclusões bastante improváveis, tais como que o usuário estaria disposto a pagar o dobro da tarifa por um conjunto de medidas secundárias, como implantação de escadas rolantes nos terminais e troca no sistema de informação, entre outras ${ }^{29}$.

\footnotetext{
${ }^{29}$ Nesse mesmo artigo, Bates (1998) cita uma série de precauções ao se realizar a pesquisa visando evitar esse tipo de distorção nos resultados.
} 


\subsection{Formatos de Resposta nas Questões de PD}

Um aspecto de grande importância em um levantamento de PD é a forma como o entrevistado irá reportar sua escolha dentre as alternativas apresentadas. Essa forma é pré-definida pelo analista e diferentes métodos podem ser usados de acordo com o que esse admite sobre a habilidade dos entrevistados em entender os cenários e explicar suas preferências. Os formatos de resposta mais utilizados são (LOUVIERE; HENSHER; SWAIT, 2000):

- Escolha discreta de apenas uma alternativa dentre um conjunto de opções concorrentes: é a forma mais confortável e simples para o entrevistado. Tem o aspecto negativo de não fornecer informação sobre as alternativas não escolhidas, o que implica em necessidade de mais respostas por entrevistado e, em relação às outras formas de resposta, necessitará observações junto a um maior número de pessoas, de forma a se obter maior variação nos atributos da amostra.

- Ordenação - ou rankeamento - das alternativas, da mais preferida à menos preferida: nesse formato todas as opções são colocadas em uma ordem de preferência pelo entrevistado. Embora todas as opções sejam contempladas, não se tem informação sobre o grau de preferência de uma alternativa sobre a outra, apenas a ordem. Com relação a essa forma: i) a dificuldade da tarefa para o entrevistado aumenta substancialmente com o número de alternativas a serem ordenadas, ii) a confiabilidade é igualmente afetada pela quantidade de alternativas e iii) há falta de informação sobre alternativas que nunca seriam escolhidas. Louviere, Hensher e Swait (2000) recomendam uma série de cuidados ao se empregar essa forma de resposta, chegando mesmo a sugerir que o analista não a utilize, face às outras opções existentes.

- Atribuição de nota às opções: também conhecido como rating, nessa forma o entrevistado fornece uma avaliação de cada uma das 
alternativas, dando-Ihes uma nota, dentro de uma escala definida pelo analista, como de 1 a 5 ou 1 a 10, por exemplo. É citado por Louviere, Hensher e Swait (2000), como o mais difundido método de resposta. Ao se empregar esse formato assume-se que os respondentes estão aptos a fornecer uma confiável e válida medida de seus graus de preferência. Ou seja, se por um lado essa é a forma que fornece as informações mais completas acerca do conjunto de escolha, é também a que mais exige das habilidades cognitivas do entrevistado. Alguns autores, como Ortúzar e Willumsen (2001), apresentam restrições a esse formato de resposta, baseados no argumento de que não há evidência de que as preferências possam ser transformadas em escalas numéricas desse tipo. Cabe ainda observar que na comparação entre este método e o de 'ordenação', parece não haver um consenso na literatura: há autores como Louviere et al. (2000) e Bates (1998), que defendem o uso do rating e vêem com reservas as respostas por ordenação ${ }^{30}$; outros, como Ortúzar e Willumsen (2001) e Bovi e Bradley (1985 apud MORIKAWA, 1989), definem a ordenação como mais simples e confiável do que a atribuição de nota.

- Aceitação ou não de uma alternativa: o entrevistado, observando o conjunto de atributos de cada opção, classifica-as em 'aceitáveis', para aquelas que ele realmente considera passíveis de uso, e 'não aceitáveis', para aquelas cujo uso estaria fora de cogitação. Esse método, por oferecer pouca informação a respeito da ordem de preferências exige, a exemplo do primeiro, maiores amostras. É o formato menos usado dentre os citados, chegando a não ser mencionado por alguns dos autores ao abordar o tema.

\footnotetext{
${ }^{30}$ Bates (1998) relata que há a preocupação de alguns pesquisadores com relação a essa forma, que seria muito onerosa e favoreceria a respostas por regras de decisão que não aquelas supostas pelo analista, como as lexicográficas. Ainda sobre essa questão, Widlert (1998) em um amplo estudo analisou 25 tipos de desenhos envolvendo as 4 opções de forma de resposta e concluiu que a tendência do entrevistado a responder lexicograficamente era bem mais forte quando esse deveria ordenar as alternativas, do que quando deveria escolhê-las par-a-par ou atribuir-Ihes uma nota ("rating").
} 
O quadro a seguir mostra, em uma escolha com 5 alternativas como seria a resposta do entrevistado em cada um dos formatos:

Tabela 4-1: Formas de resposta mais utilizadas em entrevistas de preferência declarada. Fonte: adaptado de Louviere, Hensher e Swait (2000)

\begin{tabular}{|c|c|c|c|c|}
\hline \multirow[b]{2}{*}{ Alternativas } & \multicolumn{4}{|c|}{ Formato de resposta } \\
\hline & Escolha discreta & $\begin{array}{c}\text { Ordenação (por } \\
\text { propensão ao } \\
\text { uso) }\end{array}$ & $\begin{array}{c}\text { Atribuição de } \\
\text { nota }\end{array}$ & Aceitação \\
\hline Ônibus & & 5 & 4 & não \\
\hline Metrô & & 4 & 4 & não \\
\hline Táxi & & 3 & 6 & $\operatorname{sim}$ \\
\hline Carro & $x$ & 1 & 10 & $\operatorname{sim}$ \\
\hline Carona & & 2 & 7 & $\operatorname{sim}$ \\
\hline
\end{tabular}

\subsection{Desenho do Experimento}

O desenho do experimento é a base de um estudo de PD. Envolve a observação do efeito sobre uma variável, chamada variável resposta, em função da manipulação dos níveis de uma ou mais variáveis.

Com relação à terminologia, encontram-se na bibliografia diferentes denominações para as variáveis manipuladas, podendo ser chamadas de fatores, variáveis independentes, variáveis explicativas ou atributos. Os níveis são denominados níveis dos fatores, níveis dos atributos ou simplesmente níveis. É também comumente usado o termo 'tratamento': cada nível de um atributo representa um tratamento. 


\subsubsection{Etapas da construção do desenho}

Hensher, Rose e Greene (2005) definem a construção do desenho do experimento como uma tarefa composta de uma série de etapas que incluem: i) identificação das alternativas, atributos e níveis dos atributos; ii) definição do desenho experimental, que consiste da escolha do tipo de desenho, especificação do modelo (aditivo ${ }^{31}$ ou de interação) e métodos de redução do desenho; iii) geração do desenho experimental em si e alocação dos atributos às colunas da matriz do desenho; iv) geração dos conjuntos de escolha; v) aleatorização da seqüência dos conjuntos de escolha, e vi) construção do instrumento de pesquisa.

A etapa inicial, definida como refinamento do problema, compreenderia o entendimento do sistema envolvido, observando-se todas as possibilidades de alternativas existentes, seus atributos e a forma de percepção desses pelos usuários, bem como a identificação de elementos determinantes ou característicos dessa demanda. Nessa etapa a sensibilidade do analista com relação ao funcionamento do sistema é de grande importância. Caso esse não esteja familiarizado com a situação, pode-se recorrer a fontes secundárias de informação ou técnicas como formação de grupos de discussão.

Após essa etapa, passa-se à definição das alternativas que comporão o conjunto de escolha. O ideal é que estejam incluídas nas alternativas todas as possibilidades de escolha do usuário, ou consumidor, de um mercado. No caso de a lista ser muito extensa, o analista deverá cortar algumas que julgue de menor relevância ou compor diferentes subconjuntos de escolha, que seriam aleatoriamente apresentados aos entrevistados ${ }^{32}$.

Cabe aqui comentar que há a possibilidade de apresentação das alternativas rotuladas e não rotuladas. Na opção de uso de rótulos, as alternativas aparecem

\footnotetext{
${ }^{31}$ Apenas efeitos principais.

32 Esse método é descrito a seguir.
} 
caracterizadas como, por exemplo, 'alternativa ônibus', 'alternativa táxi', e seus respectivos atributos; na apresentação não rotulada, essas são caracterizadas apenas por seus atributos e indicadas na forma 'alternativa 1', 'alternativa 2'. 0 uso de alternativas não rotuladas ofereceria menor risco de violação do principio da IAI, já que se elimina a possibilidade de que o nome de uma alternativa leve a correlações com os atributos do experimento (HENSHER; ROSE; GREENE, 2005). Por exemplo, a alternativa 'avião' poderia estar correlacionada com atributos apresentados 'conforto' e 'tempo de viagem'. O uso de rótulos, no entanto, confere maior realismo ao cenário de escolha, além de permitir que o entrevistado associe à alternativa, características omitidas. Em casos onde a marca de um produto tenha influência importante na decisão do consumidor deve-se trabalhar com a identificação das alternativas no experimento (LOUVIERE; HENSHER; SWAIT, 2000).

Definidas e identificadas as alternativas do conjunto de escolha, deve-se determinar a quantidade de atributos que serão usados para descrever cada uma delas. Essa é uma tarefa complexa, já que diferentes modos de transporte possuem atributos bastante distintos. Por exemplo, um usuário de ônibus observa características como tempo de espera, tarifa e freqüência de atrasos, enquanto um de automóvel vê outros, como custos de estacionamento, combustível e tarifas de pedágios. A incorporação de muitos atributos, se por um lado permite a melhor caracterização da alternativa para o entrevistado, e potencialmente produzirá melhores modelos, tem, no entanto, o aspecto negativo de levar a experimentos muito longos e, às vezes, complexos para o respondente.

Com relação aos níveis dos atributos, o pesquisador deverá decidir: i) quantos níveis associar a cada atributo e ii) que valores associar a cada nível. Embora comum, não é necessário que todos os atributos tenham a mesma quantidade de níveis. Esses podem ser associados a características numéricas (tarifa de $\mathrm{R} \$ 2 ; \mathrm{R} \$ 3, \mathrm{R} \$ 5 \ldots$ ) ou qualitativas (modo 'com possibilidade de atraso'; 'sem possibilidade de atraso'). Na definição da quantidade de níveis observa-se que quanto maior o número de níveis para uma variável, mais informação será 
capturada para a estimativa da utilidade $^{33}$; em contrapartida, isso representará aumento no número de combinações para o desenho do experimento. Ainda sobre os níveis, é importante também detectar os valores extremos de variação de cada atributo, o que pode ser feito, por exemplo, observando-se na situação atual os tempos máximos e mínimos possíveis dentre as alternativas disponíveis para um determinado deslocamento. Esses valores deverão servir como referência para o intervalo da flutuação dos níveis, conferindo realismo aos cenários apresentados.

Para o desenho do experimento em si, há uma ampla variedade de tipos. O mais geral é o denominado fatorial completo (full factorial design), que enumera todas as combinações possíveis, dada a quantidade de alternativas, atributos e níveis de atributos considerados. O número de combinações de um desenho fatorial completo pode ser dado pela combinação de cada nível de cada atributo com os níveis de todos os demais atributos. Por exemplo, em um experimento com cinco atributos, cada um com quatro níveis, ter-se-iam $4^{5}$, ou 1024, combinações (HENSHER; LOUVIERE, 1997).

Uma propriedade dos desenhos fatoriais completos é que esses garantem a possibilidade de análise de todos os efeitos, sejam esses efeitos principais ou de interação. Um 'efeito' significa o impacto de um tratamento sobre a variável resposta, que no caso é a escolha. Assim, um efeito principal é o efeito direto e independente de cada atributo sobre a escolha, enquanto um de interação ocorre quando a preferência por um nível de um atributo é dependente do nível de um segundo atributo. Por essa definição, percebe-se que o efeito de interação é diferente da correlação ${ }^{34}$.

Observa-se que experimentos relativamente simples quando utilizam um desenho fatorial completo levam a uma quantidade de combinações pouco viável

\footnotetext{
${ }^{33}$ Pearmain e Kroes (1990) definem que os atributos de maior interesse devem ter ao mínimo três níveis, de modo a permitir a análise de efeitos não lineares na função de utilidade.

${ }^{34} \mathrm{Na}$ interação, algumas combinações de determinados níveis de duas variáveis produzem um efeito, enquanto combinações de outros níveis dessas mesmas variáveis não terão efeito algum sobre a variável resposta. Na correlação a dependência entre as variáveis está presente em todos os 'níveis'.
} 
para ser apresentada a um entrevistado. Para contornar esse problema há algumas estratégias para redução dos conjuntos de escolha a serem apresentados (HENSHER; ROSE; GREENE, 2005): i) redução do número de níveis do desenho; ii) formação de blocos ${ }^{35}$ do desenho completo, e iii) uso de desenhos fatoriais fracionados ${ }^{36}$.

A primeira alternativa, a redução do número de níveis, reduz bruscamente a quantidade de combinações. Ao se decidir pelo uso desse recurso, é comum a utilização de apenas dois níveis por atributo ${ }^{37}$. Esse tipo de desenho é também conhecido por end-point design e pode ser adotado quando se supõe ou se dispõe de informação de que determinada variável possui uma relação linear fixa com a utilidade marginal. A potencial perda de informação sobre linearidades dos efeitos, quando se adota a redução da quantidade de níveis, é representada na Figura 4-2 a seguir:
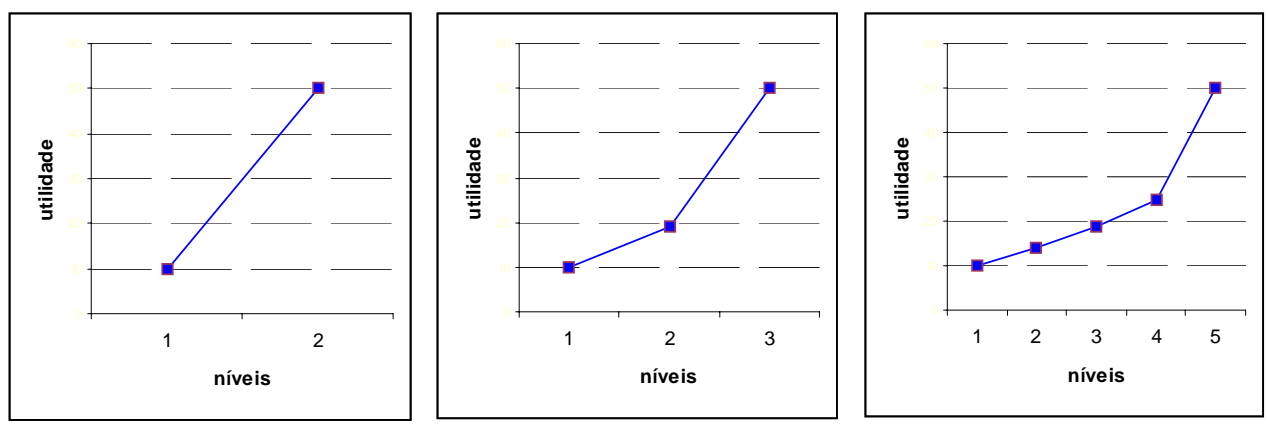

Figura 4-2: Relação entre informação obtida sobre a utilidade e o número de níveis definido para um atributo . Fonte: adaptado de Hensher, Rose e Greene (2005)

Outra opção, a formação de blocos, consiste em 'quebrar' o desenho completo. Por exemplo, um desenho de 27 combinações pode ser dividido em 3 partes identificadas e cada entrevistado responderia apenas a uma delas, ou seja, 9 combinações - ou questões. Dessa forma, a composição de um conjunto de 3 entrevistas (de um mesmo grupo) formará um conjunto fatorial completo. Um problema dessa estratégia é que a perda de uma entrevista implica na perda de

\footnotetext{
${ }^{35}$ Em inglês, "blocking".

${ }^{36}$ Denominados, em inglês, "fractional factorial designs".

${ }^{37}$ Geralmente esses valores são dados pelos valores extremos verificados na situação atual.
} 
um conjunto completo. Observa-se também que esse recurso tem seu uso limitado a desenhos não muito extensos.

A estratégia mais utilizada é, sem dúvida, a adoção de desenhos fatoriais fracionados. Se um desenho completo contempla todos os efeitos de interação possíveis, geralmente uma quantidade bem menor do que todos esses efeitos é realmente de interesse (LOUVIERE; HENSHER; SWAIT, 2000). Os desenhos fracionados envolvem a seleção de uma parte do desenho completo, de modo a permitir que efeitos de interesse - que geralmente se limitam aos efeitos principais - possam ser estimados da forma mais eficiente possível. Em contrapartida à praticidade desses desenhos, há perda de informação estatística com relação aos efeitos de interação entre atributos, problema de menor importância no caso de modelos lineares, nos quais, de acordo com Dawes e Corrigan (1974, apud HENSHER; LOUVIERE, 1997), os efeitos principais respondem por $70 \%$ a $90 \%$ da variação explicada.

Há uma ampla gama de métodos de fragmentação desenvolvidos por especialistas em desenho ${ }^{38}$. Na prática, o pesquisador, tendo definido em seu experimento o número de atributos e a quantidade de níveis para cada um desses atributos, pode gerar desenhos fatoriais - completos ou fracionados com o auxílio de softwares de análises estatísticas, tais como o SPSS ou o Minitab ${ }^{39}$.

A tarefa seguinte na elaboração do desenho, a construção dos conjuntos de escolha, consiste de algumas transformações visando tornar o desenho pronto para uso em campo (HENSHER; ROSE; GREENE, 2005). Consiste em associar aos níveis dos atributos, valores ou termos adequados, que tenham significado cognitivo aos entrevistados. Por exemplo, ao definir um atributo como 'conforto', que tenha 3 níveis, são comumente utilizados os termos 'alto', 'médio' e 'baixo'.

\footnotetext{
${ }^{38}$ Abordagens aprofundadas sobre desenhos de experimento podem ser consultadas em Louviere, Hensher e Swait (2000) e Kuehl (2000).

${ }^{39}$ Em Hensher, Rose e Greene (2005) encontra-se uma descrição detalhada de como fazê-lo.
} 
Com relação à aleatorização dos conjuntos de escolha, Hensher, Rose e Greene (2005) observam que há a possibilidade de que os primeiros conjuntos de escolha apresentados sejam utilizados pelo entrevistado para ganhar conhecimento sobre o funcionamento da pesquisa. Por outro lado, os entrevistados podem ficar aborrecidos ao final da pesquisa, quando essa inclui muitas combinações, o que tenderia a afetar as últimas respostas. Até recentemente havia a prática de incluir conjuntos de escolha extras - que não eram considerados nas análises -, para que os entrevistados pudessem praticar. Esse método caiu em desuso e vem sendo substituído pela aleatorização dos conjuntos de escolha, ou seja, as combinações não são apresentadas sempre na mesma seqüência, para diferentes entrevistados.

Sobre a construção do instrumento de pesquisa, essa deve considerar a forma prevista para a obtenção das informações junto ao entrevistado, que pode envolver: i) entrevistas pessoais, onde as respostas são dadas diretamente a um pesquisador; ii) entrevistas telefônicas; iii) uso de formulários enviados pelo correio ou e-mail, e iv) combinações das formas ii e iii. As duas primeiras formas, de acordo com Hensher e Louviere (1997), apresentam maiores limitações com relação ao tamanho da entrevista. A terceira forma, por sua vez, tem o inconveniente do baixo retorno dos questionários enviados. As entrevistas pessoais podem ser realizadas com a apresentação de cartões, método freqüentemente descrito como paper \& pencil ou com o uso de computadores. Com relação ao uso de computadores para levantamento de informações, esses têm a vantagem de possibilitar a customização do cenário de escolha às circunstâncias do entrevistado, além de permitir rapidamente checagens lógicas de consistência dentro das entrevistas eliminando erros de codificação (BATES, 1998). Widlert (1998), ao realizar um estudo comparando duas formas levantamento das informações: i) através do uso de computadores, e ii) com os tradicionais conjuntos de cartões, concluiu que a primeira apresentava resultados de maior confiabilidade, ou seja, repetidas medições levaram a resultados mais próximos. 
Ainda sobre o instrumento de pesquisa, algumas recomendações citadas na bibliografia são: i) questões demográficas devem ser apresentadas na parte final da entrevista (HENSHER; ROSE; GREENE, 2005), ii) fazer uso de histórias descritivas explicando para o entrevistado o contexto da situação, e iii) fazer uso de ilustrações. Sobre os dois últimos itens, Widlert (1998) demonstrou haver significativos ganhos na qualidade dos resultados quando as alternativas eram acompanhadas de um exemplo ilustrativo.

4.5.2. Observações sobre a complexidade do desenho

Durante a concepção do desenho do experimento é importante sempre ter em mente os conceitos da racionalidade humana definidos por Simon (1957), que a distingue entre a onisciente, ou perfeita, e a limitada. A primeira assume que o indivíduo possa absorver e reter uma grande quantidade de informações, que seja dotado de capacidade ilimitada de processamento dessas em busca da melhor solução, e que tenha uma idéia clara de suas preferências, sendo estas perfeitamente estáveis e hierarquizadas. Em situações reais, no entanto, devese trabalhar com o mundo da racionalidade limitada, que reconhece as restrições das pessoas como tomadores de decisão e onde motivos de várias ordens, como falta de tempo, de imaginação ou atenção, fazem com que apenas um pequeno número das soluções possíveis seja realmente ponderado (BEN-AKIVA; LERMAN, 1985). Na bibliografia, em temas tratando da definição do desenho do experimento, encontram-se freqüentes recomendações para que o analista, sendo o controlador dos cenários hipotéticos da pesquisa de preferência declarada, resista à tendência natural de abordar um grande número de variáveis e faça um experimento simples para o entrevistado, garantindo assim maior confiabilidade aos resultados:

Deve-se tomar cuidado quando o número de atributos é excessivo - como maior do que quatro. A conseqüente fadiga durante a entrevista faz com que os respondentes simplifiquem suas respostas, focando em um menor 
número de atributos ou simplesmente respondendo aleatoriamente ou por regras lexicográficas (SAELESMINDE, 1999 apud ORTÚZAR; WILLUMSEN, 2001).

A experiência tem mostrado que as pessoas fornecem respostas mais confiáveis se as questões consideram mudanças simultâneas em até três fatores apenas (HUBER; HANSON, 1986).

As pessoas tendem a simplificar a tarefa de responder às alternativas sempre que possível, [...] o que leva a diferentes proporções das chamadas respostas lexicográficas (WILDERT, 1998).

Mantenha o experimento de escolha simples, sem sobrecarregar o entrevistado. Muitas opções tendem a produzir fadiga no entrevistado, reduzindo o valor das respostas (ORTÚZAR; WILLUMSEN, 2001).

Enfim, a concepção do desenho envolve um desafio para o analista na definição do número ideal de alternativas, variáveis e níveis: por um lado, quanto maior a quantidade desses, teoricamente maiores as possibilidades de estimativa de um modelo adequado; por outro lado, também maiores serão as chances de obtenção de respostas de má qualidade por parte dos entrevistados, levando a modelos ruins.

\subsection{Uso Combinado de I nformações de PD e PR}

Como citado anteriormente, se os dados de PD apresentam uma grande quantidade de vantagens sobre os de PR, sem dúvida vários autores concordam que a mais importante questão e aspecto crítico envolvendo esse tipo de informação está na validação externa dos dados (MORIKAWA, 1989). Ou seja, as restrições situacionais que naturalmente fazem parte de uma decisão no mundo real, podem eventualmente ser subestimadas pelos entrevistados em uma pesquisa PD, o que pode levar a distorções em estimativas. Visando contornar 
tal tipo de problema, encontram-se na bibliografia várias recomendações destacando a importância de que dados de PR sejam utilizados conjuntamente com os de PD, durante a calibração dos modelos de escolha.

No entanto, de acordo com Kroes e Sheldon (1988) e Morikawa (1989), quando a intenção da modelagem é apenas a de se estimar proporções entre pesos dos atributos na utilidade relativa, ou seja, os tradeoffs entre esses atributos, esse é um problema pouco relevante.

No caso deste estudo não se objetiva a obtenção do um modelo para previsões de escolha modal ou de rota. Como será descrito no capítulo 6.3, busca-se aqui apenas estudar a relação entre os coeficientes da função de utilidade, o que torna menor a necessidade de incorporação de dados de PR para a calibração do modelo. 


\section{DESCRI ÇÃO DA PESQUISA DE PD REALIZADA}

Neste capítulo são apresentadas as características da pesquisa cujas informações foram utilizadas para as estimativas dos modelos de escolha. São descritos aspectos relativos à forma de realização da pesquisa de campo e às informações de PR e PD coletadas.

\subsection{Coleta dos Dados}

A pesquisa que serviu como base de informações para os estudos foi realizada entre os meses de maio e junho de 2005. O levantamento compreendeu 28 pontos de pesquisa distribuídos na malha rodoviária principal - pedagiada e não pedagiada - do estado de São Paulo. A localização tentou abranger os eixos de maior volume de tráfego e os que atenderiam a uma maior proporção de deslocamentos de longa distância entre as regiões de todo o estado ${ }^{40}$.

Foram realizadas, no total, 8256 entrevistas com motoristas de automóveis.

Os levantamentos foram executados em dias úteis, entre segunda e quintafeira, e nunca em feriados ou dias sob influência dessas datas. Os questionários foram aplicados continuamente ao longo do dia, no período entre 06:00h e 18:00h.

A realização das entrevistas em campo utilizou computadores portáteis do tipo "Palm Top", para os quais foi desenvolvido um software específico para a

\footnotetext{
${ }^{40}$ Devido ao uso de computadores para as pesquisas, a localização dos postos ficou restrita a locais com infra-estrutura adequada, como praças de pedágios, nas rodovias pedagiadas, e postos da polícia rodoviária, em rodovias não pedagiadas.
} 
pesquisa. Os dados coletados nas entrevistas eram gravados em arquivos de formato tipo texto, no momento da coleta do dado em campo, e descarregados em intervalos de três horas para um computador de maior capacidade, onde eram analisados pelo supervisor da pesquisa, para controles preliminares da amostra.

O mapa da Figura 5-1 e a Tabela 5-1 a seguir indicam a localização dos postos de pesquisa, todos situados em rodovias sob jurisdição estadual.

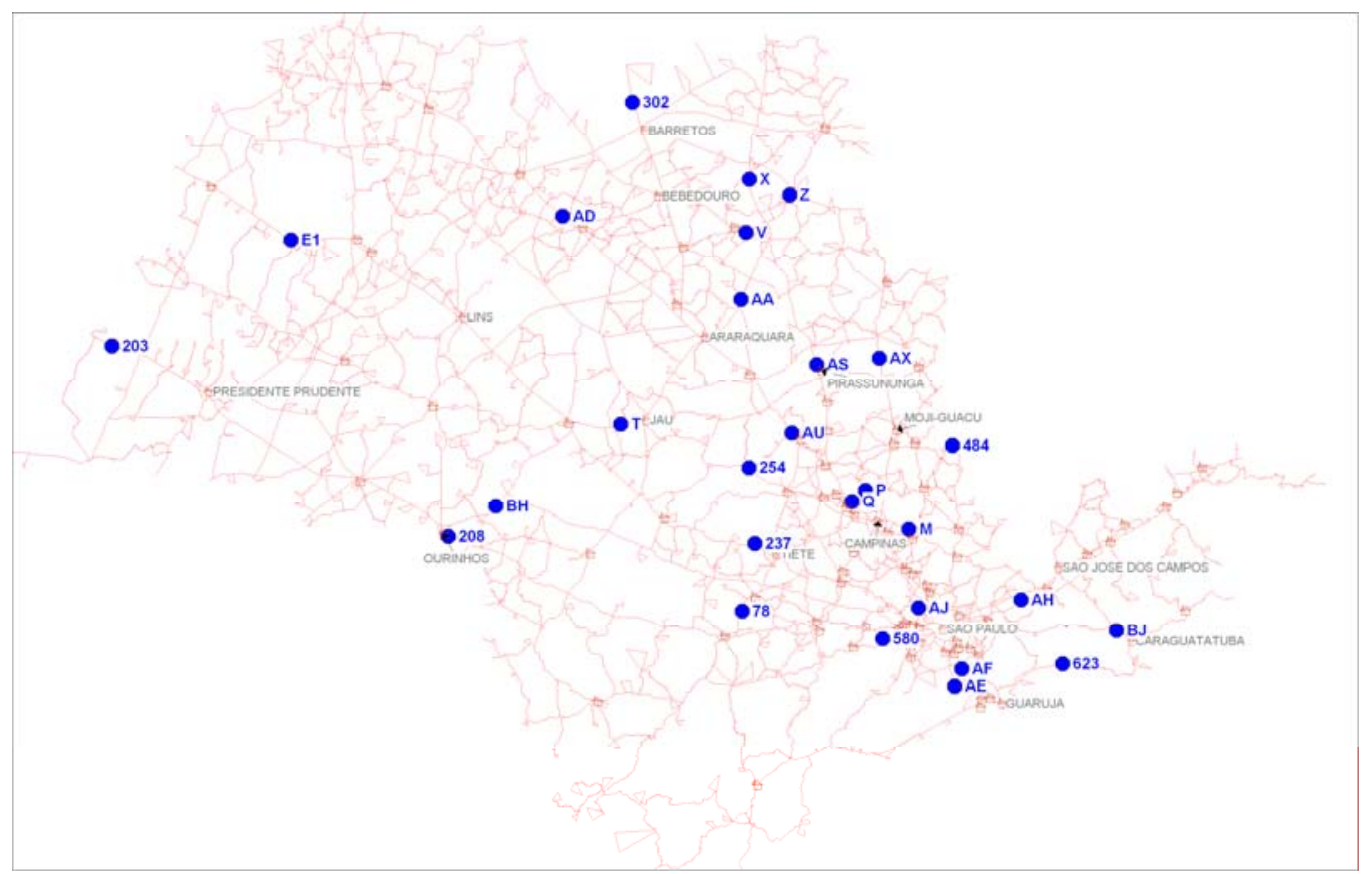

Figura 5-1: Localização dos pontos de pesquisa. 
Tabela 5-1: Localização dos postos de pesquisa

\begin{tabular}{ccc}
\hline Posto & Rodovia & Km \\
\hline 78 & SP127 & 129 \\
\hline 203 & SP270 & 639 \\
\hline 208 & SP270 & 373 \\
\hline 237 & SP300 & 178 \\
\hline 254 & SP304 & 197 \\
\hline 302 & SP326 & 445 \\
\hline 484 & SP360 & 178 \\
\hline 580 & SP270 & 46 \\
\hline 623 & SP055 & 194 \\
\hline AA & SP255 & 45 \\
\hline AD & SP310 & 398 \\
\hline AE & SP160 & 40 \\
\hline AF & SP150 & 31 \\
\hline AH & SP070 & 60 \\
\hline
\end{tabular}

\begin{tabular}{ccc}
\hline Posto & Rodovia & km \\
\hline AJ & SP330 & 26 \\
\hline AS & SP330 & 215 \\
\hline AU & SP310 & 181 \\
\hline AX & SP340 & 193 \\
\hline BH & SP225 & 310 \\
\hline BJ & SP099 & 61 \\
\hline E1 & SP300 & 576 \\
\hline$M$ & SP065 & 110 \\
\hline P & SP332 & 132 \\
\hline Q & SP330 & 119 \\
\hline$T$ & SP225 & 198 \\
\hline$V$ & SP322 & 328 \\
\hline$X$ & SP330 & 340 \\
\hline$Z$ & SP334 & 344 \\
\hline
\end{tabular}

\subsection{Características da Entrevista}

As entrevistas eram compostas de duas partes: inicialmente o motorista era questionado sobre sua situação socioeconômica e sobre a viagem que realizava, e em seguida eram apresentadas as questões de preferência declarada. Essa segunda parte consistia da aplicação de 9 questões, nas quais o entrevistado deveria escolher entre duas alternativas: uma rota pedagiada e um caminho alternativo não pedagiado.

A primeira parte da pesquisa compreendia as seguintes questões:

- Origem e destino da viagem

- Tempo estimado da viagem

- Motivo na origem:

- Em casa

- No trabalho diário

- A passeio ou visita a parentes

- A negócios 
o No estudo / faculdade

o Outros

- Motivo no destino:

- Para casa

- Para o trabalho diário

- A passeio ou visita a parentes

- A negócios

- Para o estudo / faculdade

o Outros

- Freqüência da viagem

o Diária

o $1 \times$ por semana

o $2 \times$ por semana

o $3 \times$ por semana

o $1 \times$ por mês

o Eventual / 1 $\underline{a}$ vez

- Quantidade de pedágios pagos na viagem

- Uso de algum caminho alternativo para fugir do pedágio onde se encontra $^{41}$

o se sim:

- Qual o acréscimo de tempo por esse caminho?

- Qual a freqüência de uso desse caminho? (resposta aberta)

- Propriedade do veículo

o Particular

o Alugado

o Empresa

- Sexo do motorista

- Idade do motorista

- Chefe da família (sim / não)

- Faixa de renda familiar:

o Até $\mathrm{R} \$ 600,00$

- De $\mathrm{R} \$ 601,00$ a 900,00

o De $R \$ 901,00$ a $1.500,00$

${ }^{41}$ Essa questão era apresentada apenas quando o posto de pesquisa estava localizado em uma praça de pedágio. 
o De $R \$ 1.501,00$ a $3.000,00$

o De $R \$ 3.001,00$ a $6.000,00$

o Acima de $\mathrm{R} \$ 6.001,00$

o Não informado

- Quantidade de veículos em casa

A Figura 5-2, a seguir, mostra a forma de apresentação das questões sobre as características do motorista e da viagem: 


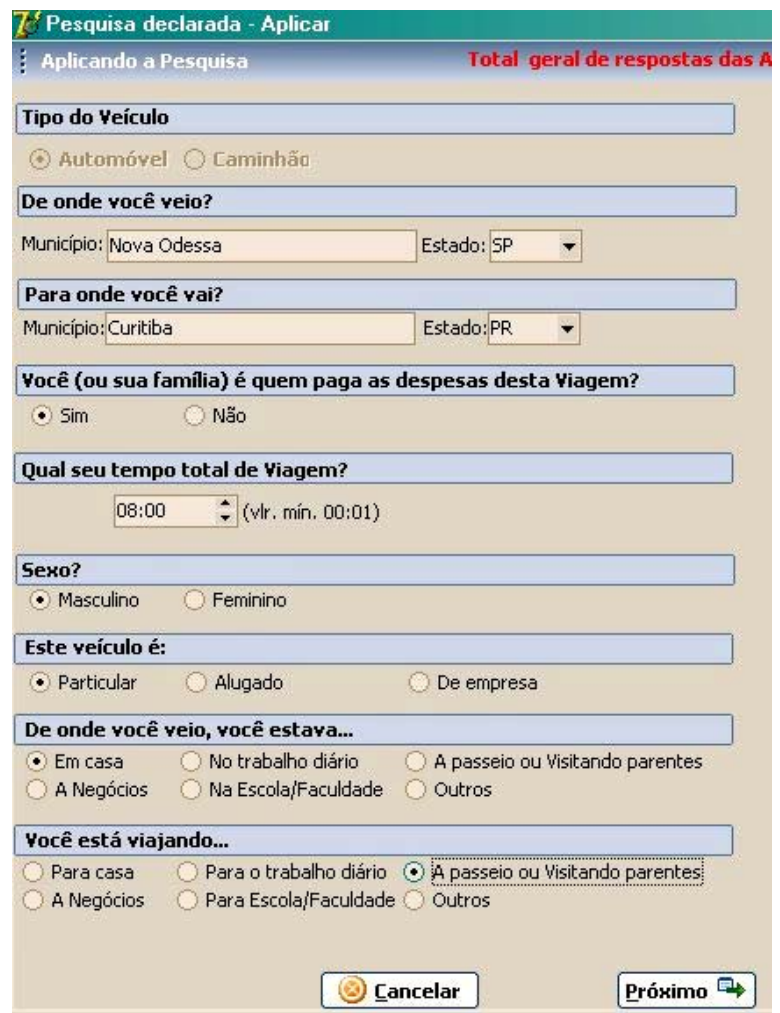

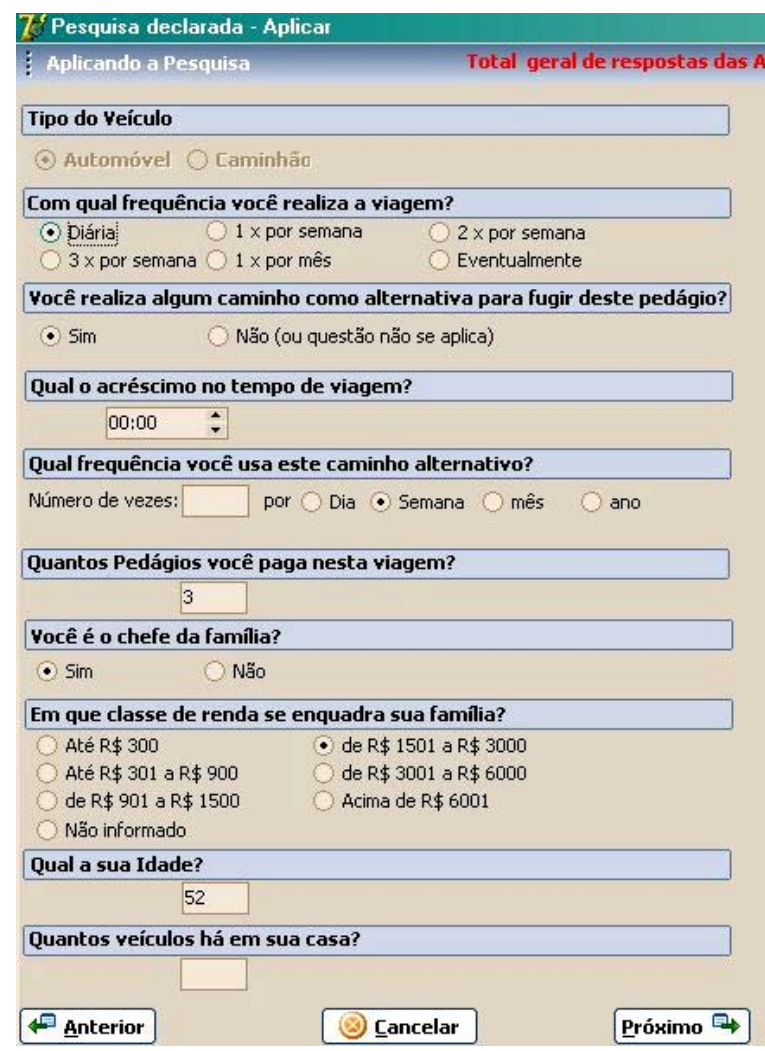

Figura 5-2: Formulário com as perguntas de preferência revelada 


\subsection{Desenho do Experimento de PD Utilizado}

As características do levantamento, onde o motorista tem sua viagem interrompida para ser entrevistado no acostamento da rodovia ${ }^{42}$, se por um lado favorecem na agilidade do levantamento de informações e trazem ganhos em tamanhos de amostras obtidas, têm, por outro lado, como ônus a condição de "stress" de alguns motoristas no momento da entrevista, que sentem estarem perdendo tempo parados na estrada. Assim, a experiência indica que a duração da entrevista é um aspecto crítico: levantamentos muito longos estarão invariavelmente associados à perda na qualidade das informações dadas pelos entrevistados. Em uma pesquisa envolvendo questões de preferência declarada, as restrições de duração da entrevista e as condições não ideais de concentração do motorista levam à necessidade de desenhos simples, menor quantidade de variáveis e níveis a serem analisados, evitando-se assim as perdas de qualidade decorrentes do efeito de fadiga do entrevistado.

O desenho do experimento envolveu três atributos e três níveis em cada um desses. A alternativa de rota pedagiada tinha como atributos a tarifa do pedágio e o tempo de percurso, enquanto a rota não pedagiada era caracterizada apenas pelo tempo de percurso, sempre maior do que o da opção pela rota pedagiada. A definição dos atributos em três, passa pelo conceito assumido de alternativas 'rotuladas' na pesquisa. Caso as alternativas fossem definidas como 'não rotuladas', seriam apenas dois os atributos: o valor da tarifa de pedágio e o tempo de viagem.

Hensher (1996b) descreveu a aplicação de um experimento envolvendo escolha de rotas rodoviárias onde considerava as alternativas como não rotuladas. Nesse caso, no entanto, as rotas apresentavam condições iguais,

\footnotetext{
${ }^{42}$ É comum encontrar em inglês a definição road-side survey para este tipo de pesquisa.
} 
havendo a opção de se utilizar uma via expressa ${ }^{43}$ pedagiada. Para o caso geral das rodovias em nosso país, há grande diferença entre a qualidade de serviço de uma rodovia pedagiada e outra não pedagiada. No experimento realizado, apesar do entrevistador solicitar ao motorista que considerasse ambas as alternativas em iguais condições de pavimento, acredita-se que esse intuitivamente associe à uma rodovia pedagiada atributos relacionados à segurança e conforto que raramente estão presentes em rodovias não pedagiadas $^{44}$. Isso justificaria o uso de um experimento com alternativas rotuladas.

Com relação aos níveis dos atributos relativos ao tempo de percurso pela rota pedagiada e pela rota não pedagiada, esses eram apresentados em função do tempo de viagem $(\mathrm{T})$ respondido pelo motorista. O valor da tarifa $(\mathrm{P})$ era prédefinido. A Tabela 5-2 mostra os valores associados aos níveis.

Tabela 5-2: Valores associados aos níveis dos atributos

\begin{tabular}{cccc}
\hline Nível & $\begin{array}{c}\text { Atr_1 } \\
\text { Tempo de viagem pela rota } \\
\text { pedagiada (min) }\end{array}$ & $\begin{array}{c}\text { Atr_2 } \\
\text { Custo do pedágio (R\$) }\end{array}$ & $\begin{array}{c}\text { Atr_3 } \\
\text { Tempo de viagem com } \\
\text { atraso pela rota não } \\
\text { pedagiada(min) }\end{array}$ \\
\hline-1 & $T-15$ & $P-30 \%$ & $T+28$ \\
0 & $T$ & $P$ & $T+40$ \\
+1 & $T+15$ & $P+30 \%$ & $T+52$ \\
\hline
\end{tabular}

Onde $\mathrm{T}$ representa o tempo de viagem respondido pelo motorista e $\mathrm{P}$, o valor definido para a tarifa de pedágio. Para o valor $\mathrm{P}$, partia-se do patamar de $\mathrm{R} \$$ 7,50 para entrevistas realizadas em rodovias de pista dupla e $R \$ 5,00$ em rodovias de pista simples. A cada 3 horas, as entrevistas até então realizadas no posto eram consolidadas em um único computador e analisada a distribuição das respostas, entre as alternativas 1 (rota pedagiada) e 2 (não

\footnotetext{
${ }^{43}$ Exemplo semelhante pode ser dado pelo trecho inicial da rodovia Castello Branco, entre São Paulo e Barueri, onde o motorista tem a opção de usar a pista central ou a pista marginal expressa pedagiada. Nesse caso ambas as rodovias são concessionadas e têm condições semelhantes de qualidade de serviço prestado.

44 Dentre esses elementos que diferenciam a infra-estrutura de uma rodovia pedagiada podem-se citar: qualidade da sinalização, telefones de emergência, serviço de socorro mecânico, atendimento a acidentes, postos de atendimento ao usuário, iluminação, presença de acostamento e $3 \underline{\text { a }}$ faixa.
} 
pedagiada). Caso se observasse grande desproporção nas respostas, como por exemplo, $30 \%$ de respostas na alternativa 1 e $70 \%$ na alternativa 2 , era feita uma redução no valor de $\mathrm{P}$, de modo a tornar a alternativa pedagiada mais atrativa e assim buscar-se o equilíbrio nas respostas para as duas opões de escolha ${ }^{45}$.

Foi empregado na pesquisa um desenho fatorial fracionado, compreendendo um total de 9 combinações, capturando apenas os efeitos principais. A Tabela 5-3 mostra as combinações de tratamentos de cada um dos 9 conjuntos de escolha apresentados

Tabela 5-3: Desenho fatorial fracionado utilizado na pesquisa

\begin{tabular}{cccc}
\hline & \multicolumn{3}{c}{ Níveis dos atributos } \\
\cline { 2 - 4 } Combinação & $\begin{array}{c}\text { Tempo de viagem rota } \\
\text { pedagiada (min) }\end{array}$ & Custo do pedágio (R\$) & $\begin{array}{c}\text { Tempo de viagem rota não } \\
\text { pedagiada(min) }\end{array}$ \\
\hline 1 & -1 & -1 & -1 \\
2 & -1 & 0 & 0 \\
3 & -1 & +1 & +1 \\
4 & 0 & -1 & +1 \\
5 & 0 & 0 & -1 \\
6 & 0 & +1 & 0 \\
7 & +1 & -1 & 0 \\
8 & +1 & 0 & +1 \\
9 & +1 & +1 & -1 \\
\hline
\end{tabular}

5.3.1. Forma de aplicação da pesquisa de PD

Como mencionado, na pesquisa de preferência declarada foram apresentadas nove questões, sempre com duas alternativas: i) rota pedagiada; ii) rota alternativa sem pedágio. A decisão que o motorista deveria tomar era apresentada da seguinte forma pelo entrevistado: “Imagine que em um trecho da sua viagem, você tenha a opção de usar uma rodovia pedagiada ou

45 O analista presente no local da pesquisa realizava, quando necessário, aumentos ou reduções no valor de $\mathrm{P}$, sempre com 'passos' de $\mathrm{R} \$ 1,50$. 
uma rota alternativa sem pedágio, ambas com as mesmas condições de pavimento, só mudando o maior tempo gasto ao utilizar a rota de fuga":

Opção 1: Rota pedagiada

$\checkmark$ Custo do pedágio

$\checkmark$ Tempo de viagem

Opção 2: Rota alternativa sem pedágio

$\checkmark$ Tempo de viagem com atraso

As figuras a seguir mostram a forma de apresentação das alternativas, sempre duas a duas. O exemplo se refere a uma entrevista onde o motorista tenha declarado ter sua viagem uma duração de 2 horas:

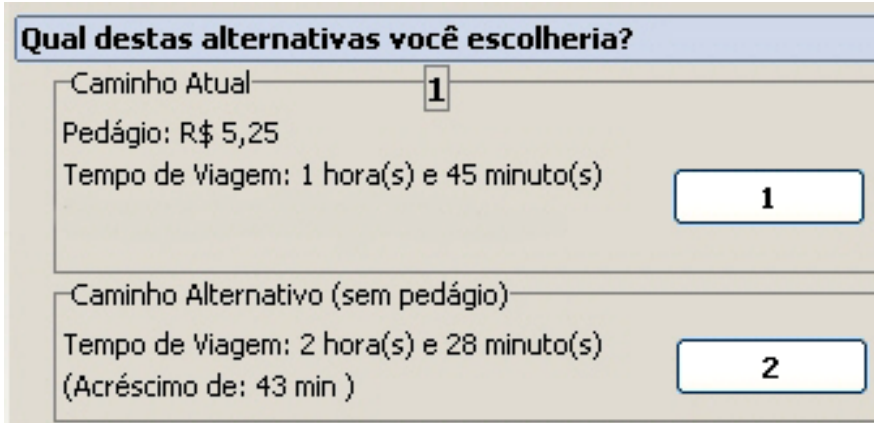

Figura 5-3: Pergunta 1 da preferência declarada

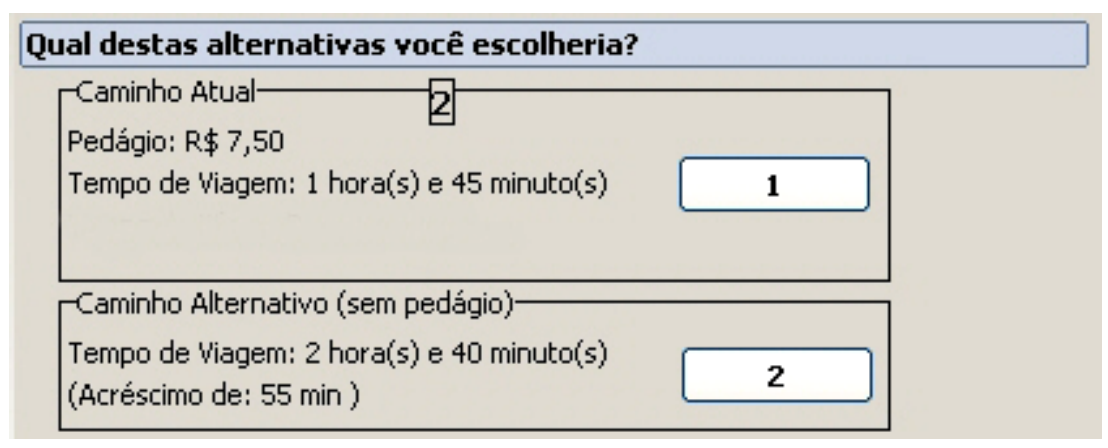

Figura 5-4: Pergunta 2 da preferência declarada 


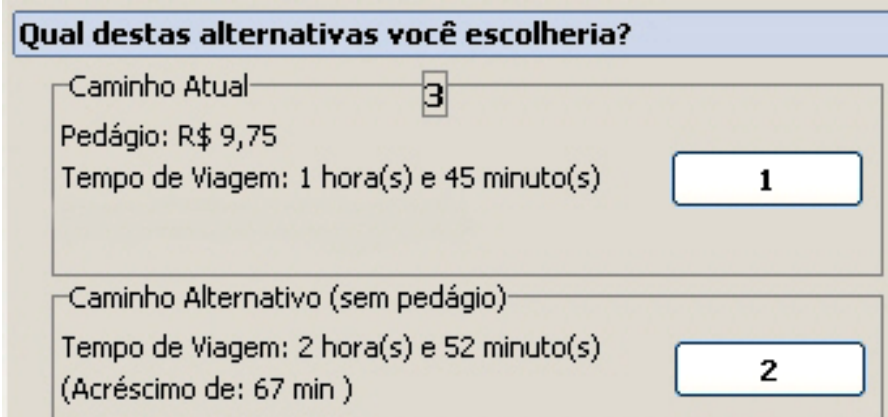

Figura 5-5: Pergunta 3 da preferência declarada

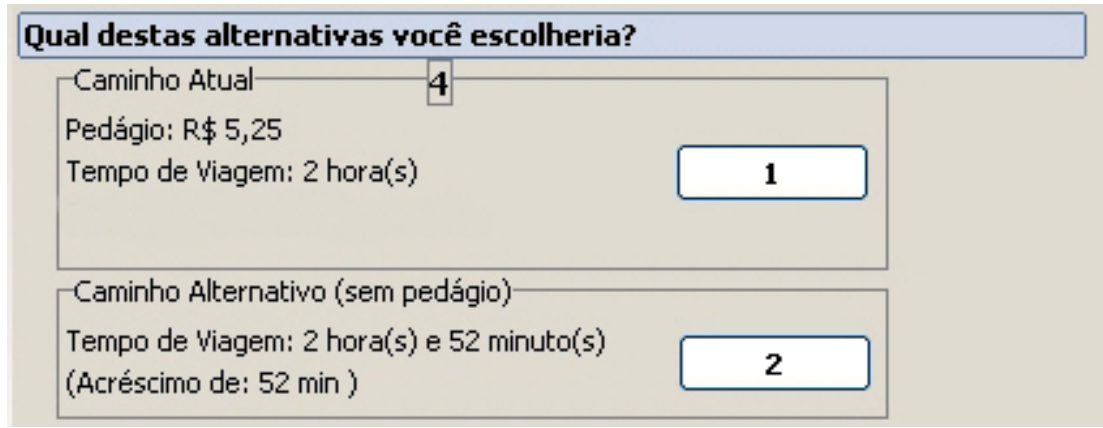

Figura 5-6: Pergunta 4 da preferência declarada

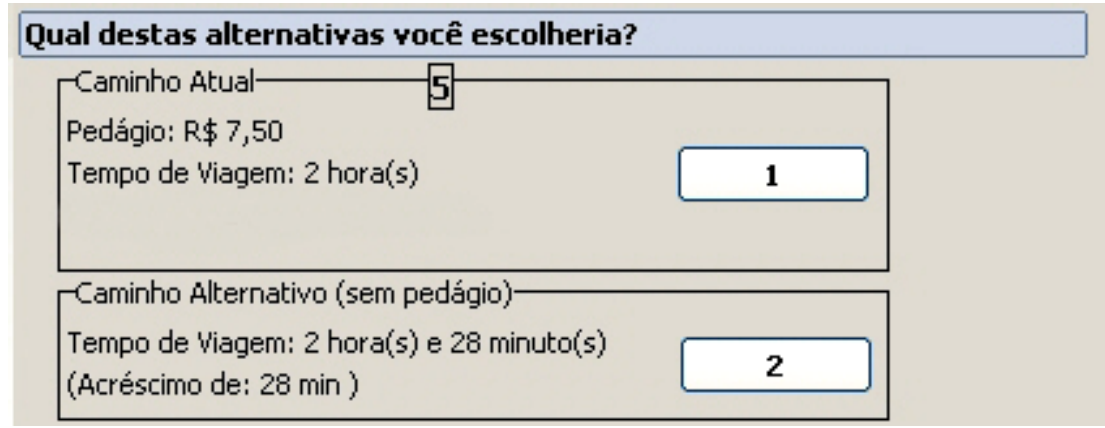

Figura 5-7: Pergunta 5 da preferência declarada

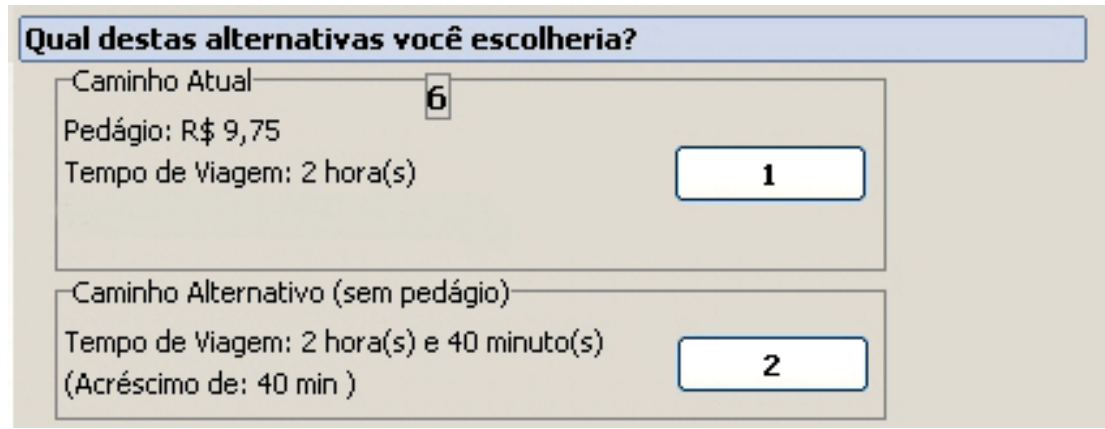

Figura 5-8: Pergunta 6 da preferência declarada 


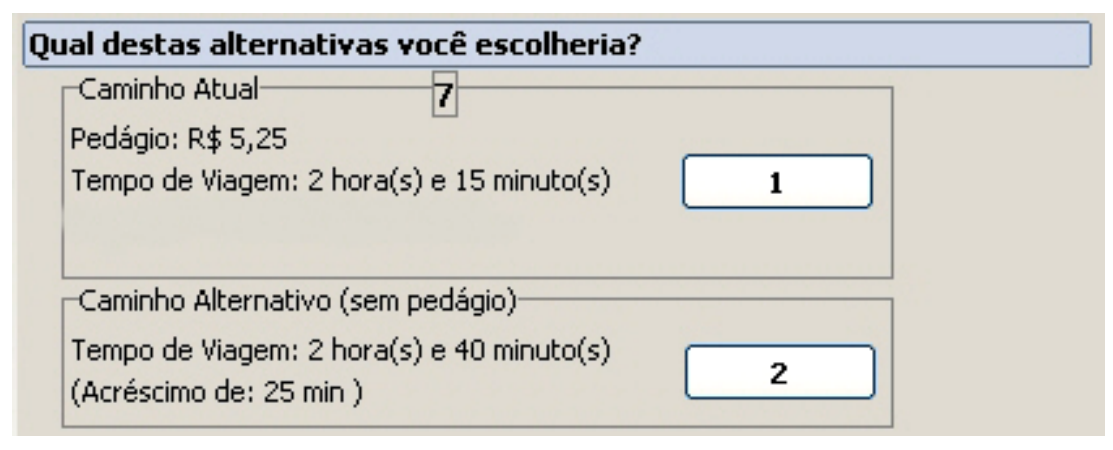

Figura 5-9: Pergunta 7 da preferência declarada

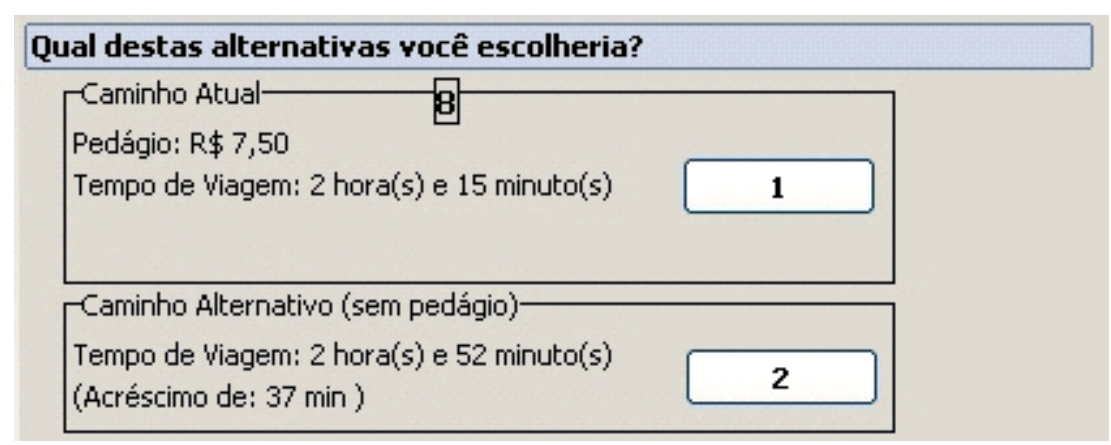

Figura 5-10: Pergunta 8 da preferência declarada

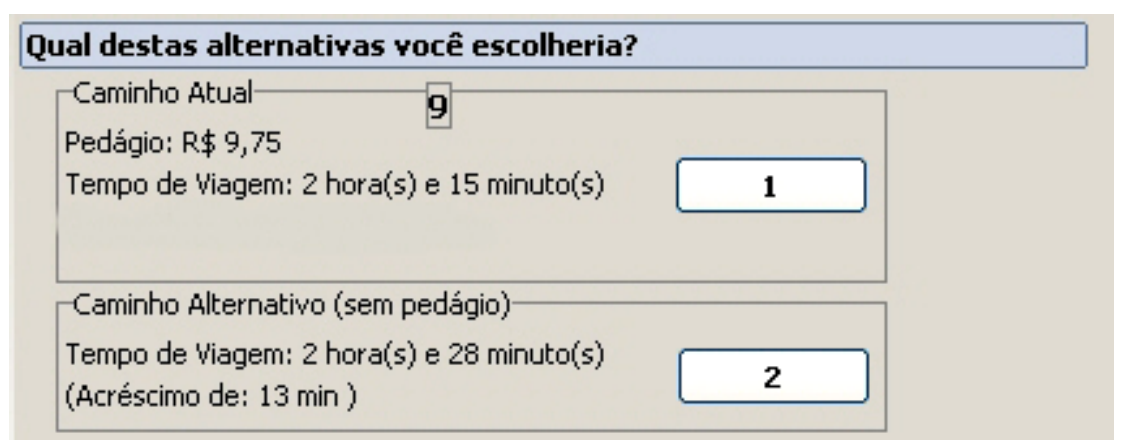

Figura 5-11: Pergunta 9 da preferência declarada

Cabe aqui a observação de que a alternativa relativa à rota pedagiada era denominada na tela do computador como 'caminho atual', mesmo quando o posto de pesquisa estava localizado em uma estrada não pedagiada. Esse problema, no entanto, não foi considerado relevante pelo fato de que, pelo procedimento da pesquisa, o entrevistador se referia às alternativas usando os termos: 'rodovia pedagiada' e 'rota alternativa não pedagiada'. 
5.3.2. Comentários sobre o desenho da pesquisa de PD

O desenho da pesquisa utilizada adotou 3 variáveis: o tempo de viagem pela rota pedagiada, o custo tarifário e o tempo com atraso pela alternativa não pedagiada. Essa característica tem o aspecto positivo de levar a conjuntos de escolha simples e que não exigem análises complexas ou demoradas para o entrevistado, o que é bastante conveniente pela forma de levantamento de informações utilizada. Como citado no item 5.3.1, pedia-se que o entrevistado considerasse ambas as alternativas em iguais condições de pavimento. Para conferir maior realismo aos cenários de escolha, uma possibilidade a analisar seria a inclusão de alguma variável que refletisse a diferença na percepção do custo operacional pelo motorista ao usar uma rodovia pedagiada e uma não pedagiada, como estimado por Zignani, Nodari e Cybis (2006), e a verificação de sua importância como um atributo de escolha.

Com relação à estruturação da pesquisa, tendo em vista conceitos discutidos no capítulo 4.5.1, podem ser feitas algumas observações sobre o formato e apresentação da pesquisa aqui utilizada:

a. Em todos os 9 conjuntos de escolha, era sempre apresentada em primeiro lugar a alternativa 'pedagiada' e em seguida a alternativa 'não pedagiada'.

b. Com relação à seqüência de apresentação dos 9 conjuntos de escolha, todas as entrevistas seguiram a mesma ordem de apresentação das combinações - indicadas na Tabela 5-3. Como conseqüência, as últimas questões são sempre as de maior atratividade para a alternativa 'não pedagiada'.

c. A entrevista iniciava-se pelas questões de PR, ficando as de PD para a segunda parte da entrevista. 
Sobre as observações dos itens a. e b., poderia ter sido aplicada no experimento a aleatorização da seqüência na apresentação dos conjuntos de escolha, definida por Hensher, Rose e Greene (2005) como uma das etapas da elaboração do desenho do experimento, e comentada no item 4.5.1.

Com relação ao descrito no item c, poder-se-iam fazer aprimoramentos seguido-se algumas das recomendações sobre a construção do instrumento de pesquisa, descritas no item 4.5.1. Assim, as questões de PD por exigir maior atenção por parte do entrevistado poderiam ser apresentadas no início da entrevista, reduzindo-se o denominado efeito que a fadiga possa ter sobre a qualidade das respostas da PD.

Um elemento não diretamente relacionado ao desenho, mas que poderia contribuir para a maior eficiência da pesquisa seria o uso de exemplos ilustrativos. Notou-se em campo, durante a execução das pesquisas, que a situação hipotética da pesquisa era intuitiva para a maior parte dos motoristas. No entanto, uma parcela mostrava alguma dificuldade de entendimento sobre o cenário de escolha, o que poderia ser contornado com o uso de ilustrações descrevendo as duas opções de escolha, como na Figura 5-12 ${ }^{46}$.

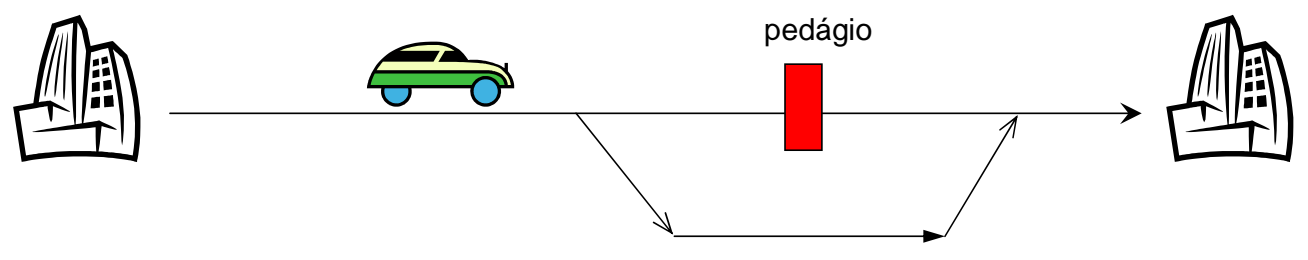

Figura 5-12: Exemplo ilustrativo da situação simulada na pesquisa

\footnotetext{
${ }^{46}$ Van Zyl e Raza (2006), ao relatar um experimento semelhante ao aqui desenvolvido, apresentam essa observação entre as recomendações finais de seu trabalho.
} 


\section{ANÁLI SES E ESTI MATI VAS}

Este capítulo compreenderá a análise do conjunto de informações obtido das pesquisas de campo. Inicialmente serão descritos os critérios utilizados para 'limpeza dos dados', feita através da eliminação de entrevistas inadequadas para as estimativas. A seguir será feita uma verificação exploratória para conhecimento da amostra pesquisada, compreendendo a análise das respostas às questões de $P R$, distribuição das escolhas e verificação da relação entre algumas variáveis. Posteriormente, serão feitas as estimativas dos modelos de escolha para alguns segmentos da amostra e analisadas as diferenças entre os valores de tempo obtidos para cada um desses segmentos. Serão também testadas algumas características do motorista e da viagem realizada, representadas por variáveis dummies, visando investigar efeitos adicionais sobre a variação do valor do tempo.

\subsection{Eliminação de Entrevistas}

Como é comum em levantamentos envolvendo preferências declaradas, uma parcela dos entrevistados não responde às questões de forma a considerar a maximização da sua utilidade, como descrito no capítulo sobre a teoria da escolha. Ortúzar e Willumsen (2001) citam a eliminação de entrevistas através de testes de consistência como uma etapa preliminar às estimativas dos modelos.

Observando-se este aspecto, o estudo realizado excluiu inicialmente da amostra dois tipos de entrevistas potencialmente inválidas: i) aquelas cujos entrevistados concentravam todas as suas respostas na alternativa 
'pedagiada', ou todas na 'não pedagiada'47 e ii) entrevistas onde apenas uma das nove respostas diferiu das demais, ou seja, os casos em que o entrevistado responde 8 vezes a alternativa 1 e uma vez a alternativa 2 , ou vice-versa. As entrevistas que se encaixavam nesse segundo caso fornecem pouca informação para a calibração de um modelo, dada sua pouca variabilidade de respostas, o que já poderia justificar sua não inclusão nas análises. Adicionalmente, foram feitas estimativas preliminares de modelos de escolha considerando apenas as entrevistas com esse padrão de resposta na amostra, tendo sido obtidos modelos fracos, com valores de rho-quadrado em torno de 0,06 e alta correlação entre os coeficientes do tempo e custo da viagem e a constante específica na função de utilidade ${ }^{48}$.

Foram também eliminadas da análise aquelas entrevistas incompletas, já que os entrevistadores eram instruídos a encerrar a pesquisa ao perceber o desinteresse do motorista em responder às questões.

Entrevistas onde o motorista declarava que as despesas da viagem, como tarifas de pedágio, eram pagas pela empresa para a qual trabalhava, também não foram consideradas para as análises, assim como aquelas onde o tempo de viagem era inferior a 20 minutos. Esse último grupo, de acordo com Hensher (1996b), por realizar viagens muito curtas não teria sensibilidade adequada para o entendimento do cenário hipotético da pesquisa.

\subsubsection{Consistência das respostas dadas por um entrevistado}

Em uma segunda etapa, após algumas análises preliminares, optou-se por introduzir um critério adicional de avaliação da qualidade das respostas.

\footnotetext{
${ }^{47}$ Esse comportamento faz parte de um processo de escolha onde o indivíduo, por motivos como intuição, crenças ou imitação de pessoas consideradas experts, gera apenas uma alternativa de escolha (Ben-Akiva e Lerman, 1985). Na pesquisa realizada, tal padrão de resposta era motivado geralmente por posturas radicalmente contra ou a favor da concessão e pedagiamento das rodovias, como relatado pelos próprios motoristas.

48 Modelos estimados excluindo-se essas entrevistas da amostra tiveram valores de rho-quadrado sempre superiores a 0,3 , como será visto a seguir.
} 
Visando detectar entrevistas onde o motorista tenha respondido aleatoriamente às questões, buscou-se analisar a presença de respostas incompatíveis - ou inconsistentes - dadas por um entrevistado. Como mencionado a entrevista era formada por 9 questões, com diferentes combinações de tarifas pela rota pedagiada e tempos de acréscimo pela rota não pedagiada. Por exemplo, se na questão 1, mostrada na Figura 6-1 a seguir, o entrevistado escolher a alternativa 1, e na questão 4 (Figura 6-2), a alternativa 2 , isso caracterizará uma incoerência entre as respostas ${ }^{49}$. Ou seja, se em uma escolha o entrevistado preferir pagar um pedágio de $R \$ 5,25$ a utilizar uma rota que lhe aumente o tempo em 43 minutos, em uma outra escolha onde tenha a opção de pagar a mesma quantia ou usar uma rota com acréscimo de 52 minutos, seria esperado que esse preferisse novamente a primeira alternativa.

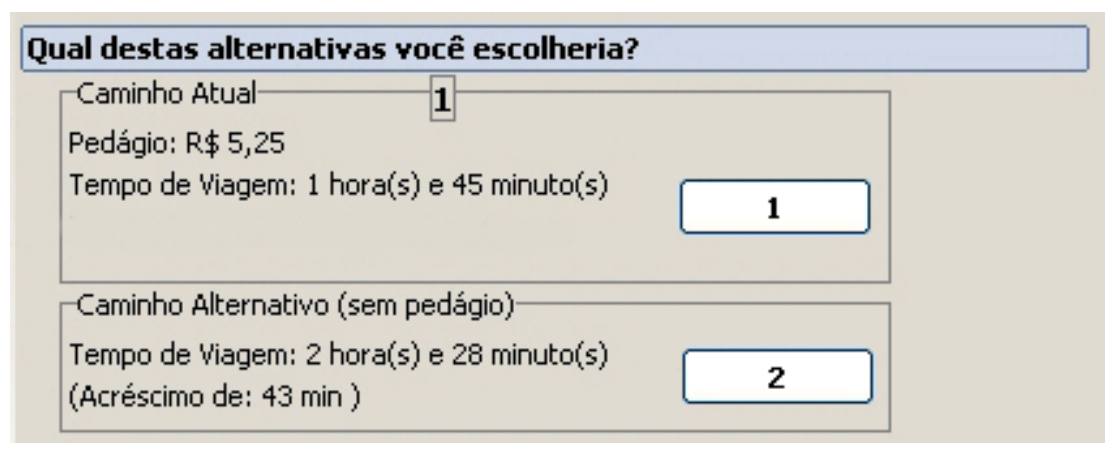

Figura 6-1: questão 1 da entrevista

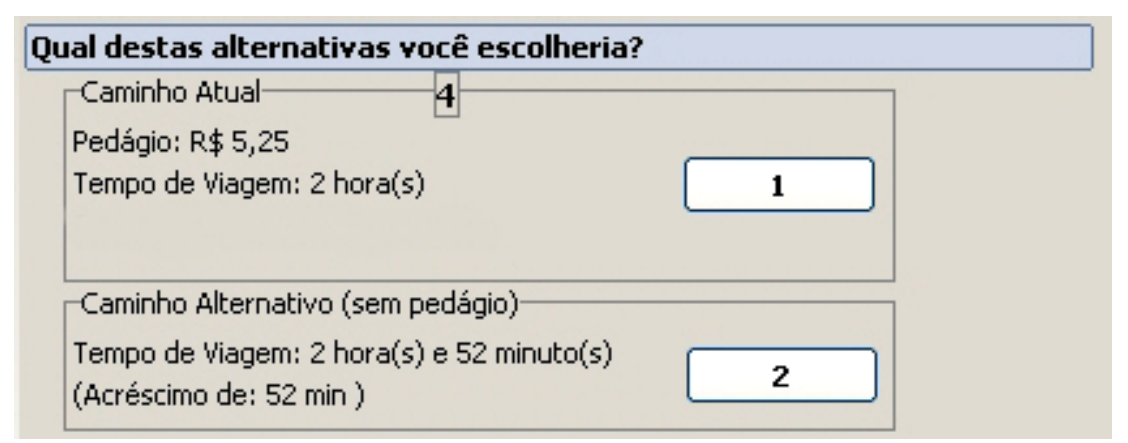

Figura 6-2: questão 4 da entrevista

\footnotetext{
49 Nota-se que a pergunta 1 não é dominante sobre a 4, já que outras combinações entre as respostas para essas duas perguntas poderão trazer informações adicionais.
} 
Seguindo essa lógica, foram verificadas uma a uma todas as combinações de respostas, chegando-se a nove que podem ser consideradas inconsistentes, descritas na Tabela 6-1.

Tabela 6-1: Combinações de respostas inconsistentes dentro de uma entrevista

\begin{tabular}{ccccc}
\hline Questão & $\begin{array}{c}\text { alternativa } \\
\text { escolhida }\end{array}$ & + & Questão & $\begin{array}{c}\text { alternativa } \\
\text { escolhida }\end{array}$ \\
\hline 1 & 1 & + & 4 & 2 \\
1 & 2 & + & 7 & 1 \\
2 & 1 & + & 5 & 2 \\
2 & 2 & + & 8 & 1 \\
3 & 2 & + & 6 & 1 \\
3 & 2 & + & 9 & 1 \\
4 & 2 & + & 7 & 1 \\
5 & 1 & + & 8 & 2 \\
6 & 2 & + & 9 & 1 \\
\hline Obs: As figuras 5-3 a 5-11 ilustram o problema mostrado nesta tabela
\end{tabular}

Cabe aqui observar que, a rigor, a utilização deste critério para avaliação da qualidade das respostas poderia ser questionável, já que pressupõe a especificidade do coeficiente da variável tempo pelas duas alternativas, ou seja, o tempo pela rota pedagiada seria percebido pelo motorista da mesma forma do que o tempo pela rota não pedagiada. No entanto, um forte indicador levou à sua aplicação como critério adicional para eliminação de entrevistas: modelos estimados para entrevistas com duas ou mais inconsistências entre as respostas tiveram indicadores de ajuste bastante ruins, se comparados aos obtidos nos modelos para as entrevistas sem nenhuma ou com apenas uma inconsistência. Desta forma, entrevistas com mais de uma inconsistência foram também eliminadas das análises.

Como já citado, a aplicação dos critérios anteriores de eliminação de entrevistas havia levado a um total de 5910 levantamentos. Desse total, verificou-se que 3340 (57\%) das entrevistas não continham nenhuma inconsistência entre 9 as respostas dadas pelo motorista. Uma parcela de 2071 (35\%) levantamentos apresentou uma inconsistência, e 499 entrevistados responderam com duas ou mais inconsistências. A aplicação do critério apresentado neste item 6.1.1 resultou na eliminação desse terceiro grupo, que representava $8 \%$ da amostra. 
A Tabela 6-2 mostra um resumo dos critérios de eliminação de entrevistas e a quantidade de levantamentos desconsiderados em decorrência da aplicação de cada um deles.

Tabela 6-2: Resumo com o total de entrevistas eliminadas

\begin{tabular}{lc}
\hline \multicolumn{1}{c}{ Critério } & Entrevistas desconsideradas \\
\hline concentração de todas as respostas na mesma alternativa & 737 \\
concentração de 8 respostas na mesma alternativa & 883 \\
entrevistas incompletas & 197 \\
tempos de viagem inferiores a 20 minutos & 529 \\
respostas inconsistentes & 499 \\
TOTAL & $\mathbf{2 8 4 5}$ \\
\hline
\end{tabular}

Observa-se que do total inicial de 8256 entrevistas, 2845 (34\% do total) foram eliminadas visando melhorar a qualidade das informações a serem utilizadas para as análises, que se restringirão aos 5411 levantamentos considerados válidos.

\subsection{Caracterização da Amostra}

As tabelas e gráficos a seguir apresentam algumas características da amostra utilizada para a estimativa dos modelos de escolha. Esta verificação tem o intuito de mensurar o tamanho da amostra por segmentos e a detecção de eventuais inconsistências sistemáticas no banco de dados ${ }^{50}$. Entrevistas descartadas pelos motivos descritos no item anterior não fazem parte das estatísticas apresentadas.

\footnotetext{
${ }^{50}$ Por exemplo, a identificação de parâmetros como tempo de viagem médio de 1200 minutos pode indicar problemas na conversão de formatos de banco de dados.
} 


\subsubsection{Estatísticas gerais da amostra}

São apresentadas neste item verificações da composição da amostra segundo algumas variáveis pesquisadas na parte da preferência revelada das entrevistas, como sexo do motorista, motivo e freqüência da viagem e distribuição dos tempos declarados de viagem.

O conjunto de informações analisado tem clara predominância de pessoas do sexo masculino, que representam quase 90\% da amostra. Das 5411 entrevistas utilizadas, 4847 são de motoristas do sexo masculino, como mostrado na Figura 6-3:

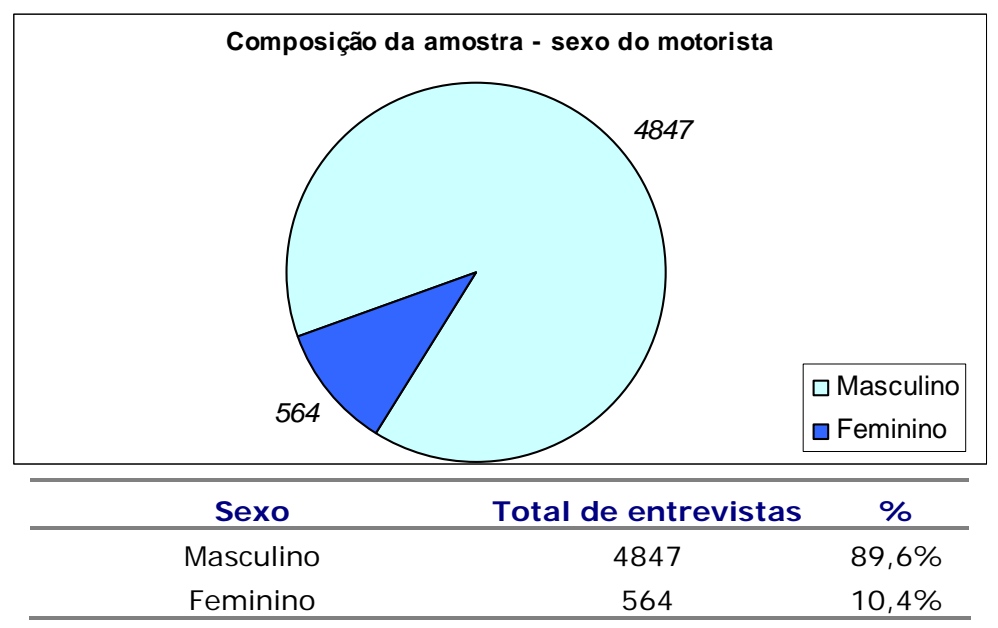

Figura 6-3: Composição da amostra por sexo do motorista

O histograma da Figura 6-4 mostra a distribuição das idades dos motoristas entrevistados. Esses têm, em média, 42 anos. A faixa de idade entre 24 e 55 anos concentra $80 \%$ das observações. 


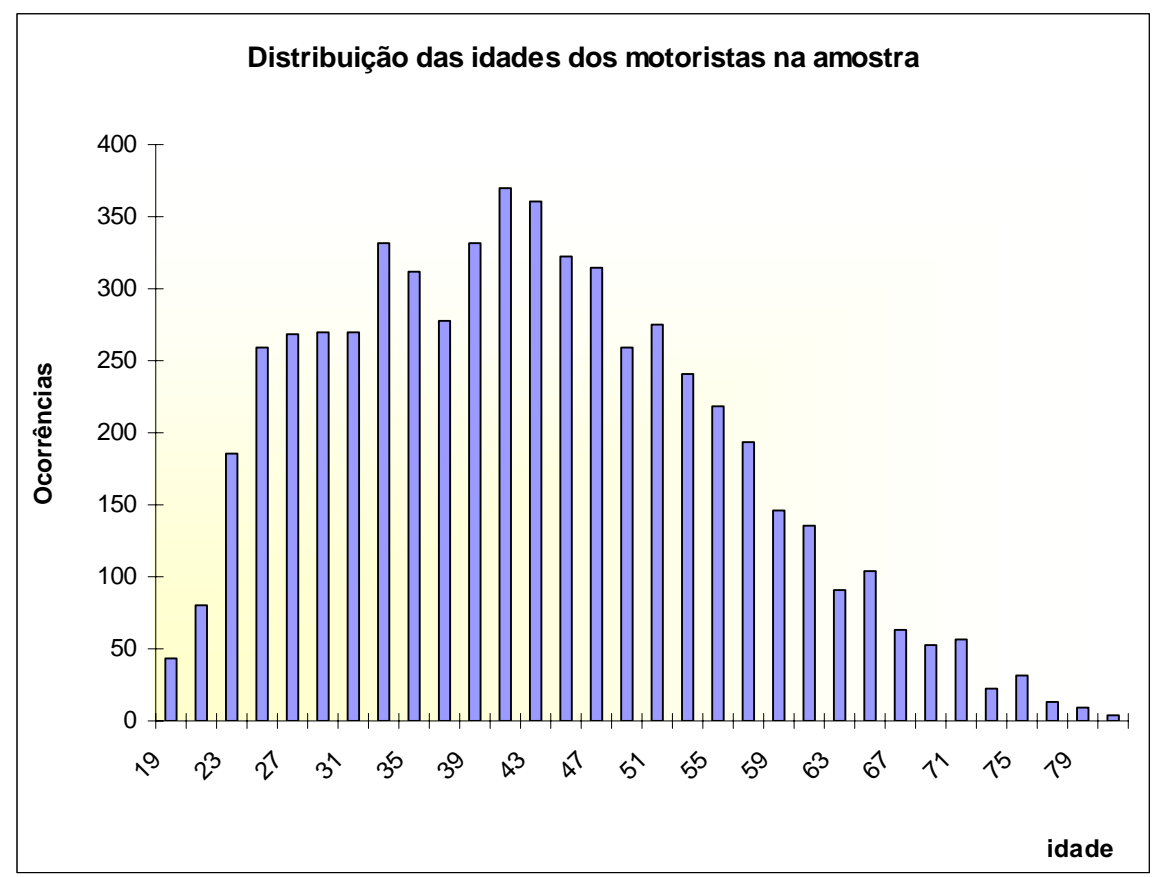

Figura 6-4: Distribuição das idades dos motoristas na amostra

A maior parte dos motoristas entrevistados, 93,1\%, eram os próprios donos do veículo. Parcelas menores, de 5,7\%, dirigiam veículo da empresa e apenas $1,2 \%$ dos entrevistados usavam automóvel alugado. A composição da amostra para a variável 'posse de veículo' é mostrada na Figura 6-5. Viagens realizadas com veículos de empresa, mas com as despesas pagas pelo motorista foram consideradas para a estimativa dos modelos.

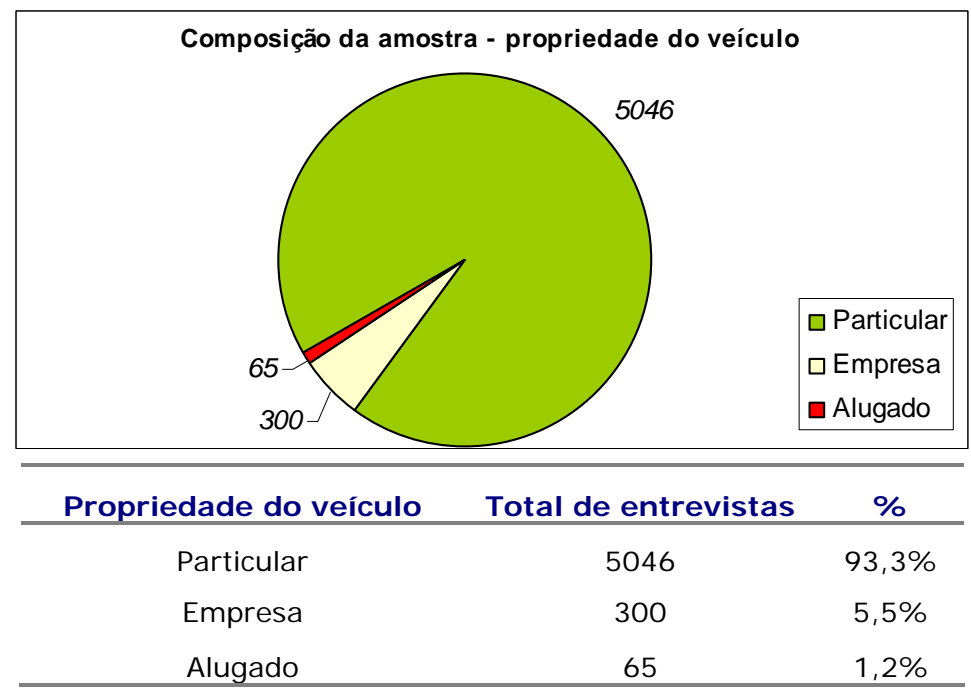

Figura 6-5: Composição da amostra por posse do veículo 
Sobre a posição na estrutura familiar, $84,5 \%$ dos entrevistados declararam-se chefes de família, como mostrado na Figura 6-6.

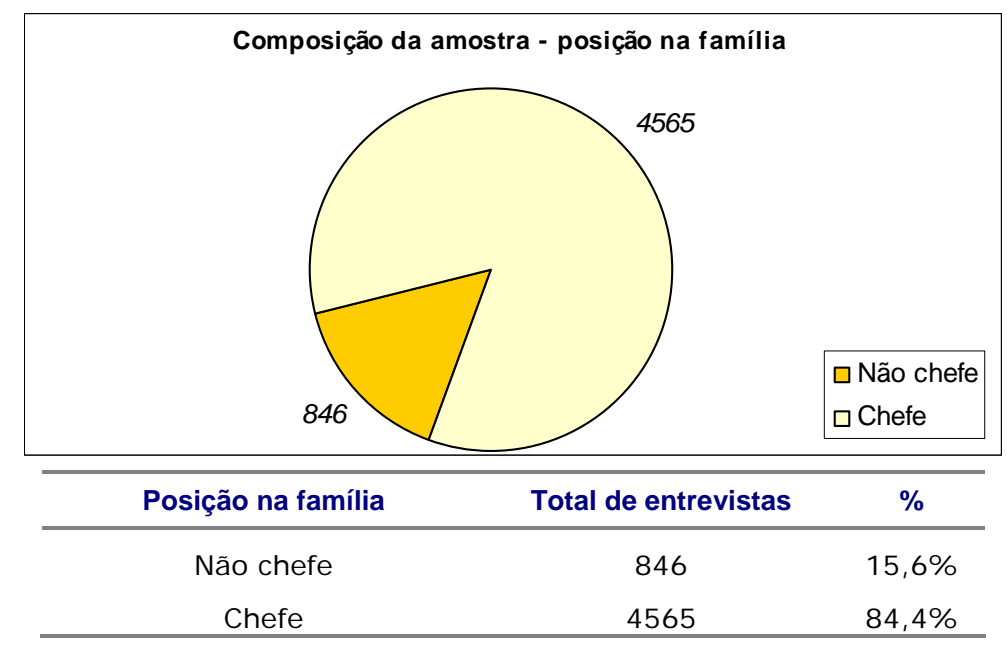

Figura 6-6: Composição da amostra por posição na família

Com relação ao número de veículos na família do entrevistado, 51\% responderam possuir um veículo e 35\%, dois. Uma parcela de 7,8\% declarou possuir 3 veículos em casa e $1 \%$ dos entrevistados afirmaram não possuir carro. A Figura 6-7 mostra a distribuição das respostas:

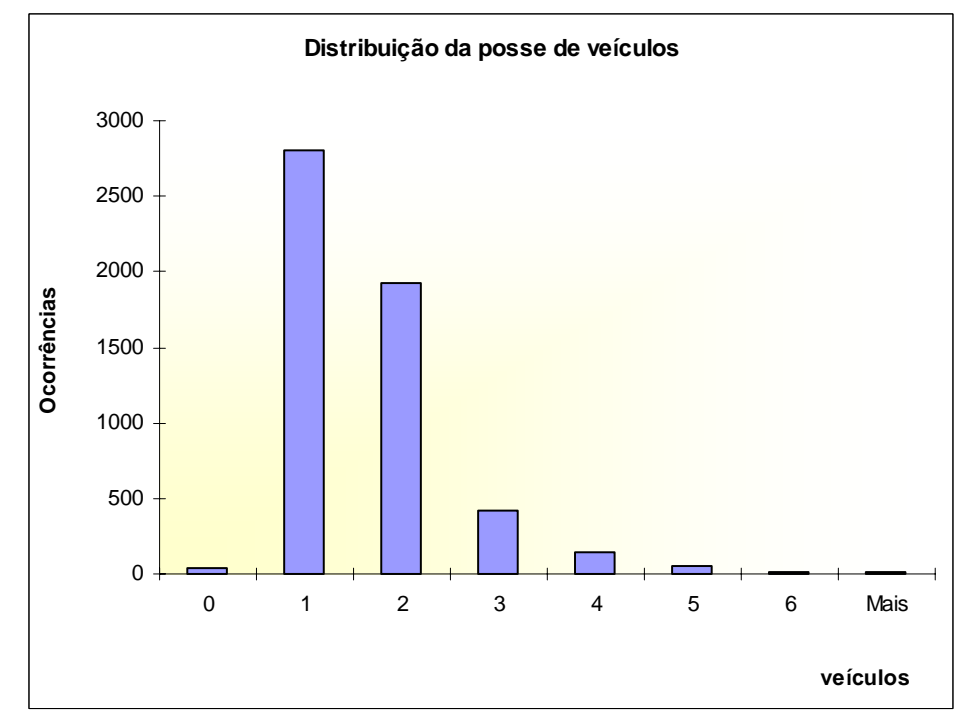

Figura 6-7: Distribuição da posse de veículos na amostra

A observação da distribuição dos entrevistados por classe de renda familiar indicou que mais da metade desses enquadra-se na faixa de renda mensal entre $\mathrm{R} \$ 901,00$ e $\mathrm{R} \$ 3000,00$, como indicado na Figura 6-8. 


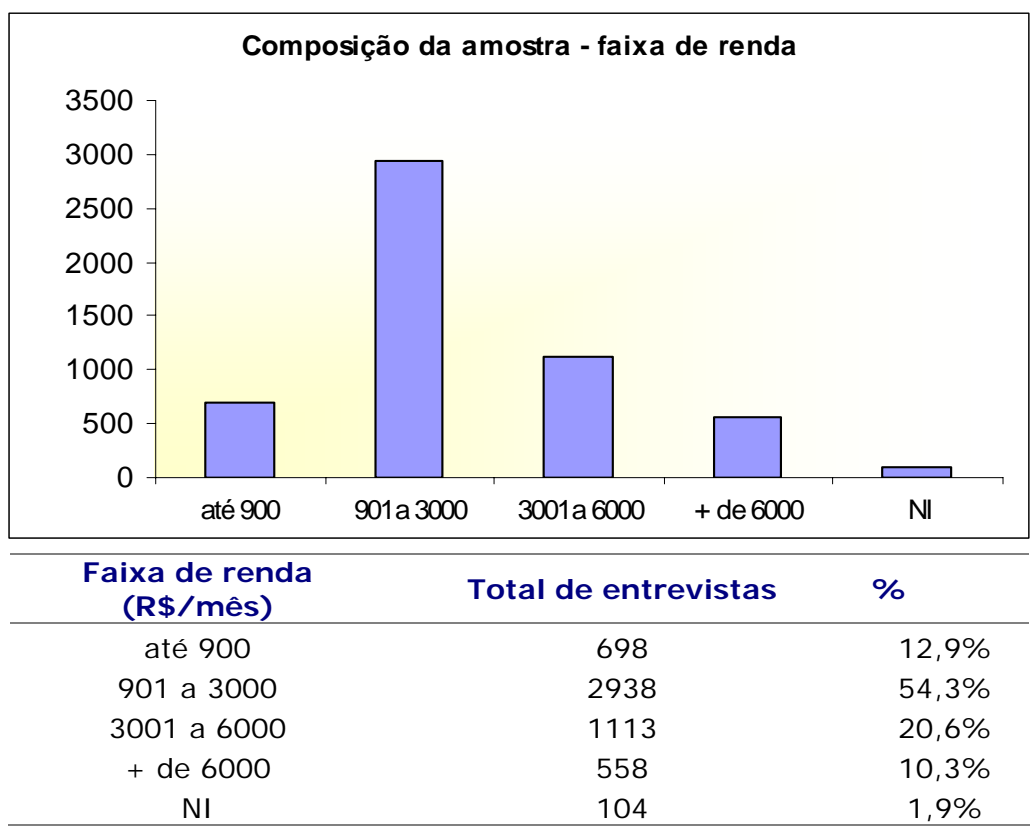

Figura 6-8: Distribuição das classes de renda na amostra

A Figura 6-9 mostra os resultados sobre a freqüência com que o motorista realizava a viagem em que foi entrevistado. A maior parte - cerca de $25,7 \%$ - declarou ser aquela de ocorrência eventual. No outro extremo, uma parcela representativa, de $18,9 \%$ dos entrevistados, afirmou realizar a viagem diariamente - 5 ou mais vezes por semana.

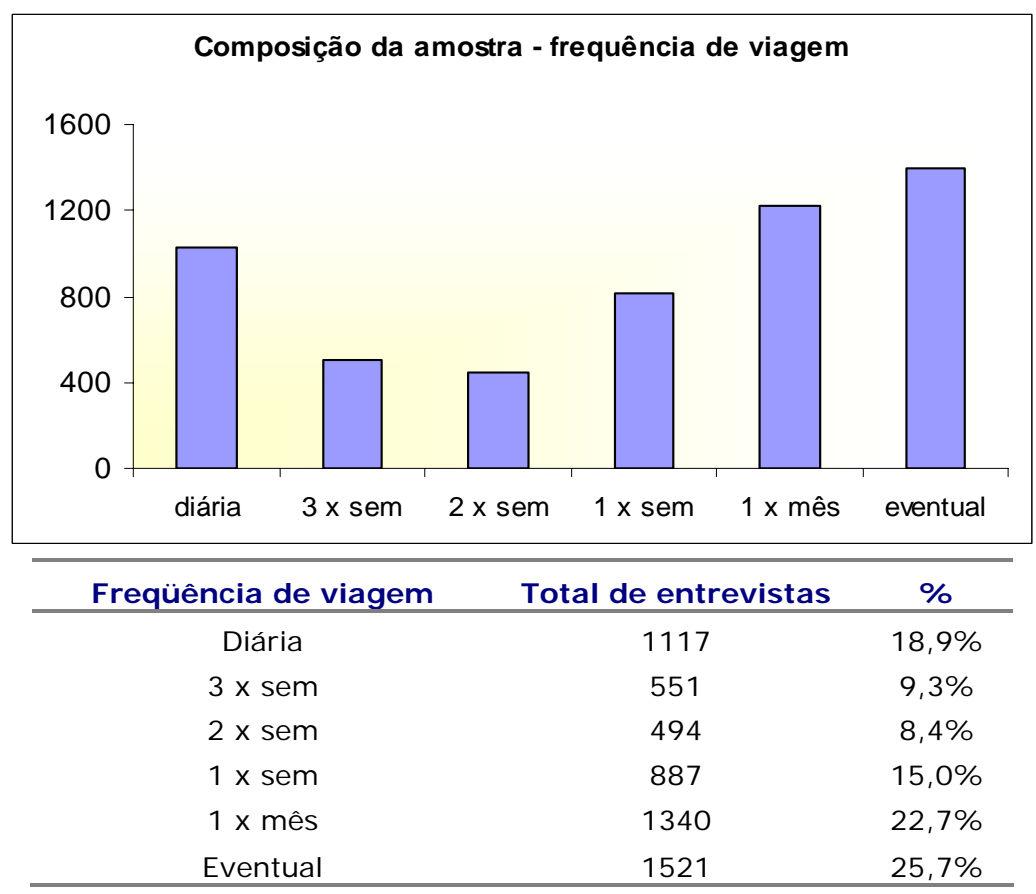

Figura 6-9: Distribuição das freqüências de viagem na amostra 
Sobre o motivo da viagem, observa-se na Figura 6-10 que 1850 entrevistados, ou 33,7\%, informaram que a viagem realizada tinha como destino o trabalho diário. As viagens com destino negócios representam uma parcela de $21,7 \%$ (1157 entrevistas). Tinham como finalidade o lazer $12,5 \%$ das viagens ${ }^{51}$, enquanto o motivo 'escola / educação' aparece com um percentual de apenas $1,1 \%$ das viagens abordadas.

Observa-se, pela informação motivo da viagem na origem, que metade dos deslocamentos pesquisados - 2956 entrevistas - teve como ponto de partida a casa do motorista. As viagens iniciadas no trabalho representam parcela de $29,1 \%$.

O intercâmbio, 'casa-trabalho' foi capturado em 1205 entrevistas, ou 20,3\% do total amostrado. O deslocamento 'trabalho-casa' representa parcela menor, de 9,4\%, assimetria provavelmente atribuída ao período do dia abrangido pela pesquisa, entre as 06:00h e as 18:00h.
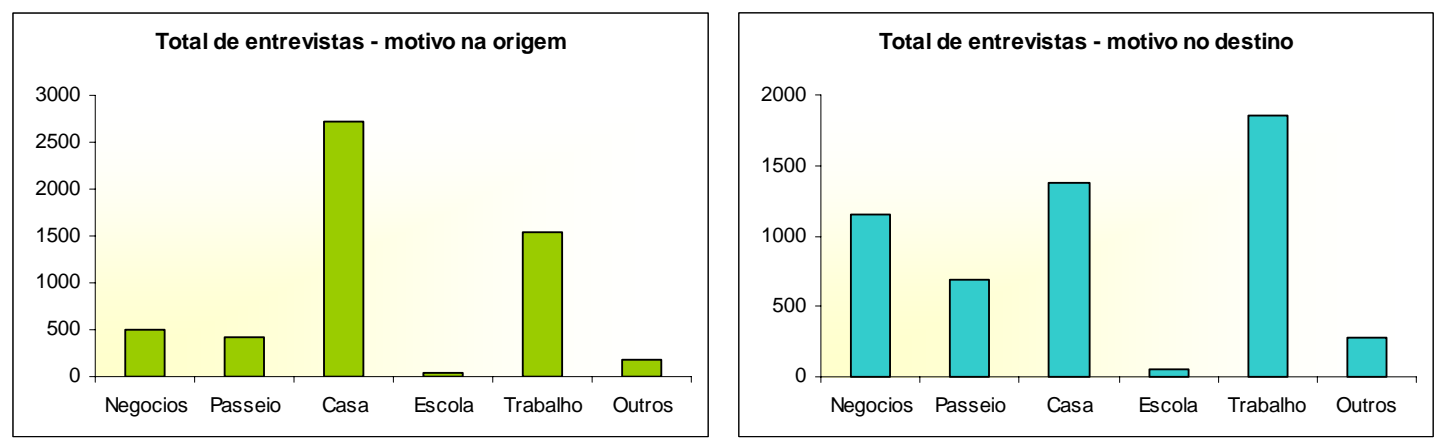

Entrevistas por motivo cruzado de viagem

\begin{tabular}{|c|c|c|c|c|c|c|c|}
\hline \multirow[b]{2}{*}{$\begin{array}{l}\text { Motivo na } \\
\text { origem }\end{array}$} & \multicolumn{6}{|c|}{ Motivo no destino } & \multirow[b]{2}{*}{$\begin{array}{l}\text { Total } \\
\text { geral }\end{array}$} \\
\hline & Negócios & Passeio & Casa & Escola & Trabalho & Outros & \\
\hline Negócios & 123 & 7 & 287 & 0 & 62 & 13 & 492 \\
\hline Passeio & 6 & 98 & 297 & 1 & 11 & 9 & 422 \\
\hline Casa & 666 & 541 & 136 & 48 & 1122 & 210 & 2723 \\
\hline Escola & 2 & 3 & 32 & 4 & 3 & 1 & 45 \\
\hline Trabalho & 348 & 37 & 495 & 3 & 633 & 28 & 1544 \\
\hline Outros & 12 & 6 & 127 & 0 & 19 & 21 & 185 \\
\hline Total geral & 1157 & 692 & 1374 & 56 & 1850 & 282 & 5411 \\
\hline
\end{tabular}

Figura 6-10: Distribuição dos motivos de viagem na amostra

${ }^{51} \mathrm{O}$ motivo lazer era denominado 'passeio' nas entrevistas. 
A distribuição dos tempos de viagem declarados pelos motoristas, mostrada na Figura 6-11, segue uma forma exponencial com média de 116 minutos e mediana 80. Cerca de $60 \%$ das viagens abordadas têm duração de até 90 minutos, 30\%, entre 91 e 240 minutos e 10\% são deslocamentos com duração superior a 240 minutos.

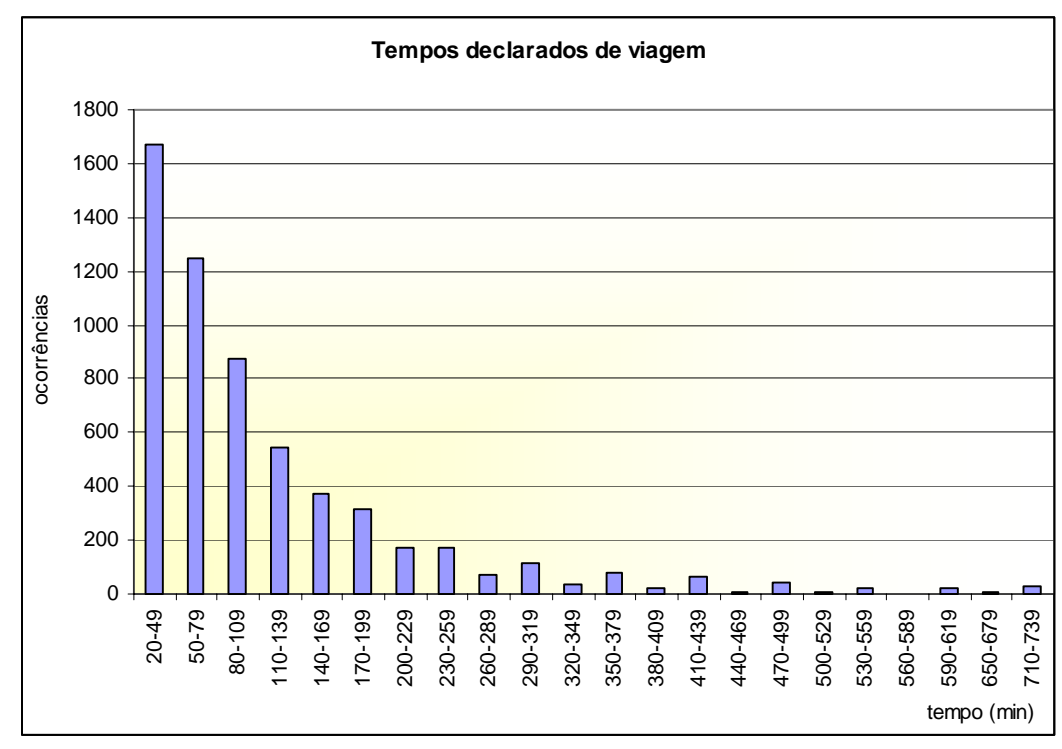

Figura 6-11: : Distribuição dos tempos de viagem na amostra

De modo geral, nas análises das características dos indivíduos e das viagens não foram observados valores que possam ser considerados fora do esperado. Embora esses valores não tenham sido comparados com dados de outras fontes, não há indícios de que haja distorções nesses dados de preferência revelada da amostra. Distribuições das freqüências de variáveis como faixa de renda, posse de veículos, tempos de viagem e idade do motorista pareceram adequadas.

6.2.2. Análise da distribuição das respostas às questões de PD

Neste item buscou-se verificar a proporção das escolhas entre as duas alternativas, para alguns segmentos da amostra. 
Com relação às escolhas feitas pelos entrevistados, foi verificada uma proporção global de $48 \%$ de respostas na alternativa referente à rota pedagiada, e $52 \%$ de preferência pela alternativa não pedagiada. Essa distribuição é bastante adequada para efeito de avaliações estatísticas de aderência do modelo, como descrito no capítulo 3.3.2.

Para a verificação da possibilidade de estimar modelos por segmentos da amostra foi também examinada a distribuição das escolhas de acordo com algumas características dos entrevistados. McFadden (1984 apud Hensher, 1996a) cita que amostras que contenham menos de 30 respostas por alternativa produzem estimadores que não podem ser analisados de forma confiável.

A seguir são apresentados os resultados das proporções de escolhas verificadas para alguns dos segmentos da amostra ${ }^{52}$. A Figura 6-12 mostra as proporções de escolha de acordo com o sexo do motorista.

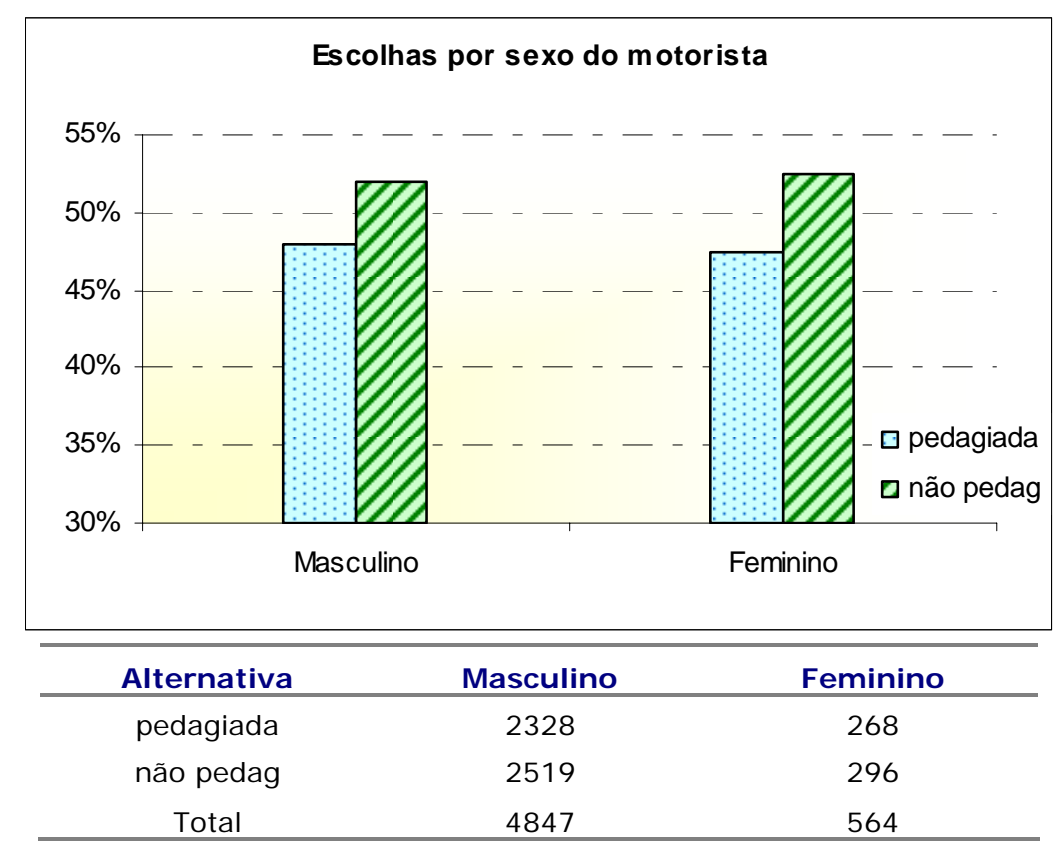

Figura 6-12: Distribuição das escolhas por sexo do motorista

\footnotetext{
52 Ressalta-se que a maior proporção de escolhas pela alternativa pedagiada desses dois grupos não implica, necessariamente, em uma preferência por determinada alternativa. Isso porque os parâmetros de custo e tempo apresentados podiam ser alterados durante a execução das pesquisas - como mencionado no item 5.3 - de modo a ter-se um equilíbrio na proporção das respostas.
} 
Observa-se na figura 6-12 que as proporções de escolhas pelas alternativas pedagiada e não pedagiada foram bastante semelhantes para motoristas do sexo masculino e feminino.

Para a variável 'chefe de família', dentre os que se declararam não ser chefes verificou-se que a alternativa pedagiada representou $46,4 \%$ das escolhas. Para os entrevistados chefes de família esse percentual foi de 48,2\%. Em ambos os segmentos houve equilíbrio entre as escolhas, como se observa na Figura 6-13.

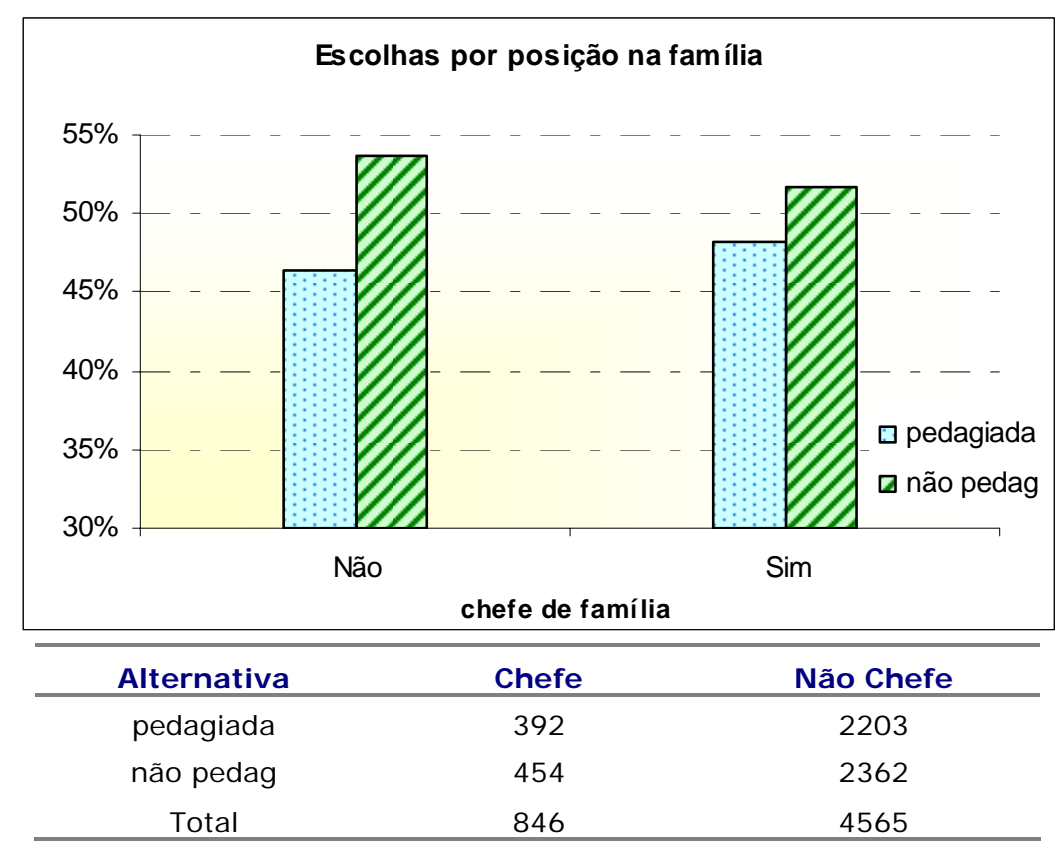

Figura 6-13: Distribuição das escolhas por posição na família

A verificação das escolhas de acordo com a faixa de renda familiar do entrevistado indicou equilíbrio entre as alternativas. Dentre todas as classes de renda, observou-se pequena variação na distribuição das respostas: a proporção entre as classes oscilou de 47\% a 49\% para escolhas pela alternativa pedagiada. Dentre entrevistados com renda declarada acima de $R \$ 6000,00$ e para aqueles que não informaram a classe de renda (categoria NI, no gráfico), há um percentual de escolhas na alternativa pedagiada ligeiramente superior ao das outras classes. Esses resultados são indicados na Figura 6-14 


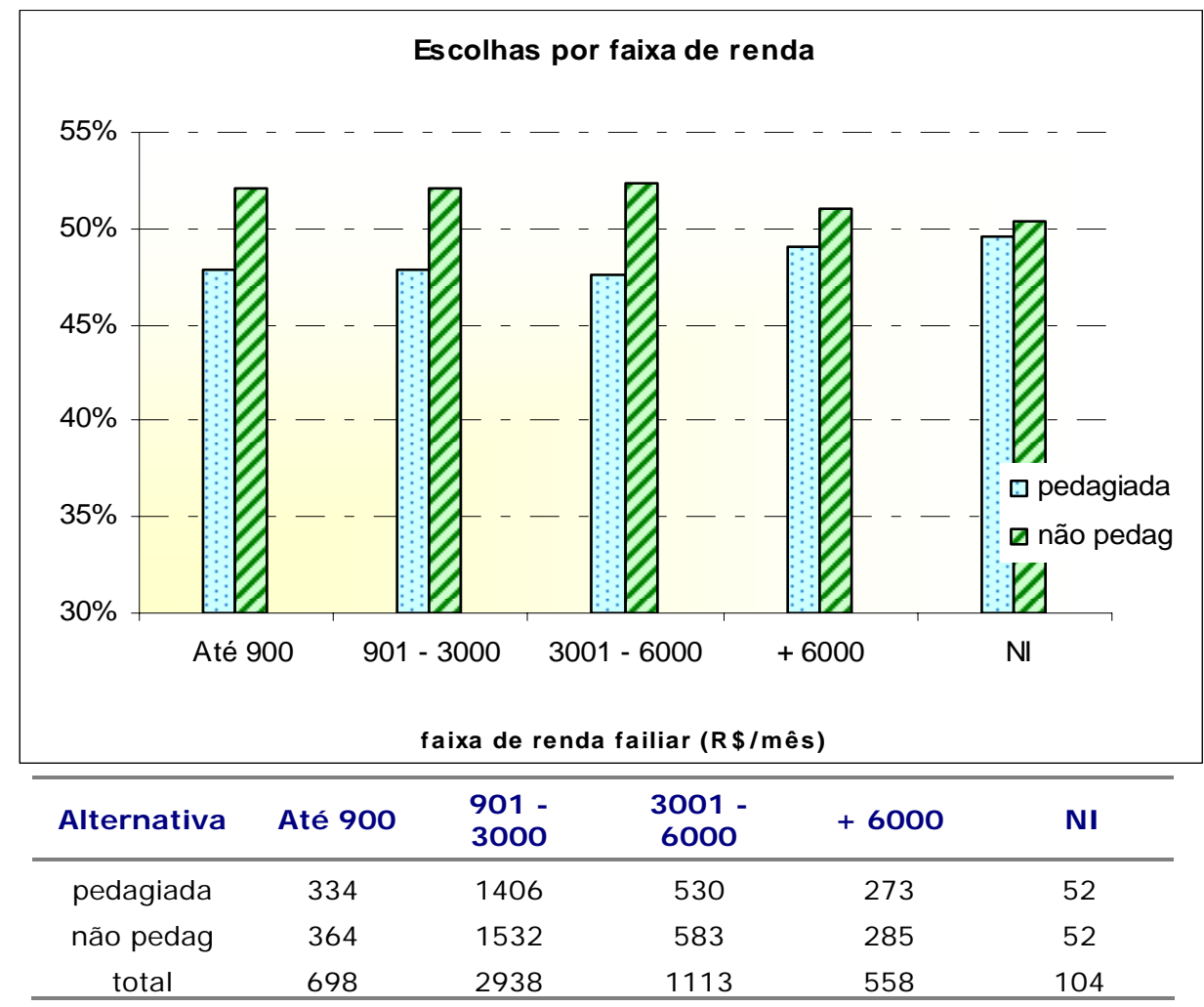

Figura 6-14: Distribuição das escolhas por faixa de renda

A análise da distribuição entre as escolhas considerando outras variáveis além das apresentadas, como motivo e freqüência de viagem, indicou equilíbrio entre as respostas, permitindo concluir que: i) a variação nos níveis da variável 'tarifa', realizada durante as entrevistas - como descrito no item 5.3, foi eficaz e ii) não há restrições de tamanho da amostra ao se realizar estimativas com subamostras nos segmentos considerados.

\subsubsection{Verificação de relação entre as variáveis}

Nesse item, ainda com o intuito de se fazer uma exploração inicial das informações disponíveis, foram analisadas possíveis relações entre algumas variáveis relativas às características socioeconômicas dos motoristas e da viagem realizada. Essas análises poderão servir como orientação durante a especificação da forma das funções de utilidade. 
Idade x Posse de veículos: Para verificar a relação entre essas duas variáveis foi feita uma análise de variância, cujo resumo é apresentado na Tabela 6-3, a seguir. Buscou-se, com isso, observar se as médias das idades para cada faixa de posse de veículos seriam diferentes.

Tabela 6-3: Análise de variância para 'idade' e 'posse de veículos'

\begin{tabular}{crrrr}
\hline \multicolumn{1}{l}{ RESUMO } & & & \\
Posse de veículos & Observações & Soma & $\begin{array}{c}\text { Média - } \\
\text { Idade }\end{array}$ & Variância \\
\hline 0 & 56 & 2074 & 37,04 & 110,69 \\
1 & 3031 & 126197 & 41,64 & 166,11 \\
2 & 2125 & 90433 & 42,56 & 146,59 \\
3 & 461 & 19475 & 42,25 & 164,42 \\
4 & 160 & 6925 & 43,28 & 196,56 \\
5 ou + & 77 & 3235 & 42,01 & 174,25 \\
\hline
\end{tabular}

\begin{tabular}{|c|c|c|c|c|c|c|}
\hline Fonte da variação & $S Q$ & $g l$ & $M Q$ & $F$ & valor- $P$ & F crítico \\
\hline \multirow{2}{*}{$\begin{array}{l}\text { Entre grupos } \\
\text { Dentro dos } \\
\text { grupos }\end{array}$} & 2729,4717 & 5 & 545,8943 & 3,4254 & 0,0043021 & 2,21561 \\
\hline & 940899,13 & 5904 & 159,3664 & & & \\
\hline Total & 943628,6 & 5909 & & & & \\
\hline
\end{tabular}

Para esse teste, teve-se que $\mathrm{F}=3,42>\mathrm{F} \mathrm{crit}^{53}=2,21$, indicando que as médias de idade por posse de veículos podem ser consideradas estatisticamente diferentes ${ }^{54}$.

$\checkmark \quad$ Faixa de renda $x$ posse de veículos: A análise de variância foi feita para testar se a posse de veículos seria diferente para cada grupo de renda familiar. Observa-se na Tabela 6-4 a seguir que a posse média de veículos cresce gradativamente com a renda familiar, como esperado.

\footnotetext{
${ }^{53} \mathrm{O}$ valor $\mathrm{F}$ critico indicado na Tabela 6-3 refere-se ao nível de significância 0,05.

${ }^{54}$ Cabe observar que tal análise poderia ter sido feita também através do teste de independência pelo qui-quadrado.
} 
Tabela 6-4: Análise de variância para 'faixa de renda' e 'posse de veículos'.

\begin{tabular}{lrrrr} 
RESUMO & & & & \\
\hline $\begin{array}{c}\text { Segmentos - faixa } \\
\text { de renda } \\
\text { (R\$/mês) }\end{array}$ & Observações & Soma & $\begin{array}{c}\text { Média } \\
\text { posse. } \\
\text { de veículos }\end{array}$ & Variância \\
\hline até 900 & 698 & 855 & 1,2249 & 0,3783 \\
901 a 3000 & 2938 & 4444 & 1,5126 & 0,5570 \\
3001 a 6000 & 1113 & 2089 & 1,8769 & 0,8365 \\
+ de 6000 & 558 & 1365 & 2,4462 & 1,6264 \\
NI & 104 & 165 & 1,5865 & 1,0216 \\
\hline
\end{tabular}

ANOVA

\begin{tabular}{lcrrrrr}
\hline Fonte da variação & SQ & gl & MQ & $F$ & valor-P & F crítico \\
\hline $\begin{array}{l}\text { Entre grupos } \\
\begin{array}{l}\text { Dentro dos } \\
\text { grupos }\end{array}\end{array}$ & 593,06 & 4 & 148,2658 & 208,6781 & $1,01 \mathrm{E}-166$ & 2,3736 \\
& 3840,97 & 5406 & 0,7105 & & & \\
Total & 4434,03 & 5410 & & & & \\
\hline
\end{tabular}

Os resultados do teste ( no qual $F=208,67>F$ crit $=2,37$ ) ${ }^{55}$ indicam que a posse média de veículos é estatisticamente diferente para as pessoas das várias faixas de renda consideradas.

Faixa de renda $x$ idade do motorista: a Tabela 6-5 mostra os resultados da análise de variância realizada.

Tabela 6-5: Análise de variância para 'faixa de renda' e 'idade'.

\begin{tabular}{lrrrr} 
RESUMO & & & & \\
\hline $\begin{array}{c}\text { Segmentos - faixa } \\
\text { de renda } \\
\text { (R\$/mês) }\end{array}$ & Observações & \multicolumn{1}{l}{$\begin{array}{l}\text { Soma } \\
\text { idade }\end{array}$} & $\begin{array}{l}\text { Média } \\
\text { Idade }\end{array}$ & Variância \\
\hline até 900 & 698 & 28445 & 40,75 & 189,28 \\
901 a 3000 & 2938 & 121615 & 41,39 & 154,63 \\
3001 a 6000 & 1113 & 47399 & 42,59 & 144,74 \\
+ de 6000 & 558 & 24911 & 44,64 & 150,78 \\
$\mathrm{NI}$ & 104 & 4588 & 44,12 & 219,77 \\
\hline
\end{tabular}

\begin{tabular}{|c|c|c|c|c|c|c|}
\hline Fonte da variação & $S Q$ & $g l$ & $M Q$ & $F$ & valor-P & F crítico \\
\hline $\begin{array}{l}\text { Entre grupos } \\
\text { Dentro dos } \\
\text { grupos }\end{array}$ & $\begin{array}{r}6896,9 \\
853634,02\end{array}$ & 5406 & $\begin{array}{r}1724,23 \\
157,90\end{array}$ & 10,9194 & $8,11 \mathrm{E}-09$ & 2,3736 \\
\hline Total & 860530,92 & 5410 & & & & \\
\hline
\end{tabular}

\footnotetext{
${ }^{55} \mathrm{O} F$ critico indicado refere-se a $\mathrm{p}=0,05$.
} 
Pela análise de variância tem-se que $\mathrm{F}=10,92>\mathrm{F}$ crit $=2,37$, permitindo a conclusão de que as idades médias dos motoristas para cada faixa de renda são estatisticamente diferentes. Verifica-se que as maiores idades médias estão associadas aos grupos de maior renda familiar.

$\checkmark$ Faixa de renda $x$ sexo do motorista: sendo as duas variáveis agrupadas em categorias, cuja distribuição é mostrada na Tabela 6-6, a análise da relação entre ambas foi feita através do teste de independência pelo qui-quadrado.

Tabela 6-6: Distribuição na amostra das variáveis 'sexo do motorista' e 'faixa de renda'

\begin{tabular}{|c|c|c|c|c|c|c|}
\hline \multirow[b]{2}{*}{ Sexo } & \multicolumn{6}{|c|}{ Classe Renda ( R\$/ mês) } \\
\hline & até 900 & 901 a 3000 & 3001 a 6000 & + de 6000 & $\mathrm{NI}$ & Total geral \\
\hline Masc & 642 & 2649 & 974 & 488 & 94 & 4847 \\
\hline Fem & 56 & 289 & 139 & 70 & 10 & 564 \\
\hline Total & 698 & 2938 & 1113 & 558 & 104 & 5411 \\
\hline
\end{tabular}

$\mathrm{Na}$ aplicação do teste, teve-se que qui-quad observ=13,24 < qui-quad crit =13,27 (4 graus de liberdade ${ }^{56}$ e $p=0,01$ ). Assim, a hipótese nula não é rejeitada no nível de significância 0,01 , indicando não haver diferença nas distribuições de indivíduos por faixa de renda entre os sexos masculino e feminino. Por essa análise pode-se concluir que homens e mulheres distribuem-se igualmente entre as classes de renda na amostra. Isso implica que, caso os modelos a serem estimados venham a indicar valores de tempo distintos por sexo, essa diferença não poderá ser atribuída a diferenças de renda associadas a cada grupo.

$\checkmark$ Faixa de renda $x$ motivo de viagem: para os três motivos no destino inicialmente analisados - trabalho diário, negócios e lazer - foram verificadas as distribuições dos entrevistados segundo as classes de renda, indicadas na Tabela 6-7. Aplicou-se o teste do qui-quadrado para analisar se a distribuição de entrevistados nas classes de renda seria diferente para cada motivo de viagem.

${ }^{56}$ Graus de liberdade $=(n \circ$ linhas -1$) \times(n$ o colunas -1$)$ 
Tabela 6-7: Distribuição na amostra das variáveis 'motivo de viagem' e 'faixa de renda'

\begin{tabular}{crrrrrr}
\hline Motivo & \multicolumn{7}{c}{ Classe Renda (R\$/ mês) } \\
& até 900 & 901 a 3000 & $\begin{array}{c}3001 \text { a } \\
6000\end{array}$ & + de 6000 & NI & $\begin{array}{l}\text { Total } \\
\text { geral }\end{array}$ \\
\hline Trabalho & 55 & 265 & 110 & 48 & 13 & 491 \\
Negócios & 299 & 1382 & 525 & 272 & 38 & 2516 \\
Outros & 344 & 1291 & 478 & 238 & 53 & 2404 \\
Total & 698 & 2938 & 1113 & 558 & 104 & 5411 \\
\hline
\end{tabular}

Da aplicação do teste, qui-quad observ $=14,3<$ qui-quad crit $^{57}=20,1$. 0 resultado indica que as distribuições entre faixas de renda não podem ser consideradas estatisticamente diferentes para os três motivos analisados. Dessa forma, pode-se admitir que eventuais variações no valor do tempo de motoristas com diferentes motivos de viagem não seriam relacionadas a diferenças de rendas.

\subsection{Estimativa dos Modelos de Escolha}

As estimativas dos modelos de escolha foram realizadas com o software de licença livre Biogeme, desenvolvido por Bierlaire (2005), da Ecole Polytechnique Fédérale de Lausanne. Esse software utiliza o método da máxima verossimilhança para a estimativa dos parâmetros.

\subsubsection{Definição da forma da função de utilidade}

Com relação à especificação da função de utilidade foi adotada a forma linear nos parâmetros que, de acordo com Gunn (2000), é a mais comumente utilizada para caracterizar a atratividade de uma alternativa, em estudos visando estimativas do valor do tempo.

${ }^{57}$ Para g.I. $=8$ e $p=0,01$. 
Cabe aqui comentar que alguns estudos, como os de Gaudry, Jara-Diaz e Ortúzar (1988) e Cherchi e Ortúzar (2003), propuseram formas não lineares para a função de utilidade, em estimativas de valor do tempo. Esses, no entanto, diferem do aqui apresentado no aspecto de que analisaram escolhas modais, e não de $\operatorname{rotas}^{58}$.

Com relação ao caso aqui abordado, diversos estudos encontrados na literatura envolvendo escolhas entre rotas pedagiadas e não pedagiadas (BRADLEY; GUNN, 1990, TRETVIK，1993, CHEN; BERNSTEIN, 1995; VAN ZYL; RAZA, 2006) consideraram adequada a forma linear nos parâmetros.

Adotou-se, então, a seguinte forma para as funções de utilidade ${ }^{59}$ :

$U_{p e d}=\alpha_{1}+\beta c_{1}+\gamma t_{1}$

$U_{\text {nped }}=\theta t_{2}$

Sendo $c_{1}$ e $t_{1}$, respectivamente, as variáveis relativas ao custo e ao tempo de viagem na alternativa de rota pedagiada, e $\beta$ e $\gamma$, seus respectivos coeficientes calculados a partir da calibração do modelo de escolha. A alternativa não pedagiada é caracterizada apenas por seu tempo de viagem $t_{2}$, sendo $\theta$ seu respectivo coeficiente. Não se supôs, a priori, que o coeficiente relativo ao tempo é genérico já que o tempo percorrido em uma rota não pedagiada pode estar incluindo fatores como o maior consumo de combustível, por exemplo, o que faria com que o motorista tivesse percepção diferente para o tempo de viagem

\footnotetext{
${ }^{58}$ O experimento relatado por Gaudry, Jara-Diaz e Ortúzar (1988) envolvia escolhas entre modos de transporte urbano. Os maiores ganhos, em relação à forma linear, do modelo logit Box-Cox empregado foram verificados nas estimativas de valores de tempo de espera. Já com relação à especificação da função de utilidade proposta por Cherchi e Ortúzar (2003), esta associava ao termo quadrático do tempo de viagem a disponibilidade de tempo livre do indivíduo - dada por seu tempo total, subtraído do tempo gasto no trabalho e com deslocamentos casa-trabalho (ver capítulo 2.2). As informações disponíveis na pesquisa utilizada para o presente estudo não permitiam uma estimativa dessa quantidade de tempo livre de cada entrevistado.

${ }^{59}$ Essa forma é bastante semelhante à adotada por Tretvik (1993) e Van Zyl e Raza (2006).
} 
por essa rota. Por esse mesmo motivo, considerou-se para a estimativa do valor do tempo a utilidade estimada para a rota pedagiada.

Nessa formulação, o valor subjetivo do tempo (VST), que corresponde à taxa marginal de substituição entre os tempos de viagem e seus custos (JARA-DíAZ, 2000), é dado por:

$V S T=\frac{\frac{\partial U}{\partial t}}{\frac{\partial U}{\partial c}}=\frac{\gamma}{\beta}$

As análises compreenderam, inicialmente, a estimativa de modelos distintos para diferentes segmentos, segundo as variáveis descritas no item 6.3.2, a seguir.

Em uma segunda etapa, foram empregadas especificações da função de utilidade como as descritas em Bates e Roberts (1986) e Bradley e Gunn (1990), que incorporam variáveis dummies como forma de estimar e testar se algumas características dos motoristas e da viagem implicam em variações no valor do tempo.

\subsubsection{Segmentos considerados para as análises}

De acordo com Bradley e Gunn (1990), a distinção entre os tipos de comportamento na percepção da relação tempo/dinheiro em uma viagem deve considerar: i) motivos de viagem; ii) classe de renda do indivíduo; iii) diferentes modos de transporte; iv) diferentes grupos de ocupação profissional; v) circunstâncias pessoais; vi) diferentes quantidades de tempo disponível para o lazer, e vi) diferentes condições de viagem. Outros autores, como Mackie et al. (2003) e Steimetz e Brownstone (2005), indicam que a duração da viagem é 
também uma importante variável que influi na valoração do tempo subjetivo de viagem de motoristas de automóvel ${ }^{60}$.

Para o estudo aqui apresentado, questões relativas a diferenças no modo de transporte ou em condições de viagem não são pertinentes, já que as alternativas do experimento prevêem apenas o modo de viagem por automóvel e os locais de pesquisa e as situações hipotéticas não consideram condições de desconforto como viagem em congestionamento, ou diferenças no estado do pavimento $^{61}$, por exemplo. Outras características envolvendo ocupação, circunstâncias pessoais ou disponibilidade de tempo não serão incluídas por não haver informação pesquisada que permitisse tal tipo de análise.

As análises iniciais compreenderam, então, a segmentação da amostra segundo três variáveis: i) o motivo da viagem; ii) a faixa de renda familiar, e iii) faixa de duração da viagem. As análises feitas no item 6.2.1 indicam não haver restrições com relação ao tamanho das amostras nos segmentos escolhidos.

\subsubsection{Estimativas por motivo de viagem}

A estimativa dos modelos segmentados por motivo de viagem considerou três motivos geralmente citados na bibliografia: 'trabalho diário', 'negócios' e ‘outros' 62 . A Tabela 6-8 mostra os parâmetros estimados para esses modelos. Por questões operacionais do software empregado nas estimativas, o custo tarifário é expresso em centavos e o tempo de viagem, em minutos.

\footnotetext{
${ }^{60}$ Mackie et al. (2003) citam também a condição de empregado/aposentado do viajante como uma importante variável que influi na variação do valor do tempo. Tal característica seria refletida na avaliação da quantidade de tempo disponível para o lazer, contemplada em estudos como os de Bradley e Gunn (1990). Esse tema será retomado adiante no trabalho.

${ }^{61}$ Como mencionado anteriormente, o entrevistador pedia para que o motorista considerasse, para responder às perguntas da $\mathrm{PD}$, que as alternativas pedagiada e não pedagiada se encontravam em iguais condições de pavimento.

62 O motivo 'trabalho diário' é o que se mais aproxima do definido como 'commuters'.
} 
Tabela 6-8: Resultados dos modelos inicialmente estimados para diferentes motivos de viagem

\begin{tabular}{|c|c|c|c|}
\hline \multirow[b]{3}{*}{ Coeficientes estimados } & & & \\
\hline & \multicolumn{3}{|c|}{ Motivo da viagem } \\
\hline & Trabalho diário & Negócios & Outros \\
\hline cte específica & $\begin{array}{c}-1,3460 \\
(-15,9397)\end{array}$ & $\begin{array}{c}-0,5234 \\
(-5,2715)\end{array}$ & $\begin{array}{c}-0,8746 \\
(-12,4995)\end{array}$ \\
\hline custo tarifário (centavos) & $\begin{array}{c}-0,0055 \\
(-32,6798)\end{array}$ & $\begin{array}{c}-0,0062 \\
(-29,8874)\end{array}$ & $\begin{array}{c}-0,0059 \\
(-40,2171)\end{array}$ \\
\hline tempo de viagem pedag. (min) & $\begin{array}{c}-0,1713 \\
(-72,4764)\end{array}$ & $\begin{array}{c}-0,1461 \\
(-55,4303)\end{array}$ & $\begin{array}{c}-0,1573 \\
(-81,2874)\end{array}$ \\
\hline tempo de viagem não pedag. ( $\min$ ) & $\begin{array}{c}-0,1715 \\
(-72,1651)\end{array}$ & $\begin{array}{c}-0,1465 \\
(-55,2499)\end{array}$ & $\begin{array}{c}-0,1569 \\
(-81,4369)\end{array}$ \\
\hline \multicolumn{4}{|l|}{ Estatísticas } \\
\hline Observações & 16650 & 10413 & 21636 \\
\hline$l^{*}(0)$ & -11541 & -7218 & -14996 \\
\hline$l^{*}(\theta)$ & -6309 & -4394 & -8741 \\
\hline$-2\left(l^{*}(0)-l^{*}(\theta)\right)$ & 10465 & 5648 & 12511 \\
\hline$\rho^{2}$ & 0,4534 & 0,3912 & 0,4171 \\
\hline$\rho_{\text {ajust }}^{2}$ & 0,4530 & 0,3907 & 0,4168 \\
\hline \multicolumn{4}{|l|}{ Resultados } \\
\hline VT $(\mathrm{R} \$ / \mathrm{h})$ & 18,66 & 14,10 & 15,85 \\
\hline
\end{tabular}

Observa-se que o parâmetro rho-quadrado dos modelos variou entre 0,39 e 0,45 e os coeficientes estimados, bem como a constante específica, foram todos significativos, no nível de significância de 0,05 e para infinitos graus de liberdade $^{63}(t=1,96)$. Os valores da estatística da taxa de verossimilhança $\left(-2\left(I^{*}(0)-I^{*}(\theta)\right)\right)$ também foram adequados, bastante superiores ao valor do quiquadrado crítico de 18,47 , para 4 graus de liberdade (número de coeficientes a ajustar) e nível de significância 0,001. Um aspecto a ser observado nos modelos diz respeito ao caráter genérico da variável tempo de viagem. Verificaram-se através de testes estatísticos - descritos no item 3.3.2.2 - que os coeficientes associados ao tempo pela alternativa pedagiada e pela não pedagiada podem ser admitidos como iguais.

Nesta estimativa inicial, o valor do tempo para um viajante indo ao trabalho diário foi calculado em $\mathrm{R} \$ 18,66 / \mathrm{h}$; superior ao valor de $\mathrm{R} \$ 14,10 / \mathrm{h}$ obtido para

${ }^{63} \mathrm{O}$ número de graus de liberdade é dado por: (tamanho da amostra - 1). Para amostras superiores a 120 observações, considera-se o número de graus de liberdade como infinito. 
um viajante a negócios. Para os demais motivos, que incluem as viagens a lazer, para escola ou de volta para casa, foi estimado o valor de $R \$ 15,85 / \mathrm{h}$.

Cabe aqui citar que para o conjunto de todas as observações, sem nenhuma segmentação da amostra, foi estimado o valor do tempo de viagem em $\mathrm{R} \$$ 16,30/h. O modelo é apresentado no apêndice A.

Com relação às diferenças no valor atribuído ao tempo por viajantes com diferentes motivos, encontram-se na bibliografia experimentos que estimam para os viajantes ao trabalho diário valores inferiores aos daqueles a negócios ao contrário do resultado aqui obtido64. Van Zyl e Raza (2006) concluíram que viajantes indo ao trabalho diário teriam valores de tempo ligeiramente inferiores aos daqueles se deslocando a negócios. Bradley e Gunn (1990) estimaram, para as viagens a negócios, valores de tempo $50 \%$ superiores ao daquelas a trabalho, enquanto Tretvik (1993) relatou experimento onde essa diferença foi superior a $70 \%$.

Por outro lado, há também estudos concluindo que os viajantes com destino ao trabalho diário seriam os que mais estariam dispostos a pagar por reduções no tempo de viagem, através de formas como a utilização de vias expressas pedagiadas (BROWNSTONE et al., 2003).

Tendo em vista resultados aqui obtidos, face aos encontrados em parte da literatura, foi feita uma nova investigação no conjunto de informações utilizado, buscando encontrar uma explicação para os valores estimados neste experimento e a aparente discrepância com o que poderia ser considerado como os valores esperados. A análise do cruzamento de informações das respostas para as variáveis 'motivo' e 'freqüência' da viagem realizada, como mostrado na Tabela 6-9, levou a algumas prováveis explicações .

\footnotetext{
${ }^{64}$ Ressalta-se aqui que os viajantes que declararam não pagar as despesas da viagem - como, por exemplo, aqueles a negócios para os quais a empresa paga os custos de combustível e pedágios não foram submetidos às perguntas de PD e PR na pesquisa.
} 
Tabela 6-9: Cruzamento das informações motivo da viagem e freqüência da viagem

\begin{tabular}{lrrrrrrr}
\hline Motivo* da & \multicolumn{7}{c}{ Freqüência da Viagem } \\
\cline { 2 - 8 } Viagem & Diária & $3 \times$ Sem & $2 \times$ Sem & $1 \times$ Sem & 1 x Mês & Eventual & Total \\
\hline Negócios & 119 & 130 & 112 & 203 & 303 & 290 & 1157 \\
Trabalho Diário & 600 & 198 & 190 & 282 & 288 & 292 & 1850 \\
Passeio & 42 & 38 & 27 & 76 & 186 & 323 & 692 \\
Para casa & 219 & 110 & 95 & 209 & 346 & 395 & 1374 \\
Escola & 13 & 8 & 9 & 14 & 10 & 2 & 56 \\
Demais & 34 & 22 & 16 & 29 & 91 & 90 & 282 \\
Total & 1027 & 506 & 449 & 813 & 1224 & 1392 & 5411 \\
\hline *-motivo no destino & & & & & & &
\end{tabular}

As informações da Tabela 6-9 apresentam indícios de que os motivos trabalho diário' e 'negócios' aparentemente não foram entendidos corretamente por parte dos entrevistados. Nota-se que, dentre as viagens declaradas como a 'negócios', há uma parcela realizada com freqüência diária. Essas viagens muito provavelmente têm no 'trabalho diário' seu verdadeiro motivo. Da mesma forma, em uma parte considerável das entrevistas onde o motorista respondeu ser o motivo da viagem o 'trabalho diário', esse declarou fazer aquela viagem com freqüências iguais ou menores do que 3 vezes por semana. É razoável supor que tais viagens sejam, na verdade, a 'negócios'.

Assim, foi feita uma alteração na classificação das respostas para a informação 'motivo de viagem', quando esse se referia a 'negócios' ou 'trabalho diário', segundo os critérios:

- viagens com motivo declarado 'negócios' e freqüência declarada 'diária' passaram a ser consideradas como a 'trabalho diário'.

- viagens com motivo declarado 'trabalho diário' e freqüência declarada igual ou menor do que 3 vezes por semana passaram a ser consideradas como a 'negócios'. 
Além disso, foram analisadas as entrevistas com relação ao motivo da viagem na origem. As viagens ao 'trabalho diário' que também tinham o 'trabalho diário' como local de início foram consideradas como viagens a ‘negócios’65.

Após os ajustes na variável 'motivo da viagem', foram novamente estimados os modelos para os três segmentos considerados. Os resultados são apresentados na Tabela 6-10, a seguir ${ }^{66}$.

Tabela 6-10: Modelos estimados por motivo de viagem após reclassificação das respostas

\begin{tabular}{lccc} 
& \multicolumn{3}{c}{ Motivo da viagem } \\
\cline { 2 - 4 } Coeficientes estimados & Trabalho diário & Negócios & Outros* \\
\hline cte específica & $-1,2304$ & $-0,9604$ & $-0,8746$ \\
& $(-7,8611)$ & $(-13,6942)$ & $(-12,4995)$ \\
custo tarifário (centavos) & $-0,0052$ & $-0,0059$ & $-0,0059$ \\
& $(-16,6928)$ & $(-41,1287)$ & $(-40,2171)$ \\
tempo de viagem pedag. (min) & $-0,1582$ & $-0,1612$ & $-0,1573$ \\
& $(-36,8951)$ & $(-83,7694)$ & $(-81,2874)$ \\
tempo de viagem não pedag. (min) & $-0,1586$ & $-0,1614$ & $-0,1569$ \\
& $(-36,5851)$ & $(-83,4607)$ & $(-81,4369)$ \\
\hline Estatísticas & & & \\
Observações & 4419 & 22644 & 21636 \\
$l^{*}(0)$ & -3063 & -15696 & -14996 \\
$l^{*}(\theta)$ & -1778 & -8964 & -8741 \\
$-2\left(l^{*}(0)-I^{*}(\theta)\right)$ & 2570 & 13463 & 12511 \\
$\rho^{2}$ & 0,4195 & 0,4289 & 0,4171 \\
$\rho_{\text {ajust }}{ }^{*}$ & 0,4182 & 0,4286 & 0,4168 \\
\hline Resultados & & & 15,85 \\
VT (R\$/h) & 18,09 & 16,41 & (mabela 6-8
\end{tabular}

Observa-se que, após a reclassificação das respostas para a questão motivo de viagem, foram estimados modelos onde a diferença entre os valores de tempo de viagem ao trabalho diário e a negócios foi reduzida, em relação à análise inicial mostrada na Tabela 6-8. Ainda assim, o valor associado ao tempo em um deslocamento a trabalho permaneceu superior ao daqueles a negócios.

${ }^{65}$ É razoável supor que essas viagens se referiam a deslocamentos feitos durante o trabalho, como saídas do escritório para reuniões ou para resolver questões de trabalho, o que está mais compatível com o motivo 'negócios'. Ver na Figura 6-10, do item 6.2.1, pode-se observar a distribuição das viagens considerando o motivo na origem e no destino.

66 Ressalta-se que todas as reclassificações realizadas na variável 'motivo da viagem' tiveram a intenção de aproximar o máximo possível o motivo 'trabalho diário' da característica 'commuter', encontrada comumente na bibliografia. 
Com relação à diferença não muito marcante entre os valores de tempo estimados para diferentes motivos de viagem, Van Zyl e Raza (2006) obtiveram resultado semelhante em experimentos realizados em rodovias da África do Sul e Índia ${ }^{67}$. Mackie et al. (2003) citam o estudo The Value of Travel Time on UK Roads, no qual o valor do tempo para viajantes ao trabalho foi estimado como sendo apenas levemente superior ao de outros motivos não relacionados a trabalho; os autores não apresentam, no entanto, o motivo de viagem 'negócios' em suas análises. Nesse mesmo artigo, os autores citam evidências de que 0 valor do tempo de motoristas de automóveis teria na distância da viagem uma fonte de variação mais importante do que no seu motivo ${ }^{68}$.

A possibilidade de que as diferenças de resultados nos motivos 'trabalho diário' e 'negócios' estivessem vinculadas a diferenças na renda média dos indivíduos em foi analisada anteriormente através de testes estatísticos, apresentados na Tabela 6-7, do item 6.2.3. Esses testes indicaram não haver diferença significativa na distribuição de indivíduos por faixa de renda nas amostras para os motivos trabalho e negócios. No entanto, como houve reclassificação dos motivos de viagem, foi feita nova análise da eventual relação entre essa variável e a renda dos motoristas. Novos testes, apresentados no apêndice $B$, também indicaram não haver diferença significativa na distribuição de indivíduos por faixa de renda nas amostras reclassificadas para os motivos trabalho e negócios.

\footnotetext{
${ }^{67}$ Embora nesse estudo, como citado, o valor atribuído às viagens a negócios tenha sido ligeiramente superior ao daquelas indo ao trabalho diário.

${ }^{68}$ Aspecto que será analisado a seguir neste estudo.
} 


\subsubsection{Estimativas por faixa de renda}

A exemplo das análises iniciais por motivo de viagens, foram feitas também estimativas de modelos segmentados de acordo com a faixa de renda familiar mensal do motorista.

As estimativas partiram de cinco categorias para esta variável: i) baixa (até $R \$$ 900,00 ), ii) média (de 901,00 a R\$3000,00), iii) média-alta (de 3001,00 a 6000,00 ), iv) alta (acima de 6000,00) e v) não informado.

Na Tabela 6-11, a seguir, estão os parâmetros estimados para os modelos dessas categorias. Entrevistas com renda não informada não foram aqui analisadas.

Tabela 6-11: Resultados dos modelos estimados para segmentos por faixa de renda familiar mensal do motorista.

\begin{tabular}{lcccc} 
& \multicolumn{3}{c}{ Faixa de renda familiar do motorista } \\
\cline { 2 - 5 } Coeficientes estimados & Baixa & Média & Média-alta & Alta \\
\hline cte específica & $-0,5832$ & $-1,0283$ & $-0,9814$ & $-0,9964$ \\
& $(-4,6015)$ & $(-15,7964)$ & $(-17,8634)$ & $(-6,7812)$ \\
custo tarifário (centavos) & $-0,0069$ & $-0,0059$ & $-0,0058$ & $-0,0054$ \\
& $(-23,6938)$ & $(-43,4928)$ & $(-51,3229)$ & $(-18,7923)$ \\
tempo de viagem pedag. (min) & $-0,1560$ & $-0,1625$ & $-0,1599$ & $-0,1572$ \\
& $(-43,5998)$ & $(-90,8317)$ & $(-106,2772)$ & $(-39,0423)$ \\
tempo de viagem não pedag. (min) & $-0,1567$ & $-0,1629$ & $-0,1602$ & $-0,1575$ \\
& $(-43,4834)$ & $(-90,5863)$ & $(-105,9833)$ & $(-38,9157)$ \\
\hline Estatísticas & & & & \\
Observações & 6282 & 26442 & 36459 & 5022 \\
$l^{*}(0)$ & -4354 & -18328 & -25272 & -3481 \\
$l^{*}(\theta)$ & -2532 & -10413 & -14530 & -2031 \\
$-2\left(l^{*}(0)-l^{*}(\theta)\right)$ & 3645 & 15830 & 21483 & 2900 \\
$\rho^{2}$ & 0,4185 & 0,4319 & 0,4250 & 0,4166 \\
$\rho_{\text {ajust }}{ }^{*}$ & 0,4176 & 0,4316 & 0,4249 & 0,4154 \\
\hline Resultados & & & & 16,53 \\
VT $(\mathrm{R} \$ / \mathrm{h})$ & 13,55 & 16,64 & & 17,55 \\
\hline
\end{tabular}

Todos os coeficientes estimados, bem como as constantes específicas, foram significativos no nível de significância de $0,05(t=1,96)$. Os modelos estimados apresentaram valores do rho-quadrado em torno de 0,4, indicando boa 
aderência aos dados. Os valores da estatística da taxa de verossimilhança também foram adequados, bastante superiores ao valor do qui-quadrado crítico de 18,47 , para 4 graus de liberdade (número de coeficientes a ajustar) e nível de significância 0,001.

Observa-se que os modelos e estimativas do valor do tempo para as faixas de renda 'média', 'média-alta' e 'alta' foram bastante semelhantes, situando-se entre $R \$ 16,53 / h$ e $R \$ 17,55 / h$. Para a verificação da existência de diferença estatística entre os grupos por faixas de renda no comportamento com relação à valoração do tempo foram estimados modelos considerando variáveis dummies $^{69}$. Os resultados desses modelos, apresentados no apêndice $C$, levaram à conclusão de não havia diferença estatisticamente significativa no comportamento dos motoristas das classes 'média', 'média-alta' e 'alta'70. Apenas aqueles pertencentes à faixa de renda 'baixa' apresentaram diferenças estatisticamente significativas em relação aos demais.

\subsubsection{Estimativas por faixa de tempo de viagem}

A duração da viagem é outra característica amplamente citada na literatura como um dos fatores que influem na variação do valor do tempo de viagem dos motoristas. Essa variável foi analisada considerando-se 3 grupos, de acordo com a duração declarada da viagem: i) duração entre 20 e 90 minutos; ii) entre 91 e 240 minutos, e iii) acima de 240 minutos $^{71}$.

\footnotetext{
${ }^{69}$ Essa forma de verificação de diferenças entre parâmetros de modelos para diferentes segmentos é explicada no item 6.3.6, a seguir.

70 Dado o resultado pouco esperado para a similaridade de comportamento segundo essa variável, foram feitos testes desagregando a classe entre $R \$ 900,00$ e $R \$ 3000,00$, que foi subdividida em duas: de $R \$ 900,00$ a $R \$ 1500,00$ e de $R \$ 1501,00$ a $R \$ 3000,00$. Os modelos estimados, apresentados no apêndice $D$, indicaram não haver diferença significativa comportamental entre essas duas categorias.

71 Como já citado, viagens com duração inferior a 20 minutos não foram consideradas para as estimativas. Para essas viagens muito curtas, os tempos de acréscimo apresentados (na pesquisa) para o uso da alternativa não pedagiada eram muitas vezes superior ao tempo da própria viagem, tornando o cenário pouco realista.
} 
A Tabela 6-12 mostra os parâmetros dos modelos estimados.

Tabela 6-12: Resultados dos modelos estimados para segmentos por faixa de duração da viagem.

\begin{tabular}{lccc} 
& \multicolumn{3}{c}{ Faixa de Duração da Viagem } \\
\cline { 2 - 4 } Coeficientes estimados & Até $90 \mathrm{~min}$ & De 91 a $240 \mathrm{~min}$ & Acima de 240 min \\
\hline cte específica & $-1,4608$ & $-0,8187$ & $0,2113^{*}$ \\
& $(-19,5441)$ & $(-6,3011)$ & $(1,0395)$ \\
custo tarifário (centavos) & $-0,0054$ & $-0,0064$ & $-0,0085$ \\
& $(-44,8125)$ & $(-33,7869)$ & $(-22,6364)$ \\
tempo de viagem pedag. (min) & $-0,1596$ & $-0,1616$ & $-0,1512$ \\
& $(-96,0938)$ & $(-66,4292)$ & $(-36,9741)$ \\
tempo de viagem não pedag. (min) & $-0,1642$ & $-0,1622$ & $-0,1520$ \\
& $(-89,6664)$ & $(-64,9357)$ & $(-36,9172)$ \\
\hline Estatísticas & & & \\
Observações & 29952 & 14247 & 4500 \\
$l^{*}(0)$ & -20761 & -9875 & -3119 \\
$l^{*}(\theta)$ & -11982 & -5610 & -1817 \\
$-2\left(l^{*}(0)-l^{*}(\theta)\right)$ & 17556 & 8530 & 2602 \\
$\rho^{2}$ & 0,4228 & 0,4318 & 0,4172 \\
$\rho_{\text {ajust }}^{2}$ & 0,4226 & 0,4314 & 0,4159 \\
\hline Resultados & & & 10,71 \\
VT (R\$/h) & 17,70 & 15,10 & \\
\hline - estatisticamente não significativo & & & \\
& & & \\
\hline
\end{tabular}

Observa-se nos modelos estimados por faixa de duração da viagem que todos os coeficientes estimados são significativos, no nível de significância de 0,05 (t $=$ 1,96). A única exceção é dada pela constante específica no modelo obtido para as viagens com duração superior a 240 minutos. Os três modelos estimados apresentaram valores do rho-quadrado em torno de 0,42 , indicando bom ajuste. Os valores da estatística da taxa de verossimilhança são bastante superiores ao valor do qui-quadrado crítico de 18,47, para 4 graus de liberdade (número de coeficientes a ajustar) e nível de significância 0,001.

Com relação aos resultados calculados de valor do tempo para cada um dos segmentos, estimou-se que o valor decresce consideravelmente para as viagens de maior duração, sendo atribuído o valor de $R \$ 17,70 / \mathrm{h}$ para viagens com até uma hora e meia, $R \$ 15,10 / \mathrm{h}$ para aquelas entre 91 e 240 minutos e $R \$ 10,71 / \mathrm{h}$ para os deslocamentos com duração superior a 4 horas. 
6.3.6. Outras características associadas a variações no valor do tempo

Das três segmentações analisadas nos itens anteriores - por motivo de viagem, faixa de renda e faixa de duração da viagem - a última foi a que indicou maiores diferenças no valor do tempo entre as classes. Observou-se que para a variável faixa de renda, os resultados apresentaram menor variação entre as categorias, sendo a diferença estatisticamente significativa apenas para indivíduos de renda baixa em relação às demais faixas. Os modelos segmentados por motivo de viagem, embora sejam usualmente adotados em estudos do gênero, aqui apresentaram variações relativamente modestas nos resultados para as classes consideradas.

Assim, os modelos segmentados por faixa de duração da viagem serão usados nas análises para verificação de efeitos adicionais de outras variáveis no valor do tempo. As variáveis relativas à faixa de renda familiar e motivo da viagem, por terem apresentado menores variações de valor do tempo em seus segmentos, serão analisadas como variáveis adicionais, também inseridas nos modelos segmentados por faixa de duração da viagem. 


\subsubsection{Análise da variação do valor do tempo com variáveis dummies}

A verificação da variação do valor tempo relacionada a uma dada característica será feita através da incorporação de variáveis dummies às funções de utilidade.

A forma aqui adotada para as funções de utilidade com a incorporação de variáveis dummies representa uma generalização daquela proposta por Bradley e Gunn (1990), sendo dada por ${ }^{72}$ :

$$
\begin{aligned}
& U_{\text {pedi }}=\alpha_{0}+\sum_{k} \alpha_{k} \cdot \delta_{i k}+\left(\beta_{0}+\sum_{k} \beta_{k} \cdot \delta_{i k}\right) \cdot c_{p e d i}+\left(\gamma_{0}+\sum_{k} \gamma_{k} \cdot \delta_{i k}\right) \cdot t_{p e d i} \\
& U_{n p e d i}=\left(\theta_{0}+\sum_{k} \theta_{k} \cdot \delta_{i k}\right) \cdot t_{n p e d i}
\end{aligned}
$$

\begin{tabular}{|c|c|}
\hline$U_{\text {pedi }}$ & utilidade da alternativa pedagiada para um indivíduo $i$ \\
\hline$U_{\text {npedi }}$ & utilidade da alternativa não pedagiada para um indivíduo $i$ \\
\hline$C_{\text {pedi }}$ & custo de tarifa pela alternativa pedagiada para um indivíduo $i$ \\
\hline$t_{\text {pedi }}$ & tempo de viagem pela alternativa pedagiada para um indivíduo $i$ \\
\hline$t_{\text {npedi }}$ & tempo de viagem pela alternativa não pedagiada para um indivíduo i \\
\hline$\alpha_{0}$ & termo principal da constante específica da alternativa pedagiada \\
\hline$\beta_{0}, \gamma_{0}$ & coeficientes principais de custo e tempo pela alternativa pedagiada \\
\hline$\theta_{0}$ & coeficiente principal do tempo pela alternativa não pedagiada \\
\hline$\alpha_{k}$ & $\begin{array}{l}\text { termo diferencial da constante específica para o segmento } k \text { representado } \\
\text { por variáveis dummies }\end{array}$ \\
\hline$\beta_{k}, \gamma_{k}$ & $\begin{array}{l}\text { coeficientes diferenciais de custo e tempo pela alternativa pedagiada para } \\
\text { um segmento } k \text { representado por variáveis dummies }\end{array}$ \\
\hline$\theta_{k}$ & $\begin{array}{l}\text { coeficiente diferencial de tempo pela alternativa não pedagiada para os } \\
\text { segmento } k \text { representado }\end{array}$ \\
\hline$\delta_{i k}$ & $\begin{array}{l}\text { variáveis dummies (0/1) indicando pertinência ou não do indivíduo i ao } \\
\text { segmento } k \text { considerado }\end{array}$ \\
\hline
\end{tabular}

onde:

\footnotetext{
72 Esses autores realizaram um experimento com alternativas não rotuladas. Desta forma, a função aqui apresentada difere da do estudo citado pela inserção de uma constante específica para a alternativa pedagiada e pela especificidade do coeficiente relativo ao tempo de viagem em cada alternativa. Embora testes estatísticos para os modelos aqui estimados tenham indicado que o coeficiente do tempo pela alternativa pedagiada seria o mesmo da não pedagiada, optou-se por manter a forma mais aberta nas estimativas dos modelos com variáveis dummies.
} 
Desta forma, o valor do tempo de viagem para um indivíduo $i$ que pertença a um segmento $k$ será dado por:

$V T_{i}=\frac{\gamma_{0}+\sum_{k} \gamma_{k} \cdot \delta_{i k}}{\beta_{0}+\sum_{k} \beta_{k} \cdot \delta_{i k}}$

Para o caso aqui estudado, cabe observar que a análise da variação dos coeficientes através de funções com dummies, de acordo com Gurajati (2000), apresenta importantes vantagens em relação ao procedimento alternativo de estimar diferentes modelos para cada segmento da amostra, como: i) necessidade de estimar um único modelo para uma característica analisada ${ }^{73}$; ii) um modelo único pode ser usado para testar uma série de hipóteses. Assim, se os coeficientes diferenciais do custo $\beta_{k}$ e do tempo $\gamma_{k}$ forem estatisticamente não significativos para um segmento, pode-se admitir que esse segmento terá comportamento semelhante ao daquele admitido como base. Utilizando-se modelos diferentes para cada segmento, essa verificação estatística da diferença entre os coeficientes estimados para os modelos de cada grupo implicaria em procedimentos operacionalmente bastante mais trabalhosos, como descrito no item 3.3.2.2.

\subsubsection{Características testadas}

Os modelos estimados com dummies para verificar se o valor do tempo sofre variação com uma dada característica do motorista ou da viagem consideraram as seguintes variáveis: i) posição de chefe da família; ii) sexo do motorista; iii) faixa de renda familiar; iv) posse de 3 ou mais veículos; v) viagem realizada durante o período de pico da manhã (entre 6:00 e 8:30); vi) pagamento de pedágios durante a viagem realizada; vii) motivo da viagem (trabalho diário, negócios ou outros), e viii) motivo lazer no destino da viagem.

\footnotetext{
${ }^{73}$ Citando um exemplo deste próprio estudo, um único modelo com dummies permite a análise da variação dos coeficientes para as faixas de renda baixa, média, média-alta e alta; pelo procedimento sem o uso de dummies, haveria a necessidade de estimar quatro modelos.
} 
Com relação às variáveis consideradas, devem ser feitas as seguintes observações:

- Para a renda familiar do motorista foi identificado anteriormente que apenas a classe de renda baixa apresentava comportamento estatisticamente diferente das demais, como analisado no item 6.3.4. $\mathrm{Na}$ tentativa de se obter um indicador que diferenciasse também o valor do tempo para a faixa de renda alta foi considerada uma dummy indicando a posse de 3 ou mais veículos. Como demonstrado na Tabela 6-4, há forte relação entre a faixa de renda e a posse de veículos na amostra.

- Alguns estudos citam que as viagens realizadas no período de pico da manhã teriam valores de tempo diferenciados, dado seu suposto maior compromisso em cumprir horários de chegada. Assim, foi proposto também um modelo com uma dummy identificando as entrevistas realizadas nesse período.

- A variável relativa ao pagamento de pedágios durante a viagem buscou identificar aquelas viagens realizadas sem o pagamento de tarifas de pedágio, usando para isso uma informação fornecida pelos motoristas.

- Com relação ao motivo da viagem, verificou-se que as viagens ao trabalho diário apresentam maior proporção de deslocamentos de curta duração do que as a negócios. Análises estatísticas mostradas no apêndice $B$ indicam que a distribuição de tempos de viagem entre esses dois motivos é diferente. Dessa forma, é possível que o maior valor atribuído ao motivo trabalho diário tenha explicação na maior proporção de deslocamentos curtos, de maior valor do tempo associado. Visando isolar os efeitos dessas duas variáveis e evitar interpretações equivocadas com relação à causa da variação do valor do tempo, foi inserida nos modelos para as diferentes faixas de duração da viagem uma dummy indicando o motivo da viagem. 
A Figura 6-15 mostra as variáveis testadas nos modelos segmentados por faixa de duração da viagem para verificação de características associadas a variações no valor atribuído ao tempo de viagem:

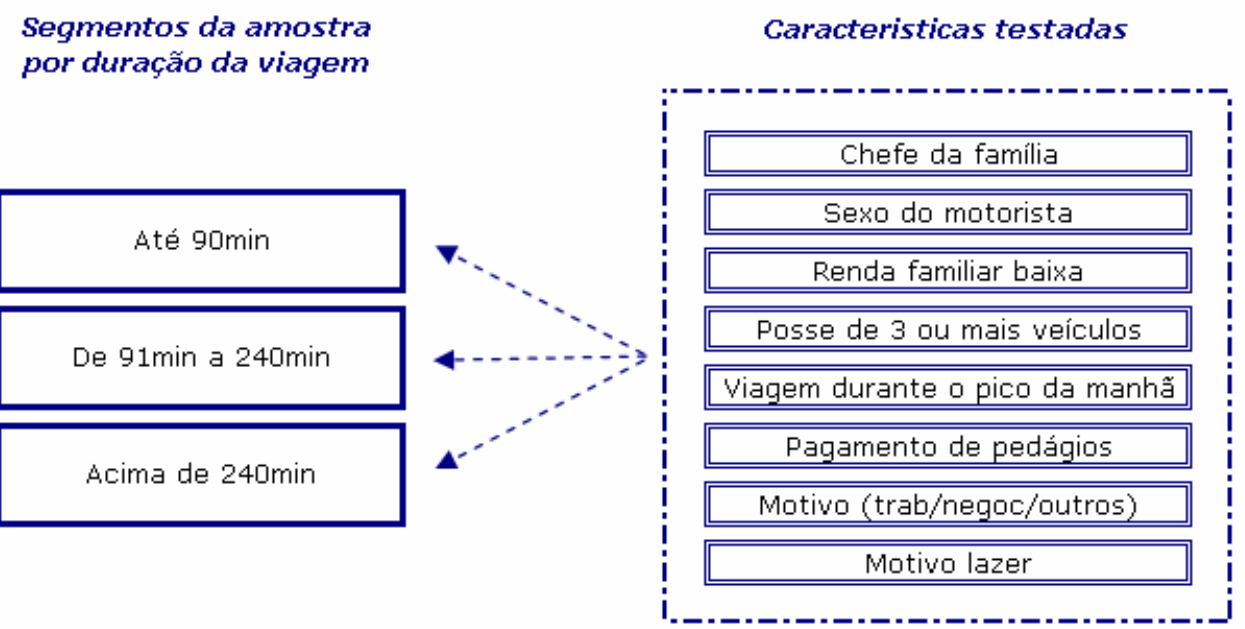

Figura 6-15: Características testadas nos modelos segmentados por faixa de duração da viagem

Para verificação da significância dos efeitos das variáveis sobre a variação do valor do tempo, essas foram testadas individualmente nos modelos ${ }^{74}$. As variáveis consideradas significativas estão representadas nos modelos para cada faixa de duração de viagem, apresentados no item a seguir.

\subsubsection{Resultados dos modelos estimados}

No apêndice $F$ são apresentados os modelos estimados com as variáveis dummies identificando cada uma das características testadas.

Em síntese, considerando as 8 características testadas para verificação de seus efeitos sobre a variação do valor do tempo de viagem, as análises indicaram os seguintes resultados:

\footnotetext{
${ }^{74}$ Tal procedimento deveu-se a questões operacionais. O software apresentava problemas de tempo excessivo de convergência quando se especificavam funções de utilidade com muitas variáveis dummies simultaneamente.
} 
- As variáveis indicando características de 'chefe da família', 'viagem realizada durante o pico da manhã' e 'motivo', classificado entre 'trabalho diário', 'negócios' e 'outros', não implicaram em efeitos significativos de variação no valor do tempo na amostra. Observou-se que motoristas chefes de família ou que realizavam viagens no pico da manhã apresentaram valores pouco superiores aos da categoria base, como esperado. No entanto, nenhum dos coeficientes das dummies inseridas para a representação dessas características mostrou-se estatisticamente significativo.

- As características descrevendo a situação sócio-econômica do motorista definida pelas variáveis 'renda baixa' e 'posse de 3 ou mais veículos', indicando o 'pagamento de pedágios' durante a viagem e o 'motivo lazer' mostraram-se fontes significativas de variação no valor do tempo nos modelos para as viagens com duração até 240 minutos. A variável indicando sexo feminino foi significativa apenas na parcela das viagens com duração entre 91 e 240 minutos.

- Nas viagens com duração superior a 240 minutos nenhum efeito adicional significativo sobre a variação do VT foi estimado. Uma possível explicação para tal resultado pode estar relacionada a questões do desenho do experimento, como os níveis adotados para os atributos. Viagens muito longas estão associadas a custos e tempos maiores e talvez os valores apresentados na pesquisa não tenham representado para os motoristas que faziam essas viagens variações tão significativas como foram para motoristas em viagens mais curtas. Deve ser considerada também a possibilidade de dificuldades na interpretação das perguntas hipotéticas da pesquisa por motoristas desse segmento: as questões envolviam sempre a escolha entre uma rota pedagiada e uma rota de fuga, com valores dos níveis considerando tempos de acréscimo na viagem e tarifas para um único pedágio ${ }^{75}$. Esse cenário é familiar a motoristas em viagens

${ }^{75}$ ver Figura 5-12 apresentada no item 5.3.2 
curtas, mas talvez não o seja para aqueles em deslocamentos de longa distância, nos quais é menos provável que o motorista altere localmente sua rota para evitar apenas uma praça de pedágio. Seria mais esperado que esse tipo de motorista que deseje evitar o pagamento de pedágios fizesse grandes alterações em seu trajeto de modo a evitar várias praças de pedágio, e não apenas uma, o que implicaria em acréscimos de tempo de viagem - e economias com tarifas - bastante superiores aos apresentados nas questões da pesquisa. No entanto, deve-se ressaltar que nada impede que esse tipo de viajante compreenda o cenário hipotético apresentado e responda corretamente às questões. Para avaliar de forma mais conclusiva essa questão, seria interessante, em levantamentos futuros, a apresentação de diferentes cenários de escolha de acordo com o tempo de viagem declarado, como adotado por Hensher (1996b), variando os níveis para o custo total tarifário e tempo de acréscimo por uma alternativa não pedagiada.

A Figura 6-16 mostra as variáveis consideradas significativas para cada segmento por faixa de duração da viagem, e a seguir são apresentados os modelos estimados com dummies para representação dessas características.

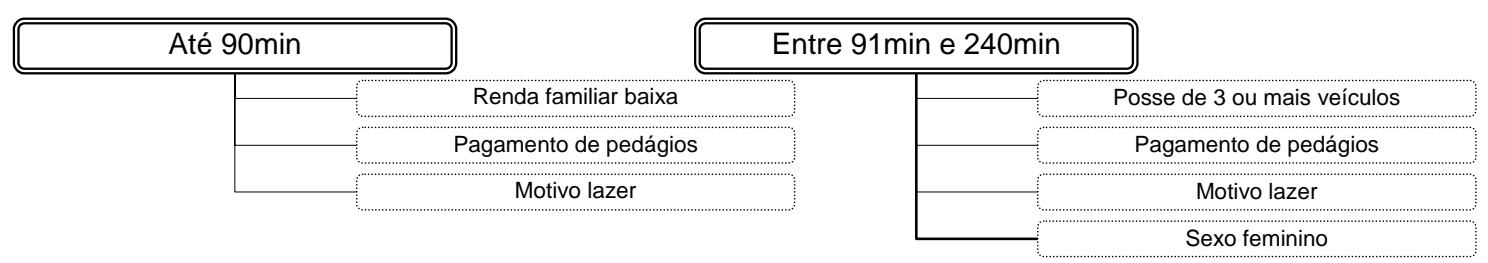

Figura 6-16: Características que indicaram variações significativas no valor do tempo

A Tabela 6-13 na página seguinte mostra os resultados do modelo com variáveis dummies estimado para identificação de variações adicionais no valor do tempo, no segmento das viagens com duração de até 90 minutos. 
Tabela 6-13: Resultados do modelo estimado para verificação de características associadas a variações no valor do tempo no segmento de viagens com até $\mathbf{9 0}$ minutos de duração.

\section{Coeficientes estimados}

Coeficientes principais

Cte. Específica $\left(\alpha_{0}\right)$

$-0,7861$

$(-7,4531)$

custo tarifário $\left(\beta_{0}\right)$ (centavos)

$-0,0059$

$(-36,1586)$

tempo de viagem pedagiado $\left(\gamma_{0}\right)(\min )$

$-0,1579$

$(-72,8549)$

tempo de viagem não pedagiado $\left(\theta_{0}\right)(\mathrm{min})$

$-0,1599$

$(-67,4369)$

Coeficientes adicionais para a característica 'renda baixa' (base: renda não baixa):

termo adicional da cte. específica

0,8918

$(4,0979)$

coef. adicional do custo tarifário

$-0,0015$

$(-3,8909)$

coef. adicional do tempo de viagem pedagiado

0,0035

$(0,7304)$

coef. adicional do tempo de viagem não pedagiado

0,0068

$(1,2999)$

Coeficientes adicionais para motoristas que não pagam pedágios (base: pagamento de um ou mais pedágios):

termo adicional da cte. específica

$-0,9580$

$(-5,9124)$

coef. adicional do custo tarifário

$-0,0006$

$(-2,0023)$

coef. adicional do tempo de viagem pedagiado

$-0,0071$

$(-1,9964)$

coef. adicional do tempo de viagem não pedagiado

$-0,0131$

$(-3,3301)$

Coeficientes adicionais para a característica 'viagem a lazer' (base: viagem com motivo diferente de lazer):

termo adicional da cte. específica

$-0,5735$

$(-1,9623)$

coef. adicional do custo tarifário

0,0013

$(2,9242)$

coef. adicional do tempo de viagem pedagiado

$-0,0200$

$(-3,1474)$

coef. adicional do tempo de viagem não pedagiado

$-0,0137$

$(-2,0076)$

\section{Estatísticas}

Observações

$l^{*}(0)$

$l^{*}(\theta)$

$-2\left(l^{*}(0)-l^{*}(\theta)\right)$

17910

$\rho^{2}$

0,4313

$\rho_{\text {ajust }}{ }^{2}$ 
Verifica-se na Tabela 6-13 que o modelo estimado considerando variáveis dummies para representação das características renda baixa, pagamento de pedágios e motivo lazer apresentou valor do rho-quadrado em torno de 0,43, indicando bom ajuste. Os valores da estatística da taxa de verossimilhança são bastante superiores ao valor do qui-quadrado crítico de 32, para 16 graus de liberdade e nível de significância 0,001.

Observa-se também que a categoria base no modelo é dada por motoristas de renda não baixa, que pagam um ou mais pedágios em sua viagem e com motivo de viagem diferente de lazer. Em cada característica analisada esses grupos são majoritários em relação àqueles analisados através das dummies; e dessa forma o valor do tempo estimado para a categoria base é representativo da maior parte da amostra.

Com relação aos coeficientes adicionais estimados para as variáveis dummies, para a característica renda baixa verifica-se pelo valor-t que os coeficientes relativos ao tempo de viagem não são estatisticamente significativos ${ }^{76}$. Já o coeficiente adicional do custo tarifário apresentou valor negativo, indicando que motoristas pertencentes a esse segmento percebem maior desutilidade no pagamento da tarifa, como esperado. Observa-se também que o termo adicional da constante específica para esse segmento de renda baixa apresentou sinal positivo. No entanto, os resultados relativos aos termos adicionais da constante não têm não tem influência na estimativa do valor do tempo, e são discutidos no apêndice G.

Para as dummies relativas ao grupo de motoristas que informou não pagar pedágios na realização da viagem em que foram entrevistados, todos os coeficientes estimados foram estatisticamente significativos. Os coeficientes indicam que motoristas desse segmento vêem com maior desutilidade comparativamente àqueles que pagam pedágio - o uso de uma rodovia pedagiada e o pagamento de tarifas, como esperado.

\footnotetext{
${ }^{76}$ No nível de significância de $0,05(\mathrm{t}=1,96)$.
} 
No segmento dos viajantes a lazer, o coeficiente adicional do custo tarifário estimado apresentou valor positivo, indicando que essas pessoas percebem menor desutilidade no pagamento do pedágio do que os viajantes por outros motivos, o que Ihes atribui maiores valores de tempo. Todos os demais coeficientes adicionais das dummies indicando essa característica foram estatisticamente significativos.

A Tabela 6-14 mostra os resultados do valor do tempo estimados para cada uma das características analisadas. Os valores foram calculados segundo a equação apresentada no item 6.3.6.1, considerando os coeficientes adicionais de custo e tempo de viagem relativos a cada categoria.

Tabela 6-14: Estimativas do valor do tempo para as categorias analisadas no segmento das viagens com até 90 minutos de duração.

\begin{tabular}{lc}
\hline Característica & Valor do tempo estimado (R\$/ h) \\
\hline Categoria base & 16,20 \\
Classe de renda baixa & 12,62 \\
Não paga pedágios durante a viagem & 15,42 \\
Viagem a lazer & 23,28 \\
\hline A variação é aqui apresentada em relação à categoria base, dada por um m
\end{tabular}

A variação é aqui apresentada em relação à categoria base, dada por um motorista de classe não baixa, que paga pedágios durante a viagem, e realizando uma viagem não a lazer

Com base nesses resultados fazem-se as seguintes observações ${ }^{77}$ :

- Motoristas de renda familiar baixa tiveram o valor do tempo estimado em cerca de $22 \%$ abaixo do da categoria base.

- Para os motoristas que declararam não pagar nenhum pedágio durante a realização de sua viagem foram estimados valores de tempo cerca de $6 \%$ inferiores em relação àqueles que pagam ao menos um pedágio.

- Viajantes a lazer tiveram estimados valores de tempo $44 \%$ superiores em relação aos não a lazer.

\footnotetext{
${ }^{77} \mathrm{~A}$ variação isolada de cada categoria pode ser consultada no apêndice F. Verifica-se que as variações percentuais no valor do tempo - em relação à categoria base - pouco se alteraram quando analisadas aqui em conjunto, o que se deve provavelmente à baixa correlação entre as 3 características analisadas simultaneamente.
} 
A Tabela 6-15, a seguir, mostra os resultados do modelo estimado para as viagens com duração entre 91 e 240 minutos.

Tabela 6-15: Resultados do modelo estimado para verificação de características associadas a variações no valor do tempo no segmento de viagens com duração entre 91 e 240 minutos.

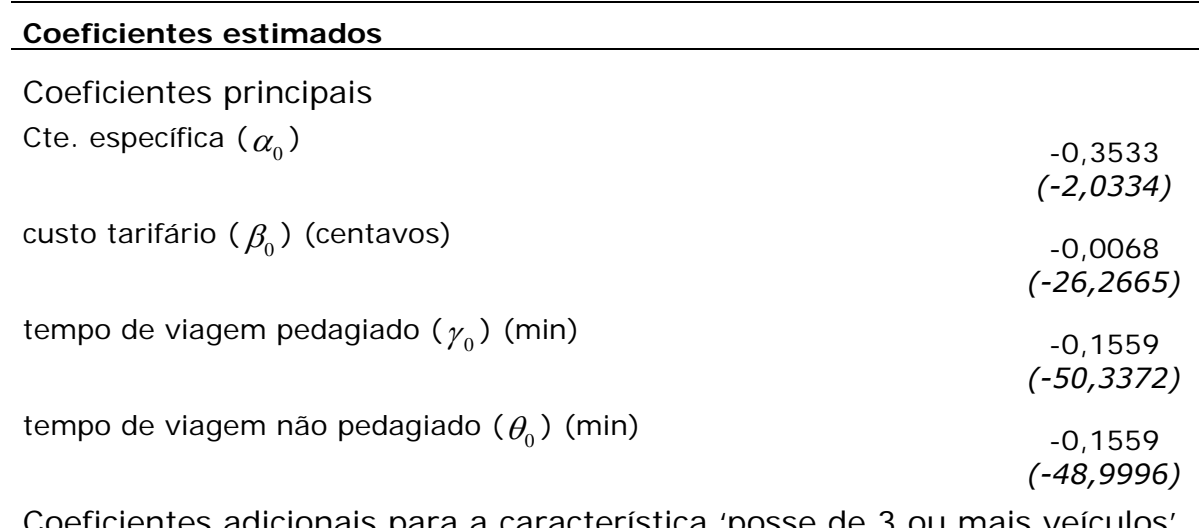

(base: posse de menos de 3 veículos):

termo adicional da cte. específica

coef. adicional do custo tarifário

coef. adicional do tempo de viagem pedagiado

coef. adicional do tempo de viagem nao pedagiado

$-0,0196$

coef. adicional do tempo de viagem não pedagiado

Coeficientes adicionais para motoristas que não pagam pedágios termo adicional da cte. específica

coef. adicional do custo tarifário

coef. adicional do tempo de viagem pedagiado

coef. adicional do tempo de viagem năo pedaglado

coef. adicional do tempo de viagem não pedagiado

Coeficientes adicionais para a característica 'sexo feminino' termo adicional da cte. específica

coef. adicional do custo tarifário

coef. adicional do tempo de viagem pedagiado 


\begin{tabular}{lc} 
Coeficientes adicionais para a característica 'viagem a lazer' & \\
termo adicional da cte. específica & $-0,9479$ \\
& $(-2,7197)$ \\
coef. adicional do custo tarifário & 0,0008 \\
& $(1,3830)$ \\
coef. adicional do tempo de viagem pedagiado & $-0,0155$ \\
& $(-2,161)$ \\
coef. adicional do tempo de viagem não pedagiado & $-0,0164$ \\
& $(-2,2307)$ \\
\hline Estatísticas & \\
Observações & 14247 \\
$l^{*}(0)$ & -9875 \\
$l^{*}(\theta)$ & -5547 \\
$-2\left(l^{*}(0)-l^{*}(\theta)\right)$ & 8656 \\
$\rho^{2}$ & 0,4383 \\
$\rho_{\text {ajust }}^{2}$ & 0,4363 \\
\hline
\end{tabular}

O modelo estimado, mostrado na Tabela 6-15, para a verificação da variação no valor do tempo de viagem associada às variáveis indicando posse de 3 ou mais veículos, pagamento de pedágios, sexo feminino e motivo lazer apresentou valor do rho-quadrado em torno de 0,43 e os valores da estatística da taxa de verossimilhança bastante superiores ao valor do qui-quadrado crítico de 37,57, para 20 graus de liberdade e nível de significância 0,001.

Observa-se nos coeficientes das dummies que para motoristas que possuem 3 ou mais veículos ${ }^{78}$ o termo adicional relativo ao custo tarifário apresenta valor positivo e o relativo ao tempo, valor negativo. Tal resultado era esperado e indica que essa parcela da amostra percebe menor desutilidade no pagamento do pedágio e maior desutilidade no tempo de viagem, características que fazem com que seu valor do tempo estimado seja superior em relação a pessoas não pertencentes a esse grupo.

Para o segmento dos motoristas que não pagam pedágios em sua viagem apenas o coeficiente adicional da dummy para o custo tarifário foi significativo.

\footnotetext{
${ }^{78}$ Essa variável pode ser considerada uma proxy para 'faixa de renda alta', como mencionado no item 6.3.6.2.
} 
Seu valor negativo indica que esses viajantes percebem maior desutilidade no pagamento de tarifas de pedágios, resultando em que seu valor do tempo seja inferior ao dos motoristas que informaram pagar ao menos um pedágio durante sua viagem.

Para motoristas do sexo feminino, os coeficientes adicionais estimados relativos ao custo tarifário foram não significativos. No entanto, os coeficientes do tempo de viagem foram consideravelmente altos e negativos, indicando que as mulheres motoristas percebem maior desutilidade do que os homens na duração da viagem.

Quanto aos coeficientes das dummies relativas ao motivo de viagem lazer, verificou-se que aquele associado ao custo tarifário não foi significativo. Os coeficientes estimados para o tempo de viagem tiveram valores negativos, a exemplo do verificado para esse motivo nas viagens com duração de até 90 minutos.

A Tabela 6-16 mostra os resultados do valor do tempo estimados para cada uma das quatro categorias analisadas, dentro do segmento das viagens com duração entre 91 e 240 minutos.

Tabela 6-16: Estimativas do valor do tempo para as categorias analisadas no segmento das viagens com duração entre 91 e 240 minutos.

\begin{tabular}{lc}
\hline Característica & Valor do tempo estimado (R\$/ h) \\
\hline Categoria base & 13,77 \\
Posse de 3 ou mais veículos & 22,13 \\
Não paga pedágios durante a viagem & 10,62 \\
Sexo feminino & 15,35 \\
Viagem a lazer & 17,06 \\
\hline A
\end{tabular}

A categoria base é dada por um motorista que possui menos de 3 veículos, paga pedágios durante a viagem, de sexo masculino e realizando uma viagem não a lazer.

Sobre os resultados do valor do tempo calculado para cada uma das categorias neste segmento de duração de viagem observa- $\mathrm{se}^{79}$ :

\footnotetext{
79 A exemplo do verificado para o segmento das viagens com duração de até 90 minutos, as variações percentuais no valor do tempo - em relação à categoria base - pouco se alteraram quando analisadas as características individual ou simultaneamente, como se pode observar no apêndice $\mathrm{F}$.
} 
- Aos motoristas que declararam ter 'posse de 3 ou mais veículos' variável que pode ser admitida como uma proxy para motoristas de renda alta, como mostrado na Tabela 6-4 - foram associados valores de tempo cerca de $60 \%$ superiores aos dos não pertencentes a essa categoria ${ }^{80}$.

- Viajantes que não pagam nenhum pedágio tiveram o valor do tempo estimado em $23 \%$ abaixo daqueles que pagam pedágios.

- Motoristas do sexo feminino, para esta faixa de duração de viagem, tiveram seu valor do tempo estimado em cerca de $11 \%$ acima dos motoristas homens.

- Pessoas em deslocamentos com motivo lazer têm valores de tempo $24 \%$ acima daquelas viajando por outros motivos.

Entre os resultados obtidos para cada um dos segmentos por faixa de duração da viagem, notaram-se algumas diferenças. Os motoristas que declararam não pagar nenhum pedágio na realização de sua viagem tiveram valores de tempo $23 \%$ inferiores, quando a viagem tem duração entre 91 e 240 minutos, e apenas $6 \%$ inferiores, nas viagens com duração até 90 minutos. A explicação para essa diferença pode estar no fato de que, para as viagens mais curtas, uma parcela dos motoristas que afirmou não pagar nenhum pedágio não estaria, na verdade, fazendo algum esforço para evitar esse pagamento: simplesmente sua rota natural não cruzaria nenhuma praça de pedágio. Já, por outro lado, em uma viagem com duração entre 1 hora e meia a 4 horas seria muito mais provável que o motorista cruzasse alguma praça de pedágio. E, nesse segmento, dentre os motoristas que declararam realizar a viagem sem pagar nenhum pedágio, provavelmente uma grande parcela está fazendo um esforço para evitar as cobranças. Ou seja, a informação que permite identificar a diferença de

\footnotetext{
80 Para essa faixa de duração de viagem, foi adicionalmente estimado um modelo identificando através de dummies, os indivíduos pertencentes à faixa de renda alta. No entanto, todos os coeficientes calculados para essa categoria foram estatisticamente não significativos, como mostrado no apêndice $H$.
} 
comportamento medida por essa variável é provavelmente mais consistente no segmento das viagens com duração entre 91 e 240 minutos.

Com relação à variável sexo, observa-se nos modelos estimados que, para o sexo feminino, as diferenças no valor do tempo são devidas principalmente à maior desutilidade no tempo de viagem, quando a viagem tem duração entre 90 e 240 minutos. Nas viagens curtas - até 90 minutos - essa maior desutilidade no tempo de viagem, em relação à dos homens, não foi significativa. Isso pode ser interpretado como se as mulheres motoristas enxergassem com desconforto essas viagens mais longas, talvez por motivos relativos à segurança.

Como ilustração dos resultados, foram construídos gráficos com as probabilidades logit de uso de uma rota pedagiada para alguns dos segmentos analisados $^{81}$. Os gráficos exibem as probabilidades em função da tarifa cobrada de pedágio para a categoria base e para aquela representada pela dummy. A Figura 6-17 mostra as diferenças de probabilidades logit de uso da alternativa pedagiada para a variável renda baixa, no segmento das viagens com duração até 90 minutos.

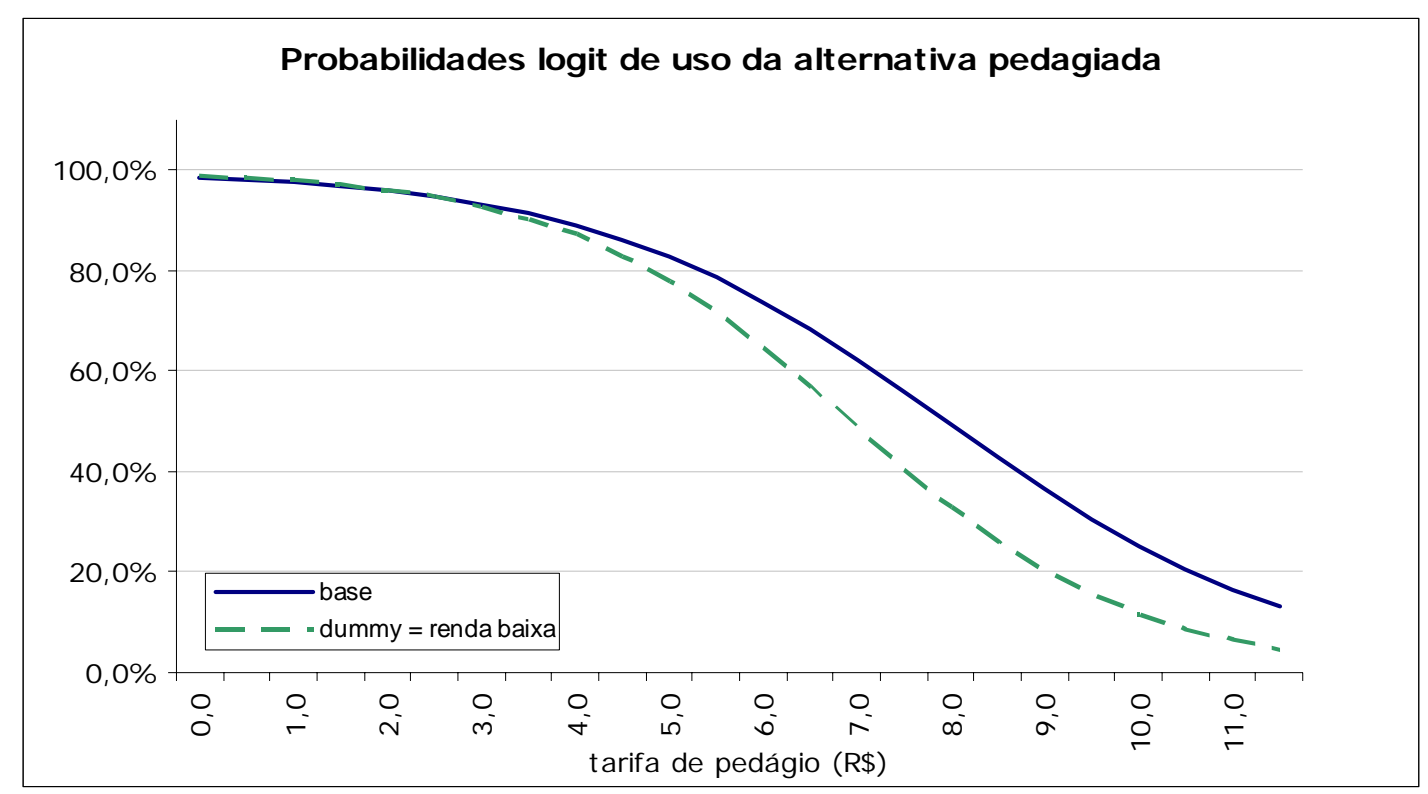

Figura 6-17: Probabilidades de uso de rota pedagiada para a variável renda, no segmento de viagens com duração de até 90 minutos.

${ }^{81}$ A descrição das probabilidades logit é feita no capítulo 3.3.1. 
O gráfico mostrado refere-se a uma viagem com duração de 55 minutos $^{82}$ e mostra que, pelas probabilidades logit, a diferença de comportamento dos indivíduos de renda baixa, em relação aos demais, passa a ser significativa a partir de tarifas superiores a $\mathrm{R} \$ 3,00$. Observa-se, por exemplo, que para uma tarifa de pedágio de $\mathrm{R} \$ 6,00$ um motorista teria uma probabilidade de $65 \%$ de utilizar a rota pedagiada, caso fosse de renda baixa, e $75 \%$ caso não pertencesse a essa classe.

A Figura 6-18 mostra as probabilidades para o segmento dos motoristas que possuem 3 ou mais veículos, no segmento das viagens com duração entre 91 e 240 minutos.

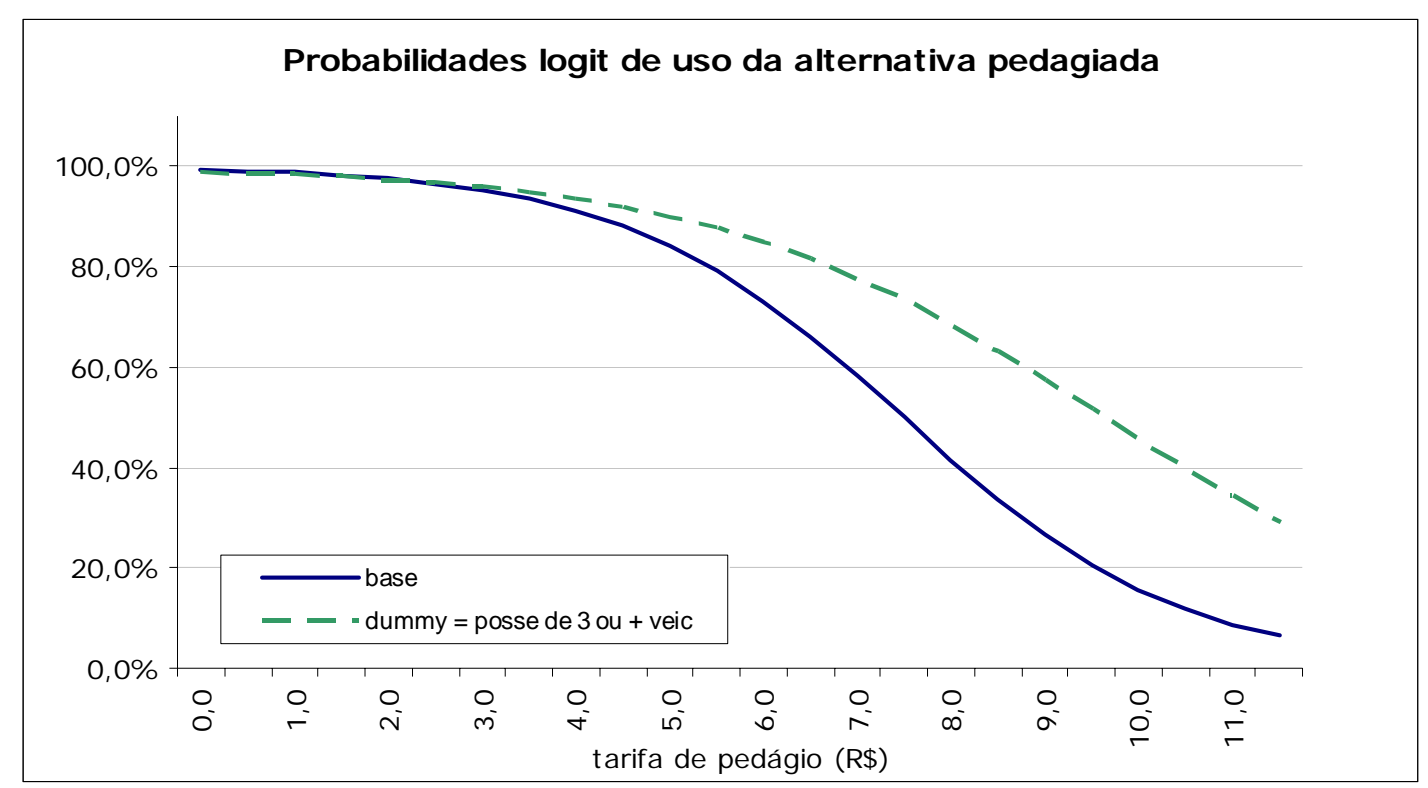

Figura 6-18: Probabilidades de uso de rota pedagiada para a variável 'posse de 3 ou mais veículos', no segmento das viagens com duração entre 91 e 240 minutos.

Observa-se na Figura 6-18 que as diferenças de comportamento estimadas pelo modelo, a exemplo do verificado na Figura 6-17, também passam a ser importantes a partir de tarifas em torno de $\mathrm{R} \$ 3,00^{83}$. O maior valor do tempo

82 Duração média para o segmento das viagens com duração de até 90 minutos. Admitiu-se para a alternativa não pedagiada um tempo de viagem 30 minutos superior ao da pedagiada, valor de acordo com os níveis apresentados na pesquisa de PD.

${ }^{83}$ O gráfico representa uma viagem com duração de 155 minutos pela alternativa pedagiada - o valor médio desse segmento - e 190 minutos pela não pedagiada. 
estimado para a categoria dos motoristas que possuem 3 ou mais veículos reflete-se na probabilidade de escolha de uma rota pedagiada. Para a tarifa de $\mathrm{R} \$ 8,00$ um motorista pertencente a essa classe teria probabilidade de $70 \%$ de escolher a rota pedagiada, enquanto para os demais essa probabilidade seria de apenas $40 \%$.

\subsection{Comparação dos Resultados com uma Informação de PR}

Como mencionado no item 4.6, o objetivo deste estudo, que envolve basicamente a análise da relação entre os coeficientes das funções de utilidade, não torna imprescindível a incorporação de dados de PR na calibração dos modelos.

Cabe ressaltar que em problemas da natureza do aqui estudado, envolvendo escolha de rotas, a obtenção de dados de PR não é simples, tendo como restrições a dificuldade de medição das escolhas ou, no caso de entrevistas de PR, os erros de estimativas dos entrevistados.

Um exemplo da complexidade da medição das escolhas de rotas pode ser encontrado em Brownstone et al (2003), que estimaram o valor do tempo usando informações de PR. Em seu estudo, a proporção de motoristas que escolhia entre uma via não pedagiada e outra via expressa pedagiada era constantemente medida através de laços contadores de veículos fixados em alguns pontos das rotas estudadas. Os laços eletrônicos mediam, além dos volumes de tráfego em cada uma das rotas, as velocidades dos veículos, o que permitia a estimativa dos tempos de viagem por cada rota, em cada período do dia.

Na pesquisa aqui utilizada era apresentada uma questão aos entrevistados que, se não fornece exatamente um dado de PR, é ao menos uma informação que 
permite uma estimativa do valor do tempo por uma fonte alternativa, para comparação com o resultado obtido através da PD. Nos casos em que o posto de pesquisa se situava em uma praça de pedágio, perguntava-se ao motorista se esse costumava utilizar alguma rota alternativa para evitar o pedágio que acabara de pagar. Em caso de resposta afirmativa, perguntava-se qual o acréscimo de tempo aproximado que a utilização dessa rota acarretava à sua viagem e com qual freqüência o entrevistado a utilizava ${ }^{84}$.

Combinando-se, para cada entrevista, a informação do tempo de acréscimo que a rota alternativa acarretava com o valor da tarifa do pedágio na praça onde foi realizada a pesquisa, foram obtidos os valores de negociação - ou tradeoffs que esses motoristas que utilizavam rotas alternativas com alguma freqüência percebiam em uma escolha entre pagar o pedágio ou usar uma rota mais longa para evitá-lo.

A estimativa do valor de tradeoff para cada observação $\left(V t d_{i}\right)$ é dada pelo quociente entre a tarifa do pedágio $\left(T_{i}\right)$ e o tempo de acréscimo declarado pelo motorista ao usar uma rota de fuga $\left(d t_{i}\right)$, como descrito abaixo:

$V t d_{i}=\frac{T_{i}}{d t_{i}}$

O valor médio calculado para o conjunto das observações foi de cerca de $R \$$ 19,00/h. Como já citado, o valor do tempo médio estimado através da PD para a amostra completa foi de $\mathrm{R} \$ 16,30 / \mathrm{h}$.

Observa-se que esse valor do tempo estimado usando informações de PR parte de uma suposição: como os motoristas da amostra afirmaram utilizar algumas vezes a alternativa pedagiada e, outras, a não pedagiada, supõe-se que esse

\footnotetext{
${ }^{84}$ Foram observadas na amostra 36 entrevistas onde o motorista respondeu positivamente à essa questão. Provavelmente a baixa proporção de respostas afirmativas a essa pergunta deveu-se ao receio dos motoristas de que a pesquisa realizada teria como finalidade a implantação de novas praças de pedágio.
} 
valor de tradeoff calculado para cada motorista esteja no limiar de sua decisão entre as duas alternativas, o que seria aproximadamente seu valor do tempo, estimado de forma determinística ${ }^{85}$. As tabelas descrevendo essas estimativas estão apresentadas no apêndice I.

\subsubsection{Valores do tempo estimados por PR e por PD}

Com relação aos resultados encontrados na bibliografia, estudos envolvendo escolhas entre rotas pedagiadas e não pedagiadas e nos quais foram feitas estimativas dos valores do tempo de viagem tanto por PD como por PR, geralmente indicaram que as estimativas feitas através de informações de PR levam a valores mais altos do que aquelas considerando dados de PD.

Bradley e Gunn (1990) em seu experimento concluíram que viajantes de automóveis dirigindo em trânsito não congestionado teriam, para os motivos 'trabalho diário' e 'negócios', respectivamente, valores de tempo 60\% e 75\% superiores quando estimados através de informações de PR. Para viagens com motivos que não esses dois, no entanto, os valores estimados por PR foram ligeiramente inferiores.

Estudos descritos por Brownstone e Small (2005), envolvendo vias expressas pedagiadas e alternativas não pedagiadas, estimaram valores de tempo por PR como sendo cerca do dobro dos valores estimados por PD. Ghosh (2000), em estudo semelhante, obteve resultados indicando que os valores de tempo estimados com dados de PR eram em média de $50 \%$ a $75 \%$ superiores aos estimados por PD. Este último autor relata ainda mais três experimentos de

\footnotetext{
${ }^{85}$ Tentou-se também estimar o valor do tempo de forma probabilística usando os dados de PR. Como descrito no item 5.2, os motoristas que responderam usar rotas alternativas, informaram também a freqüência com que realizavam aquela viagem e a freqüência com que optam pela alternativa não pedagiada, o que permitiu a criação de uma proxy para a probabilidade de escolha das alternativas. Assim, com esse conjunto de informações, estimaram-se os coeficientes das funções de utilidade através do procedimento de linearização do modelo logit binomial. O modelo estimado - mostrado no apêndice I - no entanto, não foi satisfatório, o que provavelmente tenha explicação na qualidade da informação dada pelos motoristas sobre a freqüência de uso da rota não pedagiada.
} 
estimativa do valor do tempo envolvendo escolhas entre rotas pedagiadas e não pedagiadas, onde os resultados estimados por PR foram significativamente superiores aos daqueles por PD.

Brownstone e Small (2005) levantam duas hipóteses para tal resultado, em escolhas dessa natureza: i) o de que as pessoas apresentem inconsistências em seu comportamento real, mas não no seu comportamento hipotético; ou seja, as pessoas teriam a intenção de usar a alternativa mais barata, mas na prática, com as restrições de tempo e compromissos diários, terminam por usar a alternativa pedagiada, mais cara, e ii) problemas de falha de percepção de economias de tempos de viagem, quando os entrevistados respondem a questões de PR. Esses autores relataram que, em sua pesquisa de PR, quando as pessoas eram questionadas a estimar quanto tempo economizam ao utilizar uma alternativa pedagiada - em relação à não pedagiada - essas responderam valores que eram cerca do dobro das economias que realmente obtinham ao usar essa alternativa ${ }^{86}$.

Por fim, deve-se observar que há estudos como os de Frejinger et al. (2006) e Van Zyl e Raza (2006) onde os valores de tempo estimados por PD e PR foram bastante próximos. Frejinger et al. (2006) concluíram que para viagens curtas, com até uma hora de duração, os valores de tempo eram pouco superiores quando estimados por PR, resultado que se invertia para viagens longas. Já Van Zyl e Raza (2006) estimaram para motoristas de renda alta valores de tempo próximos, usando informações de PR e PD. Para motoristas de renda baixa as estimativas usando PD indicaram valores mais altos do que aquelas feitas através de dados de PR.

\footnotetext{
${ }^{86}$ Uma discussão mais detalhada sobre o assunto pode ser encontrada em Brownstone e Small (2005), no capítulo Do Stated Preference Estimates Underestimate the Value of Time?
} 


\section{CONCLUSÃO}

O capítulo final destaca os principais resultados obtidos neste estudo - os quais são analisados e discutidos em função de conclusões encontradas na literatura e sintetiza alguns aspectos que podem ser úteis em desenvolvimentos futuros. Em seguida, são feitas considerações a respeito dos recentes estudos de previsão do comportamento da demanda, que impõem maior responsabilidade sobre as estimativas do valor subjetivo do tempo de viagem, o que leva ao item final que aborda a comparação quantitativa entre valores obtidos por diferentes experimentos.

\subsection{Análise dos Principais Resultados Obtidos}

Os modelos estimados neste estudo com a finalidade de observar a variação no valor do tempo abrangeram características dos motoristas e da viagem realizada. Em relação à viagem realizada, a análise contemplou as características: i) motivo; ii) faixa de duração; iii) pagamento de pedágios durante a viagem, e iv) realização da viagem durante o pico da manhã. As variáveis analisadas relativas a características do motorista foram: i) faixa de renda familiar; ii) posse de 3 ou mais veículos iii) posição de chefe da família, e iv) sexo.

Como descrito no item 6.3.6, as variáveis indicando posição de chefe da família e viagem realizada no pico da manhã não implicaram em variações no valor do tempo de viagem em nenhum dos segmentos analisados. Para as demais características analisadas, os principais resultados são descritos a seguir. 
- O valor médio do tempo de viagem considerando toda a amostra, sem nenhuma segmentação, foi de $\mathrm{R} \$ 16,30 / \mathrm{h}$.

- O valor do tempo dos motoristas decresceu consideravelmente com a duração da viagem, tendo sido estimado em $\mathrm{R} \$ 17,71 / \mathrm{h}$ para motoristas em viagens com duração de até 90 minutos, $R \$ 15,10 / \mathrm{h}$ para aqueles em deslocamentos com duração entre 91 e 240 minutos e $R \$ 10,70 /$ h para o segmento que realizava viagens com duração superior a 240 minutos.

- Viajantes com os motivos trabalho diário e negócios não apresentaram diferenças significativas nas estimativas do valor do tempo de viagem.

- Motoristas em viagens a lazer tiveram valores de tempo estimados entre $24 \%$ e $44 \%$ acima daqueles viajando por outros motivos, como trabalho diário e negócios.

- Para os motoristas de faixa de renda familiar baixa foram estimados valores de tempo $22 \%$ inferiores aos dos demais segmentos, no caso das viagens com duração de até 90 minutos. Para as viagens com duração superior a 90 minutos, a variável faixa de renda familiar não esteve associada a mudanças no valor estimado do tempo. Aos motoristas que declararam ter 'posse de 3 ou mais veículos' - característica proxy para motoristas de renda alta - foram associados valores de tempo cerca de $60 \%$ superiores em relação aos não pertencentes a essa categoria, no segmento das viagens com duração entre 91 e 240 minutos.

- Para o segmento das viagens com duração superior a 240 minutos, nenhuma das características testadas do motorista ou da viagem realizada indicou variações no valor do tempo. É provável que motoristas desse segmento tenham apresentado menor sensibilidade aos níveis dos atributos adotados no experimento, como descrito no item 6.3.6.3. 
- Para motoristas que informaram não pagar nenhum pedágio na realização de sua viagem estimaram-se valores de tempo entre $6 \%$ e $23 \%$ dependendo da duração da viagem - abaixo daqueles que afirmaram pagar pedágios.

Uma questão a ser observada diz respeito ao caráter genérico da variável tempo de viagem nos três modelos. No modelo estimado para viagens com até 90 minutos de duração, os coeficientes associados ao tempo pela rota pedagiada e pela não pedagiada foram estatisticamente diferentes. Para esse resultado, há a hipótese de que o tempo de viagem por uma rota não pedagiada poderia ser visto com maior desutilidade do que aquele por uma rota pedagiada . Já para o grupo de viagens entre 91 e 240 minutos ou acima de 240 minutos, os coeficientes para o tempo foram estatisticamente iguais.

A seguir são feitas observações e levantadas hipóteses explicativas para alguns dos resultados mais relevantes obtidos.

7.1.1. Variação do valor do tempo com a duração da viagem

A duração da viagem foi, dentre as características analisadas, a que mais esteve relacionada a variações no valor do tempo de viagem dos motoristas da amostra utilizada.

Estimou-se que os motoristas em viagens mais longas teriam menores valores de tempo do que aqueles em viagens de curta duração. Tal resultado poderia ser natural se considerado o fato de que um motorista realizando uma viagem de 7 horas provavelmente não perceberia um acréscimo de 20 minutos da mesma forma que outro em uma viagem de 1 hora; e assim, esse acréscimo teria menor valor subjetivo para o primeiro motorista. 
A questão da variação do valor atribuído ao tempo pelos motoristas em função da duração da viagem, em estudos envolvendo escolhas entre uma rota pedagiada e outra não pedagiada, é amplamente comentada na literatura. Os resultados e conclusões encontrados, no entanto, não são todos convergentes. Steimetz e Brownstone (2005) descreveram uma curva onde os valores do tempo decresciam na medida em que os tempos de viagem aumentavam. Os autores citam que a relação pode ter como um dos motivos a maior disponibilidade de tempo livre das pessoas que realizam viagens mais longas. E essas pessoas com mais tempo livre disponível, por sua vez, de acordo com esses autores e com Bradley e Gunn (1990), têm, comprovadamente, menores valores de tempo associados ${ }^{87}$.

Resultado semelhante foi obtido em experimento relatado por Frejinger et al. (2006), onde o valor do tempo de motoristas em viagens com duração superior a uma hora foi estimado em patamares cerca de 30\% inferiores em relação àqueles que realizavam viagens mais curtas.

Por outro lado, Van Zyl e Raza (2006) em seu experimento concluíram que o valor do tempo dobraria para motoristas em viagens longas $^{88}$. Nessa mesma linha, Mackie et al. (2003) citam conclusões obtidas do estudo "The Value of Travel Time on UK Roads", desenvolvido pelo Hague Consulting Group em 1999, no qual estimaram-se elasticidades de cerca de +0.30 para o valor do tempo em relação à distância da viagem. Ou seja, o valor do tempo cresceria com a duração da viagem, embora em proporção bem menor do que a relatada por Van Zyl e Raza (2006). Mackie et al. (2003) afirmam que uma possível explicação para o resultado estaria no fato de que a desutilidade de se gastar um real adicional é menor quando o preço absoluto da viagem é maior ${ }^{89}$.

\footnotetext{
87 A disponibilidade de tempo livre e a flexibilidade de horários de trabalho é citada na literatura como uma questão de relevância na valoração subjetiva do tempo pelos viajantes, como descrito no item 2.2 e no apêndice J.

${ }^{88}$ Esses autores consideraram como viagens longas, aquelas com duração superior a 100 minutos.

${ }^{89} \mathrm{E}$, dessa forma, esses motoristas em viagens longas teriam maior predisposição do que os demais em pagar por tarifas de pedágio e, conseqüentemente, maiores valores de tempo associados.
} 
Por outro lado, se admitirmos apenas que a desutilidade de um minuto adicional de viagem também seria menor para motoristas em viagens longas, o que é uma suposição bastante razoável, isso implicaria em menores valores de tempo para esses viajantes.

Assim, o aspecto fundamental que define a variação do valor do tempo com a distância parece envolver a medição de qual dos dois efeitos - um aumento marginal no custo ou no tempo da viagem - seria percebido de forma mais marcante por esses motoristas que realizam viagens de longa duração.

Em seu artigo, Mackie et al. (2003) reconhecem haver algumas reservas com relação à consistência de seus resultados face à teoria microeconômica e defendem que há necessidade de maiores investigações sobre os efeitos da distância no valor do tempo de viagem.

Por fim, Jiang e Morikawa (2004), em uma ampla análise teórica e experimental de estudos sobre a valoração do tempo, também destacam a duração da viagem como um dos principais fatores associados a variações nessa variável. Os autores deduziram a partir de modelos microeconômicos que, para uma dada economia de tempo de viagem ${ }^{90}$, se o indivíduo for mais sensível a uma mudança de benefício no tempo de viagem ganho do que no tempo de lazer, então o valor do tempo realmente decresceria para as viagens mais longas ${ }^{91}$. Em caso contrário, não houve conclusões claras sobre como se daria a variação do valor do tempo com a duração da viagem.

\footnotetext{
${ }^{90}$ Escolhas dentro de um mesmo modo de transporte.

${ }^{91}$ A questão poderia ser interpretada da seguinte forma: uma pessoa, ao pagar um custo maior pela viagem, estaria pensando prioritariamente em diminuir seu tempo da viagem - ou seja, a duração de uma atividade supostamente desagradável - ou em aumentar seu tempo de lazer? Para pessoas pensando principalmente em reduzir a duração da viagem, quanto maior for sua duração menos a pessoa pagaria por uma redução de ' $x$ ' minutos na viagem - e menor será seu valor do tempo. Ver no item 2.2 a descrição teórica das componentes do valor subjetivo do tempo de viagem.
} 
7.1.2. Variação do valor do tempo com a renda do motorista

Observou-se na amostra que a característica dada pela faixa de renda familiar do motorista indicou efeitos modestos sobre a variação do valor do tempo. Apenas motoristas pertencentes à faixa de menor renda tiveram valores de tempo significativamente distintos, tendo sido estimados em $22 \%$ inferiores em relação aos das demais faixas de renda - dentro do segmento das viagens com duração de até 90 minutos. Dentre os motoristas pertencentes às demais faixas definidas como 'média', 'média-alta' e 'alta', não se verificaram diferenças na valoração do tempo.

A baixa eficiência da variável definida pela faixa de renda na identificação de diferenças de valoração do tempo foi também verificada em outros estudos, como o de Van Zyl e Raza (2006), no qual os autores observaram que essa variável não esteve vinculada a diferenças significativas na valoração do tempo entre três das quatro categorias consideradas ${ }^{92}$.

Um problema conhecido associado ao levantamento dessa variável está na suspeita de que as pessoas com renda mais alta tenham tendência a informar salários abaixo dos que realmente ganham, o que pode prejudicar a qualidade dessa informação. Um indicador que contribui para a confirmação dessa hipótese na amostra utilizada está na observação de que, para as viagens com duração entre 90 e 240 minutos, os motoristas que declararam possuir 3 ou mais veículos $^{93}$, tiveram estimados valores de tempo $60 \%$ superiores aos demais.

Ainda com relação à consistência dessa informação, deve-se observar também que no presente estudo a pesquisa questionava o motorista sobre sua faixa de renda familiar - e não a renda individual. Assim sendo, essa informação poderia ter sido complementada com o levantamento de alguns dados sobre a família do

\footnotetext{
92 As categorias de faixa de renda definidas nesse estudo como 'baixa', 'média-baixa', 'média-alta' e 'alta' tiveram valores de tempo estimados em 18, 17, 18 e 20 rupias/h, respectivamente.

93 Essa característica pode ser entendida como uma proxy para pessoas de renda alta na amostra utilizada, como analisado no item 6.2.3
} 
entrevistado. Por exemplo, é natural esperar que um motorista chefe de família com renda mensal de $\mathrm{R} \$ 5000,00$ e com 4 dependentes esteja submetido a restrições monetárias muito diferentes de outro com a mesma renda, porém sem filhos. Bradley e Gunn (1990) observaram em seu experimento que os valores de tempo estimados sofriam significativas variações de acordo com a quantidade de pessoas e de trabalhadores do domicílio do entrevistado; concluíram que as pessoas morando sozinhas ou em domicílios com maior proporção de trabalhadores, as quais, conseqüentemente, teriam de repartir sua renda com menos pessoas, tiveram maiores valores de tempo estimados.

\subsubsection{Variação no valor do tempo com o motivo da viagem}

Para a amostra utilizada neste estudo observou-se que a segmentação considerando os motivos 'trabalho diário' e 'negócios' - comumente encontrada na bibliografia - não revelou diferenças importantes nas estimativas do valor do tempo dos viajantes. Por outro lado, para as viagens com o motivo lazer foram estimadas diferenças bastante expressivas no valor do tempo em relação aos demais motivos. Nos dois itens a seguir são levantadas algumas hipóteses para os resultados dos valores de tempo estimados por motivo de viagem.

\subsubsection{Baixo valor do tempo nas viagens a negócios}

Em análises considerando o motivo de viagem, comumente encontra-se na literatura que os motoristas viajando a negócios teriam os maiores valores de tempo estimados ${ }^{94}$.

Assim, um resultado que deve ser analisado deste experimento refere-se ao valor do tempo dos viajantes a negócios ter sido estimado como praticamente igual ao daqueles indo ao trabalho diário, como citado no item 6.3.3.

${ }^{94}$ Ver item 6.3.3 
Com relação às viagens classificadas como 'a negócios', Bradley e Gunn (1990) reconhecem a dificuldade de distinção entre dois subgrupos dentro desse motivo, e que supostamente teriam valores de tempo bastante distintos: i) a figura do tradicional executivo de negócios, e ii) o trabalhador que está meramente viajando a um local não fixo de trabalho, como um representante de vendas ou autônomos da construção, por exemplo.

No caso aqui estudado, os pontos de pesquisa inseriam-se predominantemente em regiões não urbanas e em rodovias de característica rural (TRB, 2000), onde as viagens realizadas provavelmente concentram uma maior parcela de viajantes a negócios que se enquadram no segundo caso citado por Bradley e Gunn (1990).

Visando verificar a hipótese de que o perfil do viajante a negócios pode variar de acordo com as características da região onde é feita a viagem, foram estimados modelos por motivo de viagem apenas para a amostra coletada em um posto de pesquisa localizado na rodovia dos Bandeirantes, entre São Paulo e Campinas. Para usuários desse corredor, que atende a deslocamentos entre regiões urbanas de alto desenvolvimento econômico, os modelos estimados levaram a valores de tempo bastante superiores para os viajantes a negócios, em relação àqueles indo ao trabalho diário. Estimaram-se valores de $R \$ 11,43 / \mathrm{h}$, $\mathrm{R} \$ 19,28 / \mathrm{h}$ e $\mathrm{R} \$ 12,98 / \mathrm{h}$ para motoristas viajando ao trabalho diário, a negócios e por outros motivos, respectivamente. Esses modelos estão descritos no apêndice $K$.

Ressalta-se que esta foi uma análise isolada e meramente exploratória. Análises mais conclusivas relacionando mudanças no perfil dos viajantes de acordo com regiões geográficas e sua caracterização socioeconômica devem envolver procedimentos bastante mais criteriosos para segmentação da amostra do que o aqui adotado. 


\subsubsection{2. $\quad$ Alto valor do tempo nas viagens de lazer}

Observou-se na amostra utilizada que os motoristas viajando a lazer tiveram valores do tempo estimados consideravelmente mais altos do que aqueles se deslocando ao 'trabalho diário' ou a 'negócios', como demonstrado no item 6.3.6. Como já mencionado, o lazer foi o único motivo de viagem - dentre os analisados - a apresentar diferenças significativas na valoração do tempo em relação aos demais.

Sobre esse resultado, um aspecto a ser observado é que as viagens a lazer são caracteristicamente de menor freqüência do que as por outros motivos, o que foi verificado na amostra (mostrado na Tabela 6-9). E assim, esses viajantes teriam menor conhecimento da região e de alternativas de rotas existentes e, conseqüentemente, menor propensão a arriscar-se em caminhos não conhecidos. Sobre isso, Hensher e Goodwin (2004) citam que uma via pedagiada proporciona maior sensação de segurança e definição mais clara de para onde está levando, o que é especialmente útil para viajantes não familiarizados com a região geográfica onde estão trafegando; e isso levaria a uma maior predisposição a pagar por pedágios para permanecer nessa via. Ainda sobre essa característica, Tretvik (1993) estimou em seu experimento que as viagens de baixa freqüência - dentro dos motivos classificados como outros que não o trabalho diário ou negócios - teriam valores de tempo 43\% superiores em relação àquelas realizadas com freqüência diária ou semanal.

Foi ainda verificada a hipótese de que as viagens a lazer estivessem associadas a menores proporções de motoristas de renda baixa. Análises estatísticas da distribuição das observações considerando a faixa de renda do motorista e o motivo da viagem - mostradas no apêndice $L$ - indicaram não haver diferenças na distribuição da renda familiar dos motoristas viajando a lazer, em relação aos demais motivos. 


\subsection{Recomendações para Estudos Futuros}

O aprendizado adquirido ao longo deste trabalho permite algumas observações que podem ser úteis em eventuais estudos de caráter semelhante. Essas são listadas a seguir e envolvem três aspectos do estudo: i) os dados a serem coletados; ii) o desenho do experimento, e iii) a aplicação da pesquisa em campo.

Com relação aos dados a serem coletados:

- Sob o aspecto teórico da valoração do tempo de viagem, uma importante contribuição foi dada por Jara-Díaz e Farah (1987), ao proporem que as pessoas com possibilidade de variar a quantidade de horas alocada ao trabalho associariam ao tempo de viagem um valor diferente daquelas que trabalham com carga horária e salário fixos ${ }^{95}$. Na pesquisa utilizada para este estudo, infelizmente não havia informação que permitisse a segmentação da amostra considerando a flexibilidade de horários ou disponibilidade de tempo livre dos motoristas entrevistados, como analisado por Bates e Roberts (1986) e Steimetz e Brownstone (2005), entre outros ${ }^{96}$. Assim, seria interessante em futuros levantamentos a inclusão de uma pergunta que permitisse a estimativa da variação do valor do tempo segundo essas características.

- O levantamento da informação sobre a renda do motorista poderia ser complementado com perguntas sobre a quantidade de pessoas que moram junto com esse no domicílio e, dessas, quantas trabalham. De acordo com Bradley e Gunn (1990) essas duas variáveis interferem consideravelmente na restrição financeira do motorista e, conseqüentemente, em seu valor do tempo.

\footnotetext{
${ }^{95}$ Ver item 2.2.

${ }^{96}$ No apêndice J são citados alguns estudos que analisaram essa característica.
} 
- Verificou-se que grande parte dos motoristas pareceu ter dificuldade em distinguir entre os motivos 'trabalho diário' e 'negócios'. Assim, seria recomendável a busca de formas mais eficazes de formulação dessa pergunta, talvez detalhando ou desagregando os motivos.

- Ainda sobre o motivo da viagem, a classificação 'negócios' pareceu englobar um grupo heterogêneo de pessoas com relação à valoração do seu tempo de viagem - como descrito no item 7.1.3.1. Dessa forma, seria recomendável a desagregação desse motivo - como em reunião, vendas, trabalho temporário - ou a complementação dessa informação com uma questão sobre a ocupação profissional do motorista.

Com relação ao desenho do experimento:

- Para os motoristas em viagens muito longas - com duração superior a 4 horas - não foram detectadas características das pessoas ou da viagem associadas a variações no valor do tempo, ao contrário do que se verificou para as viagens com duração inferior a 240 minutos. Dentre as explicações para isso pode-se especular que: i) esses motoristas, por estarem realizando viagens mais longas e cansativas, tiveram menor disposição em responder precisamente às questões, ou ii) esses motoristas não apresentaram sensibilidade suficiente à variação dos níveis adotados para os atributos definidos no experimento. Assim, seria interessante o teste de desenhos que, para viajantes de longa duração, apresentassem maior amplitude de variação nos níveis de atributos de custos tarifários e de (acréscimos de) tempos de viagem pela alternativa não pedagiada.

- Com relação ao menor (ou maior) valor do tempo estimado para viajantes de longa duração, a análise dessa questão crítica deveria incluir a concepção de um desenho que, como discutido no item 7.1.1, tente detectar se esse motorista seria mais sensível ao efeito de um acréscimo marginal no tempo ou no custo da viagem. 
- No decorrer deste estudo foi levantada a questão de que as alternativas pedagiada e não pedagiada teriam diferentes gastos com combustível associados. Isso levaria à tentação de introduzir no experimento uma variável relativa ao custo adicional de combustível por uma rota não pedagiada, o que poderia trazer maior realismo aos conjuntos de escolha e ganhos na qualidade das respostas. Deve-se atentar, no entanto, para dois aspectos: i) a introdução de uma variável adicional teria como conseqüência o aumento da complexidade do desenho, e ii) em um problema real, essa variável está altamente correlacionada com o acréscimo de tempo de viagem pela alternativa não pedagiada ${ }^{97}$.

Com relação à aplicação da pesquisa:

- Constatou-se, durante a realização dos levantamentos em campo, que a duração da entrevista é um aspecto crítico, como já citado no item 4.5.2. Somando-se a isso o fato de que o acostamento de uma rodovia é um ambiente que não propicia as condições ideais de concentração para o entrevistado, é recomendável nesses casos a utilização de experimentos com desenhos leves - com poucos atributos e níveis - e com formatos de escolhas simples. O formato de escolha adotado na pesquisa utilizada para este estudo - definido como escolha discreta de uma alternativa, descrito no item 4.4 - parece ser o mais adequado para pesquisas realizadas na rodovia. Outros formatos de escolha, como a ordenação, exigiriam maior atenção do motorista e seriam potencialmente mais demorados.

\footnotetext{
97 Assim, a introdução dessa variável de forma proporcional ao tempo de acréscimo pela não pedagiada não traria ganhos ao modelo; e, por outro lado, sua introdução em um desenho experimental ortogonal - com correlação zero entre os níveis das variáveis - poderá levar à formação de conjuntos de escolha pouco realistas com relação à variáveis consumo de combustível e tempo de viagem por uma rota não pedagiada.
} 


\subsection{O Novo Contexto das Aplicações para o Valor do Tempo de Viagem}

Como mencionado ao início deste estudo, a estimativa de valores subjetivos que as pessoas atribuem ao seu tempo de viagem é um problema cujas técnicas de análise requerem constante aprimoramento. Dentro dos dois usos característicos para o valor do tempo de viagem: i) a avaliação de projetos, e ii) a previsão de comportamento da demanda, o segundo é o que vem exigindo maior precisão das estimativas feitas. Hensher e Goodwin (2004) citam que com a crescente participação de investidores privados em projetos de infra-estrutura de transporte, o problema da estimativa do valor do tempo, se antes era direcionado principalmente à medição de benefícios de projetos em avaliações econômicas, atualmente tem-se tornado questão chave em projeções de comportamento que levam a estimativas de demanda. E nessas projeções, o uso de valores incorretos do valor do tempo de viagem pode levar a erros em estimativas de receitas, com reais conseqüências financeiras para as empresas envolvidas em um projeto ${ }^{98}$. Sobre esse aspecto, os autores citam ainda como exemplo o projeto do túnel sob o Canal da Mancha, onde estimativas incorretas sobre a parcela de viajantes que estaria disposta a pagar maiores tarifas - em relação à opção dos "ferries" existentes - para obter ganhos extras no tempo de viagem, quase causaram a falência das empresas envolvidas no empreendimento.

A atual preocupação de se obter o valor do tempo mais preciso possível para estudos envolvendo projeção de comportamento da demanda leva à natural comparação entre valores de tempo estimados por diversos estudos na busca de um 'verdadeiro' valor do tempo. No entanto, a comparação quantitativa de resultados estimados por diferentes estudos deve ser feita com bastante cautela, o que será observado no item final, a seguir.

\footnotetext{
98 No caso dos estudos de avaliação econômica, eventuais erros na estimativa do valor do tempo podem levar a que um projeto que gere menor benefício social seja equivocadamente selecionado em detrimento de outro, o que teria um grande custo social, mas não traria maiores conseqüências aparentes e de curto prazo para os consultores responsáveis. Esse assunto é amplamente discutido por Strand (1993).
} 


\subsection{A Busca do Verdadeiro Valor do Tempo de Viagem ${ }^{99}$}

Ao longo deste estudo, muitos dos resultados estimados foram comparados aos relatados em diversos estudos semelhantes encontrados na bibliografia. O que se observou, de forma geral, é que diferentes graus de compatibilidade desses resultados com conclusões citadas na bibliografia foram encontrados; e mesmo na literatura consultada os resultados de estimativas do valor do tempo de viagem apresentavam grande variação e até mesmo divergências qualitativas como na questão da variação do valor do tempo em função da duração da viagem $^{100}$.

Ilustrando esse aspecto, pode-se citar a lista compilada por Walters ${ }^{101}$ (1992 apud SCHIMITZ, 2001), contendo os resultados de vários estudos de valoração do tempo de viagem - todos encontrados em conceituadas publicações, na qual se verifica que os valores estimados em escolhas envolvendo o modo automóvel oscilam entre $30 \%$ e $254 \%$ da renda salarial do motorista.

Com relação à variação nos resultados encontrados, deve-se sempre lembrar do conceito freqüentemente mencionado na literatura de que o problema da estimativa do valor do tempo é bastante específico ao contexto analisado. Valores relatados em um experimento não coincidirão com valores relatados em outro, a não ser que as condições e o contexto sejam idênticos (GUNN, 2000). Assim, um valor subjetivo do tempo de viagem estimado a partir de um experimento para uma modelagem da escolha de rotas certamente não será válido para aplicação em problema de previsão de escolha modal, por exemplo. $\mathrm{Ou}$, no caso do presente estudo, o valor do tempo de viagem estimado em uma escolha específica entre rotas rodoviárias pedagiadas e não pedagiadas provavelmente não coincidirá com outro que considere uma escolha de mesma

\footnotetext{
${ }^{99} \mathrm{O}$ título deste item faz referência ao artigo In Search of the Value of Time: From South Africa to Índia, de Van Zyl e Raza (2006).

${ }^{100}$ Essa questão é discutida no item 7.1.1.

${ }^{101}$ A lista é apresentada no apêndice $M$.
} 
natureza, porém em ambiente urbano, onde haveria potencialmente maior quantidade de alternativas de rotas e de variáveis relevantes a serem ponderadas pelos motoristas ${ }^{102}$.

Ainda no estudo aqui apresentado, uma das principais conclusões foi a de que viajantes a lazer teriam valores de tempo bastante superiores aos daqueles em viagens ao trabalho diário ou a negócios. Essa é uma conclusão válida para a amostra aqui utilizada, coletada em um contexto específico de escolha de rotas. É bastante intuitivo, por outro lado, que em um cenário de escolha modal urbana, uma pessoa se deslocando ao trabalho associaria a seu tempo de viagem um valor maior do que uma outra indo visitar um museu, por exemplo ${ }^{103}$.

Enfim, a questão da especificidade da variável valor do tempo de viagem ao seu contexto é sintetizada da seguinte forma por Gunn (2000):

[...] não há um 'verdadeiro' valor do tempo que um 'ótimo' experimento possa medir. O verdadeiro teste de um específico valor do tempo, para um dado propósito, modo ou horizonte, é se esse fornece, ou não, avaliações que resultam em boas políticas ou em previsões de comportamento com suficiente precisão.

\footnotetext{
${ }^{102}$ Como, por exemplo, tempo de viagem em fluxo congestionado, tempo perdido com paradas em semáforos.

${ }^{103}$ Wardman (2004) estimou modelos para várias situações envolvendo escolhas entre modos de transporte urbano. Em todos eles os viajantes com motivo lazer tiveram menores valores de tempo do que aqueles se dirigindo ao trabalho ou viajando a negócios.
} 


\section{REFERÊNCI AS BI BLI OGRÁFICAS}

BARTHOLOMEU, D.B. Quantificação dos impactos econômicos e ambientais decorrentes do estado de conservação das rodovias brasileiras. Tese de Doutorado, Escola Superior de Agricultura da Universidade de São Paulo, Piracicaba, 2006.

BATES, J. Stated Preference Methods in Transport Research - Editorial. J ournal of Transport Economics and Policy, vol 22, n 1, pp 7-10, 1988.

BATES, J. History of Demand Modelling. in HENSHER, D.A., BUTTON, K.J. (eds) Handbook of Transport Modelling, Elsevier, Oxford, 2000.

BATES, J. Reflections on Stated Preference: Theory and Practice. In ORTÚZAR, J.D.; HENSHER, D.A.; JARA-DÍAZ, S.R. (eds) Travel Behaviour Research: Updating the State of Play. Elsevier, Amsterdam, 1998.

BATES, J.; ROBERTS, M. Value of time research: Summary of Methodology and Findings, 14th PTRC Summer Annual Meeting. Conference Papers, University of Sussex, julho, 1986.

BECKER, G. A Theory of the Allocation of Time. Economic J ournal, 75, pp 493517,1965 .

BEESLEY, M.E. The Value of Time Spent in Travelling: Some New Evidence. Economica, vol 32, n. 126, pp. 174-185, 1965.

BEN-AKIVA, M.; LERMAN, S. R. Discrete Choice Analysis - Theory and Application to Travel Demand. MIT Press, Cambridge, 1985.

BIERLAIRE, M. An I ntroduction to Biogeme (Version 1.4), December, 2005, Em: <http://roso.epfl.ch/mbi/biogeme/doc/tutorial.pdf>, acessado em 02/2006.

BRADLEY, M.A.; GUNN, H.F. Stated Preference Analysis of Values of Travel Time in the Netherlands. Transportation Research Record, 1285, pp 78-88, 1990.

BROWNSTONE D.; KAZIMI C.; GHOSH A.; GOLOB T.F.; VAN AMELSFORT D. Drivers' Willingness-to-Pay to Reduce Travel Time: Evidence from the San Diego I-15 Congestion Pricing Project."), Transportation Research A, 37, pp. 373-387, 2003.

BROWNSTONE D.; SMALL, K.A. Valuing Time and Reliability: Assessing the Evidence from Road Pricing Demonstrations. Paper. University of California at Irvine, October, 2004. Disponível em <http://repositories.cdlib.org/postprints/669>, acessado em 09/2006

CARSON, R.T; LOUVIERE, J.J.; ANDERSON, D.A.; Experimental Analysis of Choice. Marketing Letters 5, pp 351-368, 1994.

CHEN, O.J .; BERNSTEIN, D. AM/PM Congestion Pricing with a Single Toll Plaza. Transportation Research Record, 1498, pp. 23-31, 1995.

CHERCHI, E.; ORTÚZAR, J. D. Income, Time Effects and Direct Preferences in a Multimodal Choice Context: Application of Mixed RP/SP Models with Non-linear Utilities. In: XIII Panamerican Conference. Conference Papers. Albany, 2003. 
DE SERPA, A. A Theory of the Economics of Time. Economic J ournal, 81, pp 828-846, 1971.

DOMENCICH, T.A.; MCFADDEN, D. Urban Travel Demand - A Behavioral Analysis. Elsevier / North-Holland Publishing, Amsterdam, 1975.

EVANS, A. W. On the Theory of the Valuation and Allocation of Time. Scottish J ournal of Political Economy, 19, pp 1-17, 1972.

FREJ INGER, E., BIERLAIRE, M., STOJ ANOVIC, J., VRTIC, M., SCHUESSLER, N., AXHAUSEN, K.W. A Route Choice Model in Switzerland Based on RP and SP Data. Paper. Transport and Mobility Laboratory, Ecole Polytechnique Fédérale de Lausanne. Switzerland, Lausanne, 2006.

Em: < http://www.e-collection. ethbib.ethz.ch/show?type=incoll\&nr=1098\&part=text > acessado em 11/2006.

GHOSH, A. Heterogeneity in Value of Time: Revealed and Stated Preference Estimates from the I-15 Congestion Pricing Project. Paper. Department of Economics, University of California, Irvine, 2000. Disponível em <http://www.geocities.com/arindam_gho/vot.pdf>, acessado em 10/2006.

GREEN, P.E.; SRINIVASAN, V. Conjoint Analysis in Consumer Research: Issues and Outlook. J ournal of Consumer Research, vol 5, pp 103-212, 1978.

GONZÁLEZ, R.M. The Value of Time: A Theoretical Review. Transport Reviews 17, pp 245-266, 1997.

GUNN, H.F. An Introduction to the Valuation of Travel-time Savings and Losses. in HENSHER, D.A., BUTTON, K.J. (eds) Handbook of Transport Modelling, Elsevier, Oxford, 2000.

GUJ ARATI, D. N. Econometria Básica, Makron Books, São Paulo, 2000.

HEGGIE, I.G. Valuing Savings In Non Working Travel Time: The Empirical Dilema. Transportation Research A, 17, pp 13-23, 1983.

HENSHER, D.A. Establishing a Fare Elasticity Regime for Urban Passenger Transport: Non-Concession Commuters. Working Paper, Institute of Transport Studies, University of Sydney, October, 1996a

HENSHER, D.A. Application: Valuation Of Travel Time Savings - Choice Of Toll And Free Route. Course Materials, Institute of Transportation Studies, University Of Sydney, $1996 b$

HENSHER, D.A. Measurement of the Valuation of Travel Time Savings. J ournal of Transport Economics and Policy, vol 35, part I, pp 71-98, 2001.

HENSHER, D.A.; GOODWIN, P. Using Values of Time Savings for Toll Roads: Avoiding Some Common Errors. Transport Policy, 11, pp 171-181, 2004.

HENSHER, D.A.; LOUVIERE, J.J. Stated Preference \& Choice Methods for Land Use \& Transport Planning Applications. Course Materials, Stockholm, Sweden, 1997.

HENSHER, D.A.; TRUONG, P.T. Valuation of Travel Time Savings - A Direct Experimental Approach. Journal of Transport Economics and Policy, pp 237-261, September, 1985.

HENSHER, D.A.; ROSE, J.M.; GREENE, W.H. Applied Choice Analysis - A Primer. Cambridge University Press, New York, 2005. 
HUBER, J .; HANSON, D. Testing the Impact of Dimensional Complexity and Affective Differences of Paired Concepts in Adaptive Conjoint Analysis. School of Business Working Paper, Duke University, 1986.

JARA-DÍ AZ, S.R. Time and Income in Travel Demand - Towards a Microeconomic Activity Framework. Paper. Universidad do Chile, Santiago, 1994. Disponível em <http://www. cec.uchile.cl/ dicidet/sjara/Time\%20and\%20I ncome.PDF>, acessado em: $03 / 2006$.

JARA-Dí AZ, S.R. Allocation and Valuation of Travel-Time Savings. In HENSHER, D.A.; BUTTON, K.J. (eds) Handbook of Transport Modelling, Elsevier, Oxford, 2000.

JARA-DÍAZ, S.R. The Goods / Activities Framework For Discrete Travel Choices: Indirect Utility And Value of Time. In MAHMASSANI, H.S. (ed) In Perpetual Motion - Travel Behaviour Research Opportunities And Application Challenges. Elsevier, Oxford, 2002.

JARA-DIAZ S. R.; FARAH M. Transport Demand and Users' Benefits with Fixed Income: The Goods/Leisure Tradeoff Revisited. Transportation Research B, 21 , n으, pp. 165-170, 1987.

JARA-DIAZ, S.R.; FRIESZ, T.L. Measuring Benefits Derived from a Transportation Investment. Transportation Research B, 16, №1, pp 79-81, 1982.

JARA-DIAZ, S.R.; GÁLVEZ, T. On The Social Valuation Of Travel Time Savings. International J ournal of Transport Economics 25, pp 205-219, 1998.

JARA-DIAZ, S.R.; GUEVARA, C.A. Behind the Subjetive Value of Travel Time Savings - The Perception of Work, Leisure, and Travel from a Joint Mode Choice Activity Model. Journal Of Transport Economics And Policy, vol 37, part 1, pp 29-46, 2003.

JIANG, M.; MORIKAWA, T. Theoretical Analysis on the Variation of Value of Travel Time Savings. Transportation Research A, 38, pp 551-571, 2004.

JOHNSON, M. Travel Time and the Price of Leisure. Western Economics Journal $\mathrm{n}$ ㅇ 4, 1966.

KROES, E.P.; SHELDON, R.J. Stated Preference Methods - An Introduction. J ournal of Transport Economics and Policy, vol 22, n 1, pp 11-25, 1988.

KUEHL, R.O. Design of Experiments: Statistical Principles of Research Design and Analysis. 2nd ed. Pacific Grove - Duxbury Press, CA, 2000.

LITMAN, T. Transportation Cost Analysis: Techniques, Estimates and Implications, Victoria Transport Policy Institute, Canada, 2002

Em <http://www.vtpi.org/tca/tca0502.pdf>, acessado em 03/2006.

LOUVIERE, J.J .; HENSHER, D.A.; SWAIT, J.D. Stated Choice Methods - Analysis and Application. Cambridge University Press, Cambridge, 2000.

MACKIE, P.J .; JARA-DÍAZ, S.R.; FOWKES, A.S. The Value of Travel Savings in Evaluation. Transportation Research, Part E 37, 2001.

MACKIE, P.J .; GRANT-MULLER, S.; NELLTHORP, J.; PEARMAN, A. - Socio-Economic Cost Benefit Analysis For Transport I nfrastructure Project Appraisal. United Nations - Economic Commission For Europe I nland Transport Committee, Geneva, 2002. Disponível em: <http://www.unece.org/trans/doc/2002/wp5/TRANS-WP5-2002-07e.pdf>, acessado em: 03/2006. 
MACKIE P.J., FOWKES A.S., WARDMAN M., WHELAN G., NELLTHORP J., BATES J. Valuation of Travel Time Savings in the UK - Summary Report to the Department for Transport. Institute for Transport Studies Working Paper, University of Leeds, 2003

MCFADDEN, D.; TALVITIE, A. Demand Model Estimation and Validation. Institute of Transportation Studies, Urban Travel Demand Forecasting Project: Phase 1 Final Report Series, Volume V, University of California, Berkeley and Irvine, 1977.

MORIKAWA, T. Incorporating Stated Preference Data in Travel Demand Analysis. Doctoral Dissertation, Massachusetts Institute of Technology, Cambridge, 1989.

MUNIZAGA, M.A. Evaluation Of Mixed Logit as a Practical Modelling Alternative, Proceedings European Transport Conference, Conference Papers, Cambridge, U.K., 2002.

OORT, C.J. The Evaluation of Travelling Time. Journal of Transport Economics and Policy, 3, 279-286, 1969.

ORTÚZAR, J.D.; WI LLUMSEN L.G. Modelling Transport. J ohn Wiley \& Sons, 3ạ ed., New York, 2001.

PEARCE, D.W.; NASH, C.A. The Social Appraisal of Projects: a Text in Cost-Benefit Analysis. Macmillan, London, 1981.

SAELENSMINDE, K. Valuation of Non-market Goods for Use in Cost-Benefit Analyses: Methodological I ssues. PhD Thesis, Department of Economics and Social Sciences, Agricultural University of Norway.

SCHMITZ, R. Uma Contribuição Metodológica Para Avaliação da Tarifa de Pedágio em Rodovias. Tese de Doutorado, Engenharia de Produção UFSC, Florianópolis, 2001.

SHELDON, R.J.; STEER, J.K. The Use of Conjoint Analysis in Transport Research. PTRC Summer Annual Meeting, Conference Papers, Warwick, 1982.

SIMON, H.A. Models of Man: Social and Rational. John Wiley \& Sons, New York, 1957.

SMALL, K.A. The Scheduling of Consumer Activities: Work Trips. American Economic Review, 72, pp 467-479.

STEER, J.K.; WILLUMSEN, L. An investigation of Passenger Preference Structures. PTRC Summer Annual Meeting, Conference Papers. Warwick, 1981.

STEIMETZ S.S.C; BROWNSTONE D. Estimating Commuters" “Value of Time” with Noisy Data: a Multiple Imputation Approach. Transportation Research B, 39, pp 865-889, 2005

STRAND, S. Time in Transport: a Perverted Problem? Arguments for a Fresh Look at Time Utility Research and its Application. Transportation Research Record, 1395, pp 10-14, 1993.

Transit Cooperative Research Program. Estimating the Benefits and Costs of Public Transit Projects: A Guidebook for Practitioners, Transportation Research Board Report National Academy Press Washington, D.C., 2002.

TRAIN, K. Discrete Choice Methods With Simulation. Cambridge University Press, UK, 2003. 
TRAIN, K. Qualitative Choice Analysis: Theory, Econometrics, and an Application to Automobile Demand. MIT Press, Cambridge, 1986

TRAIN, K.; MCFADDEN, D. The Goods/Leisure Tradeoff and Disaggregate Work Trip Mode Choice Models. Transportation Research, 12, pp 349-353, Great Britain, 1978.

TRB Highway Capacity Manual - HCM 2000. Transportation Research Board. National Research Council. Washington D.C., 2000.

TRETVIK T. Inferring Variations in Values of Time from Toll Route Diversion Behavior. Transportation Research Record, 1395, pp 25-32, 1993

VAN ZYL, N. J. W.; RAZA, M. In Search of the Value of Time: From South Africa to India. In Stopher, P., Stecher, C. (eds) Travel Survey Methods - Quality and Future Directions, Elsevier, Oxford, 2006.

WARDMAN, M. Public Transport Values of Time. Transport Policy, 11, pp 363-377, 2004.

WIDLERT, S. Stated Preference Studies: The Design Affects the Results. In ORTÚZAR, J.D.; HENSHER, D.A.; JARA-DÍAZ, S.R. (eds) Travel Behaviour Research: Updating the State of Play. Elsevier, Amsterdam, 1998.

ZIGNANI, R.C.; NODARI, C.T.; CYBIS, H.B.B. Avaliação da Percepção de Custo de Diferentes Classes de Usuários em Rodovias de Qualidades Distintas. XX Anpet, Anais. Brasília, 2006. 


\section{APÊNDICE A - Modelo estimado para toda amostra sem segmentação}

A seguir mostram-se os resultados estimados para todo o conjunto das 5411 entrevistas consideradas válidas - que geram 48699 observações, ou seja, 9 por entrevistado. Os quadros apresentados nos apêndices estão no formato de saída do software Biogeme (BIERLAIRE, 2005), utilizado para as estimativas dos modelos de escolha.

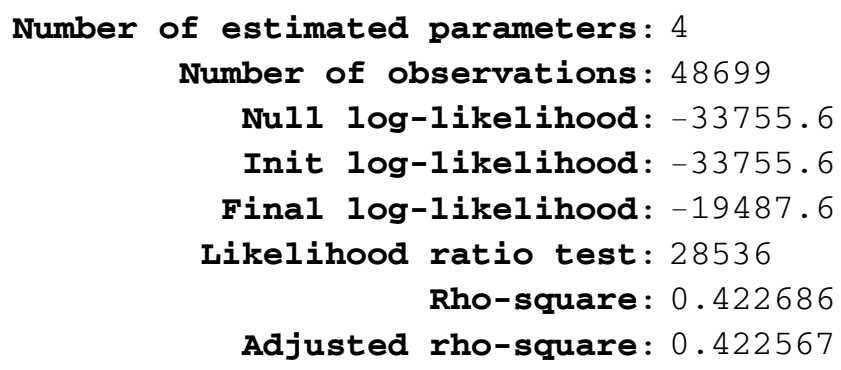

Utility parameters

\begin{tabular}{|l|c|c|c|}
\hline \multicolumn{1}{|c|}{ Name } & value & std err & t-test \\
\hline CTE_PED & $-9.4871360 e-001$ & $+4.8268183 e-002$ & $-1.9655051 e+001$ \\
\hline CTOLL & $-5.8496039 e-003$ & $+1.0164150 e-004$ & $-5.7551335 e+001$ \\
\hline \hline TALT & $-1.5930614 e-001$ & $+1.3453340 e-003$ & $-1.1841382 e+002$ \\
\hline TTOLL & $-1.5897917 e-001$ & $+1.3395931 e-003$ & $-1.1867721 e+002$ \\
\hline
\end{tabular}

Os coeficientes da tabela são:

- CTE_PED: constante específica da alternativa pedagiada

- CTOLL: coeficiente do custo tarifário pela alternativa pedagiada

- TTOLL: coeficiente do tempo de viagem pela alternativa pedagiada

- TTOLL: coeficiente do tempo de viagem pela alternativa não pedagiada

Sendo o valor do tempo de viagem dado pela relação entre os coeficientes TTOLL e CTOLL, tem-se VT=27,17 centavos/min ou $\mathrm{R} \$ 16,30 / \mathrm{h}$ 


\section{APÊNDI CE B - Verificações adicionais de relação entre variáveis dos modelos estimados}

A Tabela A-1 mostra o teste feito para verificar a existência de alguma relação entre as variáveis renda familiar e motivo de viagem na amostra.

Tabela A-1: Teste de independência da distribuição das observações por classe de renda nos motivos 'negócios' e 'trabalho diário'

observações

\begin{tabular}{lrrrrrr}
\hline observações & \multicolumn{7}{c}{ Renda } & & & \\
motivo & baixa & média & média_alta & alta & ni & \multicolumn{1}{c}{ Total } \\
\hline negócios & 299 & 1382 & 525 & 272 & 38 & 2516 \\
trabalho diário & 55 & 265 & 110 & 48 & 13 & 491 \\
\hline total & 354 & 1647 & 635 & 320 & 51 & 3007 \\
\hline
\end{tabular}

freq esperadas

\begin{tabular}{lrrrrr}
\hline motivo & \multicolumn{5}{c}{ Renda } \\
\hline negócios & \multicolumn{1}{c}{ baixa } & \multicolumn{1}{c}{ média } & \multicolumn{1}{c}{ média_alta } & \multicolumn{1}{c}{ alta } & \multicolumn{1}{c}{ ni } \\
trabalho diário & 296,20 & 1378,07 & 531,31 & 267,75 & 42,67 \\
\hline \multirow{2}{*}{ qui } & 57,80 & 268,93 & 103,69 & 52,25 & 8,33 \\
& & & & & \\
& 0,0265 & 0,0112 & 0,0750 & 0,0675 & 0,5116 \\
& 0,1359 & 0,0575 & 0,3844 & 0,3459 & 2,6216
\end{tabular}

$\begin{array}{lr}\text { qui-quad } & 4,237 \\ \text { qui-crit } & 14,860 \\ \text { signif }=0,5 \% & \end{array}$

A comparação da distribuição das ocorrências por faixa de renda para os motivos de viagem 'negócios' e 'trabalho diário' foi feita através do teste de independência pelo qui-quadrado. Para o nível de significância 0,5\% e 4 graus de liberdade, tem se que qui-quad $=4,23<$ qui-quad crítico $=14,8$, e não se rejeita $\mathrm{H}_{0}$. Assim, não se pode afirmar que motoristas viajando a negócios e ao trabalho diário tenham diferentes distribuições de renda na amostra. 
O teste para verificação da relação entre a duração e o motivo da viagem é mostrado na Tabela A-2.

Tabela A-2: Teste de independência da distribuição das observações por faixa de tempo de viagem nos motivos 'negócios' e 'trabalho diário'

observações

Faixa de tempo de viagem ( $\mathrm{min})$

\begin{tabular}{lrrrrr}
\multicolumn{1}{c}{ Motivo } & Até $90 \mathrm{~min}$ & 91 a $240 \mathrm{~min}$ & $+240 \mathrm{~min}$ & \multicolumn{1}{c}{ Total } \\
\hline negócios & 1565 & 771 & 180 & 2516 \\
trabalho diário & 434 & 49 & 8 & 491 \\
\hline Total & 1999 & 820 & 188 & 3007 \\
\hline
\end{tabular}

freq esperadas

Faixa de tempo de viagem (min)

\begin{tabular}{lrrr}
\multicolumn{1}{c}{ Motivo } & Até $90 \mathrm{~min}$ & 91 a $240 \mathrm{~min}$ & \multicolumn{1}{c}{$+240 \mathrm{~min}$} \\
\hline negócios & 1672,59 & 686,11 & 157,30 \\
trabalho diário & 326,41 & 133,89 & 30,70 \\
\hline & & & \\
qui & & & \\
& 6,92 & 10,50 & 3,28 \\
& 35,46 & 53,83 & 16,78
\end{tabular}

qui-quad 126,77

qui-crit 12,8

signif $0,5 \%$

O resultado do teste de independência pelo qui-quadrado (no qual qui-quad = 126,7 > qui-quad crítico $=12,8$ - para 2 graus de liberdade e nível de significância $0,5 \%$ ) indica que a hipótese $\mathrm{H}_{0}$, de que não há diferenças entre as distribuições das observações por tempo de viagem para os motivos considerados, é rejeitada.

Pela Tabela A-2 observa-se que, para as viagens com duração de até 90 minutos, os deslocamentos ao trabalho diário apresentam freqüências maiores do que as esperadas (434 observações, sendo 'esperadas' 326), ocorrendo o inverso para as viagens a negócios dessa duração. Ou seja, as viagens ao trabalho diário são caracteristicamente de duração mais curta na amostra. 


\section{APÊNDICE C - Resultados do modelo estimado com dummies para faixas de renda}

Apresenta-se aqui a verificação de diferenças comportamentais entre motoristas das faixas de renda: i) baixa (até $\mathrm{R} \$ 900,00$ ), ii) média (de 901,00 a $R \$$ 3000,00 ), iii) média-alta (de 3001,00 a 6000,00), iv) alta (acima de 6000,00) e v) não informado Os parâmetros estimados e os resultados do modelo são apresentados a seguir. A Tabela A-3 indica a nomenclatura utilizada.

Tabela A-3: Nomenclatura dos coeficientes do modelo apresentado

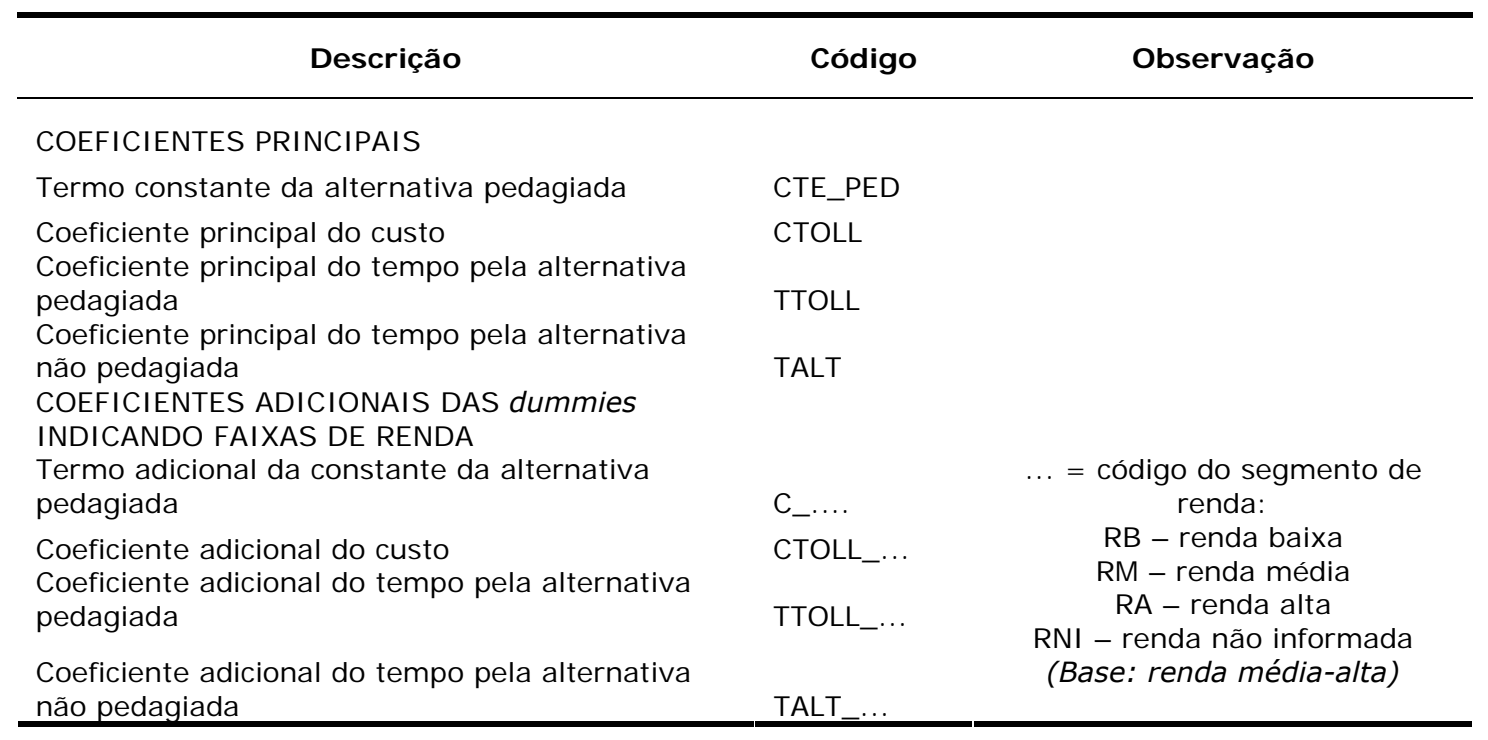

Ressalta-se que as variáveis relativas ao custo estão expressas no modelo em centavos e as relativas a tempo de viagem, em minutos.

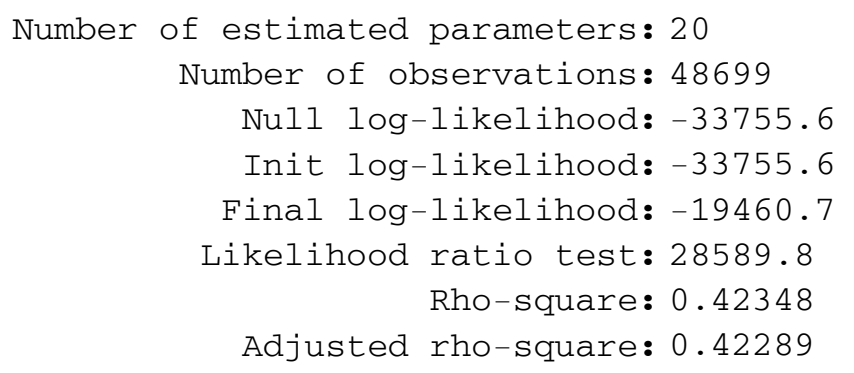


Utility parameters

\begin{tabular}{|c|c|c|c|c|}
\hline Name & Value & Std err & t-test & \\
\hline CTE_ & $8.6061996 e-001$ & $+1.0529693 e-001$ & $-8.1732670 e+000$ & \\
\hline CTE_- & $1.3589570 e-001$ & $+1.8829948 e-001$ & $-7.2169982 e-001$ & * \\
\hline CTE_RB & $+2.7753582 e-001$ & $+1.6752551 e$ & +1.656 & * \\
\hline CTE_RM & -1.673381 & +1.24 & $-1 \cdot 34$ & * \\
\hline CTE_RNI & -2.792094 & $+3.2669776 \mathrm{e}$ & -8.546 & * \\
\hline CTOLL & $-5.6632620 e-003$ & $+2.2053282 e-004$ & -2.567 & \\
\hline CTOLL_RA & +2.9089 & $+3.7372662 e-004$ & +7.78 & * \\
\hline CTOLL_RB & -1.246 & +3.70 & -3.36 & \\
\hline CTOLL_RM & $-1.9630038 e-004$ & $+2.6064486 e-004$ & -7.53 & * \\
\hline CTOLL_RNI & $+2.4011650 e-004$ & $+6.9252660 e-004$ & +3.467 & * \\
\hline TTOLL & -1.534 & $+2.8715006 e-003$ & -5.342 & \\
\hline TTOLL_RA & $-3.7794531 e-003$ & $+5.0517482 e-003$ & -7.481 & * \\
\hline TTOLL_RB & $-2.6189433 e-003$ & $+4.6235165 e-003$ & -5.664 & * \\
\hline TTOLL_RM & $-9.1097041 e-003$ & $+9.4184300 e-003$ & -1.66487 & * \\
\hline TTOLL_RNI & -7.4289 & $+1.0169307 e-002$ & -7.305 & * \\
\hline TALT & -1.5343 & $+2.8819141 e-003$ & -5.3240 & \\
\hline TALT_RA & $-4.0361226 e-003$ & $+5.0756050 e-003$ & $-7.9520029 e-001$ & * \\
\hline TALT_RB & $-3.3025225 e-003$ & $+4.6492220 e-003$ & $-7.1033874 e-001$ & * \\
\hline TALT_RM & $-9.4360271 e-003$ & $+9.4310396 e-003$ & $-1.7501948 e+000$ & * \\
\hline TALT_NI & $-7.6402590 e-003$ & $+1.0186694 \mathrm{e}-002$ & $-7.5002342 e-001$ & \\
\hline
\end{tabular}

obs: o asterisco indica os valores não significativos no nível de significância 0,05 (valor- $t=1,96$ )

Observa-se que apenas os coeficientes do custo (CTOLL) relativos à classe de renda baixa (CTOLL_RB) foram estatisticamente significativos, ao nível de significância $0,05 \quad(t=1,96)$. Os coeficientes relativos ao tempo pela rota pedagiada (TTOLL) foram, inclusive para os indivíduos de renda baixa, todos não significativos. Ou seja, as estimativas para os grupos de rendas média, alta e não informada não são estatisticamente diferentes do grupo de renda médiaalta, adotada como base. 


\section{APÊNDI CE D - Verificação da necessidade de desagregação da classe de renda média}

Os coeficientes e resultados do modelo são apresentados a seguir e seguem nomenclatura análoga à indicada na Tabela A-3 .

A classe de renda familiar média - de renda mensal entre $R \$ 900,00$ e $R \$$ 3000,00 - foi aqui desagregada em: i) de $R \$ 900$ a $R \$ 1500$, e ii) de $R \$ 1501$ a $\mathrm{R} \$ 3000$. A primeira foi definida como categoria base e a última é identificada por coeficientes das dummies CTE_PED_3000 (constante específica da rota pedagiada), CTOLL_3000 (coeficiente do custo tarifário pela rota pedagiada), TTOLL_3000 (coeficiente do tempo pela rota pedagiada) e TALT_3000 (coeficiente do tempo pela rota alternativa).

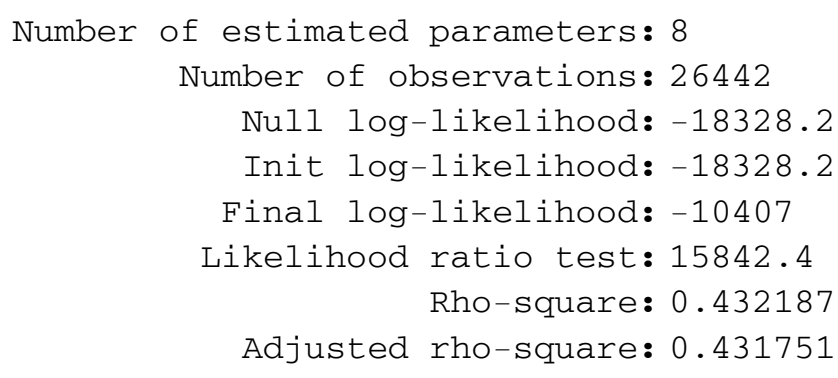

Utility Parameters

\begin{tabular}{|c|c|c|c|c|}
\hline Name & Value & std err & t-test & \\
\hline CTE_PED & $-1.0703942 e+000$ & $+1.0382911 \mathrm{e}-001$ & $-1.0309192 e+001$ & \\
\hline CTE_PED_3000 & $+8.8842746 e-002$ & $+1.3476349 e-001$ & $+6.5924939 e-001$ & * \\
\hline CTOLL & $-6.0199764 e-003$ & $+2.2446735 e-004$ & $-2.6818940 e+001$ & \\
\hline CTOLL_3000 & $+2.3067516 e-004$ & $+2.8619557 e-004$ & $+8.0600534 e-001$ & * \\
\hline TTOLL & $-1.6349265 e-001$ & $+2.9476700 e-003$ & $-5.5465045 e+001$ & \\
\hline TTOLL_3000 & $+1.4846685 e-003$ & $+3.7943033 e-003$ & $+3.9128882 \mathrm{e}-001$ & * \\
\hline TALT & $-1.6401758 e-001$ & $+2.9627305 e-003$ & $-5.5360277 e+001$ & \\
\hline TALT_3000 & $+1.8010776 \mathrm{e}-003$ & $+3.8101494 e-003$ & $+4.7270523 e-001$ & * \\
\hline
\end{tabular}

obs: 0 asterisco indica os valores não significativos no nível de significância 0,05 (valor-t $t=1,96)$

Observou-se no modelo estimado que os coeficientes das dummies foram todos não significativos, indicando que o desagrupamento dessa classe traria pouca contribuição explicativa adicional envolvendo a variável classe de renda. 


\section{APÊNDICE E - Modelo comparando motoristas entrevistados em rodovias pedagiadas e em não pedagiadas}

Seguindo nomenclatura para os coeficientes análoga à indicada na Tabela A-3, são mostrados os resultados do modelo estimado para a verificação de diferenças comportamentais entre motoristas entrevistados em rodovias pedagiadas e não pedagiadas. O segmento entrevistado em rodovias pedagiadas é identificado, no modelo, pelo sufixo '_RP'.

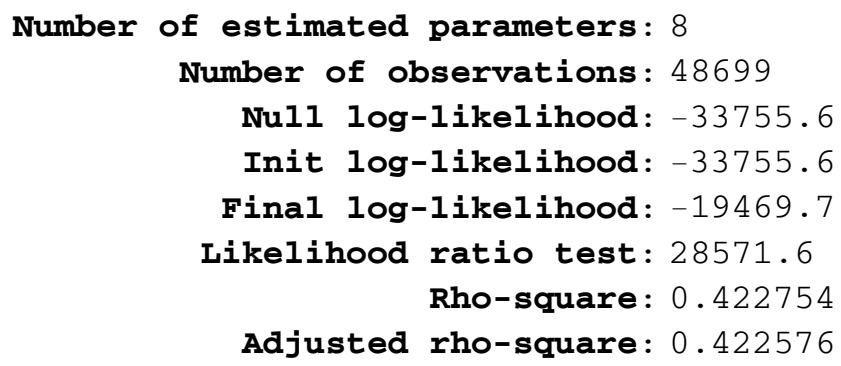

Utility parameters

\begin{tabular}{|c|c|c|c|c|}
\hline Name & Value & std err & t-test & \\
\hline CTE_PED & $-1.0072663 e+000$ & $+7.2697173 e-002$ & $-1.3855646 e+001$ & \\
\hline CTE_RP & $+1.0026429 e-001$ & $+9.2060301 e-002$ & $+1.0891154 e+000$ & * \\
\hline CTOLL & $-5.8384209 e-003$ & $+1.5960111 e-004$ & $-3.6581330 e+001$ & \\
\hline CTOLL_RP & $-3.4016682 e-005$ & $+2.0034763 e-004$ & $-1.6978830 e-001$ & * \\
\hline TTOLL & $-1.5884454 e-001$ & $+1.3451577 e-003$ & $-1.1808619 e+002$ & \\
\hline TTOLL_RP & $-2.4174465 e-004$ & $+2.2473748 e-004$ & $-1.0756757 e+000$ & * \\
\hline TALT & $-1.5932535 e-001$ & $+1.3457078 e-003$ & $-1.1839520 e+002$ & \\
\hline TALT_RP & $-2.4064365 e-004$ & $+2.2473748 e-004$ & $-1.0526937 e+000$ & * \\
\hline
\end{tabular}

Observou-se que os coeficientes adicionais de custo tarifário (CTOLL_RP) e tempo (TTOLL_RP e TALT_RP), estimados para a categoria de motoristas entrevistados em rodovias pedagiadas foram não significativos (valor- $t<1,96$ ), o que indica não haver diferenças estatísticas entre 0 valor do tempo de motoristas entrevistados em rodovias pedagiadas e não pedagiadas. 


\section{APÊNDI CE F - Modelos com dummies para verificação de outras características associadas a variações no valor do tempo}

A seguir são apresentados todos os modelos estimados para a verificação das características citadas no item 6.3.6.2, e seu efeito sobre a variação do valor do tempo de viagem.

A Tabela A-4 apresenta a nomenclatura usada para identificar os coeficientes das variáveis testadas.

Tabela A-4: Nomenclatura dos coeficientes nos resultados dos modelos com dummies

\begin{tabular}{|c|c|c|}
\hline Descrição & Código & Observação \\
\hline \multicolumn{3}{|l|}{ COEFICIENTES PRINCIPAIS } \\
\hline Termo constante da alternativa pedagiada & CTE_PED & \\
\hline $\begin{array}{l}\text { Coeficiente principal do custo } \\
\text { Coeficiente principal do tempo pela alternativa } \\
\text { pedagiada } \\
\text { Coeficiente principal do tempo pela alternativa } \\
\text { não pedagiada }\end{array}$ & $\begin{array}{l}\text { CTOLL } \\
\text { TTOLL } \\
\text { TALT }\end{array}$ & \\
\hline $\begin{array}{l}\text { COEFICIENTES ADICIONAIS DAS dummies } \\
\text { Termo adicional da constante da alternativa } \\
\text { pedagiada }\end{array}$ & $C_{-} \ldots$ & \\
\hline $\begin{array}{l}\text { Coeficiente adicional do custo } \\
\text { Coeficiente adicional do tempo pela alternativa } \\
\text { pedagiada } \\
\text { Coeficiente adicional do tempo pela alternativa } \\
\text { não pedagiada }\end{array}$ & $\begin{array}{l}\text { CTOLL_... } \\
\text { TTOLL_... } \\
\text { TALT_... }\end{array}$ & $\begin{array}{c}\ldots=\text { código da característica } \\
\text { analisada }\end{array}$ \\
\hline \multicolumn{3}{|l|}{ CARACTERÍSTICAS ANALISADAS } \\
\hline chefe da família & $\mathrm{CHF}$ & Base: não chefe \\
\hline sexo do motorista & SX & Base: masculino \\
\hline renda familiar baixa & RB & Base: renda não baixa \\
\hline posse de 3 ou mais veículos & VE3 & Base: menos de 3 veículos \\
\hline idade superior a 65 & AGE & Base: não superior a 65 anos \\
\hline viagem no pico da manhã & $\mathrm{PICO}$ & Base: fora do pico \\
\hline pagamento de pedágios na viagem & PAY & Base: paga pedágios na viagem \\
\hline motivo (trab/neg/outr) & TRA, OUTR & Base: motivo negócios \\
\hline motivo lazer no destino & DLAZ & Base: motivo não lazer \\
\hline
\end{tabular}


Como citado, as variáveis descrevendo as características do motorista ou da viagem realizada foram testadas individualmente para verificação se essas implicavam em variações estatisticamente significativas nos parâmetros que permitem estimar o valor do tempo.

Os resultados dos modelos estimados são apresentados de acordo com a seqüência mostrada na Figura A-1.

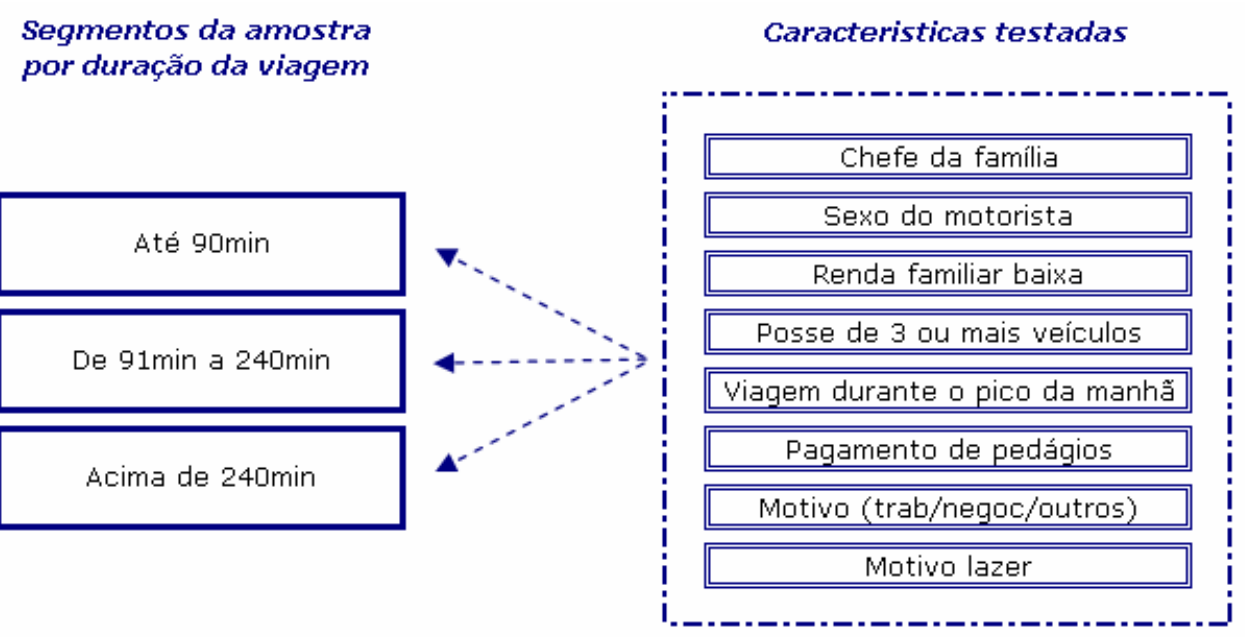

Figura A-1: modelos estimados para cada característica testada, nos segmentos de faixa de duração da viagem.

Os resultados são apresentados no formato de saída do software Biogeme (Bierlaire, 2005), utilizado para as estimativas dos modelos de escolha. 


\section{Modelos estimados para o segmento das viagens com duração de até 90 minutos}

Característica: Chefe da família

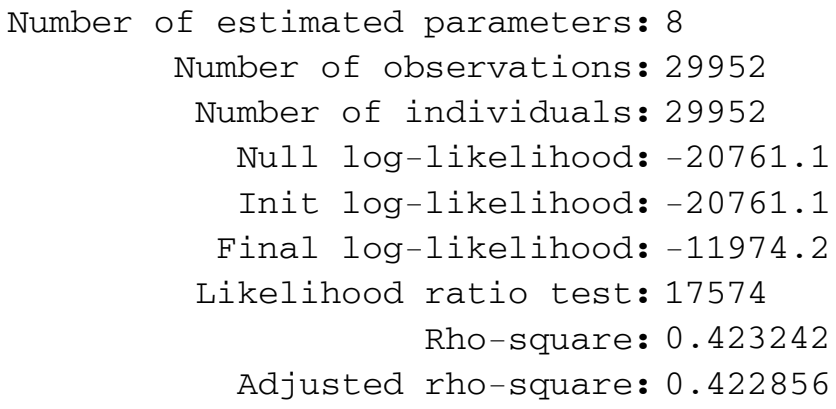

Utility parameters

\begin{tabular}{|l|c|c|c||}
\hline \multicolumn{1}{|c|}{ Name } & Value & Std err & t-test \\
\hline \hline CTE_PED & $-1.3847756 \mathrm{e}+000$ & $+1.7620167 \mathrm{e}-001$ & $-7.8590380 \mathrm{e}+000$ \\
\hline C_CHF & $-8.3441061 \mathrm{e}-002$ & $+1.9484392 \mathrm{e}-001$ & $-4.2824565 \mathrm{e}-001$ \\
\hline CTOLL & $-5.5207126 \mathrm{e}-003$ & $+2.9465135 \mathrm{e}-004$ & $-1.8736424 \mathrm{e}+001$ \\
\hline CTOLL_CHF & $+1.3075388 \mathrm{e}-004$ & $+3.2478527 \mathrm{e}-004$ & $+4.0258563 \mathrm{e}-001$ \\
\hline TTOLL & $-1.5471884 \mathrm{e}-001$ & $+4.1585744 \mathrm{e}-003$ & $-3.7204778 \mathrm{e}+001$ \\
\hline TTOLL_CHF & $-6.0471929 \mathrm{e}-003$ & $+4.5726460 \mathrm{e}-003$ & $-1.3224713 \mathrm{e}+000$ \\
\hline TALT & $-1.5860093 \mathrm{e}-001$ & $+4.5150042 \mathrm{e}-003$ & $-3.5127527 e+001$ \\
\hline TALT_CHF & $-6.7759649 \mathrm{e}-003$ & $+4.9680852 \mathrm{e}-003$ & $-1.3638987 e+000$ \\
\hline
\end{tabular}

Observa-se que os coeficientes adicionais de tempo e custo para o segmento dos motoristas chefes de família não são significativos. Assim, pode-se admitir que os coeficientes para esse segmento não serão diferentes dos da categoria base. 
Característica: Sexo feminino

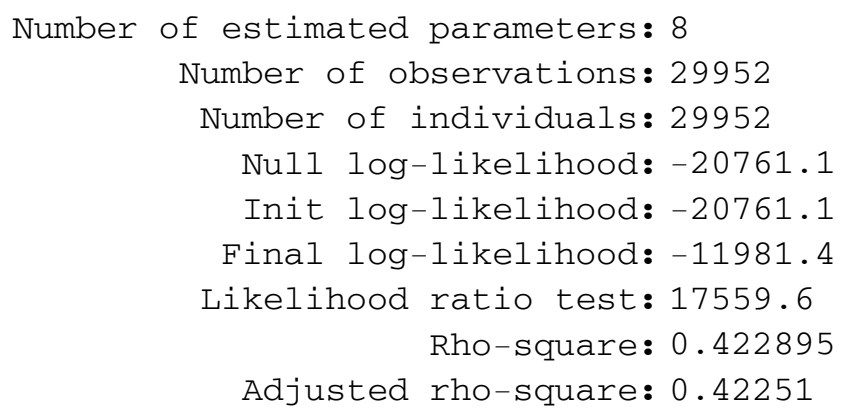

Utility parameters

\begin{tabular}{|c|c|c|c|c|}
\hline Name & Value & Std err & t-test & \\
\hline CTE_PED & $-1.4624787 e+000$ & $+8.0664640 e-002$ & $-1.8130356 e+001$ & \\
\hline C_SX & $+4.5605823 e-002$ & $+2.2349633 e-001$ & $+2.0405625 e-001$ & * \\
\hline CTOLL & $-5.4603239 e-003$ & $+1.3217365 e-004$ & $-4.1311743 e+001$ & \\
\hline CTOLL_SX & $+4.1485618 e-004$ & $+3.7659516 e-004$ & $+1.1015972 \mathrm{e}+000$ & * \\
\hline TTOLL & $-1.6036793 e-001$ & $+1.8447794 e-003$ & $-8.6930679 e+001$ & \\
\hline TTOLL_SX & $+6.0856045 e-003$ & $+5.2535792 e-003$ & $+1.1583730 e+000$ & * \\
\hline TALT & $-1.6513244 e-001$ & $+2.0108495 e-003$ & $-8.2120734 e+001$ & \\
\hline TALT_SX & $+7.9365453 e-003$ & $+5.7437440 e-003$ & $+1.3817721 e+000$ & * \\
\hline
\end{tabular}

Para o segmento das motoristas do sexo feminino os coeficientes adicionais também não foram estatisticamente significativos. A diferença, no entanto, não foi estatisticamente significativa, como se observa pelo valor-t dos coeficientes adicionais do tempo e custo de viagem para o segmento de sexo feminino. 


\section{Característica: Renda baixa}

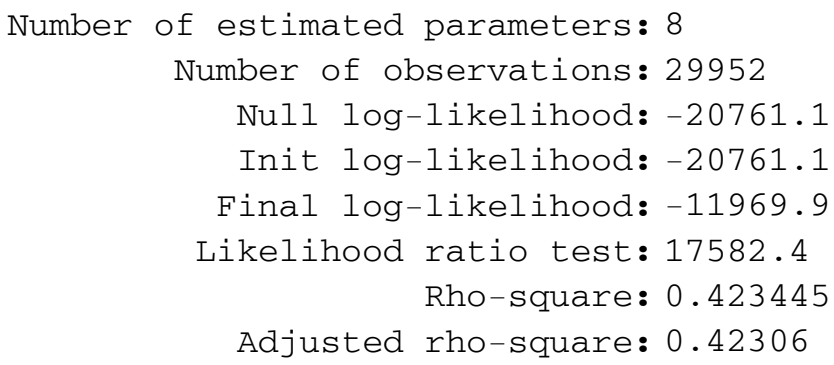

Utility parameters

\begin{tabular}{|c|c|c|c|c|}
\hline Name & Value & Std err & t-test & \\
\hline CTE_PED & $-1.5235752 e+000$ & $+8.1448278 e-002$ & $-1.8706046 e+001$ & \\
\hline C_RB & $+6.3822022 e-001$ & $+2.1444443 e-001$ & $+2.9761567 e+000$ & \\
\hline CTOLL & $-5.2899961 e-003$ & $+1.3233824 e-004$ & $-3.9973300 e+001$ & \\
\hline CTOLL_RB & $-1.2762742 e-003$ & $+3.7728694 e-004$ & $-3.3827681 e+000$ & \\
\hline TTOLL & $-1.6003574 e-001$ & $+1.8715243 e-003$ & $-8.5510904 e+001$ & \\
\hline TTOLL_RB & $+1.7809842 e-003$ & $+4.8677841 e-003$ & $+3.6587166 e-001$ & * \\
\hline TALT & $-1.6487647 e-001$ & $+2.0400840 e-003$ & $-8.0818470 e+001$ & \\
\hline TALT_RB & $+4.4244319 e-003$ & $+5.2866955 e-003$ & $+8.3689932 e-001$ & * \\
\hline
\end{tabular}

$*$ = valores não significativos no nível de significância 0,05 (valor-t=1,96)

Verifica-se que o coeficiente adicional do custo para esse segmento dos motoristas de renda familiar baixa (CTOLL_RB) é estatisticamente significativo e de valor negativo, indicando que a desutilidade do custo é maior para esse grupo. Assim, foram estimados valores do tempo em cerca de $20 \%$ abaixo do valor para categoria base (dada por pessoas de faixas de rendas média ou alta) 
Característica: Posse de 3 ou mais veículos

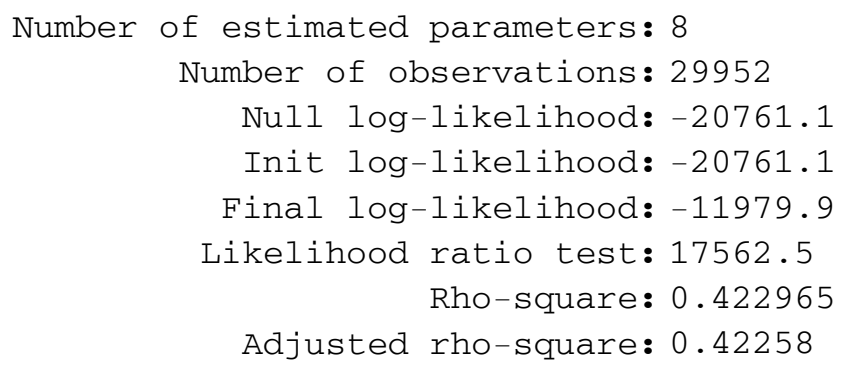

Utility parameters

\begin{tabular}{|c|c|c|c|c|}
\hline Name & Value & std err & t-test & \\
\hline CTE_PED & $-1.4596427 e+000$ & $+7.9949641 e-002$ & $-1.8257026 e+001$ & \\
\hline C_VE3 & $-5.6329426 e-003$ & $+2.3380055 e-001$ & $-2.4092940 e-002$ & * \\
\hline CTOLL & $-5.4747330 e-003$ & $+1.3182294 \mathrm{e}-004$ & $-4.1530958 e+001$ & \\
\hline CTOLL_VE3 & $+4.9895726 e-004$ & $+3.8064333 e-004$ & $+1.3108262 e+000$ & * \\
\hline TTOLL & $-1.6068678 e-001$ & $+1.8445439 e-003$ & $-8.7114643 e+001$ & \\
\hline TTOLL_VE3 & $+8.7042545 e-003$ & $+5.2539340 \mathrm{e}-003$ & $+1.6567118 e+000$ & * \\
\hline TALT & $-1.6524046 e-001$ & $+2.0124658 e-003$ & $-8.2108454 e+001$ & \\
\hline TALT_VE3 & $+8.1536444 e-003$ & $+5.6929299 e-003$ & $+1.4322404 \mathrm{e}+000$ & * \\
\hline
\end{tabular}

$*$ = valores não significativos no nível de significância 0,05 (valor-t=1,96)

Os coeficientes adicionais das variáveis dummies relativas a motoristas com posse de 3 ou mais veículos não se mostraram estatisticamente significativos dentre este segmento das viagens com duração de até 90 minutos. 
Característica: Viagem durante o pico da manhã

Number of estimated parameters: 8

Number of observations: 29952

Null log-likelihood: -20761.1

Init log-likelihood: -20761.1

Final log-likelihood: -11980.8

Likelihood ratio test: 17560.6

Rho-square: 0.42292

Adjusted rho-square: 0.422535

Utility parameters

\begin{tabular}{|l||c|c|c||}
\hline \multicolumn{1}{|c|}{ Name } & Value & std err & t-test \\
\hline CTE_PED & $-1.4166205 e+000$ & $+8.2260960 e-002$ & $-1.7221055 e+001$ \\
\hline C_PICO & $-2.6346825 e-001$ & $+2.0166437 e-001$ & $-1.3064690 e+000$ \\
\hline CTOLL & $-5.4375668 e-003$ & $+1.3664777 e-004$ & $-3.9792575 e+001$ \\
\hline CTOLL_PICO & $+1.5657875 e-004$ & $+3.2175938 e-004$ & $+4.8663306 e-001$ \\
\hline TTOLL & $-1.5983860 e-001$ & $+1.8915835 e-003$ & $-8.4499891 e+001$ \\
\hline TTOLL_PICO & $+1.0988057 e-003$ & $+4.6462593 e-003$ & $+2.3649254 e-001$ \\
\hline TALT & $-1.6411153 e-001$ & $+2.0581653 e-003$ & $-7.9736808 e+001$ \\
\hline TALT_PICO & $-8.7025894 e-004$ & $+5.0995601 e-003$ & $-1.7065373 e-001$ \\
\hline
\end{tabular}

* = valores não significativos no nível de significância 0,05 (valor-t=1,96)

Para viagens realizadas no período de pico da manhã, entre 6:00h e 8:30h, não foram estimados coeficientes adicionais de custo (CTOLL_PICO) e tempo (TTOLL_PICO) estatisticamente significativos. 
Característica: Não pagamento de pedágios

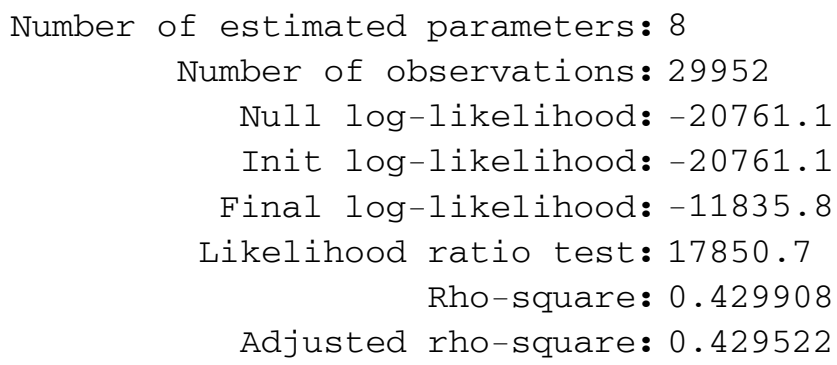

Utility parameters

\begin{tabular}{|l|c|c|c||}
\hline \multicolumn{1}{|c|}{ Name } & Value & std err & t-test \\
\hline CTE_PED & $-7.5229684 \mathrm{e}-001$ & $+1.0369221 \mathrm{e}-001$ & $-7.2550950 \mathrm{e}+000$ \\
\hline C_PAY & $-8.7211241 \mathrm{e}-001$ & $+1.6076348 \mathrm{e}-001$ & $-5.4248165 e+000$ \\
\hline CTOLL & $-5.8707269 \mathrm{e}-003$ & $+1.6066452 \mathrm{e}-004$ & $-3.6540283 e+001$ \\
\hline CTOLL_PAY & $-6.3558973 e-004$ & $+2.8721271 \mathrm{e}-004$ & $-2.2129582 e+000$ \\
\hline TTOLL & $-1.5863200 \mathrm{e}-001$ & $+2.1203725 \mathrm{e}-003$ & $-7.4813270 e+001$ \\
\hline TTOLL_PAY & $-7.5748482 \mathrm{e}-003$ & $+3.6696132 \mathrm{e}-003$ & $-2.0642089 e+000$ \\
\hline TALT & $-1.5981380 \mathrm{e}-001$ & $+2.3028521 \mathrm{e}-003$ & $-6.9398205 e+001$ \\
\hline TALT_PAY & $-1.2577473 e-002$ & $+3.9825584 \mathrm{e}-003$ & $-3.1581389 e+000$ \\
\hline
\end{tabular}

O segmento de motoristas que informaram não pagar nenhum pedágio durante a realização de sua viagem teve coeficientes adicionais de custo e tempo estimados significativos. Assim, o valor de tempo para esse grupo foi calculado em cerca de 5,5\% inferior ao da categoria base, dada por motoristas que pagam ao menos um pedágio em sua viagem.

Como observação, cita-se que verificações feitas - mostradas no apêndice E segmentando a amostra entre pesquisas realizadas em rodovias pedagiadas e não pedagiadas não levaram a diferenças significativas entre o valor do tempo desses dois conjuntos. 
Característica: Motivo de viagem (trabalho diário; negócios; outros)

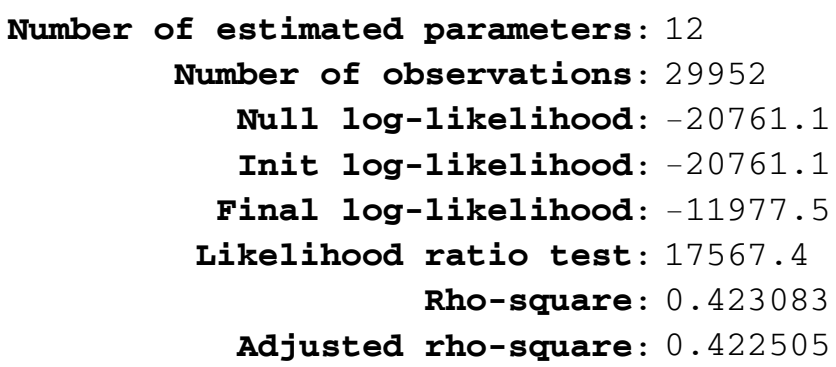

Utility parameters

\begin{tabular}{|c|c|c|c|c|}
\hline Name & Value & std err & t-test & \\
\hline CTE_PED & $-1.4102387 e+000$ & $+1.1198474 e-001$ & $-1.2593133 e+001$ & \\
\hline C_OUTR & $+9.3701322 e-003$ & $+1.6319347 e-001$ & $+5.7417323 e-002$ & * \\
\hline C_TRA & $-4.1175280 e-001$ & $+2.2684570 e-001$ & $-1.8151228 e+000$ & * \\
\hline CTOLL & $-5.5821626 e-003$ & $+1.8096021 e-004$ & $-3.0847459 e+001$ & \\
\hline CTOLL_OUTR & $+2.7866701 e-004$ & $+2.6563090 e-004$ & $+1.0490760 e+000$ & * \\
\hline CTOLL_TRA & $+3.2378706 e-004$ & $+3.9527222 e-004$ & $+8.1914955 e-001$ & * \\
\hline TTOLL & $-1.6282885 e-001$ & $+2.5591663 e-003$ & $-6.3625741 e+001$ & \\
\hline TTOLL_OUTR & $+6.1846368 e-003$ & $+3.7136201 e-003$ & $+1.6653930 e+000$ & * \\
\hline TTOLL_TRA & $+5.2197436 e-003$ & $+5.3691071 e-003$ & $+9.7218093 e-001$ & * \\
\hline TALT & $-1.6693378 e-001$ & $+2.7958363 e-003$ & $-5.9707997 e+001$ & \\
\hline TALT_OUTR & $+6.3777343 e-003$ & $+4.0470873 e-003$ & $+1.5758826 e+000$ & * \\
\hline TALT_TRA & $-5.5047393 e-004$ & $+5.9194326 e-003$ & $-9.2994375 e-002$ & * \\
\hline
\end{tabular}

$*$ = valores não significativos no nível de significância 0,05 (valor-t=1,96)

Para as viagens dentro da faixa de duração de até 90 minutos, observa-se no modelo que os coeficientes adicionais estimados para tempo e custo dos segmentos com motivo de viagem trabalho diário e outros, não foram estatisticamente significativos. 
Característica: Viagem com motivo lazer

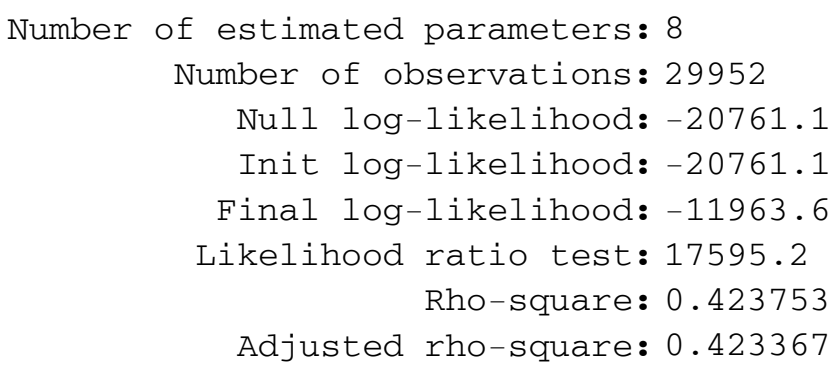

Utility parameters

\begin{tabular}{|l|c|c|c||}
\hline \multicolumn{1}{|c|}{ Name } & Value & std err & t-test \\
\hline CTE_PED & $-1.4073490 e+000$ & $+7.8283607 e-002$ & $-1.7977569 e+001$ \\
\hline C_DLAZ & $-7.4025993 e-001$ & $+2.8368276 e-001$ & $-2.6094639 e+000$ \\
\hline CTOLL & $-5.5382742 e-003$ & $+1.3026356 e-004$ & $-4.2515915 e+001$ \\
\hline CTOLL_DLAZ & $+1.1930292 e-003$ & $+4.3543493 e-004$ & $+2.7398565 e+000$ \\
\hline TTOLL & $-1.5803382 e-001$ & $+1.7962842 e-003$ & $-8.7978179 e+001$ \\
\hline TTOLL_DLAZ & $-2.1056298 e-002$ & $+6.6314742 e-003$ & $-3.1752061 e+000$ \\
\hline TALT & $-1.6337942 e-001$ & $+1.9664559 e-003$ & $-8.3083185 e+001$ \\
\hline TALT_DLAZ & $-1.6021301 e-002$ & $+7.0839967 e-003$ & $-2.2616189 e+000$ \\
\hline \hline
\end{tabular}

A verificação da variação do valor do tempo para viagens com motivo lazer mostrou diferenças bastante significativas para esse grupo. Observa-se que todos os coeficientes adicionais para esse segmento foram estatisticamente significativos, tendo sido estimados a esses viajantes valores do tempo $44 \%$ superiores aos da categoria base (motivos não lazer).

Esta análise mostra que, para a característica do conjunto de viagens amostrado, o motivo lazer representa uma fonte de variação no valor do tempo muito mais importante do que aquela dada pela diferença entre os motivos trabalho diário e negócios. 


\section{Modelos estimados para o segmento das viagens com duração entre 91 e 240 minutos}

Característica: Chefe da família

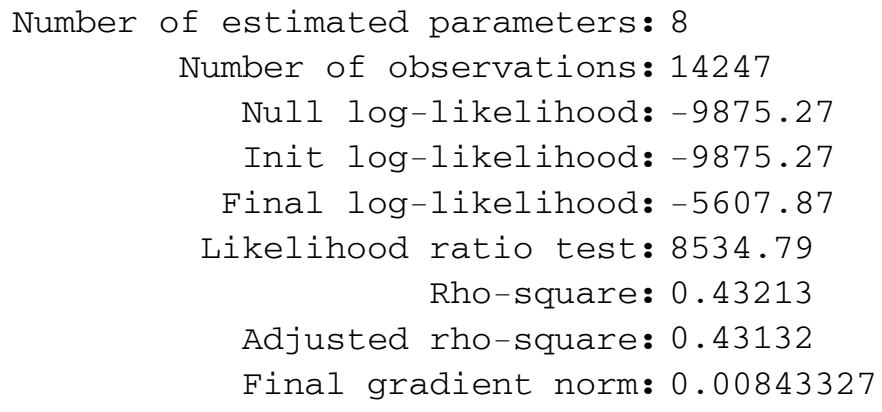

Utility parameters

\begin{tabular}{|c|c|c|c|c|}
\hline Name & Value & std err & t-test & \\
\hline CTE_PED & $-1.2633445 e+000$ & $+3.5242946 e-001$ & $-3.5846734 e+000$ & \\
\hline C_CHF & $+5.1227467 e-001$ & $+3.7957306 e-001$ & $+1.3496076 e+000$ & * \\
\hline CTOLL & $-6.4691021 e-003$ & $+5.2048949 e-004$ & $-1.2428881 e+001$ & \\
\hline CTOLL_CHF & $+5.5167515 e-005$ & $+5.6451637 e-004$ & $+9.7725271 e-002$ & * \\
\hline TTOLL & $-1.5830374 e-001$ & $+6.4957154 e-003$ & $-2.4370486 e+001$ & \\
\hline TTOLL_CHF & $-3.9847523 e-003$ & $+7.0335628 e-003$ & $-5.6653398 e-001$ & * \\
\hline TALT & $-1.6182625 e-001$ & $+6.7203309 e-003$ & $-2.4080101 e+001$ & \\
\hline TALT_CHF & $-5.3518490 e-004$ & $+7.2636873 e-003$ & $-7.3679508 e-002$ & $\star$ \\
\hline
\end{tabular}

Para viagens de duração entre 91 e 240 minutos, a condição de chefe da família não implicou em diferenças estatisticamente significativas nos coeficientes de custo e tempo em relação aos da categoria base. 
Característica: Sexo feminino

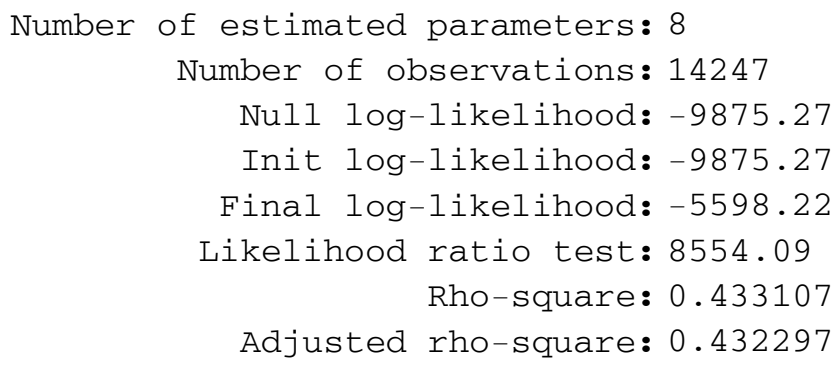

Utility parameters

\begin{tabular}{|c|c|c|c|c|}
\hline Name & Value & Std err & t-test & \\
\hline CTE_PED & $-7.5541532 e-001$ & $+1.3583956 e-001$ & $-5.5610849 e+000$ & \\
\hline C_SX & $-6.2694280 e-001$ & $+5.2213427 e-001$ & $-1.2007310 e+000$ & * \\
\hline CTOLL & $-6.3812454 e-003$ & $+2.0997169 e-004$ & $-3.0390979 e+001$ & \\
\hline CTOLL_SX & $-6.4926020 e-004$ & $+7.3829102 e-004$ & $-8.7940959 e-001$ & * \\
\hline TTOLL & $-1.5825474 e-001$ & $+2.5744961 e-003$ & $-6.1470181 e+001$ & \\
\hline TTOLL_SX & $-4.3144955 e-002$ & $+1.0195767 e-002$ & $-4.2316538 e+000$ & \\
\hline TALT & $-1.5878899 e-001$ & $+2.6334785 e-003$ & $-6.0296292 e+001$ & \\
\hline TALT_SX & $-4.2259331 e-002$ & $+1.0415714 e-002$ & $-4.0572670 e+000$ & \\
\hline
\end{tabular}

* = valores não significativos no nível de significância 0,05 (valor- $t=1,96)$

Verifica-se que, para esta faixa de duração de viagem, o coeficiente adicional do tempo para motoristas do sexo feminino foi estatisticamente significativo, o que não ocorreu para o coeficiente do custo. Assim, estimou-se que motoristas do sexo feminino teriam valor do tempo cerca de $15 \%$ superior ao dos motoristas homens. 


\section{Característica: Renda baixa}

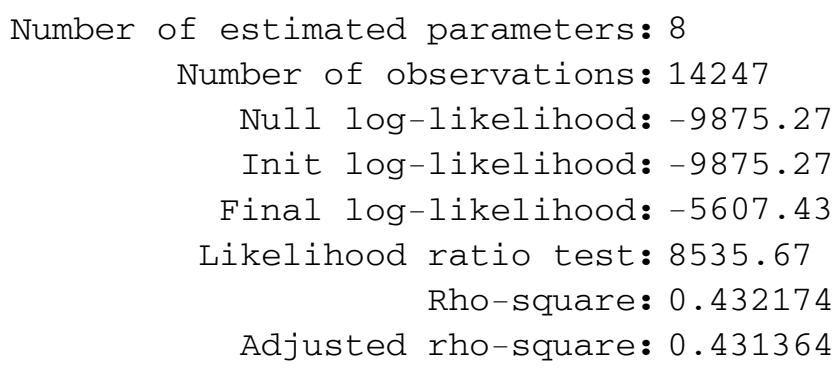

Utility parameters

\begin{tabular}{|c|c|c|c|c|}
\hline Name & value & std err & t-test & \\
\hline CTE_PED & $-8.8044895 e-001$ & $+1.3863521 e-001$ & $-6.3508320 e+000$ & \\
\hline C_RB & $+5.0962659 e-001$ & $+4.1544628 e-001$ & $+1.2266967 e+000$ & * \\
\hline CTOLL & $-6.3446999 e-003$ & $+2.1380227 e-004$ & $-2.9675550 e+001$ & \\
\hline CTOLL_RB & $-6.7337318 e-004$ & $+6.3825266 e-004$ & $-1.0550260 e+000$ & * \\
\hline TTOLL & $-1.6266099 e-001$ & $+2.6601427 e-003$ & $-6.1147469 e+001$ & \\
\hline TTOLL_RB & $+8.3287500 e-003$ & $+7.6276691 e-003$ & $+1.0919129 e+000$ & * \\
\hline TALT & $-1.6325905 e-001$ & $+2.7241840 e-003$ & $-5.9929523 e+001$ & \\
\hline TALT_RB & $+8.9114044 e-003$ & $+7.7590339 e-003$ & $+1.1485199 e+000$ & * \\
\hline
\end{tabular}

Ao contrário do verificado para o segmento das viagens com duração até 90 minutos, para as viagens com duração entre 91 e 240 minutos os coeficientes adicionais do tempo e custo para motoristas de renda baixa não foram estatisticamente significativos. 
Característica: Posse de 3 ou mais veículos

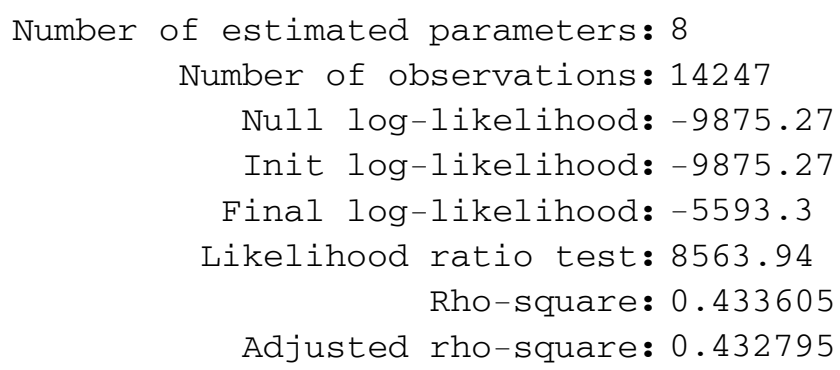

Utility parameters

\begin{tabular}{|l|c|c|c|}
\hline \multicolumn{1}{|c|}{ Name } & Value & Std err & t-test \\
\hline CTE_PED & $-6.9134923 e-001$ & $+1.4004229 e-001$ & $-4.9367174 e+000$ \\
\hline C_VE3 & $-1.0913562 e+000$ & $+3.9547287 e-001$ & $-2.7596234 e+000$ \\
\hline CTOLL & $-6.6912189 e-003$ & $+2.1876607 e-004$ & $-3.0586183 e+001$ \\
\hline CTOLL_VE3 & $+1.9545938 e-003$ & $+5.6017761 e-004$ & $+3.4892395 e+000$ \\
\hline TTOLL & $-1.5958120 e-001$ & $+2.6416037 e-003$ & $-6.0410726 e+001$ \\
\hline TTOLL_VE3 & $-2.0447042 e-002$ & $+8.2608980 e-003$ & $-2.4751597 e+000$ \\
\hline TALT & $-1.6020450 e-001$ & $+2.7052290 e-003$ & $-5.9220309 e+001$ \\
\hline TALT_VE3 & $-2.0071102 e-002$ & $+8.4491582 e-003$ & $-2.3755150 e+000$ \\
\hline \hline
\end{tabular}

Observa-se que todos os coeficientes do modelo com variáveis dummies para representação da categoria dos motoristas que possuem 3 ou mais veículos foram significativos. Estimou-se que esses motoristas teriam valor do tempo cerca de $60 \%$ superior ao da categoria base.

É interessante notar que para as viagens com duração até 90 minutos apenas o segmento dos motoristas de renda baixa teve estimados coeficientes significativos. Já para o segmento das viagens com duração entre 91 e 240 minutos apenas o segmento de renda mais alta (que tem aqui uma proxy na variável posse de 3 ou mais veículos) teve coeficientes adicionais significativos. 
Característica: Viagem durante o pico da manhã

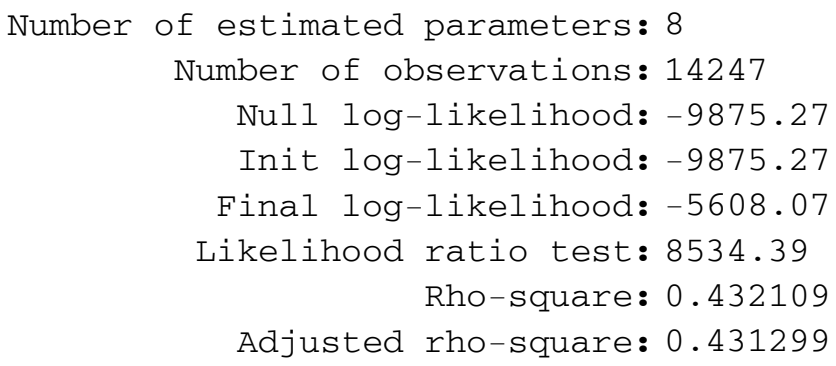

Utility parameters

\begin{tabular}{|c|c|c|c|c|}
\hline Name & value & std err & t-test & \\
\hline CTE_P & 8.44816 & $+1.4330539 e-001$ & -5.8952 & \\
\hline C_PICO & $1.6598398 e-001$ & $+3.5124824 \epsilon$ & +4.72554 & * \\
\hline CTOLL & 003 & $+2.2002077 \epsilon$ & -2.9777 & \\
\hline CTOLL__ & $+7.0153378 e-004$ & $+5.3921380 e-004$ & $+1.3010309 e+000$ & \\
\hline TTOLL & $-1.6349650 e-001$ & $+2.7449868 e-003$ & $-5.9561852 e+001$ & \\
\hline TTOLL_PICO & +1.054 & +6.5127184 & +1.619 & ) \\
\hline TALT & $-1.6424377 e-001$ & $+2.8108194 e-003$ & $-5.8432704 e+001$ & \\
\hline TALT_PICO & $+1.1849972 e-002$ & $+6.6446243 e-003$ & $+1.7833923 e+000$ & * \\
\hline
\end{tabular}

* = valores não significativos no nível de significância 0,05 (valor- $t=1,96)$

O segmento das viagens realizadas no período de pico da manhã não teve estimadas diferenças comportamentais no modelo com dummies. Verifica-se que todos os coeficientes adicionais para essa característica foram não significativos. 
Característica: Não pagamento de pedágios

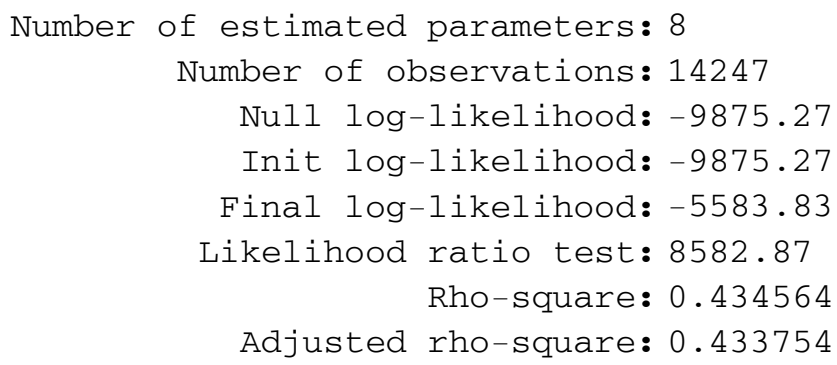

Utility parameters

\begin{tabular}{|c|c|c|c|c|}
\hline Name & Value & std err & $t$-test & \\
\hline CTE_PED & $-7.0477619 e-001$ & $+1.4988677 e-001$ & $-4.7020574 e+000$ & \\
\hline C_PAY & $+4.8569494 e-001$ & $+3.3707363 e-001$ & $+1.4409165 e+000$ & * \\
\hline CTOLL & $-6.4240521 e-003$ & $+2.1835493 e-$ & -2.9420 & \\
\hline CTOLL_PAY & $-1.6684851 e-003$ & $+6.1898575 e-004$ & $-2.6955145 e+000$ & \\
\hline TTOLL & $-1.6349370 e-001$ & $+2.7360806 e-003$ & $-5.9754710 e+001$ & \\
\hline TTOLL_PAY & $+7.0085035 e-003$ & $+6.6388520 e-003$ & $+1.0556800 e+000$ & * \\
\hline TALT & $-1.6352917 e-001$ & $+2.8056632 e-003$ & $-5.8285387 e+001$ & \\
\hline TALT_PAY & $+7.4202535 e-003$ & $+6.7358620 e-003$ & $+1.1016041 e+000$ & * \\
\hline
\end{tabular}

* = valores não significativos no nível de significância 0,05 (valor- $t=1,96)$

Para os motoristas que informaram não pagar nenhum pedágio na realização de sua viagem foram estimados coeficientes adicionais significativos para o custo, mas não para o tempo. O valor negativo para o coeficiente adicional do custo indica maior desutilidade no custo tarifário para esse segmento, sendo valor de tempo estimado em $23 \%$ inferior em relação aos viajantes que declararam pagar pedágios. 
Característica: Motivo de viagem (trabalho diário; negócios; outros)

Number of estimated parameters: 12

Number of observations: 14247

Null log-likelihood: -9875.27

Init log-likelihood: -9875.27

Final log-likelihood: -5606.95

Likelihood ratio test: 8536.63

Rho-square: 0.432223

Adjusted rho-square: 0.431008

Utility parameters

\begin{tabular}{|c|c|c|c|c|}
\hline Name & Value & std err & t-test & \\
\hline CTE_PED & $-6.7132642 e-001$ & $+1.8680403 e-001$ & $-3.5937469 e+000$ & \\
\hline C_OUTR & $-3.2524306 e-001$ & $+2.6710517 e-001$ & $-1.2176592 e+000$ & * \\
\hline C_TRA & $+5.0742671 e-001$ & $+6.3461703 e-001$ & $+7.9957941 e-001$ & * \\
\hline CTOLL & $-6.4963401 e-003$ & $+2.9023142 e-004$ & $-2.2383311 e+001$ & \\
\hline CTOLL_OUTR & $+2.1810266 e-004$ & $+4.0740346 e-004$ & $+5.3534808 e-001$ & * \\
\hline CTOLL_TRA & $-1.3497972 e-003$ & $+1.2403181 e-003$ & $-1.0882670 e+000$ & * \\
\hline TTOLL & $-1.5943677 e-001$ & $+3.5141903 e-003$ & $-4.5369419 e+001$ & \\
\hline TTOLL_OUTR & $-4.8245786 e-003$ & $+5.0756122 e-003$ & $-9.5054123 e-001$ & * \\
\hline TTOLL_TRA & $-4.2841146 e-004$ & $+1.4496394 e-002$ & $-2.9552966 e-002$ & * \\
\hline TALT & $-1.5969926 e-001$ & $+3.5877898 e-003$ & $-4.4511877 e+001$ & \\
\hline TALT_OUTR & $-5.3449467 e-003$ & $+5.1982157 e-003$ & $-1.0282272 e+000$ & * \\
\hline TALT_TRA & $+1.8011841 e-004$ & $+1.4649237 e-002$ & $+1.2295413 e-002$ & * \\
\hline
\end{tabular}

$*$ = valores não significativos no nível de significância 0,05 (valor-t=1,96)

A exemplo do observado para o segmento das viagens com duração até 90 minutos, os coeficientes adicionais aqui estimados para os motivos de viagem trabalho diário e outros não foram significativos. Isso indica que essa classificação de motivos na amostra utilizada foi pouco eficiente para a análise de variações no valor do tempo. 
Característica: Viagem com motivo lazer

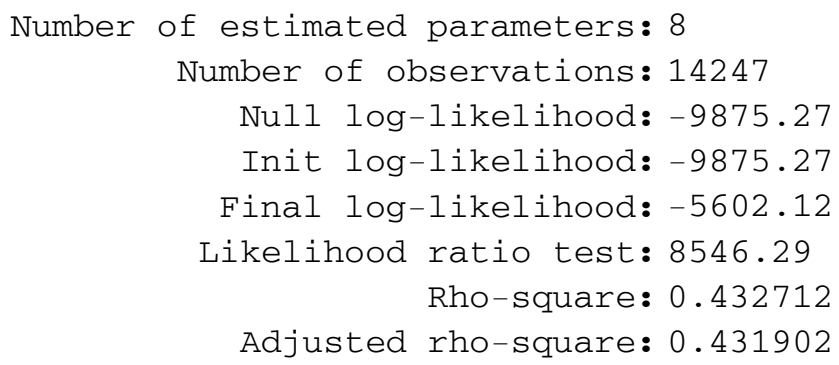

Utility parameters

\begin{tabular}{|l||c||c|c||}
\hline \multicolumn{1}{|c|}{ Name } & Value & std err & t-test \\
\hline CTE_PED & $-6.4569035 e-001$ & $+1.4416252 e-001$ & $-4.4789059 e+000$ \\
\hline C_DLAZ & $-9.7798014 e-001$ & $+3.4692375 e-001$ & $-2.8190060 e+000$ \\
\hline \hline CTOLL & $-6.5527791 e-003$ & $+2.2053389 e-004$ & $-2.9713252 e+001$ \\
\hline CTOLL_DLAZ & $+6.4394716 e-004$ & $+5.5306938 e-004$ & $+1.1643153 e+000$ \\
\hline TTOLL & $-1.5896477 e-001$ & $+2.6889208 e-003$ & $-5.9118429 e+001$ \\
\hline TTOLL_DLAZ & $-1.7415323 e-002$ & $+7.1663797 e-003$ & $-2.4301424 e+000$ \\
\hline TALT & $-1.5928479 e-001$ & $+2.7489909 e-003$ & $-5.7943006 e+001$ \\
\hline \hline TALT_DLAZ & $-1.8574013 e-002$ & $+7.3617568 e-003$ & $-2.5230409 e+000$ \\
\hline \hline
\end{tabular}

$*$ = valores não significativos no nível de significância 0,05 (valor- $t=1,96$ )

Os coeficientes adicionais de tempo relativos ao segmento dos viajantes a lazer foram significativos, tendo sido estimados para esse grupo valores de tempo $23 \%$ superiores em relação à categoria base. Observa-se que o coeficiente diferencial para o custo não se mostrou significativo. 


\section{Modelos estimados para o segmento das viagens com duração superior a 240 minutos}

Dentro deste segmento de duração da viagem observa-se que, em todos os modelos estimados, os coeficientes adicionais das dummies identificando o segmento dos analisados foram estatisticamente não significativos no nível de significância $0,05(t=1,96)$.

É interessante notar também que, em todos os modelos estimados para este segmento, o termo principal da constante específica (CTE_PED) foi não significativo, resultado não observado nos modelos obtidos para os dois demais segmentos por duração da viagem. Uma possível interpretação para esse resultado é que os motoristas de viagens mais longas teriam menor percepção a alguns atributos que os demais veriam como fator de desconforto ao usar uma rodovia pedagiada - como paradas e filas em pedágios. Essa questão é discutida no apêndice $\mathrm{G}$. 


\section{Característica: Chefe da família}

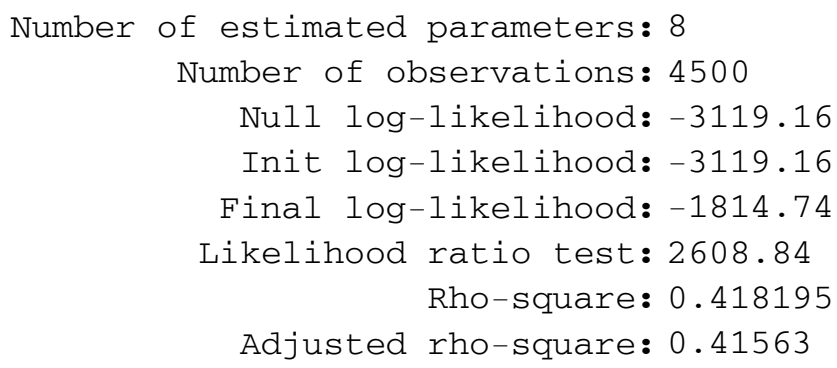

Utility parameters

\begin{tabular}{|l|c|c||c|||}
\hline \multicolumn{1}{|c|}{ Name } & Value & Std err & t-test \\
\hline CTE_PED & $+6.7063355 e-001$ & $+4.0937108 \mathrm{e}-001$ & $+1.6382045 e+000$ \\
\hline C_CHF & $-6.2367667 e-001$ & $+4.7460013 e-001$ & $-1.3141098 e+000$ \\
\hline CTOLL & $-9.9273545 e-003$ & $+7.7975084 e-004$ & $-1.2731444 e+001$ \\
\hline CTOLL_CHF & $+1.9856751 e-003$ & $+9.0155257 e-004$ & $+1.6025062 e+000$ \\
\hline TALT & $-1.6042191 e-001$ & $+7.9464328 e-003$ & $-2.0187915 e+001$ \\
\hline TALT_CHF & $+1.1237828 e-002$ & $+9.2701337 e-003$ & $+1.2122617 e+000$ \\
\hline TTOLL & $-1.5962397 e-001$ & $+7.9066253 e-003$ & $-2.0188635 e+001$ \\
\hline TTOLL_CHF & $+1.1253913 e-002$ & $+9.2136310 e-003$ & $+1.2214417 e+000$ \\
\hline
\end{tabular}




\section{Característica: Sexo feminino}

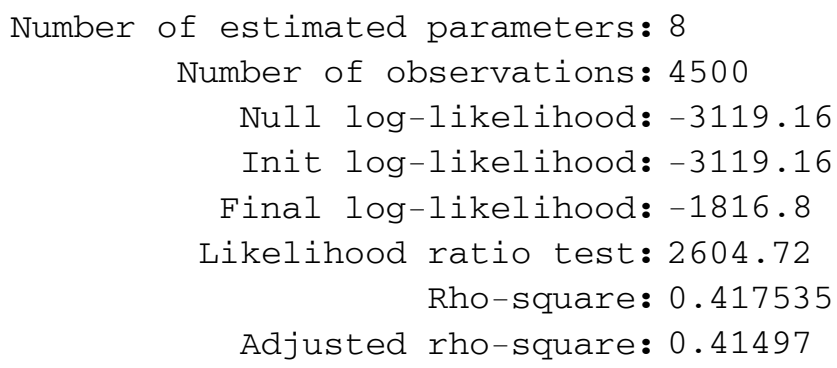

Utility parameters

\begin{tabular}{|c|c|c|c|c|}
\hline Name & Value & Std err & t-test & \\
\hline CTE_PED & $+1.6945618 e-001$ & $+2.1014925 e-001$ & $+8.0636112 e-001$ & * \\
\hline C_SX & $+1.4955701 e+000$ & $+1.2501629 e+000$ & $+1.1963001 e+000$ & * \\
\hline CTOLL & $-8.3720894 e-003$ & $+4.0054214 e-004$ & $-2.0901894 e+001$ & \\
\hline CTOLL_SX & $-2.6396420 e-003$ & $+2.0419622 e-003$ & $-1.2926988 e+000$ & * \\
\hline TTOLL & $-1.5075162 e-001$ & $+4.1390486 e-003$ & $-3.6421804 e+001$ & \\
\hline TTOLL_SX & $-1.2906613 e-002$ & $+2.0913188 e-002$ & $-6.1715188 e-001$ & * \\
\hline TALT & $-1.5158198 e-001$ & $+4.1739173 e-003$ & $-3.6316478 e+001$ & \\
\hline TALT_SX & $-1.1728770 e-002$ & $+2.0957270 e-002$ & $-5.5965161 e-001$ & * \\
\hline
\end{tabular}




\title{
Característica: Renda baixa
}

\author{
Number of estimated parameters: 8 \\ Number of observations: 4500 \\ Null log-likelihood: -3119.16 \\ Init log-likelihood: -3119.16 \\ Final log-likelihood: -1815.72 \\ Likelihood ratio test: 2606.89 \\ Rho-square: 0.417883 \\ Adjusted rho-square: 0.415318
}

Utility parameters

\begin{tabular}{|c|c|c|c|c|}
\hline Name & Value & std err & t-test & \\
\hline CTE_PED & $+8.6240180 e-002$ & $+2.1671427 e-001$ & $+3.9794417 e-001$ & * \\
\hline C_RB & $+1.2185467 e+000$ & $+7.4346230 e-001$ & $+1.6390162 e+000$ & * \\
\hline CTOLL & $-8.2677034 e-003$ & $+4.1095841 e-004$ & $-2.0118103 e+001$ & \\
\hline CTOLL_RB & $-1.9592917 e-003$ & $+1.3630712 e-003$ & $-1.4374096 e+000$ & * \\
\hline TTOLL & $-1.5175444 e-001$ & $+4.3023158 e-003$ & $-3.5272734 e+001$ & \\
\hline TTOLL_RB & $+3.5341713 e-003$ & $+1.3064021 e-002$ & $+2.7052706 e-001$ & * \\
\hline TALT & $-1.5260736 e-001$ & $+4.3378458 e-003$ & $-3.5180449 e+001$ & \\
\hline TALT_RB & $+3.9873185 e-003$ & $+1.3159932 e-002$ & $+3.0298929 e-001$ & * \\
\hline
\end{tabular}




\section{Característica: Posse de 3 ou mais veículos}

Number of estimated parameters: 8

Number of observations: 4500

Null log-likelihood: -3119.16

Init log-likelihood: -3119.16

Final log-likelihood: -1812.91

Likelihood ratio test: 2612.51

Rho-square: 0.418784

Adjusted rho-square: 0.416219

Utility parameters

\begin{tabular}{|c|c|c|c|c|}
\hline Name & Value & std err & t-test & \\
\hline CTE_PED & $+2.7557987 e-001$ & $+2.1562390 e-001$ & $+1.2780581 e+000$ & * \\
\hline C_VE3 & $-9.6093598 e-001$ & $+7.6405799 e-001$ & $-1.2576742 e+000$ & * \\
\hline CTOLL & $-8.3199446 e-003$ & $+4.0559044 e-004$ & $-2.0513167 e+001$ & \\
\hline CTOLL_VE3 & $-1.9538674 e-003$ & $+1.5814809 e-003$ & $-1.2354669 e+000$ & * \\
\hline TTOLL & $-1.4912358 e-001$ & $+4.1966750 e-003$ & $-3.5533745 e+001$ & \\
\hline TTOLL_VE3 & $-3.0251737 e-002$ & $+1.6639944 e-002$ & $-1.8180192 e+000$ & * \\
\hline TALT & $-1.4979793 e-001$ & $+4.2304533 e-003$ & $-3.5409428 e+001$ & \\
\hline TALT_VE3 & $-3.2353679 e-002$ & $+1.6797405 e-002$ & $-1.9261117 e+000$ & * \\
\hline
\end{tabular}




\title{
Característica: Viagem durante o pico da manhã
}

\author{
Number of estimated parameters: 8 \\ Number of observations: 4500 \\ Null log-likelihood: -3119.16 \\ Init log-likelihood: -3119.16 \\ Final log-likelihood: -1816.62 \\ Likelihood ratio test: 2605.08 \\ Rho-square: 0.417593 \\ Adjusted rho-square: 0.415028
}

Utility parameters

\begin{tabular}{|c|c|c|c|c|}
\hline Name & Value & Std err & t-test & \\
\hline CTE_PED & $+1.9771611 e-001$ & $+2.2777450 e-001$ & $+8.6803445 e-001$ & * \\
\hline C_PICO & $+8.2990925 e-002$ & $+5.4509489 e-001$ & $+1.5225042 \mathrm{e}-001$ & * \\
\hline CTOLL & $-8.3628531 e-003$ & $+4.2791015 e-004$ & $-1.9543479 e+001$ & \\
\hline CTOLL_PICO & $-7.3898272 e-004$ & $+1.0657858 e-003$ & $-6.9336888 e-001$ & * \\
\hline TTOLL & $-1.5148190 e-001$ & $+4.3999667 e-003$ & $-3.4427965 e+001$ & \\
\hline TTOLL_PICO & $+1.1092859 e-003$ & $+1.1372466 e-002$ & $+9.7541368 e-002$ & * \\
\hline TALT & $-1.5224967 e-001$ & $+4.4367604 e-003$ & $-3.4315505 e+001$ & \\
\hline TALT_PICO & $+7.5781092 e-004$ & $+1.1460372 e-002$ & $+6.6124460 e-002$ & * \\
\hline
\end{tabular}




\section{Característica: Não pagamento de pedágios}

Number of estimated parameters: 8

Number of observations: 4500

Null log-likelihood: -3119.16

Init log-likelihood: -3119.16

Final log-likelihood: -1810.88

Likelihood ratio test: 2616.56

Rho-square: 0.419433

Adjusted rho-square: 0.416868

Utility parameters

\begin{tabular}{|l|c|c|c|c||}
\hline \multicolumn{1}{|c|}{ Name } & Value & Std err & t-test \\
\hline CTE_PED & $+3.6911884 e-001$ & $+2.1527727 e-001$ & $+1.7146205 e+000$ & * \\
\hline C_PAY & $-1.7548178 e+000$ & $+9.0574991 e-001$ & $-1.9374198 e+000$ & $*$ \\
\hline CTOLL & $-8.6823940 e-003$ & $+4.1009836 e-004$ & $-2.1171491 e+001$ & \\
\hline CTOLL_PAY & $+1.9022046 e-003$ & $+1.6616170 e-003$ & $+1.1447913 e+000$ & $*$ \\
\hline TTOLL & $-1.5055126 e-001$ & $+4.1692155 e-003$ & $-3.6110214 e+001$ & \\
\hline TTOLL_PAY & $-2.2583217 e-002$ & $+1.9947120 e-002$ & $-1.1321542 e+000$ & * \\
\hline TALT & $-1.5134739 e-001$ & $+4.2018758 e-003$ & $-3.6019007 e+001$ & \\
\hline TALT_PAY & $-2.2243416 e-002$ & $+2.0158756 e-002$ & $-1.1034121 e+000$ & * \\
\hline \hline
\end{tabular}


Característica: Motivo de viagem (trabalho diário; negócios; outros)

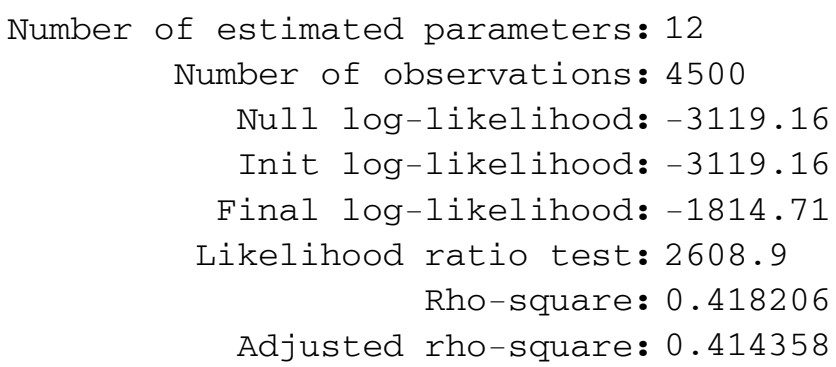

Utility parameters

\begin{tabular}{|l|c|c|c||}
\hline \multicolumn{1}{|c|}{ Name } & Value & std err & t-test \\
\hline CTE_PED & $+2.0994873 e-002$ & $+3.5789857 e-001$ & $+5.8661516 e-002$ \\
\hline C_OUTR & $+4.5978512 e-002$ & $+4.4192794 \mathrm{e}-001$ & $+1.0404075 e-001$ \\
\hline C_TRA & $+1.0450159 e-004$ & $+1.3929492 e+000$ & $+7.5021824 e-005$ \\
\hline CTOLL & $-8.3140458 e-003$ & $+7.0406077 e-004$ & $-1.1808705 e+001$ \\
\hline CTOLL_OUTR & $+1.1404548 e-004$ & $+8.4238515 e-004$ & $+1.3538401 e-001$ \\
\hline CTOLL_TRA & $-3.7312326 e-003$ & $+3.8531289 e-003$ & $-9.6836432 e-001$ \\
\hline TTOLL & $-1.5560119 e-001$ & $+6.9874664 e-003$ & $-2.2268613 e+001$ \\
\hline TTOLL_OUTR & $+7.4309680 e-003$ & $+8.6089393 e-003$ & $+8.6316882 e-001$ \\
\hline TTOLL_TRA & $-6.2682778 e-002$ & $+4.1258562 e-002$ & $-1.5192672 e+000$ \\
\hline TALT & $-1.5642964 e-001$ & $+7.0041264 e-003$ & $-2.2333926 e+001$ \\
\hline \hline TALT_OUTR & $+7.2466813 e-003$ & $+8.6634470 e-003$ & $+8.3646629 e-001$ \\
\hline TALT_TRA & $-6.2693238 e-002$ & $+4.1425607 e-002$ & $-1.5133933 e+000$ \\
\hline
\end{tabular}




\section{Característica: Viagem com motivo lazer}

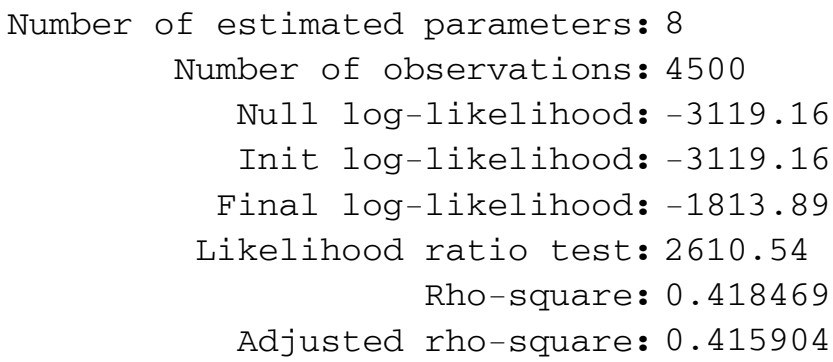

Utility parameters

\begin{tabular}{|l|c|c|c||}
\hline \multicolumn{1}{|c|}{ Name } & value & Std err & t-test \\
\hline CTE_PED & $-2.2705940 e-002$ & $+2.3290795 e-001$ & $-9.7488904 e-002$ \\
\hline C_DLAZ & $+1.1154925 e+000$ & $+5.1155776 e-001$ & $+2.1805797 e+000$ \\
\hline CTOLL & $-8.1210281 e-003$ & $+4.4574934 e-004$ & $-1.8218822 e+001$ \\
\hline CTOLL_DLAZ & $-1.6841792 e-003$ & $+9.4030206 e-004$ & $-1.7911044 e+000$ \\
\hline TTOLL & $-1.5107886 e-001$ & $+4.6340469 e-003$ & $-3.2601928 e+001$ \\
\hline TTOLL_DLAZ & $-2.2325533 e-003$ & $+9.6595983 e-003$ & $-2.3112278 e-001$ \\
\hline TALT & $-1.5196321 e-001$ & $+4.6727367 e-003$ & $-3.2521244 e+001$ \\
\hline TALT_DLAZ & $-1.8527596 e-003$ & $+9.7325734 e-003$ & $-1.9036688 e-001$ \\
\hline
\end{tabular}




\section{APÊNDICE G - Observações sobre o valor negativo da constante específica da alternativa pedagiada}

Um valor negativo atribuído à constante especifica da alternativa pedagiada foi observado na maior parte dos modelos aqui estimados. Estudos semelhantes, descritos por Ghosh (2000), Brownstone e Small (2004) e Steimetz e Brownstone (2005) estimaram também modelos com essa característica.

Cabe observar que havia inicialmente a expectativa de que o motorista percebesse na alternativa pedagiada alguns atributos favoráveis, relacionados a sua qualidade superior em relação a uma rodovia não pedagiada, não abordados no desenho do experimento. Assim, esse valor negativo da constante especifica poderia ser considerado pouco esperado.

Há algumas hipóteses explicativas para tal resultado. Por exemplo, pode-se especular que para o caso das rodovias do estado de São Paulo - onde foram realizadas as entrevistas - de forma geral mesmo aquelas não pedagiadas encontrem-se em boas condições de conservação e sinalização. Dessa forma, a diferença de qualidade entre uma rodovia pedagiada e outra não pedagiada - e que resultaria no esperado sinal positivo para a constante da alternativa pedagiada - talvez não tenha sido um fator marcante na percepção dos motoristas entrevistados ${ }^{104}$.

Outro possível fator de insatisfação para os motoristas ao usar rodovias pedagiadas refere-se ao maior nível de fiscalização e controle existente nessas, como citado por Bartholomeu (2006). Equipamentos 'impopulares' como os medidores eletrônicos de velocidade são amplamente utilizados em rodovias pedagiadas e muito raros naquelas não pedagiadas.

\footnotetext{
104 Observa-se que, como já citado, para responder aos cenários hipotéticos da pesquisa de PD pedia-se que o motorista considerasse as alternativas pedagiada e não pedagiada em mesmas condições de pavimento. No entanto, ainda assim era esperado que outras características positivas, como segurança e conforto, fossem associadas à alternativa pedagiada pelos entrevistados.
} 
A explicação mais provável para esse resultado, no entanto, pode estar na desutilidade do pagamento de uma tarifa adicional. Ou seja, o simples fato de ter de realizar um pagamento durante a viagem - independentemente da quantia - poderia ser visto como fator de insatisfação pelo motorista ${ }^{105}$. Outra suposição seria que o fato de ter de parar o carro durante a viagem para pagar uma tarifa em dinheiro ${ }^{106}$ e, provavelmente, enfrentar filas na praça de pedágio, seja visto como um fator de considerável insatisfação pelos motoristas. Um indicador de que isso é visto como fator de desutilidade é que muitos motoristas pagam taxas pela instalação e manutenção de sistemas de cobrança eletrônica em seus veículos ${ }^{107}$ para evitar essa insatisfação durante a viagem.

Com relação aos termos adicionais da constante estimados nos modelos com dummies, observa-se que para as categorias com maiores valores de tempo associados - como pessoas com posse de 3 ou mais veículos - foram estimados coeficientes adicionais negativos para a constante específica da alternativa pedagiada. Dentro do raciocínio citado no parágrafo anterior, essas pessoas que usualmente têm maior nível de exigência de qualidade de serviços, perceberiam nas paradas e eventuais esperas para pagamento do pedágio maior insatisfação do que as demais. No outro extremo, grupos menos exigentes - como os motoristas de renda baixa - tiveram estimados termos adicionais positivos para a constante específica da alternativa pedagiada, como observado na Tabela 6-13.

\footnotetext{
105 Contemplando esse aspecto, Van Zyl e Raza (2006) inseriram em seu experimento o nível zero para tarifa de pedágio - dentro da alternativa pedagiada, visando detectar as respostas emotivas com relação ao pedagiamento.

106 O que já implica ao motorista na preocupação de ter dinheiro 'em cash' na carteira antes de iniciar a viagem.

107 Esses sistemas "tag-transponders", denominados comercialmente "Sem Parar" no estado de São Paulo, têm uma taxa de adesão de $R \$ 48,34$, e $R \$ 8,62$ de manutenção mensal. Operadores do sistema estimam que um terço das passagens por pedágios sejam feitas atualmente por sistemas eletrônicos de cobrança.
} 


\section{APÊNDI CE H - Verificação da característica 'faixa de renda alta', para as viagens com duração entre 91 e 240 minutos}

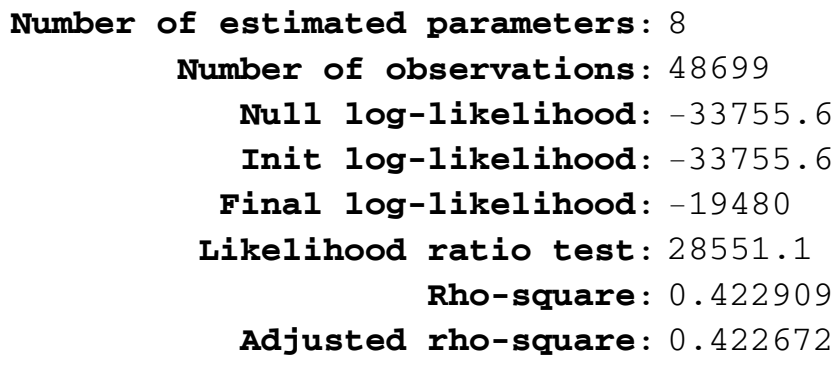

\begin{tabular}{|c|c|c|c|c|}
\hline Name & Value & std err & t-test & \\
\hline CTE_PED & $-9.3497199 e-001$ & $+5.0701663 e-002$ & $-1.8440657 e+001$ & \\
\hline C_RA & $-6.3576586 e-002$ & $+1.6415146 e-001$ & $-3.8730441 e-001$ & * \\
\hline CTOLL & $-5.9236467 e-003$ & $+1.0781998 e-004$ & $-5.4940160 e+001$ & \\
\hline CTOLL_RA & $+5.5401510 e-004$ & $+3.2034735 e-004$ & $+1.7294200 e+000$ & * \\
\hline TTOLL & $-1.5924446 e-001$ & $+1.4153931 e-003$ & $-1.1250900 e+002$ & \\
\hline TTOLL_RA & $+2.0431580 e-003$ & $+4.3910630 e-003$ & $+4.6529919 e-001$ & * \\
\hline TALT & $-1.5956404 e-001$ & $+1.4213231 e-003$ & $-1.1226444 e+002$ & \\
\hline TALT_RA & $+2.0766211 e-003$ & $+4.4136995 e-003$ & $+4.7049444 e-001$ & * \\
\hline
\end{tabular}

Verifica-se que todos os coeficientes adicionais relativos ao segmento de faixa de renda alta foram não significativos, indicando não haver diferenças no valor do tempo em relação à categoria base. 


\section{APÊNDI CE I - Estimativa do valor do tempo com informações de PR}

A Tabela A-5 a seguir mostra, para cada uma das entrevistas onde o motorista informou utilizar uma rota de fuga ao pedágio: i) o local do posto de pesquisa ${ }^{108}$; ii) a freqüência de utilização dessa a rota; iii) o tempo de acréscimo que essa acarretava na viagem, e iv) o valor do pedágio na praça onde foi realizada a pesquisa. Na coluna 5 à direita está o valor do tempo estimado, calculado como o quociente entre o valor da tarifa do pedágio e o tempo de acréscimo na viagem. Informações relativas à freqüência de uso da rota de fuga não foram utilizadas para as estimativas.

Ressalta-se que os valores das colunas 2 e 4, 6 e 7 são as respostas dadas pelos motoristas. O valor do pedágio, na coluna 3 , refere-se à tarifa cobrada de veículos de passeio e foi coletado na data de realização da pesquisa.

Tabela A-5: Estimativa do valor do tempo através de valores informados

\begin{tabular}{|c|c|c|c|c|c|c|c|c|}
\hline \multirow{2}{*}{$\begin{array}{l}\text { Posto de } \\
\text { pesquisa }\end{array}$} & \multirow{2}{*}{$\begin{array}{l}\text { Tempo } \\
\text { de } \\
\text { viagem } \\
\text { (min) }\end{array}$} & \multirow{2}{*}{$\begin{array}{c}\text { Tarifa do } \\
\text { pedágio } \\
\text { [A] } \\
(\mathrm{R} \$)\end{array}$} & \multirow{2}{*}{$\begin{array}{c}\text { Acréscimo } \\
\text { de tempo } \\
\text { pela rota } \\
\text { alternativa } \\
\text { [B] } \\
\text { (min) }\end{array}$} & \multirow{2}{*}{$\begin{array}{c}\text { Valor do } \\
\text { tradeoff } \\
\text { [A/B] } \\
\text { (R\$/min) }\end{array}$} & \multirow{2}{*}{$\begin{array}{l}\text { Freqüência } \\
\text { da viagem }\end{array}$} & \multicolumn{2}{|c|}{$\begin{array}{l}\text { Freq de uso da } \\
\text { rota alternativa }\end{array}$} & \multirow{2}{*}{$\ln \left(P_{\text {ped }} / P_{\text {nped }}\right)$} \\
\hline & & & & & & vezes & por & \\
\hline Q & 40 & 4,5 & 30 & 0,15 & Diária & 1 & Mes & 2,9444 \\
\hline $\mathrm{Q}$ & 60 & 4,5 & 15 & 0,30 & Diária & 1 & Semana & 1,3863 \\
\hline AS & 120 & 4,2 & 30 & 0,14 & Diária & 1 & Semana & 1,3863 \\
\hline $\mathrm{T}$ & 40 & 6,1 & 20 & 0,31 & Diária & 1 & Semana & 1,3863 \\
\hline $\mathrm{T}$ & 20 & 6,1 & 10 & 0,61 & Diária & 1 & Semana & 1,3863 \\
\hline $\mathrm{T}$ & 40 & 6,1 & 10 & 0,61 & Diária & 1 & Semana & 1,3863 \\
\hline$A X$ & 60 & 3,9 & 10 & 0,39 & Diária & 1 & Semana & 1,3863 \\
\hline $\mathrm{Q}$ & 30 & 4,5 & 10 & 0,45 & $1 \times$ sem. & 1 & Mes & 1,0986 \\
\hline $\mathrm{AJ}$ & 15 & 5,1 & 40 & 0,13 & $1 \times$ sem. & 1 & Mes & 1,0986 \\
\hline AJ & 40 & 5,1 & 15 & 0,34 & $1 \times$ sem. & 1 & Mes & 1,0986 \\
\hline AS & 360 & 4,2 & 15 & 0,28 & $1 \times$ sem. & 1 & Mes & 1,0986 \\
\hline $\mathrm{T}$ & 20 & 6,1 & 30 & 0,20 & $1 \times$ sem. & 1 & Mês & 1,0986 \\
\hline V & 20 & 3,7 & 30 & 0,12 & $1 \times$ sem. & 1 & Mês & 1,0986 \\
\hline 203 & 120 & 4,2 & 15 & 0,28 & $1 \times$ sem. & 1 & Mes & 1,0986 \\
\hline Z & 10 & 5,2 & 10 & 0,52 & Diária & 15 & Mes & 0,8473 \\
\hline $\mathrm{Q}$ & 180 & 4,5 & 15 & 0,30 & $3 \times$ sem. & 1 & Semana & 0,6931 \\
\hline $\mathrm{Q}$ & 40 & 4,5 & 30 & 0,15 & $3 \times$ Sem. & 4 & Mes & 0,6931 \\
\hline $\mathrm{AA}$ & 120 & 8,0 & 40 & 0,20 & $3 \times$ sem. & 4 & Mes & 0,6931 \\
\hline$A X$ & 90 & 3,9 & 15 & 0,26 & Diária & 2 & Semana & 0,4055 \\
\hline $\mathrm{Q}$ & 40 & 4,5 & 10 & 0,45 & Diária & 2 & Semana & 0,4055 \\
\hline AJ & 30 & 5,1 & 15 & 0,34 & Diária & 10 & Mes & 0,4055 \\
\hline
\end{tabular}

\footnotetext{
108 Os locais se referem a praças de pedágios, cuja localização pode ser observada na Figura 5-1,
} apresentada no item 5.1. 


\begin{tabular}{|c|c|c|c|c|c|c|c|c|}
\hline \multirow[b]{2}{*}{$\begin{array}{l}\text { Posto de } \\
\text { pesquisa }\end{array}$} & \multirow{2}{*}{$\begin{array}{c}(2) \\
\text { Tempo } \\
\text { de } \\
\text { viagem } \\
\text { (min) }\end{array}$} & \multirow{2}{*}{$\begin{array}{c}(3) \\
\text { Tarifa do } \\
\text { pedágio } \\
\text { [A] } \\
\text { (R\$) }\end{array}$} & \multirow{2}{*}{$\begin{array}{c}(4) \\
\text { Acréscimo } \\
\text { de tempo } \\
\text { pela rota } \\
\text { alternativa } \\
\text { [B] } \\
\text { (min) }\end{array}$} & \multirow{2}{*}{$\begin{array}{c}(5) \\
\text { Valor do } \\
\text { tradeoff } \\
{[A / B]} \\
(\mathrm{R} \$ / \mathrm{min})\end{array}$} & \multirow{2}{*}{$\begin{array}{l}\text { Freqüência } \\
\text { da viagem }\end{array}$} & \multicolumn{2}{|c|}{$\begin{array}{c}\text { (7) } \\
\text { Freq de uso da } \\
\text { rota alternativa }\end{array}$} & \multirow[b]{2}{*}{$\ln \left(P_{\text {ped }} / P_{\text {nped }}\right)$} \\
\hline & & & & & & vezes & por & \\
\hline V & 90 & 3,7 & 30 & 0,12 & Diária & 20 & Mes & 0,4055 \\
\hline $\mathrm{Q}$ & 40 & 4,5 & 15 & 0,30 & Diária & 3 & Semana & $-0,4055$ \\
\hline Q & 40 & 4,5 & 20 & 0,23 & Diária & 3 & Semana & $-0,4055$ \\
\hline $\mathrm{Q}$ & 30 & 4,5 & 10 & 0,45 & Diária & 3 & Semana & $-0,4055$ \\
\hline $\mathrm{Q}$ & 40 & 4,5 & 10 & 0,45 & Diária & 3 & Semana & $-0,4055$ \\
\hline Q & 30 & 4,5 & 10 & 0,45 & Diária & 3 & Semana & $-0,4055$ \\
\hline Q & 60 & 4,5 & 15 & 0,30 & Diária & 3 & Semana & $-0,4055$ \\
\hline Z & 40 & 5,2 & 15 & 0,35 & Diária & 3 & Semana & $-0,4055$ \\
\hline 203 & 20 & 4,2 & 10 & 0,42 & Diária & 3 & Semana & $-0,4055$ \\
\hline 203 & 60 & 4,2 & 20 & 0,21 & Diária & 3 & Semana & $-0,4055$ \\
\hline V & 20 & 3,7 & 10 & 0,37 & $3 \times$ sem. & 2 & Semana & $-0,6931$ \\
\hline V & 25 & 3,7 & 30 & 0,12 & Diária & 5 & Semana & $-0,9163$ \\
\hline Q & 30 & 4,5 & 15 & 0,30 & Diária & 6 & Semana & $-1,7918$ \\
\hline V & 20 & 3,7 & 10 & 0,37 & Diária & 6 & Semana & $-1,7918$ \\
\hline $\mathrm{Q}$ & 40 & 4,5 & 10 & 0,45 & Diária & 6 & Semana & $-1,7918$ \\
\hline
\end{tabular}

Utilizando-se as informações das colunas 3 e 4 calculou-se para cada entrevista o valor de tradeoff, cuja média foi de $R \$ 0,32 / \min$ (ou $R \$ 19,03 / \mathrm{h}$ ).

\section{- Estimativa do valor do tempo aplicando os dados de PR a um modelo de escolha}

Para a estimativa do valor do tempo por uma forma probabilística usaram-se as informações das colunas 6 e 7 da Tabela A-5 para se obter uma proxy para a probabilidade de escolha da alternativa pedagiada $\left(\frac{P_{\text {ped }}}{P_{\text {nped }}}\right)$. A estimativa dos parâmetros da função de utilidade através da linearização do logit seguiu a forma (ORTÚZAR; WILLUMSEN, 2001):

$\ln \left(\frac{P_{p e d}}{P_{\text {nped }}}\right)=\lambda\left(C_{\text {nped }}-C_{p e d}-\alpha\right)=\lambda\left(C_{n p e d}-C_{p e d}\right)+\lambda \alpha$

sendo $^{109}$,

$C_{p e d}=\beta C_{p e d}+\gamma t_{p e d}$

$C_{\text {nped }}=\gamma t_{\text {nped }}$

${ }^{109}$ Admitiu-se para esta estimativa que o coeficiente do tempo de viagem é o mesmo para as alternativas pedagiada e não pedagiada. 
tem-se que:

$\left.\ln \left(\frac{P_{p e d}}{P_{\text {nped }}}\right)=-\lambda \beta c_{\text {ped }}-\lambda \gamma\left(t_{\text {ped }}-t_{\text {nped }}\right)\right)+\lambda \alpha$

Assim, analogamente à forma descrita no item 6.3.1, o valor do tempo seria dado por:

$V S T=\frac{\frac{\partial C}{\partial t}}{\frac{\partial C}{\partial c}}=\frac{\lambda \gamma}{\lambda \beta}$

A Tabela A-6 mostra os resultados da regressão linear e os coeficientes estimados para as funções de custo.

Tabela A-6: resultados da regressão para obtenção dos parâmentros da função de utilidade com dados de PR

\begin{tabular}{lr}
\hline \multicolumn{2}{c}{ Estatística de regressão } \\
\hline R múltiplo & 0,39582 \\
R-Quadrado & 0,15667 \\
R-quadrado ajustado & 0,10556 \\
Erro padrão & 1,00213 \\
Observações & 36 \\
\hline
\end{tabular}

\begin{tabular}{lrrrrr} 
ANOVA & \multicolumn{6}{c}{ SQ } & \multicolumn{1}{c}{ SQ } & \multicolumn{1}{c}{ F } & F de signif \\
\hline Regressão & 2 & 6,156980099 & 3,07849005 & 3,06539371 & 0,06010676 \\
Resíduo & 33 & 33,14098653 & 1,004272319 & & \\
Total & 35 & 39,29796663 & & & \\
\hline
\end{tabular}

\begin{tabular}{lcccccc}
\hline Coeficientes & Valor & Erro padrão & Stat $t$ & valor- $P$ & $\begin{array}{c}95 \% \\
\text { inferiores }\end{array}$ & $\begin{array}{c}95 \% \\
\text { superiores }\end{array}$ \\
\hline$\lambda \alpha$ & $-1,5337$ & 0,9138 & $-1,6784$ & 0,1027 & $-3,3929$ & 0,3254 \\
$\lambda \beta$ & 0,2882 & 0,1956 & 1,4734 & 0,1501 & $-0,1097$ & 0,6861 \\
$\lambda \gamma$ & 0,0303 & 0,0191 & 1,5886 & 0,1217 & $-0,0085$ & 0,0691 \\
\hline
\end{tabular}

Observa-se, pelo valor-t, que nenhum dos coeficientes estimados é estatisticamente significativo, ao nível de significância $0,05(t=1,96)$. O valor do tempo estimado pelo quociente entre $\lambda \gamma$ e $\lambda \beta$ seria de $\mathrm{R} \$ 6,30 / \mathrm{h}$. Como já mencionado no texto, é bastante provável que a informação - fundamental para essa estimativa - referente à freqüência de uso da alternativa não pedagiada, em relação à freqüência de viagem, seja de pouca precisão. 


\section{APÊNDICE J - Influência da disponibilidade de tempo livre e da flexibilidade de horários na valoração do tempo}

Como mencionado no capítulo final deste estudo e no item 2.2, Jara-Díaz e Farah (1987) defendem que as pessoas com flexibilidade em sua carga horária de trabalho - e conseqüentemente, em sua renda - associariam ao tempo de viagem um valor diferente daquelas que têm a obrigação de cumprir uma carga horária definida e salário fixo.

Essa característica foi contemplada em diversos estudos de valoração do tempo, como os de Bates e Roberts (1986), Bradley e Gunn (1990), Jiang e Morikawa (2004) e Steimetz e Brownstone (2005).

No experimento descrito por Bradley e Gunn (1990), uma informação coletada nas entrevistas permitiu a segmentação da amostra em quatro grupos, de acordo com a quantidade declarada de horas livres durante a semana (denominado "personal free time"). Para os grupos com menor disponibilidade de horas livres foram estimados os maiores valores de tempo. Steimetz e Brownstone (2005) classificaram os entrevistados em trabalhadores em tempo integral ou parcial, sendo os valores de tempo estimados para os primeiros, consideravelmente maiores. Jiang e Morikawa (2004) verificaram também que o valor do tempo cresceria para pessoas com maiores cargas horárias de trabalho. 


\section{APÊNDICE K - Modelos segmentados por motivo de viagem para motoristas no eixo Campinas - São Paulo}

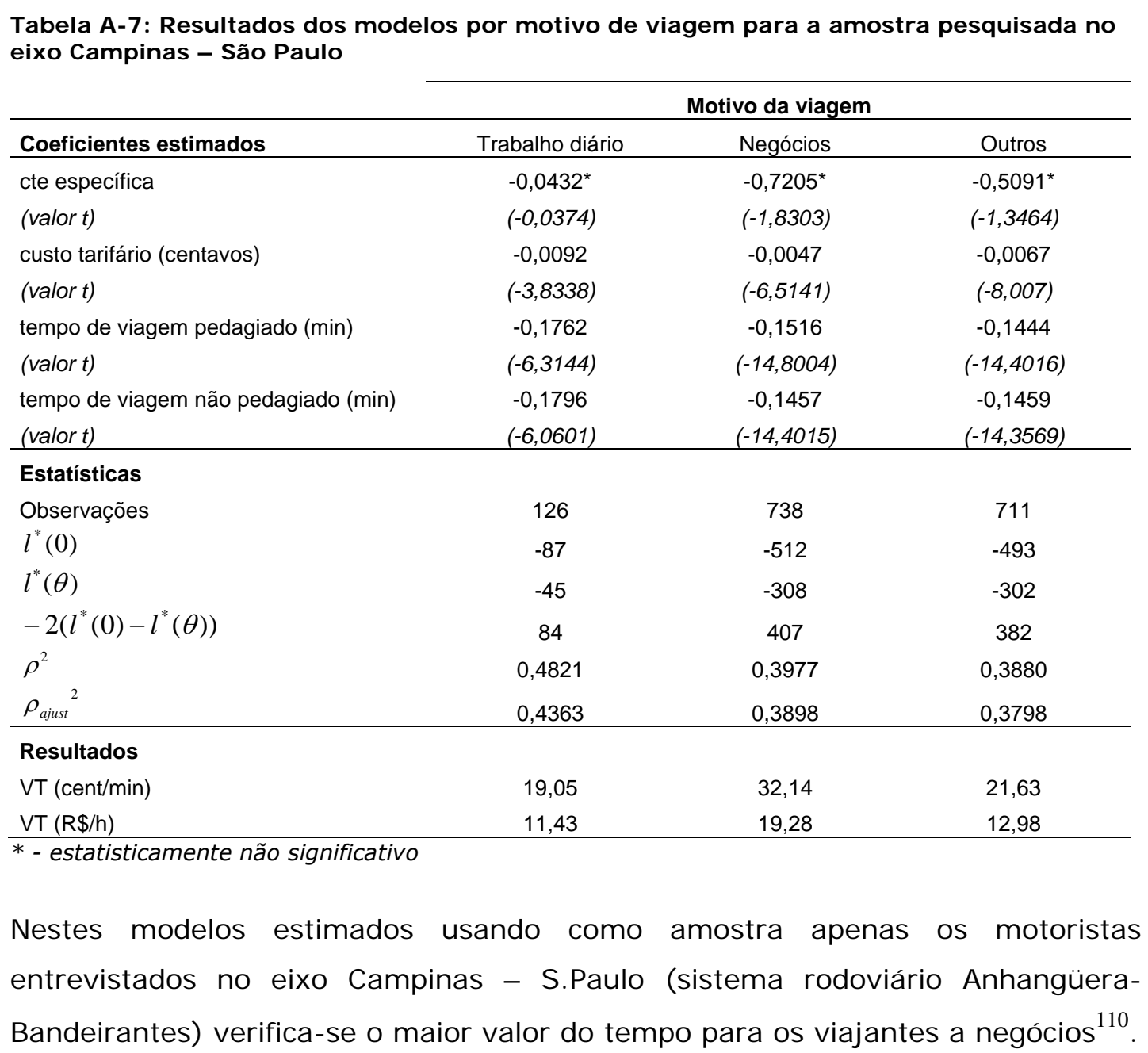

\footnotetext{
110 Testou-se a hipótese de que houvesse diferentes proporções de viagens curtas - que têm maiores valores de tempo - nos diferentes motivos de viagem. Tal hipótese, no entanto, não se confirmou nos testes estatísticos realizados para a subamostra utilizada.
} 


\section{APÊNDI CE L - Distribuição das observações por faixa de renda para motivos lazer e não a lazer.}

A Tabela A-8 a seguir mostra a distribuição das observações segundo as variáveis 'faixa de renda' e 'motivo lazer'.

Tabela A-8: Teste de independência da distribuição das observações por faixa de renda para os motivos 'lazer' e 'não lazer'

freq observadas

\begin{tabular}{|c|c|c|c|c|c|c|}
\hline \multirow[b]{2}{*}{ motivo } & \multicolumn{5}{|c|}{ Faixa de renda } & \multirow[b]{2}{*}{ total } \\
\hline & até 900 & 901 a 3000 & 3001 a 6000 & + de 6000 & $\mathrm{NI}$ & \\
\hline Lazer & 105 & 362 & 138 & 74 & 13 & 692 \\
\hline Não lazer & 593 & 2576 & 975 & 484 & 91 & 4719 \\
\hline Total geral & 698 & 2938 & 1113 & 558 & 104 & 5411 \\
\hline
\end{tabular}

freq esperadas

\begin{tabular}{|c|c|c|c|c|c|}
\hline \multirow[b]{2}{*}{ motivo } & \multicolumn{5}{|c|}{ Faixa de renda } \\
\hline & até 900 & 901 a 3000 & 3001 a 6000 & + de 6000 & $\mathrm{NI}$ \\
\hline Lazer & 89 & 376 & 142 & 71 & 13 \\
\hline Não lazer & 609 & 2562 & 971 & 487 & 91 \\
\hline \multicolumn{6}{|l|}{ qui } \\
\hline & 2,77 & 0,50 & 0,13 & 0,10 & 0,01 \\
\hline & 0,41 & 0,07 & 0,02 & 0,01 & 0,00 \\
\hline
\end{tabular}

qui-quad obs

4,03

qui-crit

14,86

signif $0,5 \%$

Verifica-se pelo teste de independência pelo qui-quadrado (qui-quad $=4,03<$ qui-quad crit $=14,86$ ) que a distribuição das observações nas faixas de renda não é estatisticamente diferente para motoristas viajando a lazer e não a lazer. 


\section{APÊNDI CE M - Compilação de valores de tempo em função da renda estimados em diferentes estudos}

Tabela A-9: Valores do tempo de viagem (em função do salário) estimados por diversos estudos

\begin{tabular}{|c|c|c|c|c|}
\hline Estudo & País & $\begin{array}{c}\text { Valor do } \\
\text { Tempo } \\
\text { (\% sal) }\end{array}$ & Motivo & Modo \\
\hline Beesley (1965) & Reino Unido & $33-50$ & Trabalho & Automóvel \\
\hline Quarmby (1967) & Reino Unido & $20-25$ & Trabalho & $\begin{array}{l}\text { Auto } \times \text { Transp. } \\
\text { público }\end{array}$ \\
\hline Stopher (1968) & Reino Unido & $21-32$ & Trabalho & $\begin{array}{l}\text { Auto } x \text { Transp. } \\
\text { público }\end{array}$ \\
\hline Oort (1969) & Estados Unidos & 33 & Trabalho & Automóvel \\
\hline Thomas \&Thompson (1970) & Estados Unidos & 86 & Interurbana & Automóvel \\
\hline \multirow{2}{*}{ Lee \& Dalvi (1971) } & \multirow{2}{*}{ Reino Unido } & 30 & Trabalho & Ônibus \\
\hline & & 40 & Trabalho & Automóvel \\
\hline Wabe (1971) & Reino Unido & 43 & Trabalho & Auto $\times$ Metrô \\
\hline Talvitte (1972) & Estados Unidos & $12-14$ & Trabalho & $\begin{array}{l}\text { Auto } \times \text { Transp. } \\
\text { público }\end{array}$ \\
\hline Kraft \& Kraft (1974) & Estados Unidos & 38 & Interurbana & Ônibus \\
\hline Mc Donald (1975) & Estados Unidos & $45-78$ & trabalho & $\begin{array}{l}\text { Auto } x \text { Transp. } \\
\text { público }\end{array}$ \\
\hline Ghosh e outros (1975) & Reino Unido & 73 & Interurbano & Automóvel \\
\hline \multirow{2}{*}{ Guttman (1975) } & \multirow{2}{*}{ Estados Unidos } & 63 & Lazer & Automóvel \\
\hline & & 145 & Trabalho & Automóvel \\
\hline \multirow{2}{*}{ Hensher (1977) } & \multirow{2}{*}{ Austrália } & 39 & Trabalho & Automóvel \\
\hline & & 35 & Lazer & Automóvel \\
\hline Nelson (1977) & Estados Unidos & 33 & Trabalho & Automóvel \\
\hline Hauer Greenough (1982) & Canadá & $67-101$ & Trabalho & Metrô \\
\hline Edmonds (1983) & Japão & $42-49$ & Trabalho & $\begin{array}{l}\text { Auto } x \text { Transp. } \\
\text { público }\end{array}$ \\
\hline Deacon \& Sonstelie (1985) & Estados Unidos & $52-254$ & Lazer & Automóvel \\
\hline Hensher \& Truong (1985) & Austrália & 105 & Trabalho & $\begin{array}{l}\text { Auto } \times \text { Transp. } \\
\text { público }\end{array}$ \\
\hline Guttman \& Menashe (1986) & Israel & 59 & Trabalho & Auto $x$ Ônibus \\
\hline Fowkes (1986) & Reino Unido & $27-59$ & Trabalho & Trem x Táxi \\
\hline Hau (1986) & Estados Unidos & 46 & Trabalho & Auto $x$ Ônibus \\
\hline Chui \& McFarland (1987) & Estados Unidos & 82 & Interurbano & Automóvel \\
\hline Mohring e outros (1987) & Singapura & $60-129$ & Trabalho & Ônibus \\
\hline \multirow{2}{*}{ Cole Sherman (1990) } & \multirow{2}{*}{ Canadá } & $93-170$ & Trabalho & Automóvel \\
\hline & & $116-165$ & Lazer & Automóvel \\
\hline
\end{tabular}

Fonte: Walters, 1992 apud Schimitz, 2001. 